\title{
FOSTERING INTERCULTURAL LEARNING THROUGH PROJECT-BASED LEARNING IN VIETNAMESE TERTIARY EFL CLASSES: A PARTICIPATORY ACTION RESEARCH STUDY
}

By

\section{TA NGOC HIEN MINH}

\begin{abstract}
A thesis
submitted to the Victoria University of Wellington in fulfilment of the requirements for the degree of

Doctor of Philosophy in Applied Linguistics
\end{abstract}

Victoria University of Wellington 2021 


\section{ACKNOWLEDMENTS}

First of all, I would like to express my deepest gratitude to my primary supervisor, Associate Professor Jonathan Newton for his invaluable guidance, constructive criticism, patience, and kindness. I was greatly enlightened by his wisdom and always felt motivated to strive for the best thanks to his encouragement and confidence in me. I am also profoundly indebted to my second supervisor, Dr Corinne Seals for her academic support, particularly her enthusiastic guidance on qualitative data analysis.

My special thanks go to the Vietnamese Ministry of Education and Training and Victoria University of Wellington (VUW) for funding my study. I would also like to thank the Faculty of Humanities and Social Sciences at Victoria University for a research grant, which made my fieldwork possible in Vietnam.

I am very grateful to the staff at the School of Linguistics and Applied Language Studies (LALS), especially Bernie Hambleton, Janet Attrill, Patrick Coelho, Matthew Vink, and Barry Lewis for their administrative assistance; also to the librarians Rebecca Hastie and the late Tony Quin for their assistance with study resources; lastly to the advisors at VUW Student Learning, especially Kirsten Reid, Kristen Sharma, and Brittany Hoback for their proofreading.

My special thanks go to the teacher, student, and employer participants for their time and cooperation. I highly appreciate the University and Faculty of Foreign Language leaders and colleagues in my university for their support before and throughout my data collection.

I wish to thank all my $\mathrm{PhD}$ friends at LALS, especially Vola Ambinintsoa, Wei Wei, Juliet Kennedy, Priska Pramastiwi, Diep Tran, Thao Le, Thao Tran, Hao Dao and Ha Nguyen for sharing with me their academic and social life experience, and for the laughs, the photos, and the delightful dinners we had together. I sincerely thank my dear friends, Huong Giang and Lita Lyu, for their continuous assistance and encouragement.

Last but not least, my wholehearted thanks go to my dear family for always standing beside me, understanding, encouraging and supporting me. My PhD journey would not have been possible without their company. 


\begin{abstract}
Intercultural competence (IC) is increasingly recognized globally as a goal of education. In Vietnam, despite emphasis on intercultural competence in national language education, research has shown the peripheral role of addressing culture in EFL classes although research on the topic of how to cultivate intercultural language teaching and learning (ICLTL) is growing. This study investigated affordances for intercultural learning through project-based learning $(\mathrm{PBL})$ in an EFL program at a Vietnamese university. It followed an interpretive research paradigm and qualitative research approach. It included two related studies. Study 1 was an ethnography-informed study, which involved 14 teachers, 265 students, 6 graduates and their employers. Data were collected from classroom observations, student focus group interviews, and interviews with teachers, graduates and employers. This preliminary research revealed few opportunities for intercultural learning in this program. Specifically, it found that culture was rarely addressed, and the main instructional method for culture was fact transmission. Moreover, teachers showed limited understanding of ICLTL and students expressed the need for further culture learning. Study 2 was a participatory action research study, in which a semester-long project was introduced to foster intercultural learning. Study 2 included two workshops, one at the beginning and one in the middle of the project. In these workshops, the researcher and three teachers collaboratively learned about ICLTL, and planned PBL lessons. Drawing on a thematic analysis of classroom data and teachers' and students' reports, the findings showed teachers' improved practices and understanding of ICLTL and PBL, and indications of students' IC development throughout the project. This research contributes to the growing scholarship on ICLTL by providing evidence for the efficacy of PBL for intercultural learning. Additionally, the study highlights the impact of teacher professional development on teaching practice and extends understanding of how to incorporate PBL in a textbook-based and exam-oriented EFL context.
\end{abstract}


Table of Contents

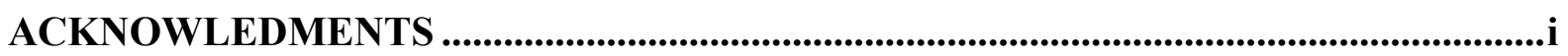

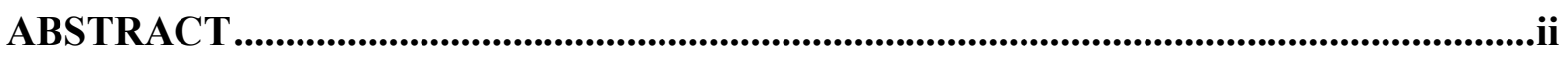

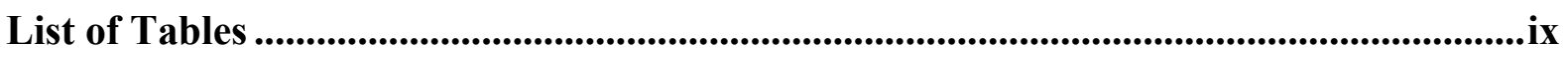

List of Figures..................................................................................................................................

List of Acronyms and Abbreviations .........................................................................................xi

Transcript Conventions.......................................................................................................................xii

Chapter 1: Introduction ............................................................................................................ 1

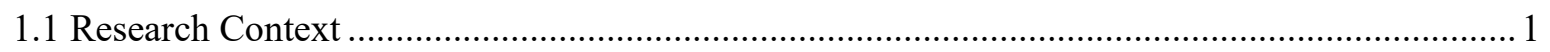

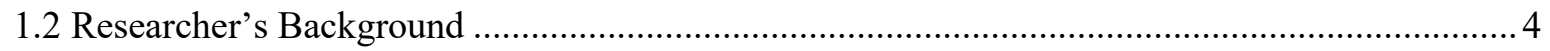

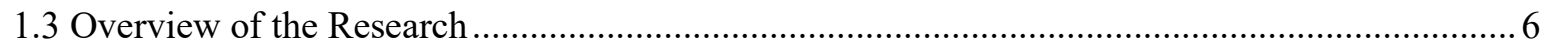

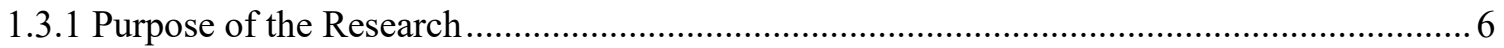

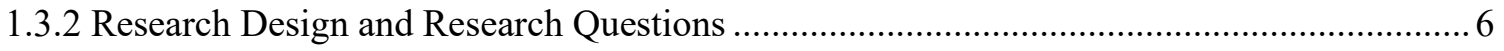

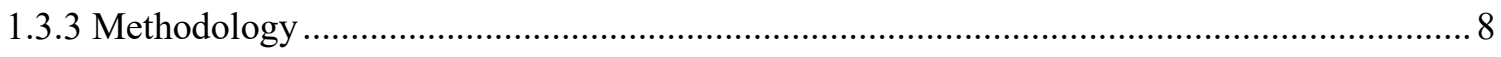

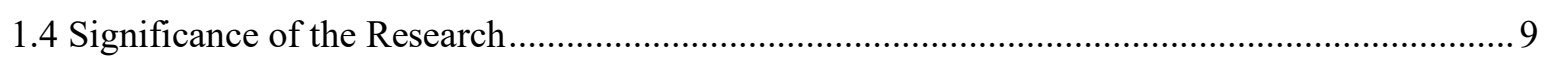

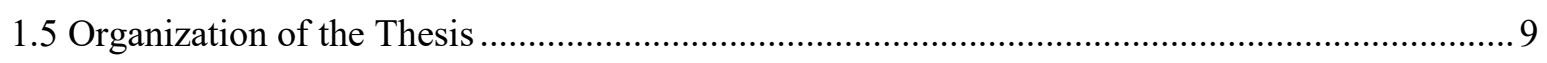

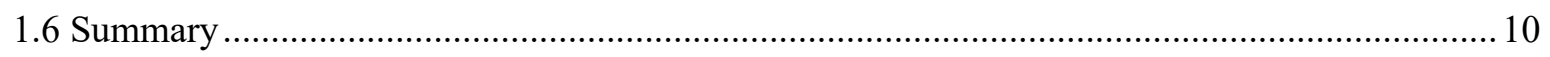

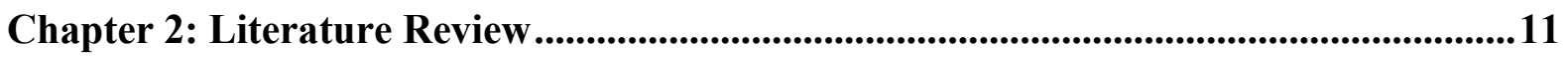

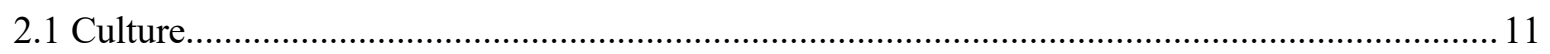

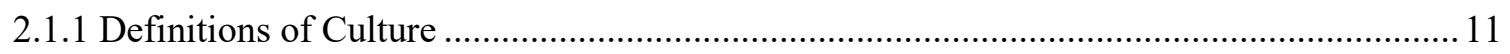

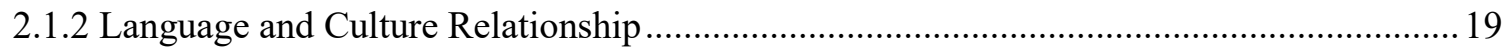

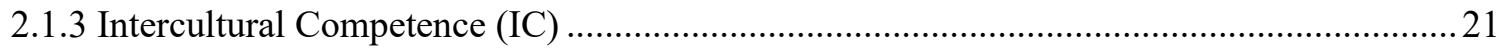

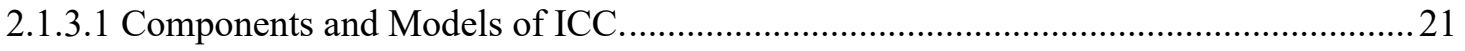

2.1.3.2 Byram's Model of Intercultural Communicative Competence.....................................24

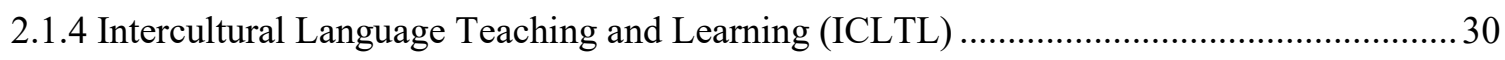

2.1.4.1 Principles of an Intercultural Approach to Language Education. ................................... 30

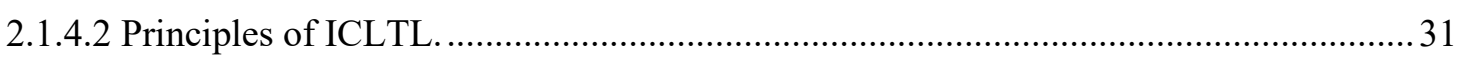

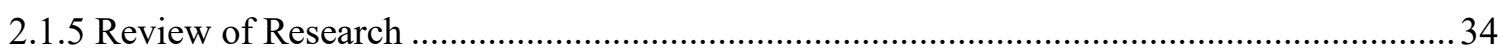

2.1.5.1 Research on Teachers' Beliefs and Practices of Teaching Culture.................................. 35

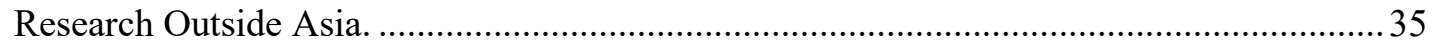

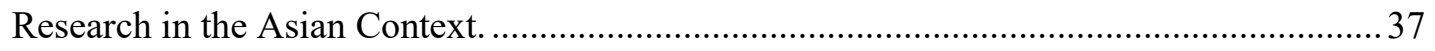

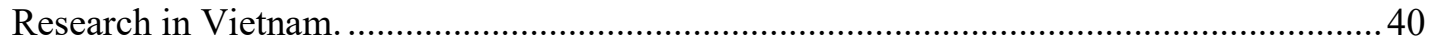

2.1.5.2 Research on the Intercultural Innovation in Language Class........................................ 41

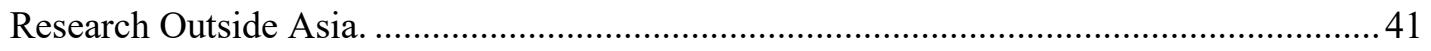




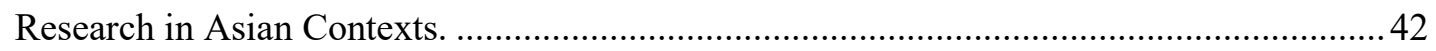

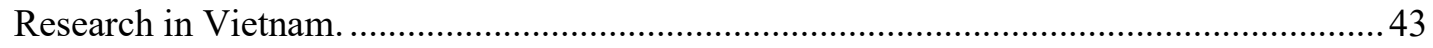

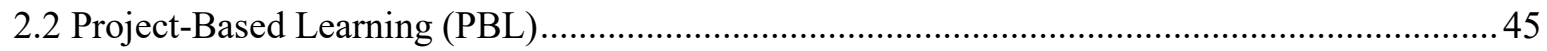

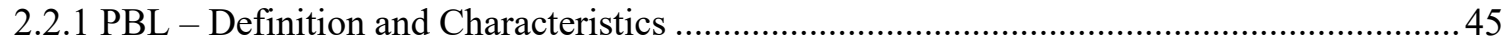

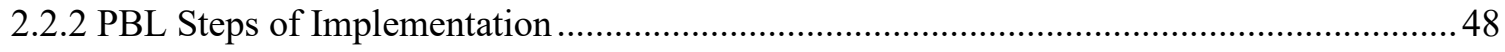

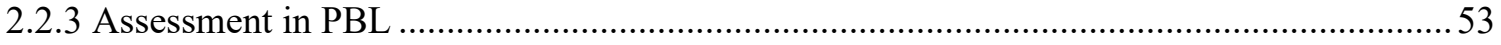

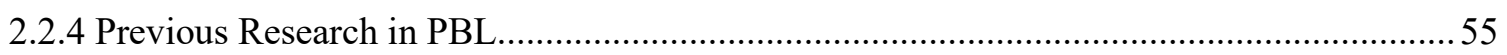

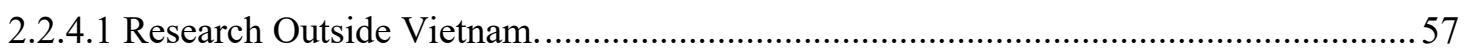

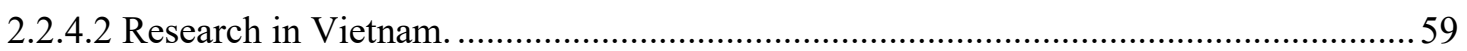

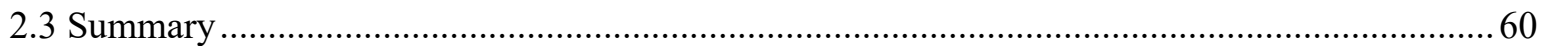

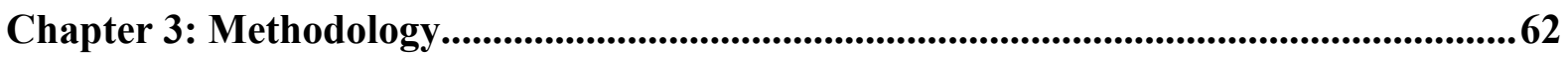

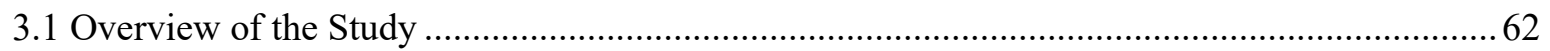

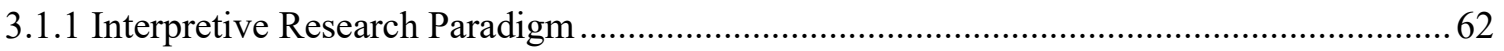

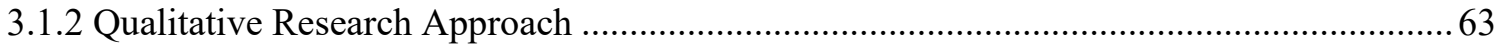

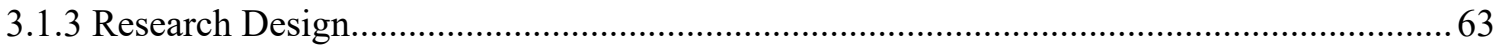

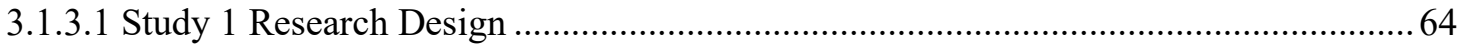

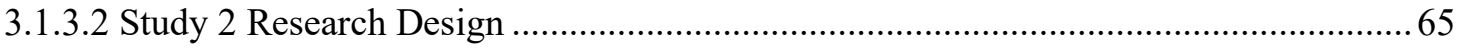

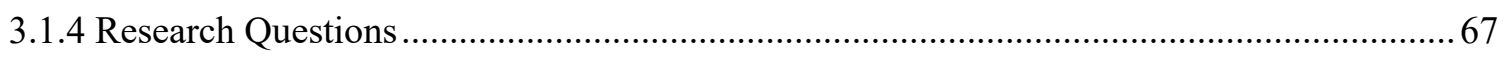

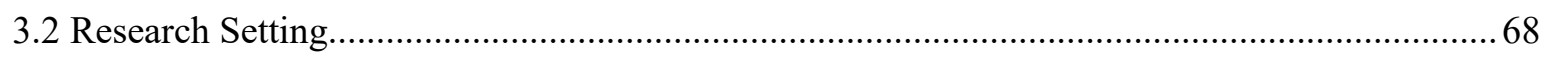

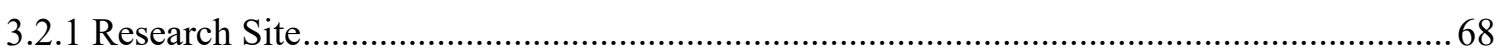

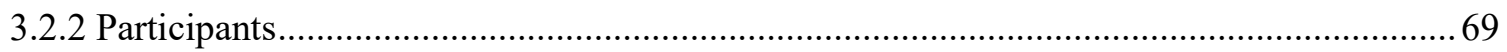

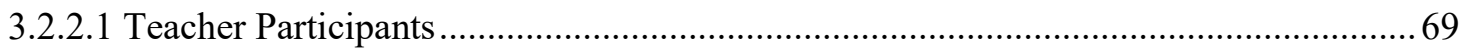

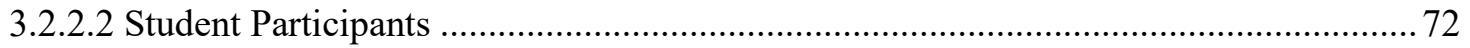

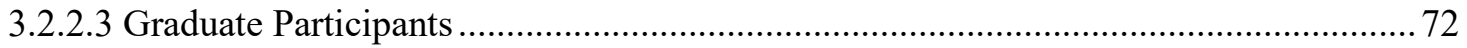

3.2.2.4 Employer Participants ........................................................................................... 73

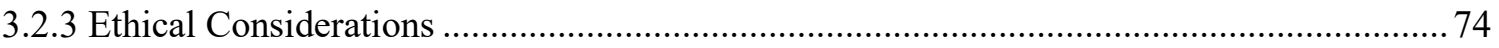

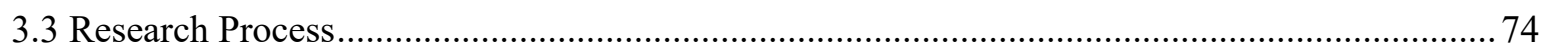

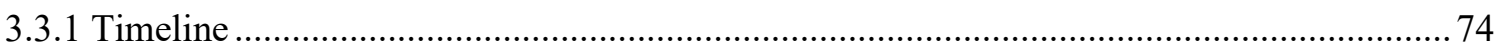

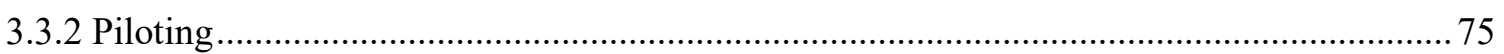

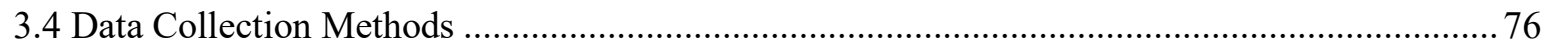

3.4.1 Classroom Observations (in both Studies 1 and 2) …........................................................ 77

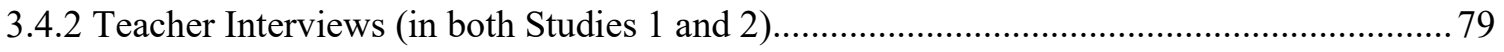

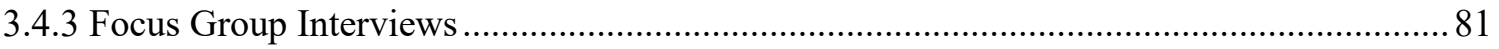

Student Focus Group Interviews (in both Studies 1 and 2) ..................................................... 81

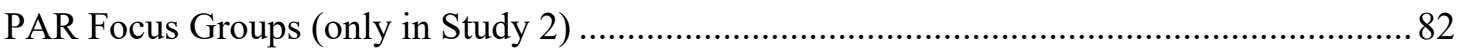




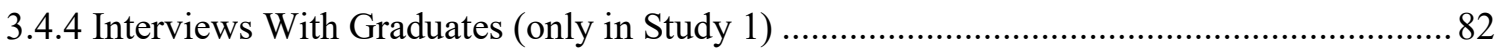

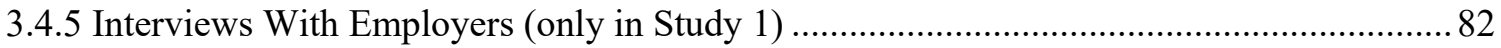

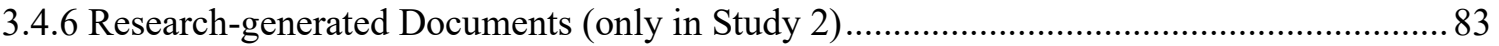

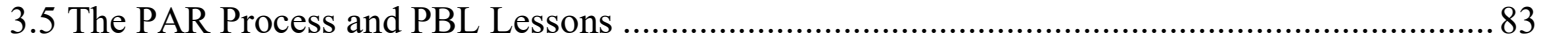

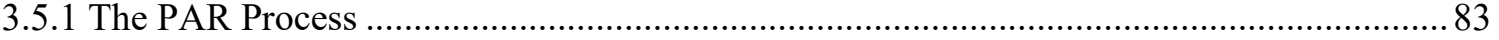

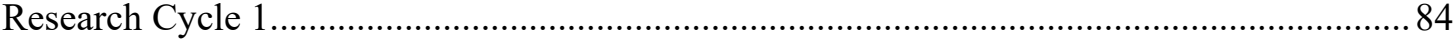

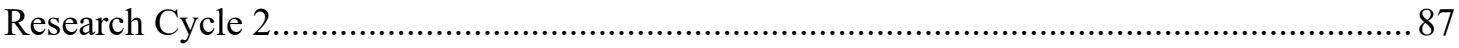

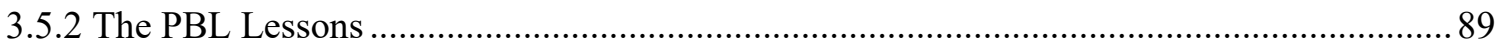

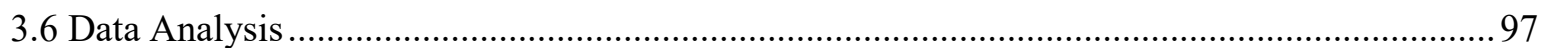

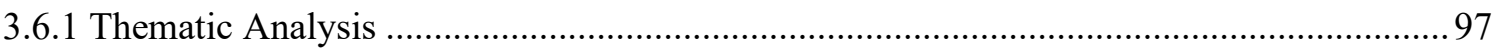

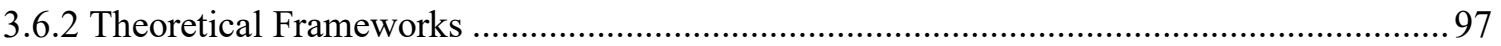

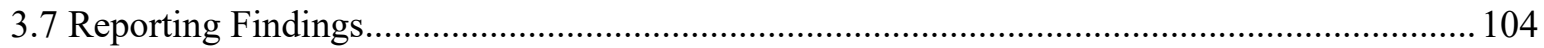

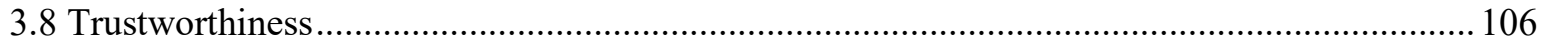

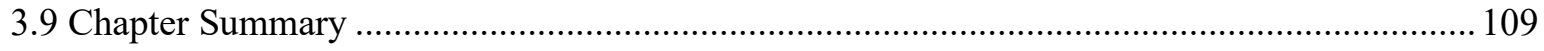

Chapter 4: Study 1 Findings and Discussion................................................................................110

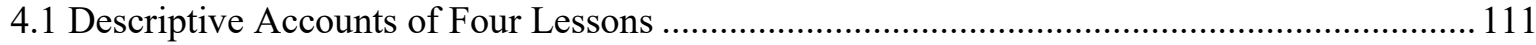

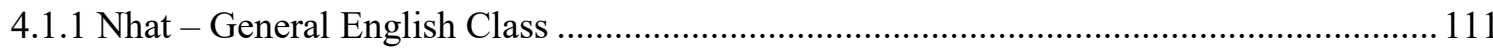

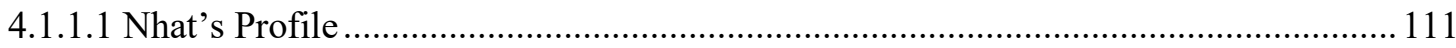

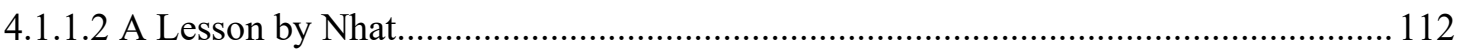

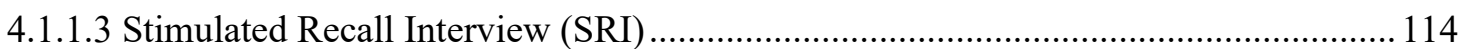

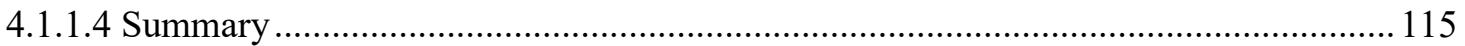

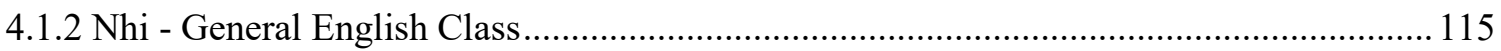

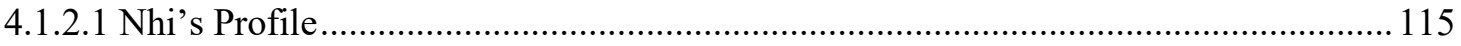

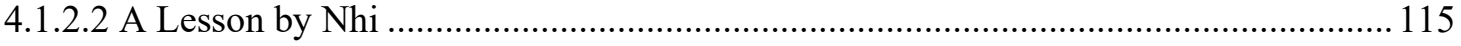

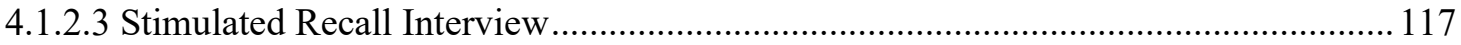

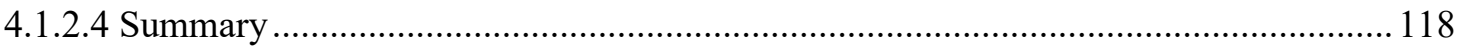

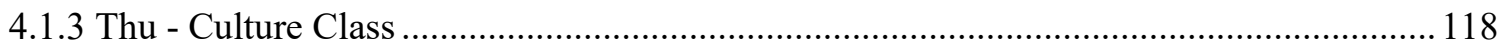

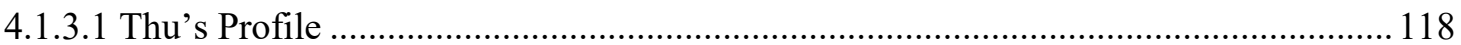

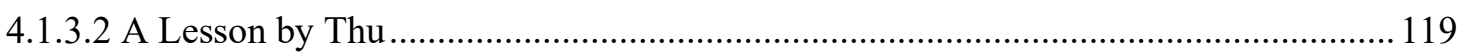

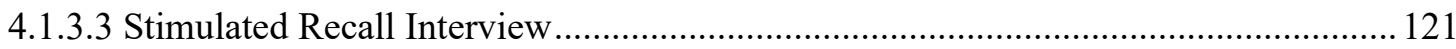

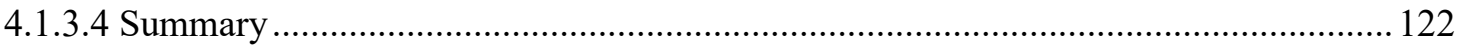

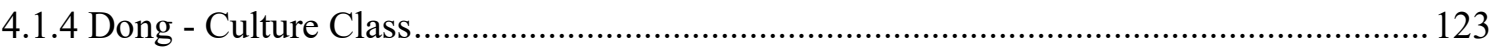

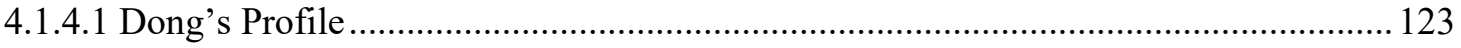

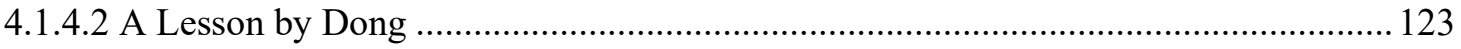

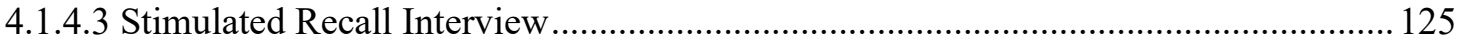




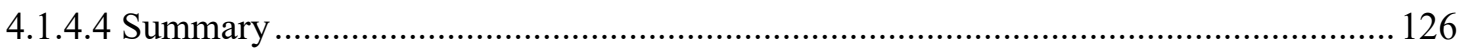

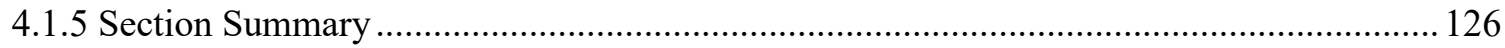

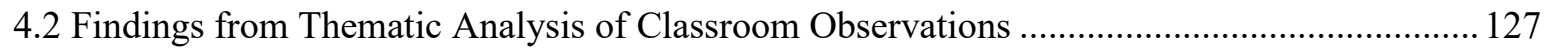

4.2.1 Cultural and Intercultural Content in General EFL classes.............................................. 127

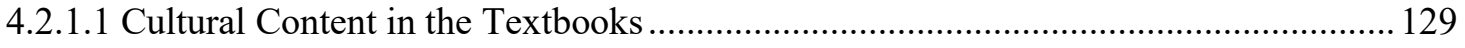

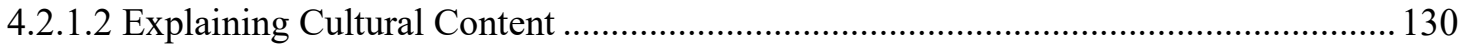

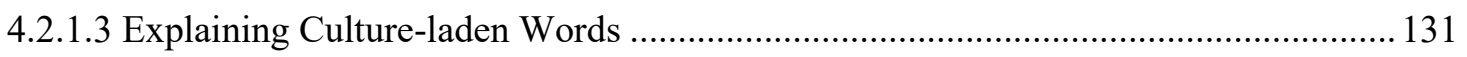

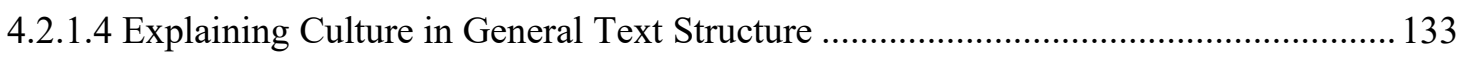

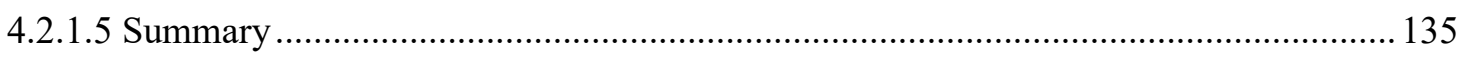

4.2.2 Representations of Cultural and Intercultural Content in CCC classes ............................. 135

4.2.2.1 Lecturing on General "Culture in Communication" Concepts .................................... 136

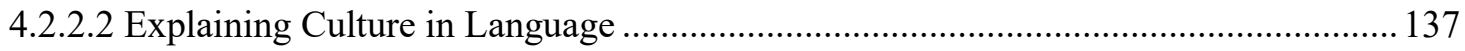

4.2.2.3 Raising Students' Intercultural Awareness via Activities........................................... 138

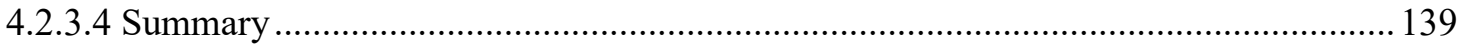

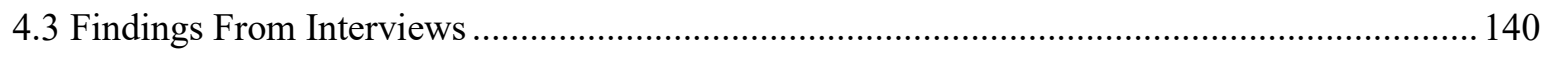

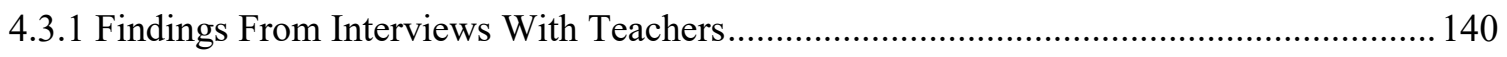

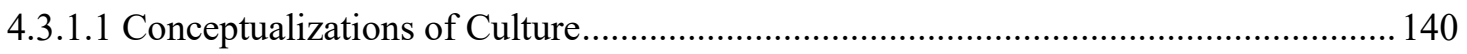

4.3.1.2 Role of Culture Teaching in Foreign Language Education ...................................... 144

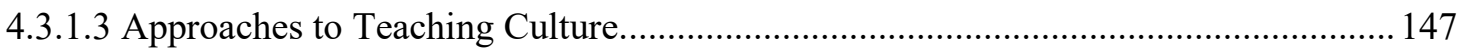

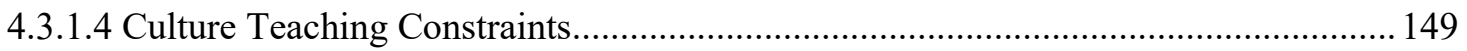

4.3.2 Findings From Student Focus Group Interviews ............................................................ 154

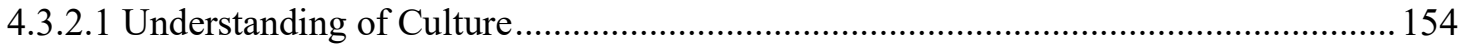

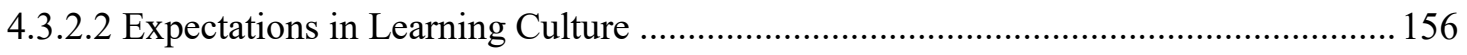

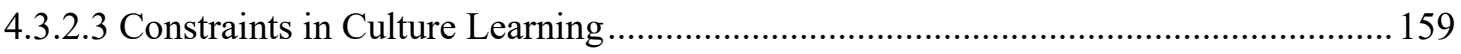

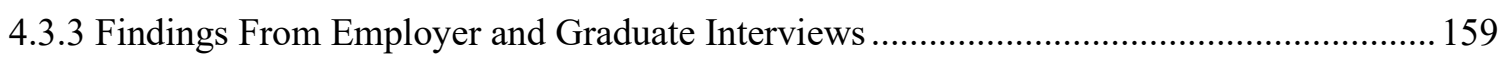

4.3.3.1 The Significance of Intercultural Skills in International Companies........................... 160

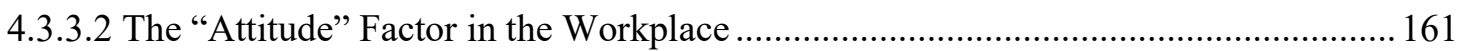

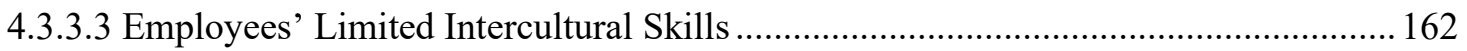

4.3.3.4 Suggestions for Culture Teaching at the University ................................................... 164

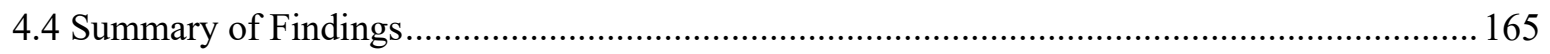

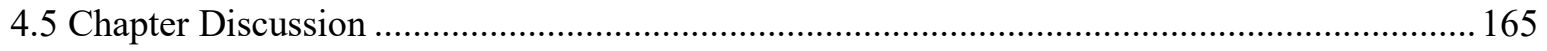

4.5.1 Representations of (Inter)cultural Content in the EFL classes......................................... 165

4.5.1.1 (Inter)cultural Representations in General EFL Classes ............................................. 165

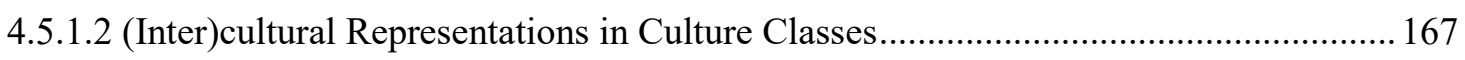

4.5.2 Teachers' Perceptions of the Role and Value of Culture in Language Teaching and Learning 


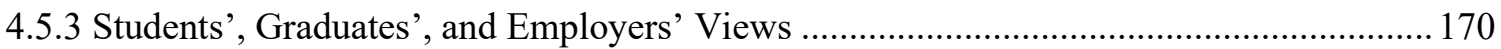

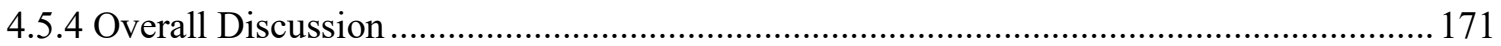

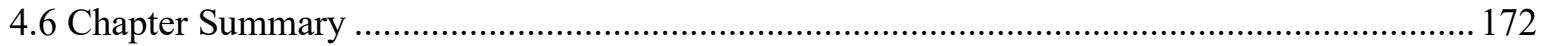

Chapter 5: Study 2 Findings and Discussion........................................................................173

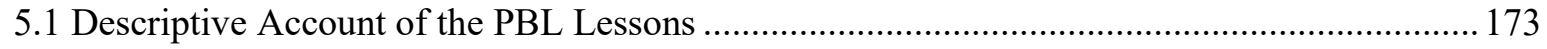

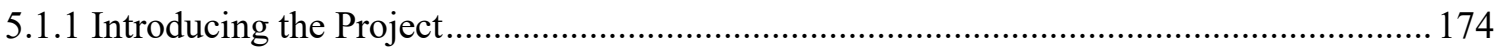

5.1.2 Guiding and Supporting Student Project Work .............................................................. 176

5.1.3 Evaluating Students' Performances ............................................................................... 182

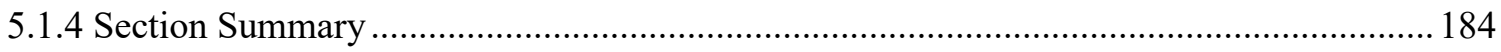

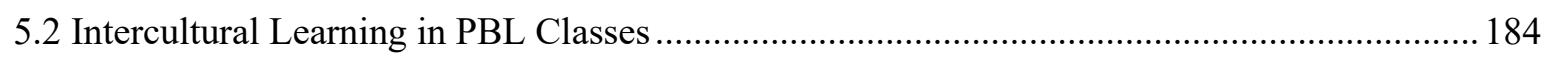

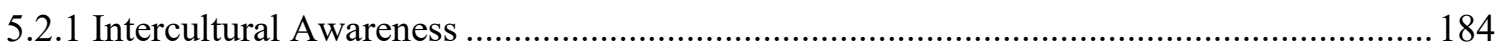

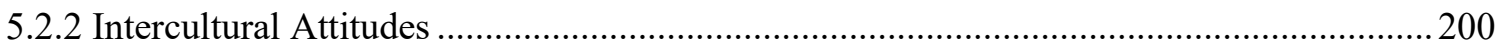

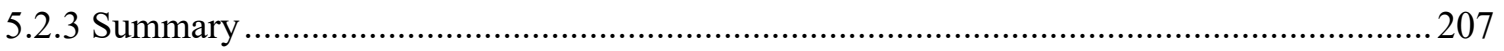

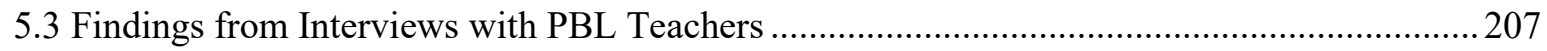

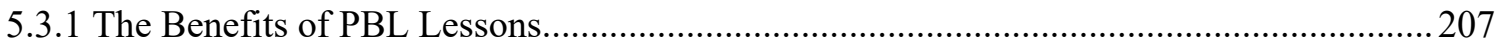

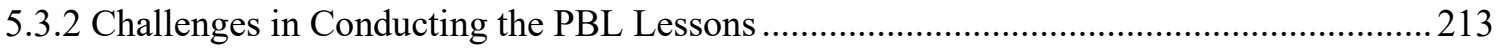

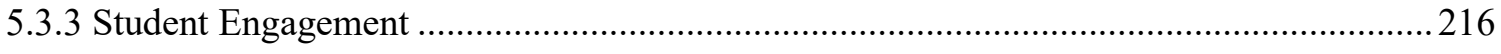

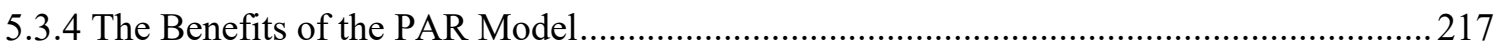

5.4 Findings from PBL Student Focus Group Interviews and Reflections...................................220

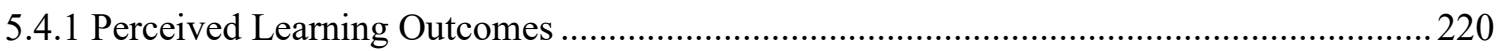

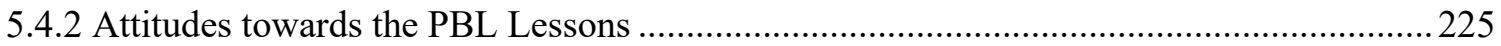

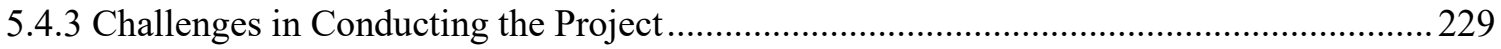

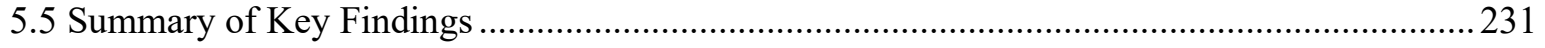

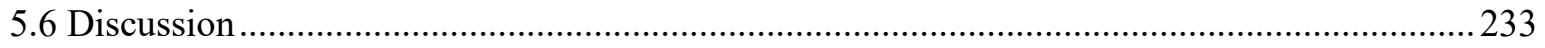

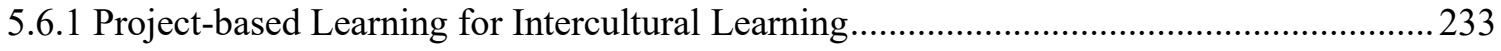

5.6.2 Participatory Action Research for Teacher Professional Development ..............................235

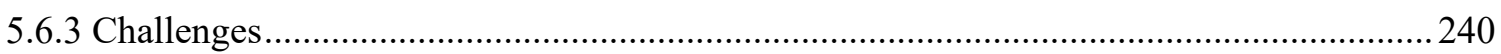

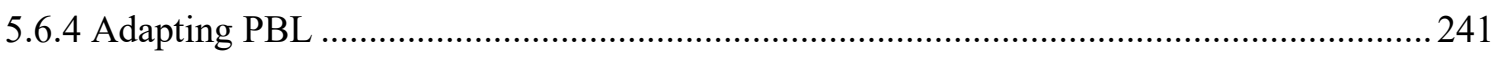

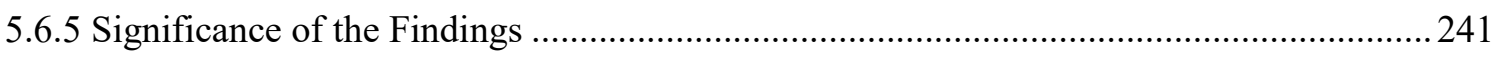

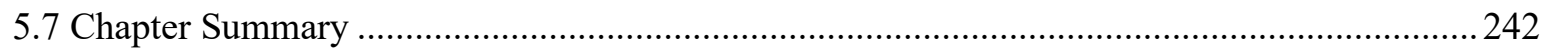

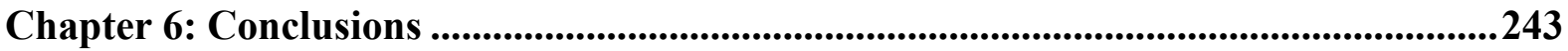

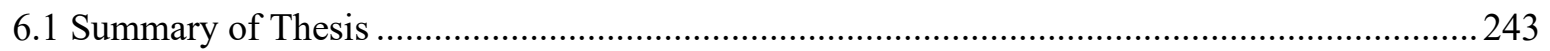

6.2 Implications for Teaching and Teacher Professional Development …...................................246

6.3 Limitations and Recommendations for Further Research....................................................2. 250

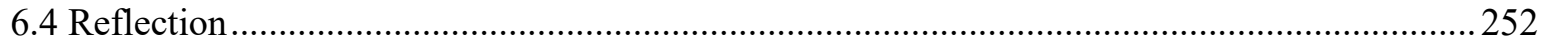


6.5 Concluding Remarks..

.252

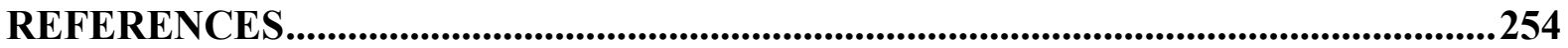

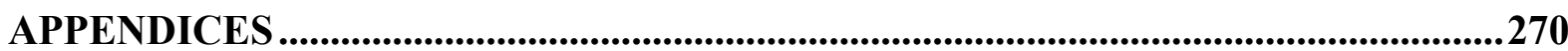




\section{List of Tables}

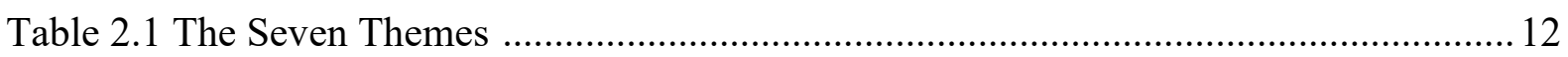

Table 2.2 Principles of Intercultural Language Teaching and Learning ............................... 31

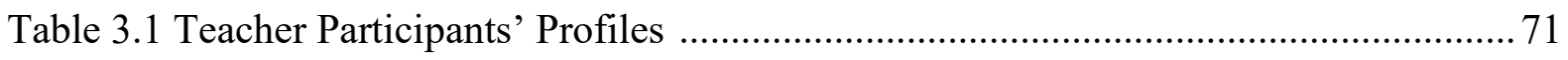

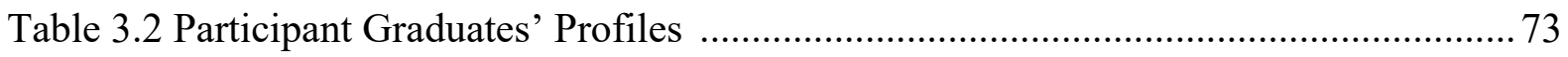

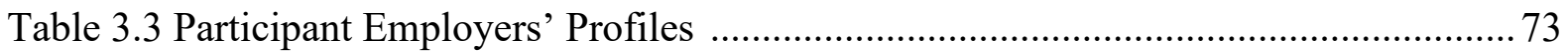

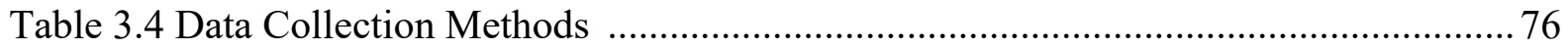

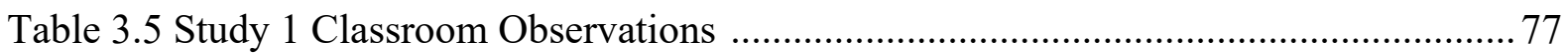

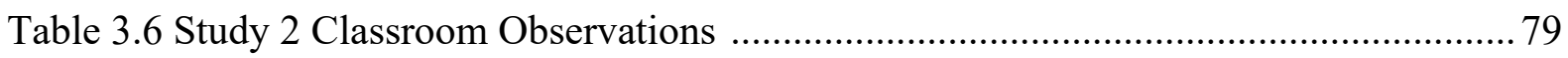

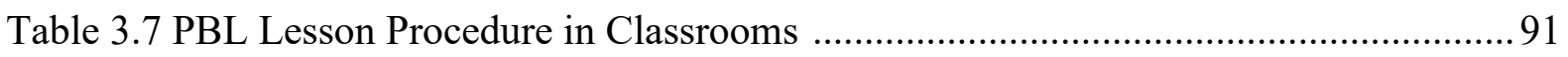

Table 3.8 Intercultural Content in Eight PBL Lessons ....................................................... 92

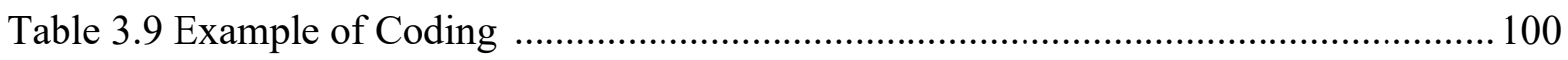

Table 3.10 Sample Analysis of How Tan Implemented a PBL Lesson.................................. 102

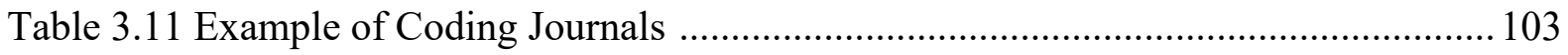

Table 4.1 Representations of (Inter)cultural Content in General EFL Lessons .................... 128

Table 4.2 Representations of (Inter)cultural Content in CCC Lessons ............................... 136

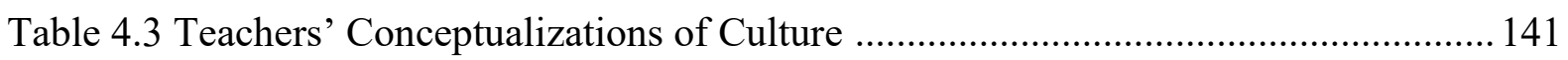

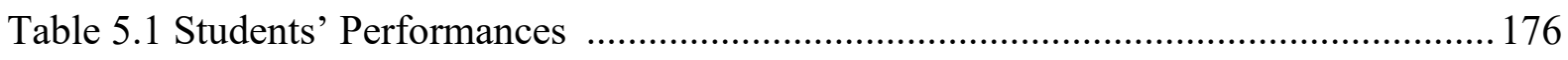

Table 5.2 Sample Intercultural Activities in Lesson 2 in the Three Classes ........................ 178 


\section{List of Figures}

Figure 2.1 Trompenaars and Hampden-Turner's Onion Model …......................................... 13

Figure 2.2 Hofstede and Hofstede's Onion Model of Culture ............................................... 13

Figure 2.3 Ting-Toomey and Chung's Iceberg Model of Culture ....................................... 14

Figure 2.4 Points of Articulation Between Culture and Language ...................................... 20

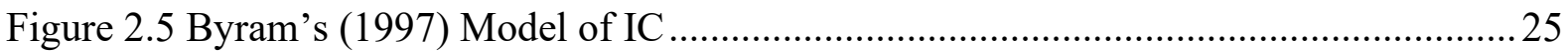

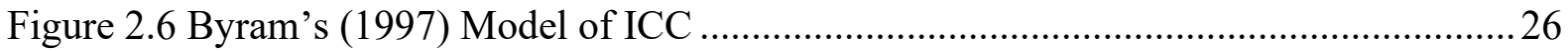

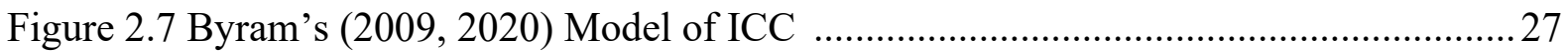

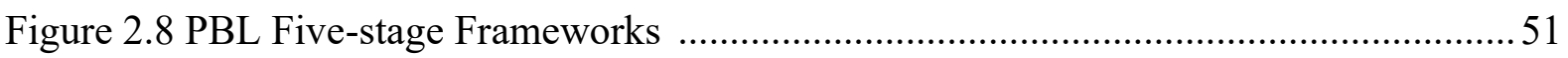

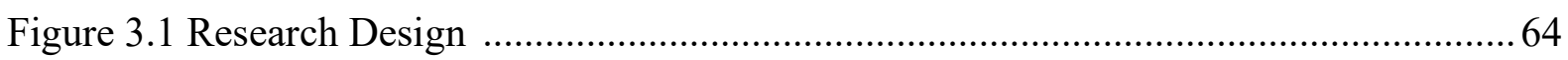

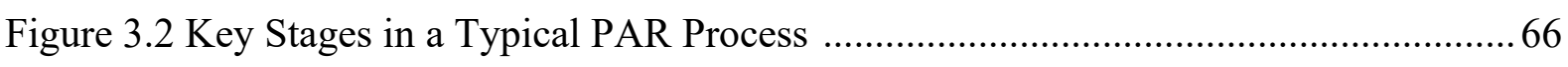

Figure 3.3 The Interconnected Model of Professional Growth ........................................... 83 


\section{List of Acronyms and Abbreviations}

CALL Computer-assisted language learning

CCC Cross-cultural communication

CEFR Common European Framework of References for Languages

CLT Communicative Language Teaching

CO Classroom Observations

$\mathrm{CoE} \quad$ Council of Europe

EFL English as a Foreign Language

FG Focus Group

IC Intercultural Competence

ICC Intercultural Communicative Competence

ILT Intercultural Language Teaching

ILTL Intercultural language teaching and learning

ICLL Intercultural language learning

iCLT Intercultural communicative language teaching

FFL Faculty of Foreign Languages

FL Foreign language

L1 First language

L2 Target language

NNS Non-native speaker

NS Native speaker

Obs Observations

PAR Participatory action research

PBL Project-based learning

PBLL Project-based language learning

SRI Stimulated Recall Interview

TBLT Task Based Language Teaching 


\section{Transcript Conventions}

\begin{tabular}{ll}
\hline \multicolumn{1}{c}{ Symbol } & \\
\hline “” & What is said by teachers or students \\
( ) & English translation of Vietnamese answers \\
$\ldots$ & Researcher's explanations \\
$\ldots$ & unfilled pause \\
{$[\ldots]$} & {$[\ldots]$ deleted text } \\
{$[$ sic $]$} & Indicate that something incorrectly written is intentionally left as it \\
& was in the original \\
T & Teacher \\
S1 & Student 1 \\
S2 & Student 2 \\
Ss & More than one student \\
{$[$ laughed] } & An explanation of actions or behavior \\
{$[$ advantage] } & A word added or replaced to clarify meaning \\
$?$ & The speaker is asking a question or raising the intonation \\
\hline & Falling intonation \\
$!$ & Emotional emphasis at the end of a phrase/sentence \\
&
\end{tabular}


This page is intentionally left blank. 


\section{Chapter 1: Introduction}

Intercultural competence (IC) is increasingly identified internationally as an educational goal. However, in Vietnam, despite emphasis on intercultural competence in national language education, research has shown it has a peripheral role in EFL classes. The current study was undertaken to address this gap. It investigates affordances for intercultural learning through project-based learning (PBL) in an EFL program at a Vietnamese university. This chapter introduces the study. It first presents the background to the research including the research context, the researcher's self-account, and the rationale for the research. Then it continues with an overview of the research, which is followed by discussion of the significance of the study. Finally, the chapter ends by describing the thesis organization.

\subsection{Research Context}

Intercultural competence has been increasingly recognized globally as an educational goal in response to international economic development. For the teaching of English as a foreign language, scholars have argued that language education needs to address intercultural goals alongside language goals (Corbett, 2003; Liddicoat et al., 2003; Newton et al., 2010), or enrich linguistic competence with intercultural competence (Byram \& Wagner, 2018). To realize these intercultural goals, scholars have suggested the adoption of intercultural language teaching and learning (ICLTL) principles, which highlight exploratory and experiential learning (Liddicoat \& Scarino, 2013; Newton et al., 2010). As Newton (2016) and Liddicoat (2008) argue, teachers can help foster students' intercultural competence by providing them with opportunities for intercultural exploration and experience. One way these learning processes can be fostered is through PBL, which has been shown to be effective in language learning classrooms (Affandi \& Sukyadi, 2016; Bakar et al., 2019; Beckett \& Miller, 2006; Stoller, 2006; Sultan \& Javaid, 2018).

In Vietnam, the languages selected as foreign language subjects in schools have changed throughout Vietnam's history, depending on its political situations (Nguyen, 2017). For example, French was popular in the 1880s under French colonial rule (Do, 2006). English and French were used in the South Vietnam educational system during the American war (1954-1975) while Chinese and Russian were taught in the North of Vietnam due to Chinese and Russian influence in the North. 
Since Vietnam enacted "Doi Moi” policy - its open-door market-oriented policy in 1986, it has expanded political and economic relations with the West. According to Hoang (2020) and Nguyen (2017), English has gained the status in Vietnamese education as the most selected foreign language to study by Vietnamese students at all educational levels. It is also widely used in communication in tourism, science and technology, trade, and advertising (Sundkvist \& Nguyen, 2020). However, English is largely absent from the everyday lives of most people in Vietnam, especially in rural areas. The focus of my study is on the lives of university students who are seeking to work in professions or industries where they are likely to need to use English or encounter it.

In language education, the status of English is reflected in many governmental documents. For example, the Government Decree 1400/QD-TTg (Government, 2008) states that the overall objective of foreign language education is enhancing learners' English ability so that they can use English independently and confidently for studying and working in multicultural and multilingual contexts. This is seen to be crucial for the goals of national industrialization and modernization. This policy document thus calls for change in language teaching to achieve these goals. In particular, it explicitly specifies adoption of the Common European Framework of Reference for Languages: Learning, Teaching, and Assessment (CEFR) as a framework for foreign language (FL) teaching and learning at all levels of education in Vietnam.

The national policy emphasizes preparing language learners for intercultural communication. However, previous research has revealed a trend in Vietnamese tertiary classrooms for teacher-centered teaching methods and exam-based curricula with little attention to developing students' intercultural skills (Chau \& Truong, 2019; Doan, 2014; Ho, 2011; Nguyen, 2011; Nguyen, 2013, 2015; Tran \& Dang, 2014). In rare cases when culture is addressed, the focus is on providing cultural facts and presenting English native norms as the model, which does not align with current theories of the field (cf. Liddicoat \& Scarino, 2013; Newton, 2016; Newton et al., 2010).

The findings from these empirical studies reveal mismatches between scholars' increasing calls for greater incorporation of intercultural learning and the Vietnamese government's interculturally oriented policies on the one hand, and the current Vietnamese foreign language classroom practices on the other. 
One of the reasons for these mismatches is that teachers are not cognizant of intercultural language teaching and have limited opportunities for professional development in this area. For instance, Nguyen $(2013,2015)$ shows that teachers are not well informed about the inclusion of intercultural learning goals in the Vietnamese national foreign language education policy. Scholars have identified intercultural competence as an under-valued goal in Vietnam EFL classes (Chau \& Truong, 2018; Ho, 2011; Nguyen, 2011; Nguyen, 2013). Similarly, there is a lack of teacher professional development focused on intercultural language teaching (Nguyen, 2013). According to Le (2015a), the limited availability of highquality in-service professional development is a significant barrier to the quality of teaching English in Vietnam. In addition, little research has been conducted on how such professional development impacts EFL teachers in Vietnam on addressing cultural content.

To date, there has only been one main study investigating how teacher professional development influenced the integration of culture into Vietnamese EFL classes by Tran (2020). The author guided three teachers through two workshops and observed the teachers' post-workshop teaching practices and emerging perceptions of an intercultural stance in EFL lessons. Tran (2020) focused on the extent to which the teachers followed a pre-determined lesson design in their post-workshop lessons. She found that the workshops had a positive impact on the three participant teachers' implementations of intercultural lessons.

As mentioned above, teacher professional learning for intercultural teaching and learning (ICLTL) is under-researched in Vietnam. In addition, no research has been conducted to investigate a project-based learning approach to foster ICLTL in this context despite a call for IC in Vietnamese educational policy and reported benefits of PBL in worldwide scholarship. Given these reasons, this study is conducted to fill this gap. It focuses on investigating the viability of fostering intercultural teaching and learning via a PBL approach. The research includes two studies. Study 1 is an ethnographically informed study, which involved 14 teachers, 265 students, 6 graduates and their employers. Data were collected from classroom observations, student focus group interviews, and interviews with teachers, graduates and employers. Study 2 is participatory action research, in which a semester-long project was introduced to foster intercultural learning. This phase included two workshops, one at the beginning and one in the middle of the project. In these workshops, the researcher and three teachers collaboratively learned about ICLTL, and planned PBL lessons. 


\subsection{Researcher's Background}

This section briefly describes my professional and personal experience, which has motivated me to conduct this research. My great interest in the intercultural dimension of English teaching began when I attended a cross-cultural course in my last semester at university. My eyes were glued to the board when my teacher introduced iceberg theory, which describes culture as an iceberg including visible components on the surface and hidden components under the water. I was especially interested in knowing the hidden aspects of the iceberg, which includes complex ideas, attitudes, and values. My interest grew in every lesson, as we covered such topics as body language and face-threatening acts.

I realized I became more tolerant after I figured out that people's behaviors that might be considered inappropriate or unacceptable could be, in many cases, traced down to their limited understanding of cross-cultural differences. Therefore, I thought it could be possible to enhance people's interaction and lessen misunderstanding if they were equipped with cross-cultural knowledge. However, at that time, the lectures were limited to some differences between English-speaking countries and Vietnamese cultures. Born in a family with a mother and father from different backgrounds in Vietnam, I was deeply aware that differences existed even within a country. Therefore, I aspired to enrich my knowledge and my intercultural competence as much as possible.

After graduation, I worked as an English language teacher at a university. Coincidentally, I was assigned to teach cross-cultural communication (CCC) courses for English majors. The teaching materials were chosen by the English faculty. They were a collection of outdated pieces of writing on English-speaking countries' cultural elements from various books by different authors. The compiled books focused on addressing etiquette in America and Britain, general descriptions of various facial expressions, gestures, body languages, and their meanings. As stated in the guidelines for teaching the course, the teachers' task was mainly conveying the information in the books, and clarifying what students found vague. The students had to listen to teachers, memorize and do follow-up tasks. The objective of the course was to help students broaden their cultural knowledge and know how to communicate successfully.

As a dedicated teacher, I always strived to deliver lessons in a way that sounded interesting, easy to understand, easy to remember, and, most significantly, valuable for the students' 
future work. A thorough study of the books reinforced my feeling that if I followed them and the guidelines for teachers, my lessons would not achieve what I thought the intercultural communication course was meant to achieve in terms of preparing students for their future life. This was because students in this scenario would be too passive and there would be no intercultural communication. For these reasons, I decided not to follow the books and I replaced them with what I found from reliable media sources and designed interactive activities based on them. In addition, I assigned students projects so that they could engage in experiential learning.

To my amazement and delight, the students enthusiastically took part in the lessons. From my observations, they shared their tasks of interviewing foreigners, writing scripts for their plays, making videos, searching for images and background music, making their films, acting, and surfing the net for information. They even designed costumes for plays, such as clothes for an Indian wedding. When a group presented, other students watched with great interest and commented, raised questions, and took part in the groups' follow-up activities. The success of the lessons was much more than I had expected. The students' feedback was very positive. They all said they found the course interesting, valuable, and profitable to them in terms of language, intercultural communication, collaboration skills, and more tolerant attitudes toward cultural differences. Despite the students' preference for my newly designed lessons, I felt unsatisfied. I kept wondering whether my practices aligned with any intercultural teaching principles.

In addition to these professional concerns, I encountered some problems in personal intercultural encounters. Among these, I was most confused by an older American friend's reaction to our kindness on his birthday. Before our American friend's birthday, we, a group of Vietnamese students, thought we should give our American friend a big surprise by preparing a birthday party for him in a restaurant. So, on his birthday we asked him to go out with us without notifying him of the party. When he came to the restaurant, knowing our intention, he got angry. We were so shocked and hurt. Later, I realized that we had intended to show care and kindness. We had previously read from some articles that Americans loved surprise parties. However, the American friend had interpreted our behavior as disrespectful as he valued directness and preferred to be informed of the event. This showed me the complexities of intercultural encounters - that I cannot generalize about a group of people based simply on their nationality. 
After the birthday event, when I conducted my EFL lessons, I kept wondering what challenges my students would face, especially in their future intercultural encounters, if the lessons mostly focused on language goals. Although there was a CCC course as mentioned above, the lessons were delivered in a teacher-centered fact-giving manner. Additionally, the CCC lessons were only for students in the last semester of their university study and were only an extra, optional course. Considering all these factors, I concluded that the current teaching situation could not fully address students' needs for their future intercultural communication.

Reflecting on my professional concerns and personal intercultural experience, I decided to pursue my Ph.D. journey. I aimed to enhance my knowledge of ICLTL and through my research to contribute to an understanding of ICLTL in the field, and in particular in the enhancement of intercultural learning in my university and in Vietnam.

\subsection{Overview of the Research}

This section provides an overview of the research purpose, the design of the study, research questions and methodology.

\subsubsection{Purpose of the Research}

This study was conducted to contribute to EFL teaching in Vietnam tertiary education. Specifically, it aims to foster students' intercultural competence as a response to the Vietnamese government's call for developing interculturally competent graduates so as to support Vietnam's international engagement. This study investigates the process of adopting the PBL approach to foster intercultural learning. The study focuses on how a small group of teachers developed their expertise in facilitating intercultural learning, indications of students' intercultural competence, and teachers' and students' perceptions of their PBL experience.

\subsubsection{Research Design and Research Questions}

The research was conducted in two linked studies. 


\section{Study 1 Objectives}

Study 1 aimed to identify the affordances for adopting a PBL innovation to foster intercultural learning in a Vietnamese tertiary context. It involved document analysis, and rich ethnographically informed descriptions of the teaching practices and stated perceptions of EFL teachers at a Vietnamese university and perceptions of other stakeholders. A thematic analysis of the collected data identified factors that acted as affordances or constraints on the PBL innovation.

\section{Study 2 Objectives}

Study 2 aimed to examine the efficacy of adopting the PBL approach to foster intercultural learning. This study involved two workshops in which three teachers collaborated and learned about intercultural language teaching and learning. In the workshops, the teachers developed their expertise through designing PBL lessons in collaboration with the researcher, and with each other. Study 2 sought to provide evidence of the extent to which teachers were able to successfully implement the PBL lessons and their emerging understandings about intercultural language teaching and learning (iCLT) and PBL, and of students' engagement with intercultural learning.

Study 1 answered the following overarching question:

\section{RQ1: How is culture addressed in a Vietnamese EFL university context?}

Note that this question does not presuppose that if and when cultural themes or content appears in a lesson that it will be addressed interculturally. Section 2.1.1 of the literature review discusses the different approaches to engaging with culture in the language classroom, some of which align with the principles of an intercultural approach, and some of which do not. For this reason, the following questions refer to "cultural and intercultural content", in order for the research to fully capture all the ways that culture appears and is addressed in language teaching and learning.

This question is divided into five sub-questions:

1(a) How are cultural and intercultural content evident in the teaching of general EFL English classes and EFL culture classes at a university in Vietnam? 
1(b) How do teachers explain this cultural and intercultural content in stimulated recall interviews?

1(c) How do teachers perceive the role and value of cultural and intercultural content in language teaching and learning?

1(d) How do students perceive cultural and intercultural content in their language learning?

1(e) How do employers in international companies and recently graduated employees evaluate the importance of intercultural communication skills?

Study 2 addressed the following overarching question:

\section{RQ2: How can project-based learning foster intercultural teaching and learning in a}

\section{Vietnamese EFL university context?}

This overarching question is divided into the following sub-questions:

2(a) How did the three teachers implement the PBL lessons?

2(b) What intercultural learning processes were evident in the PBL lessons?

2(c) How did the teachers perceive the PBL lessons?

2(d) How did the students perceive the PBL lessons?

\subsubsection{Methodology}

This section presents a brief overview of the methodology used in the thesis. Details are given in Chapter 3. This study employed the interpretive qualitative case study approach (Chen, Shek \& Bu, 2011; Hua, 2016) and Participatory Action Research (Ragsdell, 2009; MacDonald, 2012; Bergold \& Thomas, 2012) as the research methods to address the research questions. In Study 1, the researcher observed teachers' normal classroom teaching practices and investigated their perceptions of culture teaching. In study 2 , the PAR project consisted of two research cycles. Cycle 1 began with reflections based on materials from Study 1 findings and Workshop 1. This was followed by the planning, then the implementation of PBL lessons 1-4. This ended the first cycle. The second cycle began with the reflections of lessons 1-4. Then, the cycle continued with planning PBL lessons 5-8 and implementing these lessons. This cycle ended with reflections. 
The study was conducted at a university in the north of Vietnam during a fifteen-week semester. The teacher participants were EFL tertiary teachers at that university. The student participants were the students in the classes taught by these teachers.

The three main data collection methods were: video-recorded post-workshop classroom observations of the teachers' teaching, audio-recorded post-observation interviews with teachers, and pre-workshop-one focus groups and post-workshop-two focus groups with students. For data analysis, I followed the process of qualitative data analysis suggested by Creswell (2012), Patton (2002), and Merriam and Tisdell (2016), and the thematic analysis method suggested by Braun and Clarke (2006, 2012).

\subsection{Significance of the Research}

This research is significant in four main ways. First, it contributes to the current understanding of how culture is addressed in foreign language teaching by reporting on findings on the representations of culture/interculture in EFL classrooms in a Vietnamese tertiary context. Second, the research contributes to the under-researched area of adopting project-based learning (PBL) to foster intercultural learning, especially in Asian and Vietnamese tertiary contexts. It provides evidence of teachers' practices and students' intercultural learning in project-based learning (PBL) lessons, and teachers' and students' perceptions of this instructional approach. Third, the research adds to the understanding of contextual factors that challenge intercultural learning and teaching in the context. Finally, the research provides insights into the effectiveness of the participatory action research model in teacher professional development through presenting how the researcher and the teachers successfully collaborated to conduct the PBL lessons. All these contributions provide pedagogical, theoretical, and methodological implications, which are helpful to applied linguistic researchers, language education policymakers, curriculum designers, teacher trainers, and language teachers.

\subsection{Organization of the Thesis}

The thesis consists of six chapters. Chapter 1 introduces the thesis. It presents the background to the research, the rationale, and objectives of the study, the overview of the study, and the significance of the study. Chapter 2 is devoted to a literature review that critically discusses previous research and key concepts underpinning the study, such as concepts about culture, 
language, intercultural competence and intercultural language teaching, and project-based learning. Chapter 3 describes and justifies the methodology and methods used in the research. Specifically, it details the interpretive paradigm, participatory action research, data collection methods, thematic analysis, ethical issues, and trustworthiness. Chapters 4 and 5 report on and discuss findings of Study 1 and Study 2 respectively. Chapter 4 details the findings and discussion of these findings on how culture was addressed in the context and what teachers and students thought about culture learning and teaching. Chapter 5 presents findings and discussion of findings on how teachers' expertise evolved in terms of implementing PBL lessons, and teachers' and students' stated experience of PBL lessons. Finally, Chapter 6 concludes the thesis. It summarizes main findings, draws pedagogical, methodological, and theoretical implications, discusses the limitations of the study, and proposes directions for further research.

\subsection{Summary}

This introductory chapter has provided an outline of the study. It first presented the background to the study, in which it briefly situated the research in the area of intercultural language teaching and learning. Then it indicated the gap in the field and explained how the research fills the gap by justifying the research purpose and providing an overview of the study, its research questions, and methodology. Next, the chapter continued with a discussion of the significance of the research. Finally, it ended with a description of the thesis organization. In the next chapter, I will critically review the literature underpinning the research. 


\section{Chapter 2: Literature Review}

This chapter reviews the literature relevant to my study and provides the theoretical frameworks underpinning my research. My study investigates the current situation of addressing culture in language teaching in a Vietnamese tertiary context, and the feasibility of adopting PBL (Project Based Learning) in fostering Intercultural Language Teaching and Learning (ICLTL) through an intervention. Accordingly, this chapter includes two overarching categories (1) Culture and (2) Project. It begins with a review of key theorizations of culture, the relationship between culture and language, intercultural competence, and ICLTL principles. Then it reviews research studies on teachers' beliefs and their practices in addressing culture in language teaching. Next, the chapter discusses the second main theme "PBL", detailing key concepts of PBL, characteristics of PBL, stages in PBL implementation, and PBL assessment. This section is followed by a review of PBL studies related to the topic. The chapter ends with a summary of the literature review and highlights the gap in the field, which is addressed in the current study.

\subsection{Culture}

\subsubsection{Definitions of Culture}

Culture is a common concept across disciplines such as cultural studies, education, sociology, and anthropology, and thus it has been variably defined. Due to its complexity, the debate around conceptualizations of culture has attracted a large number of scholars. This thesis is not meant to cover all definitions of culture. Instead, I will review key understandings of culture that relate to language teaching and intercultural communication. Specifically, I will begin with a summary of themes developed from definitions of culture in social science by Faulkner et al. (2006). From this classification of themes across multiple disciplines, I investigate major perspectives in defining culture in language teaching from three groups of classifications: visualized models of culture definitions; Kramsch's (2006, 2013, 2015) modernist and post-modernist perspectives; Liddicoat and Scarino's (2013) conceptualizations of culture in language teaching. The review continues with some definitions of culture and ends with a summary of the review. 
In social science, a significant way of grouping definitions of culture is based on their themes. Faulkner et al. (2006) outline seven themes from their thorough compilation of more than 300 definitions of culture across disciplines in social science as in Table 2.1 below

Table 2.1

The seven themes (Summarized from Faulkner et al., 2006, p.30)

\begin{tabular}{cl|l}
\hline \multicolumn{1}{c|}{ Theme } & Definitions of culture \\
\hline 1. Structure/ Pattern & Culture as a system of framework of elements \\
\hline 2. $\quad$ Function & Culture as a tool toward some end \\
\hline 3. $\quad$ Process & The ongoing social construction of culture \\
\hline 4. $\quad$ Products & Artefacts \\
\hline 6. $\quad$ Pefinement & $\begin{array}{l}\text { As a sense of individual or group cultivation to higher intellect or } \\
\text { morality. }\end{array}$ \\
\hline 7. $\quad$ Group Membership & $\begin{array}{l}\text { Group-based power (including postmodern and postcolonial } \\
\text { definitions). }\end{array}$ \\
\hline
\end{tabular}

The first three themes: structure, function, and process are commonly found in the majority of compiled definitions of culture while one or more of the other terms may be integrated into a conceptualization (Faulkner et al., 2006). What themes are emphasized in a definition indicates the position of the scholar. For example, a focus on structure/pattern or function theme may indicate positivist or neo-positivist positions, while stress on communicative and social processes shows an interpretive nature. A definition is critical if power is highlighted.

In language teaching, the first main groups of scholars offer visualized models of culture such as an onion (Hofstede et al., 2010; Trompenaars \& Hampden-Turner, 1998), and an iceberg analogy of culture (Ting-Toomey \& Chung, 2005; Weaver, 1993). Both Trompenaars and Hampden-Turner (1998) and Hofstede et al. (2010) offer the onion model with the layers of the onion reflecting different dimensions of culture. While in Trompenaars and HampdenTurner's (1998) model, culture contains three layers: artefacts and products as the outer layer, norms and values as the middle layer, and basic assumptions as the core (see Figure 2.1), in Hofstede et al.'s (2010) model, culture consists of four layers symbols, heroes, rituals, and values as the core (see Figure 2.2). Despite the differences in the number of layers and their 
names, these two onion models are fundamentally similar in having the non-observable element at its core and observable elements in outer layers.

\section{Figure 2.1}

Trompenaars and Hampden-Turner's onion model

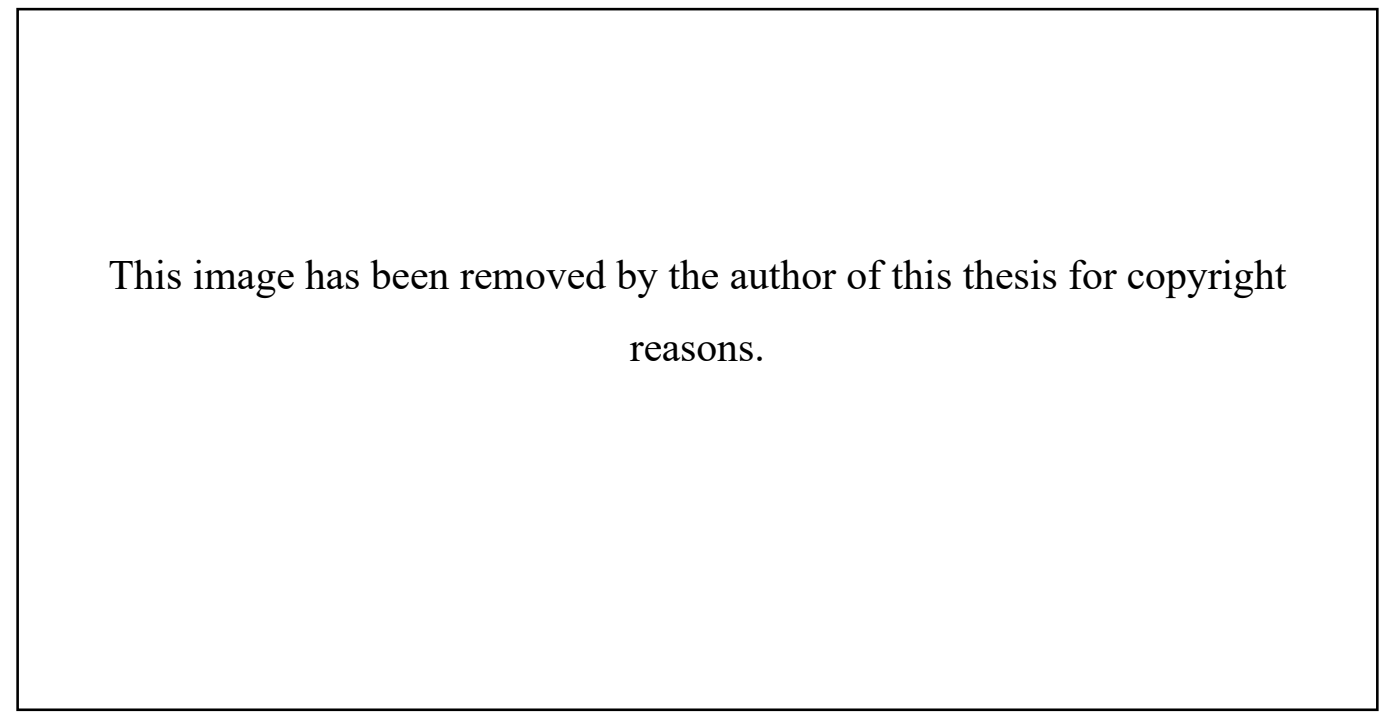

(Source: Trompenaars \& Hampden-Turner, 1998, p.22)

\section{Figure 2.2}

Hofstede and Hofstede's onion model of culture

This image has been removed by the author of this thesis for copyright reasons.

(Source: Hofstede \& Hofstede, 2005, p.7) 
Alternatively, culture is envisioned as an iceberg (Ting-Toomey \& Chung, 2005; Weaver, 1993). Ting-Toomey \& Chung's (2005) model of culture (see Figure 2.3) differs from Weaver's (1993) in its division of the invisible part of the iceberg into more small components while the visible part is similar in the two models. In the latter model, the first layer under the dividing line consists of intermediate-level culture like symbols, meanings, and norms and the layer underneath includes deep-level culture like traditions, beliefs, and values. This model also explains universal human needs as the root of the deep culture.

\section{Figure 2.3}

Ting-Toomey and Chung's iceberg model of culture

This image has been removed by the author of this thesis for copyright reasons.

(Source: Ting-Tomey and Chung, 2005, p.28)

The above iceberg and onion culture analogies are similar in dividing culture into visible and invisible parts and present a perspective of seeing culture as a thing. These models limit themselves to defining culture as static. As Liddicoat (2002) states, "culture is not about information and things, it is about actions and understanding". Characterizing culture as a 'thing' can easily lead to "essentialist and deterministic" descriptions of others, which, according to Baker (2015), impede intercultural communication. Furthermore, Bennet (2013) asserts that it is time to retire the image of the iceberg because "the metaphor does not in any way imply that culture is a process of coordinating meaning and action - rather, it implies 
that culture is an entity with mysterious unknown qualities" (para. 4) and "we want our students or clients to engage culture in a dynamic way, enabling them to understand complex cultural identity formation and generate mindful intercultural communication" (para. 5).

\section{Modernist - postmodernist perspectives}

Another way of classifying culture proposed by Kramsch (2006, 2013, 2015) distinguishes modernist and post-modernist perspectives. A modernist perspective sees culture as contained by territorial, ethnic, or ideological boundaries. This perspective allows for comparisons between behaviors across ostensible culture boundaries (Kramsch, 2015). This modernist view can be further sub-divided into humanistic and sociolinguistic views. From a humanistic perspective, culture is the product of canonical print literacy learned in school and is synonymous with general knowledge of literature and the arts. This is a 'big C' view of culture. A growing focus on communication and interaction in social contexts led to humanistic views of culture being supplemented by sociolinguistic views, which focus on 'little c' culture or 'small cultures' (Holliday, 1999) as seen in the way native speakers behave and communicate in their everyday lives (Kramsch, 2013, p.66). Kramsch (2013, p.70) finds this modernist view of culture problematic as she notes that this view is being challenged by the status of English as a lingua franca that "knows no national boundaries and by global social actors who contest the supremacy of the native speaker as well as the notion of neatly bounded speech communities". As Kramsch (2015) notes, despite the increasing irrelevance of such views, they are still pervasive in textbooks and teachers' memories.

In contrast to modernist views, a postmodernist perspective treats culture as discourse and identity (Kramsch, 2006, 2013, 2014). Culture as Discourse (with capital D) refers to the "ways of using language, or thinking, feeling, believing, valuing, and of acting that can be used to identify oneself as a member of a socially meaningful group or social network" (Gee, 1990 , p. 143). Culture is the meaning given to their practices by participants in a social group in a given time, and space, over the historical life of the group. Kramsch (2013) supports this post-modernist view and notes that learning a foreign culture without an understanding of one's own discursive practices would lead to a limited understanding of the Self. In addition, culture as identity emphasizes the individual rather than a collective group, gives people agency and power to control their destiny (Kramsch, 2006). 
Overall, while the modernist views see culture as monolithic entities, the postmodernist perspectives highlight culture as "portable schemas" of the meaning-making process and its subjectivity (Kramsch, 2014, p. 409).

\section{Liddicoat and Scarino (2013)' conceptualizations of culture}

Liddicoat and Scarino (2013) propose a four-way conceptualization of culture: (1) culture as national attributes; (2) culture as societal norms; (3) culture as a symbolic system; and (4) culture as practices.

Culture as national attributes. First, culture is seen as synonymous with the particular attributes of a national group, typically defined as inhabitants living within national boundaries. Accordingly, culture relates to where it is rather than what it is. In essence, culture is viewed as essentialized, recognizable, stereotypical attributes of a national group. There are a number of problems with this approach. First, in treating culture as a singular monolithic phenomenon (Liddicoat, 2017), the diversity within cultures is overlooked. Second, this view leads to an emphasis on cultural arts and on factual information about a country (e.g., history, geography, and institutions), which limits its value for language education. Third, contact with cultures is limited to observing the cultural 'other', rather than engaging with lived culture. Overall, in this approach to culture, the relationship between language and culture remains tenuous.

Cultures as societal norms. According to this approach, a culture is defined as practices and values of a certain cultural group such as ways of showing politeness or organizing certain types of text. Accordingly, cultural competence is understood as knowledge about what people are likely to do and the values attached to their actions or beliefs. In language classes, this view can pose some problems. First, learners may use another cultural paradigm as the lens to interpret an interlocutor. Second, while the ways people engage in a culture can vary according to individuals and contexts, this approach tends to describe cultures as static and homogeneous (Liddicoat \& Scarino, 2013; Liddicoat, 2002, 2011), thus results in stereotyping in culture learning.

Cultures as a symbolic system. Within this approach, participants who complete their practices in daily life mutually construct and interpret the meanings of their behaviors, which allows for a collective sense of meaningful experience. In language teaching, taking this 
approach of culture as symbolic systems could engage students in the construction of meaning rather than merely provide exposure to cultural information. This helps build up interpretive resources for the understanding of contextualized, negotiated, and variable actions (Liddicoat \& Scarino, 2013).

Cultures as practices. While culture has been defined above as coherent, static, uniform in the three above views, in this view - cultures as practices, culture is a dynamic set of actions and understandings created by individuals in their living experiences. Thus, participants in a culture do not necessarily co-construct a coherent, logical culture whole but individuals' meaning-making can be contradictory or contested within a social group. Similarly, individuals supposedly from the same culture may have different or even conflicting interpretations of the same event.

Among the above four ways of viewing culture in language education, the first three ways can be categorized into a static view of culture and the last - a dynamic view of culture (Liddicoat, 2002). A static view of culture is represented by the following characteristics (1) cultural knowledge mainly perceived as artefacts and facts, (2) culture teaching via transmission of factual information, (3) cultural competence as recalling cultural information, (4) tenuous culture-language relationship.

Adopting this static view in the language class might pose risks to culture learning because this view possibly results in learners' defining cultures as bounded by geographical borders, stable, unproblematized and being a monolithic whole. However, culture is unstable, constantly changing, and open to variations in the meaning-making and interpretations of the same event by different individuals, in different contexts in a social group. As such, it is necessary to adopt a dynamic view of culture that sees culture as "a set of practices in which people engage in order to live their life" (Liddicoat, 2002, p.7).

\section{Comparing the frameworks}

There are, by and large, some commonalities among the classifications in Faulkner et al. (2006), Kramsch (2006, 2013, 2015), and Liddicoat and Scarino (2013) even though the two latter classifications are more specifically intended for language teaching. Following are some example definitions of culture that fall into one, two, or all these classifications. These definitions illustrate the evolution in the way scholars view culture over a two-decade period. 
First, Kramsch's (1998) early definition of culture as "membership in a discourse community that shares a common social space and history, and common imaginings" (p. 10) indicates a membership theme proposed by (Faulkner et al., 2006). A few years after Kramsch's (1998) definition, Liddicoat et al. (2003) defined culture as: "a complex system of concepts, attitudes, values, beliefs, conventions, behaviors, practices, rituals, and lifestyle of the people who make up a cultural group, as well as the artefacts they produce and the institutions they create (p. 45)." This definition stresses a theme of Structure/Pattern and includes the theme Group Membership in the list of themes proposed by Faulkner et al. (2006). This definition also belongs to the modernist perspectives (Kramsch, 2006, 2013, 2015). Subsequently, Spencer-Oatey (2008) defined culture as:

... a fuzzy set of basic assumptions and values, orientations to life, beliefs, policies, procedures and behavioural conventions that are shared by a group of people, and that influence (but do not determine) each member's behaviour and his/her interpretations of the 'meaning' of other people's behaviour. (p. 3)

Similarly, Lustig et al. (2010) saw culture as "a learned set of shared interpretations about beliefs, values, norms, and social practices, which affect the behaviors of a relatively large group of people" (p. 25). According to the list of themes by (Faulkner et al., 2006), these four definitions highlight a theme of structure/pattern and also integrate group memberships, function, and process. These can also be assigned to the list of modernist definitions (Kramsch, 2006, 2013, 2015).

Under Liddicoat and Scarino's (2013) classification, the above four definitions of culture do not treat culture as practices. The "culture as practices" perspective views culture as something that we "do" rather than something that we "have". Holliday (2018) introduces a grammar of culture containing particular social and political structures, personal trajectories, underlying universal cultural processes, and particular cultural products. This model highlights a structure theme and also integrates four other themes: a product, a process, a group membership, a power, and a function (Faulkner et al., 2006). Interestingly, Holliday (2018) locates cultural practices in the cultural product component of his "grammar of culture", which, according to Baker (2015), indicates a more static view of cultural practices. In summary, culture has been conceptualized from different perspectives. Despite various ways of viewing culture by scholars such as Faulkner et al. (2006), Kramsch (2015), and 
Liddicoat and Scarino (2013), the common point of views identified is that culture can be viewed in either of the two ways: as monolithic, tacit, separate elements; or the active meaning-making processes.

The different perspectives in how understandings of culture are employed are the theoretical basis for me to understand how teacher and student participants perceive culture and culture teaching and learning in my research context. I take the view of seeing culture as a dynamic, active meaning process. For Study 1 of my research, I adopt the lens of seeing culture as a dynamic process to investigate teachers' beliefs and the current integration of culture into their teaching practices, and other stakeholders' perspectives. For Study 2 of my research, in cooperation with other PAR teacher participants, I adopt the dynamic view of seeing culture in designing PBL lessons. We believe that this way of viewing culture in teaching will assist in enhancing students' intercultural competence.

\subsubsection{Language and Culture Relationship}

Language and culture are inseparable and inextricable (Baker, 2016; Byram, 1997; Liddicoat et al., 2003; Liddicoat \& Scarino, 2013; Newton et al., 2010; Witte, 2014). Culture is "embedded" in language "as an intangible, all-pervasive, and highly variable force (Crozet \& Liddicoat, 1999). The interdependence of this relationship is complicated and various aspects of this language-and-culture nexus has been presented by scholars in language teaching.

In one of her early works, Kramsch (1998) describes the language and culture relationship in three ways:

1. Language expresses cultural reality: people can express facts and ideas, and reflect their attitudes through language

2. Language embodies cultural reality: people can give meaning to their experience through the means of communication

3. Language symbolizes cultural reality: people can use language as a symbol of their social identity

In her later work, (Kramsch, 2013, p.62) further explains the role that language plays in the language-and-culture relation. She states that "language is not a bunch of arbitrary linguistic forms" and that the presumable culture such as habits, beliefs, institutions, and monuments would be nothing more than "observable realities" without language and symbolic systems. 
She highlights the crucial role of language and argues that it is the language that allows us to give meaning to these "observable realities", thus, enable them to become "cultural phenomena" (Kramsch, 2013, p.62).

While Kramsch (1998) focuses on language's essential role of meaning making in the constitution of culture, Crozet and Liddicoat (1999) are more concerned with culture's embeddedness in language at different levels of communication. These authors illustrate the culture-and-language relationship along a continuum in Figure 2.4 below.

\section{Figure 2.4}

Points of articulation between culture and language (adapted from Crozet \& Liddicoat, 1999, p. 116)

This image has been removed by the author of this thesis for copyright reasons.

It is clear from Figure 2.4 that culture and language are intertwined. One end of the continuum is "world knowledge" - understood as literature, history, geography in traditional "teaching culture, "world knowledge" is closer to culture than language. Next, culture is in the text structure (spoken or written). Culture also influences pragmatic norms such as different ways of showing politeness and interactional norms (e.g., how to open and close a conversation). Finally, at the "language" end of the continuum, where one would be likely to think of culture-free space, culture is, in fact, present in the linguistic and paralinguistic structures, in words, syntax, and non-verbal language. By showing the presence of culture at different communication levels, these "points of articulation between culture and language" might be clear for language teachers to understand and become more aware of the cultural element in their language teaching, and thus regulate their teaching practices in the way that they desire. 
From a different angle, Risager (2007) suggests two ways of understanding the relationship between culture and language: a generic and a differential. In the generic sense, "language and culture are under all circumstances inseparable: human language is always embedded in culture" (Risager, 2007, p.12). The differential sense involves considering the question: "what forms of culture actually go with the language in question?". This differential understanding suggests avoiding an essential connection between one language and one culture.

Risager (2007) further explains the language-culture nexus as local integration. That is, local integration of linguistic, languaculture, discursive, and other cultural flows in various social networks. The author emphasizes that this integration can be dialogical or conflictual since it occurs in the participants' process of co-construction, negotiation, or struggle for meaning and identities. In addition, the connection can be convergent or divergent. The author goes on to highlight the language's meaning and a reference potential, which makes the core of the language-culture nexus since this potential works as a bridge to link language with physical, social, and cultural reality. The complexity in the relationship of language and culture has led to different examinations of its different aspects. It is the interdependence of this nexus that forms the tenets of intercultural competence and intercultural language teaching, which I will mention in the following section.

\subsubsection{Intercultural Competence (IC)}

2.1.3.1 Components and Models of ICC. There is an abundance of synonyms and near-synonyms in the literature that refer to a similar conceptual core, such as "intercultural sensitivity” (Bennet, 1994), intercultural awareness and intercultural skills (CoE, 2001), “intercultural intelligence” (Earley \& Peterson, 2004), "intercultural effectiveness" (SpencerOatey \& Stadler, 2009), “intercultural communicative competence” (Byram, 1997, 2012), “critical cosmopolitanism” (Holliday, 2011), intercultural competences (Dervin, 2010), and more recently, global competence and intercultural maturity (Griffith et al., 2016), and intercultural capability (Howard et al, 2019).

It is widely perceived in the growing body of scholarship that intercultural competence is one of the ultimate goals of education, "a vital competence in our contemporary world" (Dervin, 2010, p.158). However, until now, there has not been agreement on how intercultural 
competence should be defined. One attempt in defining intercultural competence is Deardorff's (2006) definition "the ability to communicate effectively and appropriately in intercultural situations based on one's intercultural knowledge, skills, and attitudes" (pp. 247-248). Barrett (2013) argues that this definition is problematic due to lacking other components, showing limited reference to intercultural communicative competence, and failing to specify the meaning of "competence" and "intercultural". The need to understand the term "intercultural competence" thus should be addressed by understanding its components as well as models of intercultural competence.

Despite the lack of consensus in a precise definition of intercultural competence, most scholars generally agree that IC includes cognitive, affective, and behavioral dimensions (Arasaratnam-Smith, 2017; Chen, 2014). A number of scholars (e.g., Miike, 2012; Nakayama \& Martin, 2014) argue that, in addition to the dimensions of affect, cognition, and behavior, models of IC should include moral dimensions such as mutual respect, sincerity, tolerance, and responsibility, which regulates the earlier three dimensions. In addition, Barrett's (2016) framework proposes that intercultural competence consists of 14 sub-components within four main components: values, attitudes, skills, knowledge, and critical understanding. Chen (2017) proposes that it is impossible to establish a common list of components of IC due to the variety of ways that it has been operationalized. Likewise, Byram (2009) argues that an agreed and definite definition of IC is impossible because of the evolution of theories and of the constant social changes.

Regarding models of intercultural competence, Spitzberg and Changnon (2009) reviewed over 300 IC models across disciplines in social science. Then they categorized these models into five types of models as follows:

1. Compositional models identify the various components of IC without specifying the conditional relations among these components. These models include relevant components such as attitudes, skills, knowledge, and behaviors that make up IC.

2. Co-orientational models center on how communication takes place within intercultural interactions and how intercultural understanding, perceptions, and meaning are constructed during these interactions. 
3. Developmental models clarify the evolving nature of IC through growing levels of interaction and relationships.

4. Adaptational models emphasize individuals' abilities to adapt their attitudes, understanding and behaviors during intercultural encounters.

5. Causal path models propose specific causal relationships between different components of IC and view IC as a theoretical linear system.

Spitzberg and Changnon (2009) pinpoint two main problems concerning these models. First, they observe that many terms (e.g., adaptability, sensitivity, etc.) used to describe intercultural competence in these five types of models have not yet been properly operationalized or validated in empirical research. Second, they note that many of these models have been developed within western European and North American societies, thus are prone to an ethnocentric bias. In reviewing models from various disciplines, Griffith et al. (2016) propose that a model of ICC should (a) provide specific definitions of the overall construct and its sub-dimensions, (b) include both cognitive and non-cognitive components, and (c) clarify the relationship between sub-dimensions. These authors maintain that despite being multidimensional in nature, the majority of models focus only on attitudes (or attitudes and cognitions), and thereby lack focus on the behavioral or performance-relevant component of ICC. Other models provide weak definitions or do not clarify the relationship among subdimensions.

Offering another way of reviewing IC models in terms of context, Chen (2017) categories IC models into four main types: general models, models for intercultural adaptation, models for education and training, and models for global communication. Specifically, in the education/training context, Moeller and Nugent (2014) and Sinicrope et al. (2007) identify influential models including Bennet's (1993) developmental model of intercultural sensitivity, Byram's $(1997,2009)$ models of intercultural communicative competence, and Deardorff's (2006) process model of intercultural competence. Bennet's model maps the development in intercultural competence over the continuum from ethnocentric (from Denial to Defence and Minimization) to ethno-relative stages (from Acceptance to Adaptation and Integration). Deardorff's model depicts the process of acquiring intercultural competence and the inter-relations of attitudes, knowledge, groups of skills (observing, evaluating, analyzing, and relating), and acquired outcomes (i.e., adaptability, flexibility, empathy, effective 
communication, and appropriate behaviors) in intercultural encounters. Byram's model is comprised of five savoirs: knowledge, attitudes, skills of interpreting and relating, skills of discovery and interaction and critical cultural awareness. Byram details each savoir as the goals for learners to achieve in order to be interculturally competent.

Despite being influential, these models are not criticism-free. For example, Liddicoat et al. (2003) argue that Bennet's model presents a linear development of IC, which may not always hold true. They note that interculturality and language are loosely connected in the model and there is no clear specification of the place of language and language teaching. Similarly, Scarino (2009) also argues that the descriptions are limited in their high generalization and fail to recognize that the specific tasks and contexts may influence intercultural sensitivity. As for Deardorff's model, Deardorff (2008) acknowledges that her 2006 model has a Western bias.

Among the above three models in education, Byram's (1997) ICC model is the most influential ICC framework in language education (Dervin, 2010) and specifically, is situated in the context of foreign language teaching and learning (Moeller \& Nugent, 2014; SpencerOatey \& Stadler, 2009). My thesis, which seeks to understand the current situation of teaching and learning culture in the Vietnamese tertiary context and investigate the possibility of fostering intercultural competence, adopts Byram's model. Following is a closer examination of Byram's (1997) model of intercultural communicative competence.

2.1.3.2 Byram's Model of Intercultural Communicative Competence. Byram's (1997) ICC model consists of linguistic competence, sociolinguistic competence discourse competence, and intercultural competence (Figure 2.5). While the terms of IC and ICC are usually used interchangeably by many scholars, Byram makes a clear distinction between these two terms. The scholar views Intercultural Competence (IC) (Figure 2.6) as the individual's ability to interact in their own language with people from another country and culture using their knowledge, attitudes, and skills in intercultural communication.

Intercultural Communicative Competence (ICC), on the other hand, refers to the individual's ability to interact with people from another country and culture in a foreign language by acting as a mediator. 
Figure 2.5

Byram's (1997, p.73) Model of ICC

This image has been removed by the author of this thesis for copyright reasons. 
Figure 2.6

Model of IC (Byram,1997, p.34)

This image has been removed by the author of this thesis for copyright reasons.

Byram also details the savoirs of IC in his above IC model as follows:

- Savoir être (attitudes): curiosity and openness, readiness to suspend (dis)belief about other cultures, and belief about one's own. This requires the ability to decentre, to analyze one's beliefs and behaviors from others' points of view, to relativize one's self and value others.

- Savoirs (knowledge): of self, others, and the processes of societal and individual interaction. Knowledge of self refers to knowledge about one's own country and social groups and cultures. This type of knowledge is usually acquired through formal education. Knowledge of the others - the interlocutors' countries and identities - is usually relational. Knowledge of the processes of interaction is vital to successful interactions.

- Savoir comprendre (skills of interpreting and relating): ability to interpret documents or events from another culture, to explain them and relate them to documents or events from one's own such as identifying concepts and connotations, handling dysfunctions and contradictions, and identifying unresolvable issues.

- Savoir apprendre/faire (skills of discovery and interaction): Discovering is concerned with the ability to recognize and build up new knowledge of a culture and cultural practices, which leads to an understanding of their meanings and relationship to other 
phenomena - other knowledge both in documents and interactions. Interacting refers to the ability to operate knowledge, attitudes, and skills in interactions such as managing time constraints, dysfunctions, establishing relationships, and mediating.

- Savoir s'engager (critical cultural awareness/political education) means the ability to evaluate critically, and on the basis of explicit criteria, perspectives, practices, and products in one's own and other cultures (Byram, 1997).

Byram's ICC model has another shape in subsequent Byram (2009) and most recent Byram (2020) (Figure 2.7). Basically, all the elements of the initial (1997) version are maintained in the revised versions. The difference is the placing of critical cultural awareness in the center of IC in the latter version to emphasize its significance in the educational function of language teaching and the role of IC development in intercultural citizenship education (Byram, 2008, 2009).

\section{Figure 2.7}

Byram's (2009, 2020) Model of ICC

This image has been removed by the author of this thesis for copyright reasons. 
The significance of Byram's ICC model has been widely acknowledged. For example, Díaz Dasli (2017) highlight this model as a cornerstone in the field of language and intercultural communication as it marks the vital inclusion of the intercultural dimension in language education. In the same vein, Risager (2007) indicates that Byram's model contains both linguistic and cultural parts. Similarly, Baker (2011) maintains that Byram's model is one of the most detailed accounts of IC. He notes that Byram (1997) proposes the "intercultural speaker" as a substitute for the traditional model for foreign language learners, which signifies Byram's acknowledgement of the importance of negotiated communication with no interlocutor as the model for the other to follow. Moreover, this model is particularly influential in the field of foreign language didactic (Belz, 2003; Hoff, 2014; Sercu, 2004), it reflects an exploratory approach to learning (Newton et al., 2010), ties language learning with education for citizenship and democracy (Hoff, 2014), and is one of the major models of ICC and ICC assessment (Sinicrope et al., 2007), the most detailed model of ICC and its assessment in language education and research (Liddicoat \& Scarino, 2010).

On the other hand, the drawbacks of this model have been pointed out (e.g., in Hoff, 2014; Liddicoat et al., 2003; Liddicoat \& Scarino, 2013; Matsuo, 2012; Risager, 2007; Sercu, 2004). The critiques center on the type of Byram's ICC model, the conceptualization of culture in the model, and suggestions to make the model more comprehensive.

The first source of criticism targets the issues arising from the compositional type of Byram's model. For example, Matsuo (2012) argues that this model is limited in supporting teachers' practical pedagogical purposes due to failing to signify the relationship between components. Liddicoat et al. (2003) further pinpoint the weak articulation of the relationship between intercultural elements and other components of language competence. Byram (2009) acknowledges the model's lack in representing the dependence and interdependence among the competencies when its competencies are displayed in a kind of "list model", not a "structural model" (Bolten, in Rathje, 2007).

Criticism also concerns the notion of culture and language and culture relationship in Byram's model. Kramsch (1999) contends that in reality, the boundaries between cultures are not so rigid, not as homogeneous as in Byram's description of his ICC model. Byram (2009) refutes this view and explains that this is a simplification for didactic purposes. Regarding the language and culture relationship, Liddicoat and Scarino (2010) note that the model of 
savoirs does not detail the way language and culture affect each other and how the learner understands this relationship.

In addition to articulating the weaknesses in this model, scholars offer some suggestions. Scholars recommend expanding Byram's ICC model in some ways. First, Sercu (2004) discusses Byram's model in light of educational theory (i.e., domain-specific knowledge, cognitive strategies, metacognitive strategies, and affective characteristics). She argues that Byram's model addresses the knowledge, cognitive strategies, and affective characteristics well, but lacks metacognitive strategies - the knowledge and beliefs involved in students' self-regulating mechanism to plan, monitor, and evaluate their learning process.

Commenting on Sercu's suggestion, Liddicoat and Scarino (2013) note that the inclusion of the metacognitive strategies would integrate a stronger educational dimension to the savoirs and add reflection on learning into the model. In addition, Risager (2007) suggests that Byram's model should be extended with a global perspective. She argues that Byram's model concerns the individual and personal development of intercultural communicative competence, thus the focus is restricted on an I-You relationship while a more social understanding of the intercultural speaker as a mediator between different people or groups is desired. Discussing the Self and otherness in the light of Bildung theories, Hoff (2014) maintains that the model fails to recognize conflicts, ambiguity, and differences both as challenges and potentials for successful intercultural encounters. Despite these critiques, Byram's model remains the most thorough and clearly articulated model in the field of foreign language education (Newton et al., 2010).

This research, which aims to investigate the current integration of culture into foreign language teaching and the feasibility of adopting PBL in the Vietnamese tertiary context to foster intercultural communicative competence, is informed by Byram's model for the following reasons. First, in the Vietnamese tertiary context, the CEFR is adopted. As Byram's ICC model represents all the major competencies in the CEFR (intercultural awareness, knowledge, attitudes, and skills) it may be relevant to the Vietnamese context. Moreover, the objectives of foreign language education in the intercultural stance are clearly stated in the model, which might illuminate the expected outcomes that guide teachers in their pedagogical practices. Specifically, and interestingly, the assumed drawback that the 
reality is not so homogeneous as described in Kramsch's model turns out to coincide with my actual research context.

To foster students' IC in language classes, principles for integrating culture and language are of paramount significance to guide language teachers. The following sections will discuss recent theories about intercultural language teaching and learning.

\subsubsection{Intercultural Language Teaching and Learning (ICLTL)}

Intercultural language learning has become a major field of international scholarship within education and applied linguistics (e.g., Díaz, 2013; Liddicoat \& Scarino, 2013; Witte, 2014). Since its origin in the mid of $20^{\text {th }}$ century, the term "intercultural" and its associations have been conceptualized and worked on, for example, ICC (Byram, 1997), the intercultural speaker (Byram, 1997; Deardorff, 2006); principles for intercultural language teaching and learning (Crozet \& Liddicoat, 1999; Liddicoat \& Scarino, 2013; Newton et al., 2010; Witte, 2014), assessing intercultural competence assessment (Sercu, 2004) and assessing intercultural communication competence (Fantini, 2012). These concepts have contributed to an understanding of different aspects of the intercultural approach in language education. In the following section, I will focus on key characteristics of an intercultural approach and principles of intercultural language teaching and learning, which inform my research.

\subsubsection{Principles of an Intercultural Approach to Language Education. Below} are three characteristics of an intercultural approach to language education that distinguish it from traditional approaches. First, in the intercultural approach, language and culture receive equal importance. That is, culture is no longer considered an add-on or a separate component in a language class. Rather, language, culture, and learning are "fundamentally interrelated processes" (Liddicoat et al., 2003, p.43), which means IC is addressed alongside and language. The intercultural approach does not negate previous methods or require a new method (Corbett, 2003; Newton, 2016). "What it does require is for teachers to build an explicit focus on interculturality into the communicative experiences available to learners" (Newton, 2016).

Second, the ultimate goal of an intercultural approach is "intercultural communicative competence" rather than a traditional unrealistic goal of "native speaker competence" (Byram, 1997; Guilherme, 2002). In other words, an intercultural approach trains learners to 
be intercultural speakers, who can act as mediators, or find a "third place" (Kramsch, 1993) so that they can understand themselves and others from their own and others' perspectives. Therefore, the intercultural speakers are more skilled, more "privileged" than the monolingual speakers of the target language (Kramsch, 1998).

Finally, the shift from communicative competence to intercultural competence pedagogy has required a reconceptualization of language teachers' roles. Byram (1997), Corbett (2003), and Kohler (2015) emphasize teachers as intercultural mediators in the classroom rather than cultural knowledge providers as in the traditional approach. Similarly, according to Liddicoat (2008), an intercultural teacher can facilitate language learning by providing culturally rich language experiences and guide students with their questions. Through the learning processes, the teachers help students to make connections between the known language and culture and the new ones. To undertake this role, the teachers require professional knowledge, disciplinary knowledge, interactional competence, interpretative and relational competence, methodological competence, intercultural attitudes and beliefs, and a critical cultural perspective (Kramsch, 2004).

2.1.4.2 Principles of ICLTL. Liddicoat et al. (2003) and Liddicoat (2008) propose a set of principles for intercultural language learning as guidance for curriculum design and classroom interactions. Subsequently, Liddicoat and Scarino (2013) introduce principles for intercultural language teaching and learning. In the New Zealand context, Newton et al. (2010) and Newton (2016) propose principles for intercultural communicative language teaching. Table 2.2 below presents a brief overview of these intercultural principles.

Table 2.2

Principles of Intercultural Language Teaching and Learning

\begin{tabular}{lll}
\hline $\begin{array}{l}\text { Principles for Teaching and } \\
\text { Learning Languages } \\
\text { from an Intercultural }\end{array}$ & $\begin{array}{l}\text { Principles for } \\
\text { Intercultural } \\
\text { communicative } \\
\text { Perspective (Liddicoat et al., } \\
\text { 2003; Liddicoat \& Scarino, } \\
\text { (Newton et al., 2010, }\end{array}$ & $\begin{array}{l}\text { Principles for teaching Intercultural } \\
\text { Spoken Communication (Newton, 2016) }\end{array}$ \\
\hline p.63) & 1. Integrates language & $\begin{array}{l}\text { 1. Mine the social context of learning } \\
\text { a. Use culturally responsive pedagogies to } \\
\text { and culture from the }\end{array}$ \\
$\begin{array}{l}\text { 1. Active construction: } \\
\begin{array}{l}\text { Learning involves the } \\
\text { purposeful and active } \\
\text { construction of knowledge }\end{array}\end{array}$ & beginning. & \begin{tabular}{l} 
school and community by recognizing and \\
\hline
\end{tabular}
\end{tabular}


within a sociocultural context of use.

2. Making connections:

Learning is based on previous knowledge and requires challenges to initial conceptions that learners bring. The challenges lead to new insights through which learners make connections, to reorganize and extend their existing framework of knowledge.

3. Social interaction: Learning is social and interactive. 4. Reflection: Learning involves becoming aware of the processes underlying thinking, knowing, and learning through conscious awareness and reflection. 5. Responsibility: Learning depends on learners' attitudes and disposition towards learning.
2. Engages learners in genuine social interaction.

3. Encourages and develops an exploratory and reflective approach to culture and culture-inlanguage.

4. Fosters explicit comparisons and connections between languages and cultures.

5. Acknowledges and responds appropriately to diverse learners and learning contexts.

6. Emphasizes intercultural communicative competence rather than native-speaker competence. connecting to learners' home knowledge, languages and practices.

b. Expose learners to diversity of World Englishes and raise awareness of English as an international language.

2. Focus on intercultural learning objectives.

Foster and affirm intercultural learning achievements in tandem with linguistic and communicative achievements.

3. Adopt intercultural classroom practices. Provide opportunities for learners to:

a. Engage with culture in and around language from the beginning;

b. Interact and communicate in the language; c. Explore, reflect on, compare and connect experiences, knowledge and understandings; d. Put learning into practice beyond the classroom, making choices and acting in interculturally informed ways.

Sharing some commonalities, these principles have guided teachers in their practical pedagogies in the integration of culture into teaching practices. Specifically, these authors highlight the significance of students' active experiential learning. They suggest that teachers should provide students opportunities for their comparison of different cultures and reflection. For example, Liddicoat and Scarino (2013) provide a more updated version of Liddicoat et al. (2003)'s principles with more thorough explanation, such as connection means "connect the new to what is already known", and bringing the "intracultural experiences" to connect with the new experiences. In addition, this connecting process means "making connections with diverse cultures, identifying similarities and differences between the known and the new, and establishing complex interrelationships between the similarities and differences that are perceived" (Liddicoat \& Scarino, 2013, p.57). Drawing on previous relevant literature, they list two aspects of intercultural reflections: affective and cognitive, and provide a detailed explanation of reflection.

Liddicoat and Scarino (2013) also identify four interacting processes for experiential and reflective learning: noticing, comparing, interacting, and reflecting. They explain that 
teachers play a pivotal role in assisting students to become independent noticers of lived experiences of language and culture, such as through posing questions or guiding students about what can and should be noticed. The process of comparing can involve comparisons between learners' background culture and language with the target culture and language, and between what learners have already known and what is new to them. The interacting process involves learners in negotiating understandings, accommodating or distancing from understandings presented by others. The process of reflection not only allows learners to think about their experience of cultural and linguistic diversity but also about how learners will react to the diversity and find ways to engage constructively with the diversity. In brief, in this approach, language, culture, and learning are all central to the language curriculum, as Liddicoat et al. (2003) argue:

Intercultural language learning involves developing with learners an understanding of their own language(s) and culture(s) in relation to an additional language and culture. It is a dialogue that allows for reaching a common ground for negotiation to take place, and where various points of views are recognized, mediated and accepted (Liddicoat et al., 2003, p.46).

While Liddicoat et al. (2003) and Liddicoat and Scarino (2013)'s principles are centered on the context of language education in general, Newton et al. (2010)'s principles for intercultural communicative language teaching (iCLT) were designed specifically to guide subject language teachers in New Zealand schools and encourage them to build an intercultural stance into communicative language teaching. Newton et al. (2010) articulate the distinct features of iCLT compared to traditional approaches, including (1) encouraging learners to explore cultural artefacts, compare and reflect on the values laden in the artefacts rather than transmitting information in a big C-culture approach; (2) creating links between knowledge and learners' lived experiences; (3) helping students to gain insights into the subjective nature of stereotypes; and (4) encouraging the self and the other, to look at own culture from other perspectives. These principles align with views about intercultural language teaching by Corbett (2003), Liddicoat et al. (2003), and Witte (2014).

Drawing on these principles, Newton (2016) is a 're-visioning' of the Newton et al. (2010)'s iCLT principles, in which this earlier set of principles are updated and revised to focus on the application of intercultural language learning principles to teaching English as an international language. In essence, the principles of both Newton et al. (2010) and Newton 
(2016) align with Liddicoat and Scarino (2013)'s principles in encouraging exploring and interacting interculturally. What is more emphasized in Newton's is that his principles value the diversity of students' backgrounds and learning contexts. Furthermore, iCLT targets intercultural communicative competence rather than native-speaker competence. This concurs with Byram (1997)'s ICC model which shifts the notion of native-speaker competence to an intercultural speaker.

The ICLTL principles have been influential to research in New Zealand and other contexts. For example, Howard et al. (2016) used the iCLT framework to assess New Zealand school teachers' understanding of intercultural language teaching. Oranje (2016) developed a cultural portfolio project as a learning tool in three New Zealand secondary school language classes. Kennedy (2016) explored opportunities for developing Chinese students' IC in a foreign language classroom based on the iCLT principles. In the Vietnamese tertiary context, Ho (2011) and Nguyen (2013) adopted these ICLTL principles to examine teachers' perceptions of culture teaching and their practices. More recently, Tran (2020) conducted participatory action research and adopted iCLT principles to design cultural lessons in her study.

The above principles of ICLTL and iCLT have served as the guidelines for the design and implementation of ICLTL. What is commonly emphasized is the learners' active construction in the exploration and meaning-making of the linguistic and cultural diversity in which the students build up their interpreting, comparing, interacting, and reflecting skills. These principles are relevant to my study, which aims to foster intercultural language teaching and learning in EFL classes in a tertiary context.

\subsubsection{Review of Research}

Scholarship in the field of ICLTL is paying attention to numerous aspects such as teachers' perceptions and practices (e.g., Castro et al., 2004; Luk, 2012; Young \& Sachdev, 2011), students' perceptions (Drewelow, 2012; Drewelow \& Mitchell, 2015), teacher professional development in ICLTL (Byram, 2015; Lázár, 2011; Tolosa et al., 2018), and the intercultural teachers (Aguilar, 2009; Byram et al., 2002; Kramsch, 2003). This section gives a brief review of previous studies in relation to this research, which investigates teachers' perceptions and practices of teaching culture (Study 1 of the research); and the feasibility of fostering intercultural language learning (Study 2 of the research). On account of that, this 
section will focus on recent research related to these two topics. The review begins with the scholarship outside Asia, followed by the scholarship inside Asia, and finally ends with the scholarship in Vietnam. This approach is taken because context is important in understanding how intercultural language learning is interpreted.

2.1.5.1 Research on Teachers' Beliefs and Practices of Teaching Culture. There is a well-established relationship between teachers' beliefs and their practices (e.g., Borg, 2011; Buehl \& Beck, 2014; Pajares, 1992). Reflecting this relationship, research on the teaching of culture in the language classroom, whether interculturally oriented or not has shown particular interest in teacher cognition and practices (e.g., East, 2012; Luk, 2012; Oranje \& Smith, 2018; Sercu et al., 2005; Young \& Sachdev, 2011).

Research Outside Asia. In European contexts, many studies have been investigating teachers' beliefs and practices of addressing the cultural/intercultural dimension in foreign language classes. For example, Castro et al. (2004) conducted an electronic survey with 35 teachers of English in Spanish secondary school contexts to examine teachers' perceptions of objectives in foreign language education and how they supported cultural objectives in foreign language lessons. They found that the teachers prioritized language objectives over culture teaching objectives. In case teachers attended to the cultural elements in the lessons, they aimed to develop students' familiarity with other cultures rather than open attitudes towards other cultures.

In a formative study on teacher cognition and practices in Europe, Sercu et al. (2005) obtained survey results from 424 secondary school teachers in seven countries - Belgium, Bulgaria, Mexico, Poland, Spain, and Sweden. The research found that most teachers were favorably disposed to addressing culture in language teaching. The teachers reported that treated language and culture equally in language teaching and express willingness towards the teaching of culture. However, notably, these teachers' favorable disposition contrasted with their teaching practice, which did not focus on addressing culture. Another finding was that time limitation and the teachers' overloaded linguistic curricula hindered their practice of an intercultural approach.

In another large, multi-context study, Young and Sachdev (2011) investigated beliefs and practices of experienced teachers in the US, UK, and France regarding the ICC model in their 
language classrooms from diaries, focus groups, and questionnaires. Despite the disparity in participants' responses, most reported the relevance of interculturality to their work. However, the teachers in Young and Sachdev (2011) also reported that ICC was given relatively little emphasis in their syllabi and they seemed to be unwilling to put the intercultural approach into practice.

Similarly, in a South American context, Salcedo and Sacchi (2014) found in their survey that in-service EFL schoolteachers understood teaching culture as part of their roles and that the teachers believed they had necessary pedagogical and content knowledge. However, interview data revealed the teachers' lack of skills for delivering intercultural content and thus focusing on cultural products rather than on developing exploring and reflecting skills. Additionally, contextual factors of time and students' English levels led EFL students to prioritize linguistic over cultural dimension.

Peiser and Jones (2014) conducted a qualitative study to examine teachers' perceptions about the role of intercultural understanding in foreign language teaching. This study used semistructured interviews with 18 teachers in 13 secondary schools in the North-West of England between May 2008 and June 2009. The findings showed the profound impact of teachers' interests, personalities, and intercultural experience on their attention to the cultural dimension of language lessons.

In the New Zealand context, Oranje and Smith (2018) administered a questionnaire with items adopted from Sercu et al. (2005). The researchers examined the extent to which 79 responding teachers' beliefs and practices aligned with intercultural language teaching. The findings indicated two mismatches between their favorable dispositions towards intercultural language teaching (ILT) and their practices. First, while few teachers reported their preference for the linguistic dimension over the cultural dimension, more reported putting that intercultural approach into practice. Second, most of the participants in this study agreed that language education should develop a reflective understanding, which contributes to students' understanding of their own identities and cultures, and their comparisons between their culture and other cultures. However, there was a deficiency of reflective processes in their practice. This indicates a mismatch between teachers' perceptions and their practices. Other studies in the New Zealand context also show teachers' stated support for an intercultural language teaching approach. For example, schoolteachers were found to focus 
on factual knowledge in the target culture (East, 2012), which demonstrates limitations in their understanding of intercultural language teaching. In another study, Conway and Richards (2018) investigated how teachers understood reflection as a learning tool and what they implemented to foster students' intercultural competence using this tool of reflection. The study involved 12 teachers. Two teachers each of French, German, two Samoan, two Spanish, three teachers of Japanese, and one of Chinese participated in surveys and individual interviews. The study found that most of the teachers failed to provide opportunities for their learners to develop their intercultural competence although they acknowledged the value of reflection for intercultural learning.

In Australia, Mahoney (2009) conducted a qualitative case study to investigate how two nonnative speaking Japanese language teachers in New South Wales taught culture and why. The study also sought to understand teachers' attitudes and beliefs on teaching culture and how these attitudes and beliefs were influenced by past experiences. Data were collected through interviews and classroom observations. The findings were that their thoughts on teaching culture reflected concepts of ICLTL, and culture was treated as observable and factual in their classroom practices. Another finding was that both teachers' attitudes towards teaching culture were influenced by their past experiences. Also, in the Australian context, Monoley (2008) identified evidence of Japanese teachers' successful modelling of intercultural lessons. Monoley (2013) found that Chinese teachers had a limited understanding of ICLTL. Similarly, Liddicoat (2012) found that teachers in Indonesia could develop students' intercultural learning through representing culture as dynamic, analyzing culture in language, problematizing language, and expressing personal identity.

In the African context, intercultural language teaching and learning has not been greatly focused on. For example, in Tanzania, Biswalo (2015) found that secondary EFL teachers had a limited understanding of ICLTL. However, their practices indicated some evidence of fostering intercultural learning in the context.

Research in the Asian Context. Similar to the scholarship outside Asia, a growing number of studies in many Asian countries have been conducted to investigate teachers' teaching practices and perspectives. In Hong Kong, Luk (2012) investigated how EFL teachers defined culture and found that most of the participants viewed culture as products (e.g., food and clothing) and structural elements (e.g., beliefs, customs, traditions). Although 
the teachers showed positive attitudes towards the integration of culture into language teaching, these teachers remained "ambivalent" about the purpose of ICLT. In addition, in the interviews, these teachers reported that culture had a peripheral role as "sweeteners before the main course" in their language lessons (Luk, 2012, p.256).

In a Chinese EFL context, Tian (2013) surveyed 96 university teachers, interviewed and observed 11 teachers' classroom lessons to understand their perceptions of IC and teaching practices in relation to cultural content. An interesting finding was that the teachers included an additional dimension to the common IC dimensions. Tian (2013) called this dimension "Chineseness". By "Chinesses", Tian was referring to the moral value initiated by Confucianism. Classroom observations revealed a traditional teaching approach with an irregular focus on culture teaching. These findings were significant because they provided insights into how the Chinese teachers viewed IC and how they addressed culture in their classes. However, the researcher did not explain the relationship between the extra "Chineseness" component with other common IC components or its influence on the teachers' teaching practices. Similarly, the survey findings of Zhou (2011) and Wang (2014) revealed teachers' objectives of improving students' cultural knowledge rather than intercultural skills and their teacher-centered instruction approach.

In the Middle East (Iran and Saudi Arabia), scholars have investigated teachers' perceptions and teaching practices. For example, in the studies of Estaji and Rahimi (2018) and Al-Amir (2017), teachers displayed awareness of the need to foster students' ICC. In contrast, in Zare et al. (2015), the teachers did not consider intercultural skills important and their practices were linguistically oriented.

In Indonesia, recent studies have explored teachers' perspectives and understandings of ICLTL (Abdulrahman et al., 2016; Gandana, 2015; Gandana \& Parr, 2013; Siregar, 2016). Gandana and Graham (2013) provided insights into a case study teacher who faced fundamental tensions in constructing her intercultural professional identity as an English language teacher. Her stated barriers included a curriculum that illustrated an over-simplified understanding of culture and language, limited teaching resources, and a hierarchical collegial relationship. Because of the challenges, this teacher had to make instructional choices that did not match her stated beliefs about teaching culture. Gandana (2015) studied three case study teachers' conceptualizations of culture and teaching culture, and intercultural 
competence in an Indonesian tertiary context. The findings were that the teachers viewed culture as values, norms, beliefs, and traditions, within a nation.

Siregar (2016) conducted a multiple-phase study and provided insights into the essentialist view of culture in the national Indonesian language policy, the affordances for adopting an intercultural stance in the curriculum, and the implementation of an intercultural approach in language classes. Siregar (2016) found that the essentialist view of culture in the top-down policy matched the teachers' essentialist beliefs about culture and the separation between language and culture in the curriculum design and classroom implementation.

Abdulrahman et al. (2016) used multiple data sources to depict teachers' attitudes about integrating the teaching of culture. The findings were that the teachers supported teaching cultural objectives alongside language but were ambivalent in prioritizing between language teaching and culture teaching. Their stated constraints included lack of cultural knowledge, curriculum requirements, time constraints, and linguistic-based textbooks.

More recently, Munandar and Newton (2021) adopted a qualitative case study research to investigate how five Indonesian EFL teachers from various Indonesian high school contexts addressed culture and interculturality, their pedagogical assumptions, and related teaching factors. Data included 13 classroom observations, stimulated recall interviews with teachers, narrative frames completed by the teachers, policy and curriculum documents, and a student focus group interview. A thematic analysis of the data revealed that the teachers believed and highlighted the cultural, moral, and religious values of the local society in their practice. Teachers' religious and cultural backgrounds, Indonesian state policies on education, language, religion, and patriotism affected teachers' beliefs and practices of addressing the cultural dimension in the language classes. These beliefs and classroom practices showed the complexity of the notion of culture and interculturality in these specific Indonesian contexts.

In Thailand, Cheewasukthaworn and Suwanarak (2017) investigated 16 university teachers' understandings of ICC in their mixed-method study. The findings were that the teachers had a general grasp of ICC and they considered presenting cultural content the main approach in teaching culture. Another finding was that the teachers negated the significant role of ICC in students' communication despite acknowledging that ICC was an important goal in English language teaching today. 
In Cambodia, Lim and Keuk (2018) explored how seven Cambodian teachers of English in a tertiary context conceptualized English and how their conceptualization impacted on their practice in terms of culture teaching. Data collection methods involved interviews with teachers and document analysis. Through a sociocultural analysis, these scholars found that the participating teachers did not aim to enrich students' cultural knowledge or intercultural skills in their practices. Instead, they strictly focused on grammatical competency, which conforms to the native-speaker linguistic norms. More recently, Nhem (2020) conducted a qualitative study to investigate three Cambodian schoolteachers' views and practices of textbook adaptation and how this adaptation developed students' intercultural awareness. Findings from classroom observations and interviews revealed that the teachers were more concerned with providing students with cultural information rather than developing their intercultural awareness. However, the teachers viewed the role of culture and of integrating culture in language classes as essential, which was an advanced view of culture in language classes compared to findings in Lim and Keuk (2018).

Research in Vietnam. In Vietnam tertiary contexts, many studies such as Nguyen (2013, 2015), Le (2015b); Nguyen (2016), Trinh (2016), and Vo (2017) have investigated teachers' beliefs. Nguyen (2013) found that teachers prioritized teaching language skills over culture, and they lacked relevant professional training and knowledge to address culture. In addition, this scholar found many obstacles in the teachers' teaching practices such as time constraints, lack of materials. Notably, he found that the national language policy, which emphasized interculturality, was not well communicated to the teachers. This might partly explain teachers' limited focus on culture in their beliefs and teaching practices. Furthermore, Nguyen (2013) found that the participant teachers held a static view of teaching cultures. Observations also showed that they did not take an integrated view of teaching both language and culture. The teachers simply explained certain cultural points in the textbook or provided cultural information randomly. In the same vein, Trinh (2016) found that teachers had broad views and equated the role of teaching culture and language skills. Despite using various activities (lecture, quizzes and games, dialogues, culture research, and discussions) the teachers simply focused on providing cultural knowledge. Other studies by Doan (2014), Tran and Dang (2014), Chau and Truong (2018), and Chau and Truong (2019) also revealed similar findings. 
In brief, teachers in many places in the world have acknowledged the importance of addressing culture in language teaching. However, generally, teachers' teaching practices often conflict with their perceptions (except for Australian contexts). In practice, they tend to either allot little time for teaching culture or simply transmit cultural knowledge. This indicates a marginalized status of culture in language education. Additionally, this situation shows that the teachers need to be supported in adopting an intercultural approach.

Similarly, in the Vietnamese context, teachers showed limited knowledge of intercultural language teaching. In addition, Vietnamese teachers revealed unique obstacles in teaching cultures including their lack of professional development, and not being well-informed of government policy of training interculturally competent graduates. Vietnamese teachers believed in students' willingness to learn culture. In stark contrast, in some western contexts (e.g., Sercu et al., 2005), teachers reported not emphasizing culture learning due to students' low interest in other cultures. Overall, the body of research has shown increasing interest in how teachers perceive culture teaching and their actual classroom practices.

\subsubsection{Research on the Intercultural Innovation in Language Class. Scholars}

worldwide have also focused on examining how intercultural innovation can be implemented in language classes and their outcomes.

Research Outside Asia. In a secondary school in New Zealand, Feryok and Oranje (2015) examined how a foreign language teacher of German adopted a project designed to promote intercultural communicative language teaching. They observed how the teachers implemented the lessons after they were introduced to the project. Feryok and Oranje (2015) found that the teacher adopted the project as a formal assessment rather than focusing on fostering students' intercultural competence while performing the project.

Howard et al. (2019) reported on a qualitative case study design using interviews with the teachers, non-participatory lesson observations, teacher-written reflections, and focus group interviews with students. The five participant teachers and the research team met for a twoday workshop so that teachers could build their knowledge of intercultural language teaching (ILT) (teachers reported not being aware of ICLTL principles before the workshops). After that, the teachers applied the ILT approach in their classes. Findings indicated that some students increased their openness to difference and became more confident in, and willing to, engage with other cultures. These positive gains in students' IC development suggest that 
positive changes in teachers' teaching practices are likely to occur when teachers are provided with training on the ILTL approach, which possibly results in an improvement in students' intercultural capability.

Research in Asian Contexts. Using the portfolio approach, Su (2011) examined the effects of the cultural portfolio project on (1) students' specific aspects of cultural knowledge development, (2) students' self-awareness, evaluation, and modification of stereotypes toward the target cultures; and (3) students' change in perception of, and attitude toward, cultural learning in a private university in Taiwan. Results indicated that students experienced an active process of constructing knowledge rather than memorizing cultural facts. Most students reported moving from an ethnocentric view to respecting cultural differences and becoming more aware of the diversity within a culture. These results suggest positive outcomes of a portfolio intervention on students' IC development.

Moreover, fostering students' IC was adopted in reading classes in a study by Yu and Van Maele (2018). The researchers conducted an action research study on how 77 second-year undergraduate students' intercultural awareness was developed in an English reading course at an independent college of a major Chinese university. The study integrated intercultural learning with critical thinking by challenging students to select, analyze, and raise questions about English texts on aspects of Chinese culture. The findings showed that a majority of participants demonstrated a level beyond basic awareness, which suggests that reading courses can be utilized for fostering Chinese students' intercultural awareness.

Next, in a qualitative action research study, Hazaea (2019) investigated the development of critical intercultural awareness among EFL students through a critical reading enrichment course at a Saudi university. The teacher-researcher provided the participants with tools from critical discourse analysis for analyzing intercultural texts. After that, students were asked to complete their assignment by reading a text about a dinner invitation and then writing creatively on that topic. Findings showed that the participants demonstrated a balanced intercultural awareness associated with the discourse of food diversity, improved intercultural knowledge, skills, and attitudes. The study suggests that critical discourse analysis can be an effective strategy to increase EFL students' critical intercultural awareness.

In the Japanese context, McConachy (2013) investigated the effect of students' engagement with pragmatics-based ideas and texts on their intercultural awareness. McConachy (2013) 
aimed to build students' intercultural awareness and interpretation of language through using textbook dialogues. The participants were four Japanese tertiary EFL students, with intermediate English levels. The author devised a sequence of three analytical discussion tasks to guide students to understand the cultural dimension of apologizing as a speech act. The three analytical discussion tasks included a meta-pragmatic focus, a discoursal focus, and an intercultural focus. The meta-pragmatic focus required students to draw inferences regarding the feelings of the dialogue characters and justify their ideas. The discoursal focus required students to focus on the apology in terms of its internal structure and positioning within the dialogue. For the intercultural focus, students were asked to reflect on the act of apologizing in Japanese and consider how apologizing strategies in the given dialogue might vary and why. The students' discussions in the three analytical discussion tasks were audiorecorded and used for data analysis. The findings show that the students began to explore the relationship between language and culture, formulated understandings and interpretations of language use, which could lead to the development of intercultural awareness.

Research in Vietnam. Ho (2011) described an intervention adopting an innovative intercultural approach to foster students' ICC. He first examined the curriculum, then teachers' perceptions and classroom practices, and students' perceptions to investigate the situation of teaching culture in the tertiary context before adopting an intercultural stance. His finding was that culture was marginalized at all levels i.e., curriculum, in teachers' perceptions and practices, and students' perceptions. Another finding was that teachers' traditional instruction approach depended on cultural topics and the teachers separated culture from language in their practices. This finding was consistent with Nguyen's (2013) finding. The intercultural class in Ho's (2011) study adapted an intercultural stance informed by Newton et al. (2010) and Liddicoat and Scarino (2003). Ho collected data from multiple sources including pre and post-tests, case studies, self-evaluation questionnaires, reflective journals, and focus group interviews to triangulate his findings on the students' intercultural learning outcomes. The results were that learners in the intervention group increased in four components of IC: knowledge, attitudes, skills, and awareness.

In Truong and Tran (2014) the students participated in learning activities designed to develop intercultural skills while watching parts of the film in each lesson. These activities included observing, recognizing, analyzing cultural contents (e.g., what the native speaker characters in the film said and acted), practicing language (e.g., listening and identifying verbal and non- 
verbal components in the film), and reflecting on their own culture (e.g., acting out in front of the class and sharing this experience of acting). The findings showed that students improved their cross-cultural knowledge and increased awareness of their cultural stereotypes.

Recently, Tran (2020) conducted a two-phase qualitative participatory action research study. In Phase 1, the study explored the nature of the teaching of culture by three tertiary EFL teachers and their stated perceptions of culture teaching. This phase's cross-case analysis showed that the teaching of culture was intermittent and unplanned and that the teachers held a static view of culture with little awareness of intercultural language teaching. Phase 2 investigated the impact of two professional development workshops on these case study teachers' classroom practices and their emerging perceptions of intercultural language learning (ICLL). Findings from classroom observation and interview data showed a positive impact of the workshops on the teachers' teaching practices. Specifically, the teachers could implement the redesigned intercultural lessons, which were adapted from the currently used textbook. The lessons involved six stages: forming hypotheses, role-playing, listening, analyzing and comparing, relating/ reflecting, and revising hypotheses. In addition, findings revealed teachers' shifting perceptions toward a more focus on culture, and a growing understanding of intercultural language teaching.

In conclusion, the body of research for the past years has shed light on the differences in how language teachers and students in different locations perceive culture teaching, and how they address culture in their language classes. Despite the contextual differences, a variety of foreign languages, and various methods of data collection and data analysis, the whole body of research has indicated a common trend in teachers' favor for ILT, and limited focus on ILT in practice. Furthermore, positive outcomes of the intervention reported from these studies suggest a high probability of fostering students' ICC in various contexts.

Similar to the scholarship outside and inside Asia, the Vietnamese scholarship has recognized the importance of integrating an intercultural dimension into language teaching and learning. However, to compare with the scholarship outside and inside Asia, little research in Vietnam has addressed (a) teachers' knowledge and skills in facilitating intercultural learning and developing materials for intercultural learning, and (b) teachers' implementation of intercultural language teaching and learning principles. Consequently, this shortage does not seem to support the national language policy, which recognizes the importance of 
intercultural awareness in EFL education. This has motivated me to conduct this study to investigate the feasibility of adopting an interculturally-informed project to foster ICLTL in the Vietnamese tertiary context.

\subsection{Project-Based Learning (PBL)}

\subsubsection{PBL - Definition and Characteristics}

Project-based instruction or project-based learning (PBL) was first initiated by David Snedden who taught science in American agriculture classes. Later, in the early 1900s, PBL was further developed by William Heard Kilpatrick, a student of John Dewey. In essence, the project method aims to create opportunities for learners' active, deliberate participation in their learning activities (Beckett \& Miller, 2006). PBL has been explored in various contexts, different stages of schoolings, and in a variety of disciplines in social and natural science.

There have been various definitions of PBL. For example, outside the language education field, the Buck Institute for Education (BIE), a leading American research and development organization, defines PBL as "a teaching method in which students learn by actively engaging in real-world and personally meaningful projects" (Buck Institute for Education, 2020). In another definition, PBL is a student-centered form of instruction, which is based on three constructivist principles: learning is context-specific, learners are actively involved in the learning process and they achieve their goals through social interactions and the sharing of knowledge and understanding (Cocco, 2006, as cited in Kokotsaki et al., 2016).

Outside the language education field, Thomas (2000) proposes five key features of PBL:

1. PBL projects are central, not peripheral to the curriculum.

2. PBL projects are focused on questions or problems that "drive" students to encounter (and struggle with) the central concepts and principles of a discipline.

3. Projects involve students in a constructive investigation.

4. Projects are student-driven to some significant degree.

5. Projects are realistic, not school-like.

PBL was introduced into second language education in the 1990s (Hedge, 1993). Fried-Booth (2002) defines PBL as "student-centered and driven by the need to create an end-product". Since its introduction, PBL has been embraced as an effective approach for purposeful 
language learning (Fried-Booth, 2002; Stoller, 2002) because this approach has helped to improve students' language skills, content learning, real-life skills, and motivation despite evidential dissatisfaction (Stoller, 2006). Interest in adopting PBL in foreign language education has been growing globally (Fang \& Warschauer, 2004) and it has been adopted in a variety of instructional settings. Stoller (2006) identifies ten characteristics of PBL in language learning contexts:

1. Process and product-oriented

2. The project is partially determined by learners, leading to a sense of ownership in learners.

3. The length of the project covers a period of time (rather than a teaching session).

4. Skills are integrated.

5. Can enhance both language and content learning

6. Opportunities for learners to work in groups and independently

7. Learners are responsible for their roles in the gathering, processing, and presenting their project.

8. Teachers and learners take up new roles and responsibilities.

9. The project outcome is a tangible product.

10. Students reflect on the process and the product.

The two sets of key features of PBL outlined above share many commonalities such as having a process and product orientation, promoting learners' autonomy and collaboration, as well as developing a sense of ownership in learners. Despite the commonalities, some of the features outlined by Stoller (2006) are specific to language education in the way that they emphasize concurrent content and language learning. Another unique feature is that advocates for PBL in language learning view PBL as "complement" mainstream methods rather than "replace" them (Haines, 1989, p.1, as cited in Stoller, 2006). The above features of PBL in language teaching present the essence of PBL that distinguishes this approach from traditional teacher-centric and linguistically oriented language teaching methods. Many of these features are congruent with contemporary approaches to language teaching such as communicative language teaching (CLT) and task based language teaching (TBLT). Despite considerable overlap, what distinguishes PBL from these approaches is feature 3 in the 
preceding list, that is, a multiple phase project develops over an extended time period and multiple lessons, often involving a full semester of work devoted to the project objective.

Underpinning the ten characteristics of PBL listed above are four features, which warrant further explanation. First is authenticity.

In PBL, learners are exposed to real-life tasks during the completion of their projects (Markham, 2003). This means that learners can engage in authentic situations in which they can communicate with people beyond the classroom, or have real-life roles, which are similar to the real world outside the classroom (Woo et al., 2007). In completing these authentic tasks, learners use multiple life skills such as interviewing, problem-solving and critical thinking, which necessitate teamwork as well as autonomy. Real-life tasks are motivating, challenging and help learners to activate their prior knowledge gained in classroom lessons and flexibly apply their knowledge in real-life situations.

Second, in PBL, the role of the teacher as a facilitator, or coach is foregrounded (Helle et al., 2006). As a facilitator, the teacher generates activities and students enhance their real-life skills such as problem-solving, critical thinking through completing these activities (FriedBooth, 2002). To maximize the benefits of project work, teachers should consider the proper proportion of teacher guidance and learner autonomy (Alan \& Stoller, 2005).

Third, project work helps develop learner autonomy by giving learners the responsibility to monitor their learning from the beginning to the end of their project. Specifically, students can select the project topic and participate in the designing, planning, and implementing of their project with teachers' facilitation (Markham et al., 2003; Stoller, 2006). Scholars have observed students' increased autonomy, motivation in their learning, which lead to more acquisition of knowledge (Dressler et al., 2019; Setyarini, 2019; Yuliani \& Lengkanawati, 2017).

Fourth, a special feature of PBL is collaborative teamwork (Beckett \& Miller, 2006; Dressler et al., 2019) among students, between students and the teacher, and between students and experts. Through teamwork, the students mutually benefit from sharing knowledge and developing collaborative work skills (Rokhmawan \& Wulandari, 2019).

Fifth, PBL offers opportunities for learners to harness and develop multiple intelligences. Gardner (2006) formulated the following list of nine intelligences that are possessed and can 
be fostered in learning: (a) linguistic, (b) logical/mathematical, (c) musical, (d) spatial/visual, (e) kinesthetic, (f) interpersonal, (g) intrapersonal, (h) naturalistic, and (i) existential intelligences.

In summary, PBL creates a learning environment that allows students to explore their own interests and provides rich opportunities for students to enhance their learning potentials (Baş \& Beyhab, 2010; Gomez \& Garcia, 2020). One important factor that needs to be considered in the project-based approach is the steps to implement a project work, which is presented in the following section.

\subsubsection{PBL Steps of Implementation}

As a student-driven and teacher-facilitated learning approach, PBL has distinct steps of implementation. Papandreou (1993) states that every project is a series of activities undertaken by learners and these activities make up the process of the project implementation. This author introduces a model with six steps in the process of project work as follows:

Step 1: Preparation: teacher introduces the topic to the students, and students are invited to discuss with team members and raise questions

Step 2: Planning: $\quad$ teacher and students determine the modes of gathering information, analyzing and assigning work among team members

Step 3: Research: students collect information from various resources while working individually or in groups

Step 4: Conclusions/ Results

students reach conclusions after completing their analysis of information collected

Step 5: Presentation students present their final products to the whole class, teachers, or external audiences 
While Papandreou (1993) names each step with core objectives of project work, Alan and Stoller (2005) present a ten-step process with a clear description of the roles of teachers and learners in the steps below:

\section{Step 1: Students and instructor agree on a theme for the project}

The students and instructor reach a consensus on the project theme. It is essential in this step for the instructor to work out ways to develop the students' ownership of the project whether the project is structured, semi-structured, or unstructured.

\section{Step 2: Students and instructor determine the final outcome of the project}

The students and instructor decide on the final outcome of the project (e.g., bulletin board display, brochure, letter, oral presentation, video, etc.). They also discuss the most appropriate audience for their projects (e.g., classmates, teachers, program director, parents, or other external audiences).

\section{Step 3: Students and instructor structure the project}

With the theme and final outcome in mind, the instructor and students detail the project work activities to orientate students throughout the completion of the project. The working out of the guiding details involves assigning work responsibilities. Furthermore, students figure out the timing for gathering, sharing, analyzing information, and presenting their final project.

\section{Step 4: Instructor prepares students for the demands of information gathering}

At this stage, the instructor assists students in their information-gathering process through instructional activities. These activities prepare students with language, skills, and strategies for their information-gathering tasks. For example, if students will be conducting interviews to collect information, the instructor might organize activities in which students practice forming questions, taking notes, and asking for clarification.

\section{Step 5: Students gather information}

At this point, students collect information with the skills and language practiced in Step 4. The instructor provides relevant resources for information on students' requests if possible.

Step 6: Instructor prepares students to compile and analyze data 
Students need to compile, analyze and synthesize the information they have collected. In order to prepare students to complete these tasks on their own, the instructor designs tasks so that students can practice skills like categorizing and comparing.

\section{Step 7: Students compile and analyze information}

After being equipped with analyzing skills from the preparatory activities in Step 6, the students are ready to conduct their analyzing tasks such as organizing data, critically evaluating the information collected and determining which information to use, and which to set aside.

\section{Step 8: Instructor prepares students for the language demands of the final activity}

At this point, the instructor prepares students for the presentation of the final product through language and skill improvement activities such as oral presentation skills.

\section{Step 9: Students present the final product}

Students present the final outcome of their projects.

\section{Step 10: Students evaluate the project}

Students reflect on the language and content that they have acquired during the completion of the project. Furthermore, they give recommendations to improve similar future projects. The instructor gives feedback on students' feedback and content learning.

Recently, building on insights from previous works in PBL, Stoller and Myers (2019) introduces a PBL five-stage framework with five distinct cycles of student engagement and teacher's guidance (Figure 2.8). 
Figure 2.8

PBL five-stage framework (Stoller \& Myers, 2019, p.27)

This image has been removed by the author of this thesis for copyright reasons.

\section{Stage 1: Preparation cycle}

Similar to Steps 1 and 2 in the ten-step process (Alan \& Stoller, 2005), this cycle in the fivestage framework entails the determination of project theme, final outcome, and plans for implementation. What is more clearly explained than previous works is the inclusion of recommendations for the focus on the themes which (a) are relevant to students' 
communities, studies and life, (b) can motivate students, and (c) are themes with plentiful reference resource available.

\section{Stage 2: Information gathering data cycle}

Apart from describing various types of information gathered and methods of information collection as in (Alan \& Stoller, 2005; Papandreou, 1993), Stoller and Myers (2019) outlines possible emphases of scaffolding instruction such as introducing gambits for requesting repetition, clarification, elaboration, and teaching language of openings and closings. This inclusion of examples of scaffolding might be of great benefit to language teachers in implementing PBL.

\section{Stage 3: Information processing cycle}

Scaffolding instruction is present at all levels of information processing such as organizing, analyzing, and synthesizing data. This cycle is iterative and students benefit from being guided throughout the stage.

\section{Stage 4: Information display cycle}

The presence of scaffolding instruction continues to be highlighted at this stage. Stoller and Myers (2019) suggest some ways of guiding students before "displaying” their project outcomes such as discussing the manner of presentations, and creating chances for rehearsal and feedback if students are expected to perform projects orally.

\section{Stage 5: Reflection cycle}

Like previous works on PBL, at this last stage of project implementation, Stoller and Myers (2019) encourage students' reflection on what they have learned from the project, both from the process and the outcome. Furthermore, these researchers suggest that teachers should also engage in reflective processes to identify project strengths and drawbacks.

While Alan and Stoller (2005) highlight students' responsibilities in each step, Stoller and Myers (2019) emphasize the scaffolding role that the instructor takes in each project step such as gathering information, analyzing data, and preparing the final outcome of the project. Stoller and Myers (2019) believe that their evolution of thinking as reflected in the five-stage framework can resolve the limitations of earlier works by highlighting the iterative nature of 
PBL, recognizing different types of teacher scaffolding and student engagement, and emphasizing the value of reflection and evaluation. As Rasku-Puttonen et al. (2003) argue, flexible and proper scaffolding is crucial to students' success in their projects. Though students have ownership of their project, they do need the teacher's support during the completion process (Grant, 2011).

At the time of my data collection, I adopted the steps proposed by Alan and Stoller (2005) as the theoretical frameworks for conducting the PBL lessons. In addition, the teachers and I agreed that we should scaffold students in all stages of the PBL lessons. Therefore, the current research aligns most closely with the framework proposed by Stoller and Myers (2019). In addition to mastering the necessary steps in project-based learning, the instructor needs to understand and perform an effective assessment, which is discussed in the next section.

\subsubsection{Assessment in PBL}

Assessment in PBL can be different and challenging compared to assessment in traditional teaching methods in terms of what to assess, how to assess, and who assesses.

In disciplines other than language teaching, various assessment practices can be integrated into evaluating project outcomes. For example, homework assignments, laboratory exercises, final project papers, and presentations are used to measure content outcomes. Implementation evaluation, informal evaluation and project papers are employed to assess scientific process learning outcomes. In addition, the assessment of the overall outcomes can be conducted through a peer review form, a faculty review panel, a final research presentation, and a final paper (Baker, 2006).

In language teaching, assessing project work should involve evaluating what students learn, the processes and efforts that lead to the final product, and what the learning outcomes are (Blumenfeld et al., 1991). Therefore, as in other fields, in language teaching, both formative and summative assessment should be integrated as a part of an effective assessment program (Slater et al., 2006; Solomon, 2003). Formative assessment is generally designed for giving feedback throughout the process of implementing projects, while summative assessment is expected to provide students with the overall degree of their performance at the end of the course (Markham, 2003). 
Assessment in PBL can be made by not only the teacher but peers and the learners as well. Peer assessment allows learners to evaluate their own team members' work or peers' work by offering suggestions for improvement or giving support. Peer assessment during the learning process helps learners to evaluate their peers' final projects more easily (Moss, 1997). Selfassessment enables students to evaluate their own work by reflecting on the performance, work progress, draft and texts, and overall learning process that leads to their achievement (Moss, 1997). However, peer and self-assessment can be problematic when some students doubt the fairness in their peers' evaluation or experience (Hattum-Janssen \& Pimenta, 2006). The problem may arise when self-assessment results in higher grades than teacher assessment (Topping, 2003), or stricter ratings (Matsuno, 2009). Such concerns about reliability in formative assessment can be resolved by triangulation in assessment with different assessment sources such as teachers, peers, students (Huerta-Macias, 1995). Moreover, if students are trained on how to self-assess and receive guidance and support, positive results can be possibly obtained (Ana \& Martha, 2007; Xiao \& Lucking, 2008).

Apart from internal assessors such as teachers, peers, and students, there can be external assessors who are PBL audiences like community members, experts, and parents (Solomon, 2003). External assessors can observe language content, the amount of work produced, presentation, continuity, involvement, use of self-access materials, and give their judgment on the overall achievement of the group instead of individual students.

To achieve reliable and effective assessment, rubrics should be employed to guide teachers and students in their evaluation process (Grant, 2002; Lenz et al., 2015). A rubric is a set of criteria used for evaluating students' work (Moss, 1997). As a scoring tool to differentiate levels of student performance, rubrics should contain three features: (a) a set of aspects of product or performance, (b) a scale with numerical scores describing each level of performance, and (c) criteria with specific indicators for evaluating a product or performance's quality (Markham, 2003). Different levels of performance and the criteria needed to achieve these levels must be well defined and students should know and understand these criteria before the implementation of the project (Moss, 1997). 
To help make rubrics accessible to students, Jonsson and Panadero (2017) recommend the following points in the design and use of rubrics:

- Avoid summarizing into a total score so that the aspects of assessment are clearly explained and strength and weakness in relation to individual criteria are noticeable.

- Use several quality levels

- Use task-level specificity

- Explain the criteria and quality levels, make the rubric available, digitally or on paper, and provide the students with the rubric before they perform the task.

- Use direct criteria, so that they may guide student performance and facilitate selfassessment and reflection.

Conducting an effective assessment is crucial in project-based learning. While the traditional assessment practices focus on grades and rote learning to obtain results for administrative uses, which is an assessment of learning, in PBL the purpose of assessment is not an assessment of learning, but for enhancing learning through feedback, self and peer assessment (Moss, 1997; Munoz-Restrepo, 2017; Solomon, 2003).

In Study 2 (PAR), together with other PAR members, I applied these theories in assessing the students' project, including their progress in implementing the project and the final project itself. However, my research does not emphasize the assessment aspect of intercultural learning. Rather, we focus on whether there were positive indications of students' intercultural learning in the project.

\subsubsection{Previous Research in PBL}

A wide range of studies has investigated the effects of PBL in various contexts around the globe and at different stages of schooling, from pre-school to junior, secondary and higher education (Kokotsaki et al., 2016). For example, at the preschool and primary school level, Habok (2015) investigated the effects of applying concept maps as a tool to foster experiential reasoning and understandings of relations among children in their last year at a Hungarian kindergarten. In addition, Kaldi et al. (2011) examined the impacts of implementing an environmental project on Greek primary school students' content knowledge and attitudes towards self-efficacy, task value, group work, and peers from different ethnic backgrounds. Karaçalli and Korur (2014) looked at the fourth-grade PBL 
students' academic achievement and retention of knowledge in a science course in Turkey. Overall, these studies have revealed positive outcomes of students' academic learning, group work skills, motivations and attitudes.

Similarly, studies have also indicated positive results in secondary PBL students. For example, in an American secondary context, Hernandez-Ramos and De La Paz (2009) found that PBL students had significant gains in content knowledge and historical thinking in the history course compared to students in traditional instruction classes. Al-Balushi and AlAamri (2014) conducted a quasi-experimental study with 62 eleventh-grade female science students to investigate the effects of environmental projects on students' environmental knowledge and attitudes towards science. The findings were that the students in the experimental group performed better in both the environmental knowledge test and the science attitudes survey.

Scholars have also explored the effectiveness of the PBL approach in higher education in different countries. In recent work, Guo et al. (2020) contend that among 76 studies reviewed, many have proved that PBL enhances students' content knowledge (e.g., Alsamani \& DaifAllah, 2016; Mohamadi, 2018), learning strategies (e.g., Barak \& Dori, 2005; Stefanou et al., 2013), skills (e.g., Brassler \& Dettmers, 2017), motivation (e.g., Helle et al., 2007), and product quality (e.g., Affandi \& Sukyadi, 2016; Torres et al., 2019).

In the field of language education, PBL has been beneficial in enhancing learners' language skills (Stoller, 2006) and meta-cognitive skills because PBL "involves a variety of individual or cooperative tasks such as developing a research plan and questions, and implementing the plan through empirical or document research that includes collecting, analyzing, and reporting data orally and/or in writing" (Beckett, 2002, p.54). In a narrower field of teaching English as a foreign language, a growing number of studies have been investigating the effectiveness of PBL. For example, in a recent review of 39 PBL studies in China from 2002 to 2007, Wang (2020) found that almost all the studies focused on the macro aspects of project-based language learning (PBLL) such as motivation, collaboration, and autonomy of the learners while the extent of the language development and instructor factors had not been sufficiently elaborated. A myriad of studies has investigated the impact of PBLL on students' language skills. These studies have found that PBL facilitates vocabulary learning (Alsamani \& Daif-Allah, 2016), writing skills (Affandi \& Sukyadi, 2016; Grant, 2017; Sadeghi et al., 
2016; Sultan \& Javaid, 2018), speaking skills (Astawa et al., 2017; Vaca Torres \& Gomez Rodriguez, 2017), listening (Bakar et al., 2019), and independent learning and presentation skills (Farouck, 2016). Due to the scope of my research, my review of previous research will focus on studies investigating the adoption of PBL in improving students' intercultural competence in both world and Vietnam language class contexts.

2.2.4.1 Research Outside Vietnam. While a lot of studies have been conducted to examine PBL using computer-assisted language learning (CALL) to enhance intercultural learning (e.g., Chen, 2019; Kusumaningputri \& Widodo, 2018; Lenkaitis et al., 2019), a limited number of studies have used PBL to foster intercultural learning without CALL in teaching a foreign language. In the same line with studies on PBL in EFL learning, several studies have affirmed the benefits of PBL towards intercultural learning (Allen, 2004; Belpoliti \& Fairclough, 2016; Feryok \& Oranje, 2015; Liu, 2018; Ruan \& Du, 2013; Su, 2011; Worawong et al., 2017). For example, in Denmark, Ruan and Du (2013) investigated the implementation of a PBL approach in a Chinese culture course at Aalborg University. Results of this study showed that both students and teaching staff appreciated a supportive environment to learn culture. They also displayed their preference for relevant content including not only descriptive culture but also complex and dynamic aspects of culture, motivating activities that apply theories to practice, give real-life experiences, diverse learning methods, and sources that emphasize student-centered learning.

In an American context, Allen (2004) illustrated a PBL project in which postsecondary students of French identified stereotypes about the cultures of French-speaking countries, conducted open-ended investigations, and accepted or rejected the validity of the stereotypes based on supporting and contradictory evidence. They compiled the information they gathered during their explorations, along with rationales explaining their thinking processes, in a portfolio. As a result of completing the project, students not only gained insight on a specific aspect of their own and francophone cultures but also recognized the impact their own perspectives had on understanding another culture. They became aware of their own process of learning, engaged in critical thinking, and familiarized themselves with resources for future cultural explorations. Finally, Allen (2004) suggested that a similar project might be implemented in upper-level high school classes as well as university classes and is appropriate for the study of any target culture. 
In another American context, Belpoliti and Fairclough (2016) reviewed the development and implementation of inquiry-based cultural projects in a Spanish Heritage Language (SHL) Program. They described four PBL curricula and illustrated how university students in this SHL program enhanced their Spanish while carrying out research to understand Hispanic cultures through utilizing different project tools, including the Internet, surveys, interviews, and field data collection. The authors found that the students gained understanding of the Hispanic cultures representing in their perspectives, products, and practices when they gathered materials related to cultural expressions and analyzed these materials.

In a Taiwanese college context, $\mathrm{Su}$ (2011) conducted a study to examine the effects of the cultural portfolio project on (1) students' concept development in their perceptions of the target language culture and their own, (2) students' evaluation of stereotypes towards English-speaking cultures, and (3) students' self-awareness and perception of EFL and cultural learning process. The author collected data from students' cultural portfolio projects, classroom observation, and interviews. The findings from the study indicated that the cultural portfolio project enabled the students to actively engage in their learning, gain insight into specific aspects of the target language cultures, acknowledged the diversity within these cultures, and developed their critical thinking.

Also in Taiwan, Liu (2018) integrated an EFL writing project to facilitate culture and language learning for 32 low-proficiency college EFL learners and investigated the effects of this course using a questionnaire survey, students' reflection papers, and the teacher's observation and personal notes. The study found positive learning results. In addition to these positive results, this study also discussed how the teacher used students' writings to teach some essential intercultural communication skills to prepare students as EFL users.

In a Thai context, Worawong et al. (2017) conducted an action research study to investigate the impact of the CEFR project on 40 Thai third-year university students' intercultural competence and their attitudes toward the project class. Data were collected from observations and questionnaires. Findings revealed students' positive attitudes towards PBL and intercultural competence in terms of nonverbal communication.

Overall, these reviewed studies have shown positive results of adopting PBL in fostering intercultural learning in classroom contexts outside Vietnam including European countries, America, Taiwan, and Thailand. Students in these studies, with English or other languages as 
a foreign language, have enhanced their intercultural competence as well as demonstrated their preference for the PBL approach. The authors have argued that the process of actively engaging in gathering materials, and working with the materials in the implementation of the project do enhance students' cultural knowledge, critical thinking, and intercultural competence.

Although these studies have provided a deep understanding of how PBL was implemented in various contexts and the outcomes of these PBL projects, there are some limitations in some of the reviewed studies in terms of the consistency between research goals and findings; and between what findings revealed and researchers' state research outcomes. For example, Allen (2004) gave a detailed description of the project such as the steps of the project, how students were guided and what they gained from the project. However, this author did not clarify the specific aims of the study, which posed a challenge for readers to evaluate the findings in relation to the research goals. Regarding the relevance of the findings and the research questions, Worawong et al. (2017) focused their data analysis on only the dimension of nonverbal communication while their research question referred to students' multiple dimensions of intercultural communication. Finally, while Liu (2018) argued that the project applied in the research enhanced students' intercultural communication skills, his findings simply revealed students' gains in static cultural knowledge.

2.2.4.2 Research in Vietnam. Research on adopting PBL to enhance intercultural learning in Vietnam remains limited in number and the volume of comprehensiveness. In fact, to date, only two studies of this type have been conducted in Vietnam. First, in a Vietnamese university context, Ngo (2014) conducted a pilot study with 20 graduate English majors in an intercultural communication course. The course lasted 45 hours. The students were divided into groups and the teacher facilitated students' project implementation in four steps: (1) structuring the project work, formation of project groups and topics, assigning member roles; (2) gathering information from various sources; (3) analyzing data gathered; (4) presenting and discussing the final reports. The author found that the PBL approach did improve the students' IC skills, English skills, research skills, social skills, and collaborative skills. Second, Allison and Do (2015) implemented a drama project and a cultural project in a university context in Vietnam. The drama project required students to choose a popular novel or short story from English-speaking countries, create scripts based on the chosen story, and perform. The implementation of this project involved five stages: grouping and assigning 
tasks, locating materials and writing scenarios, assigning roles and learning scripts, practicing and acting, and performing. The cultural project required students to produce a brochure presenting some cultural information about their homeland and a presentation about a city in an English-speaking country. The authors proposed that the students would improve their cultural knowledge through examining the content of their chosen story and in the selection of costumes for their performances in the drama project. Further, they would improve their cultural knowledge of their homeland and other cities in the world in the cultural project.

As the number of studies on PBL in intercultural learning in the Vietnamese context is rare, the insights gained from these two studies may be of assistance to understand how PBL affects students' intercultural learning in the context. However, these studies have several limitations. First, Ngo (2014) and Allison and Do (2015) fail to fully define what IC skills are and articulate how they were developed in the study. Moreover, Allison and Do (2015) limited their focus on enhancing students' knowledge of cultural facts rather than intercultural skills. Finally, these authors did not elaborate on their data collection instruments and data analysis, which limits the trustworthiness of their findings.

In brief, the reviewed studies have shown that PBL has enhanced students' foreign language learning and intercultural skills in many contexts. Thus, I would argue that a PBL approach might be adopted in a university Vietnam context. Because little research has been conducted to examine the effectiveness of PBL in enhancing intercultural learning in Vietnam, I conducted this study to provide insights into how PBL is implemented. In addition, it is significant to understand teachers' and students' perceptions about this approach in fostering students' intercultural learning in Vietnam.

\subsection{Summary}

This chapter has outlined the key concepts, theories, and previous research related to this study. It comprises two big sections: Section 1 about culture and Section 2 about projectbased learning. First, Section 1 presents principal ways of conceptualizing culture in language and the argument among scholars in the conceptualizations of culture. Although there are multiple ways of conceptualizing cultures, two main approaches are: looking at culture as static and looking at culture as dynamic. Next, the chapter discusses the relationship between language and culture. Then, it continues with the concepts and models of IC, focusing on Byram's (1997) IC model. Section 1 moves on to present iCLT principles (Newton et al, 
2010), principles for teaching spoken communication (Newton, 2016), and principles for ICLTL (Liddicoat and Scarino, 2013). Section 1 ends with a review of previous studies on the teaching of culture in the classroom in various contexts. In general, the studies reveal a need to enhance intercultural learning.

Section 2 presents theories about project-based learning such as PBL's characteristics, steps in implementing a project, assessment in PBL. This section also discusses previous studies using PBL to facilitate intercultural learning in the classroom in various contexts. Although PBL has been utilized at a large scale in other disciplines, the number of studies on fostering intercultural learning using PBL remains limited.

This literature review chapter has provided deep insights into the current theories and research relevant to my study. It also clarifies the frameworks used for this study. Finally, it shows the gap in the literature that this study aims to fill, that is, investigating the feasibility of fostering intercultural learning using PBL in a Vietnamese university context. The following chapter will present the methodology used in this study. 


\section{Chapter 3: Methodology}

This chapter outlines the research methodology for the current research. The research involved two related qualitative studies. The first was an ethnographically-informed study on the current situation of culture teaching in language classrooms in a Vietnamese university context. The second was a Participatory Action Research (PAR) study on project-based intercultural learning in this context.

The chapter begins with an overview of the research including research paradigm, qualitative approach, research questions, and research design. Then it describes the research setting including the research site, the participants, and outlines how ethical considerations were addressed. It continues with the information on the data collection process, data analysis, and how trustworthiness was achieved.

\subsection{Overview of the Study}

\subsubsection{Interpretive Research Paradigm}

As Hesse-Biber (2017) states, a research methodology is derived from a researcher's paradigm - worldview, which is comprised of ontology and epistemology. An ontology is defined as "a philosophical belief system about the nature of social reality - what can be known and how"; and an epistemology - "a philosophical belief system" about who constructs the knowledge (p. 6). Due to diverse ontological and epistemological assumptions, a study falls into one of three major categories - positivist, interpretive and critical (HesseBiber, 2017; Merriam \& Tisdell, 2016).

Positivist researchers treat reality as being "out there" and "observable, stable, and measurable" (Merriam \& Tisdell, 2016, p. 9). They adopt a "value-neutral stance" and use standardized measurement instruments to investigate a research issue (Hesse-Biber, 2017). Typically, quantitative methods are used for data analysis and the roles of the researcher and research participants are distinguished. In contrast, interpretivist researchers hold the view that knowledge is socially constructed; there are "multiple realities, or interpretations, of a single event" (Merriam \& Tisdell, 2016, p.9). They see themselves and the participants as "co-creators in the knowledge-building process and emphasize the perspectives of the participants" (Hesse-Biber, 2017, p.6). Qualitative methods are usually adopted by 
researchers within the interpretive tradition. Finally, critical research does more than interpreting people's meaning-making of reality. Its goal is to critique, challenge and particularly produce changes, and empower (Merriam \& Tisdell, 2016).

The current study lies within an interpretive tradition. The alignment is reflected in two ways: (1) multiple interpretations of the realities are considered, (2) the participants are the cocreators of the knowledge-building process. First, multiple interpretations include my own and the teachers' and students' perceptions and practices of culture teaching and learning in this context and of the development and impact of a PAR-based PBL innovation. This process of interpretation was supported by both my etic and emic roles in the research. As the researcher, I held the etic perspective of an outsider and the emic perspective of an insider - a Vietnamese university teacher of English. These different perspectives allow for multiple interpretations of the phenomenon being researched and therefore place a premium on the interpretation process. In addition, the study adopts an interpretive approach through the participants' roles in co-creating the meanings of the research.

\subsubsection{Qualitative Research Approach}

According to Denzin and Lincoln (2013), "qualitative researchers study things in their natural settings, attempting to make sense of, or interpret, phenomena in terms of the meanings people bring to them" (p. 29). Furthermore, the goal of qualitative research is "to achieve an understanding of how people make sense out of their lives, delineate the process (rather than the outcome or product) of meaning-making, and describe how people interpret what they experience (Merriam \& Tisdell, 2016, p.15). Accordingly, the qualitative research design fits well with the objectives of this study. First, it allows the researcher to explore the EFL teachers' perceptions and experiences of culture teaching (Study1); and teachers' experience in the PBLL innovation (Study 2). In addition, qualitative research allows the researcher to collect data from a variety of sources for triangulation, which gives deep insights into a phenomenon (Heigham \& Croker, 2009). In the current study, multiple sources of data for triangulation included class observations, interviews, and reflections.

\subsubsection{Research Design}

Although both studies fall under the umbrella of qualitative research, each of them adopts a distinct design. Figure 3.1 gives an overview of research designs in Study 1 and Study 2. 


\section{Figure 3.1}

Research design

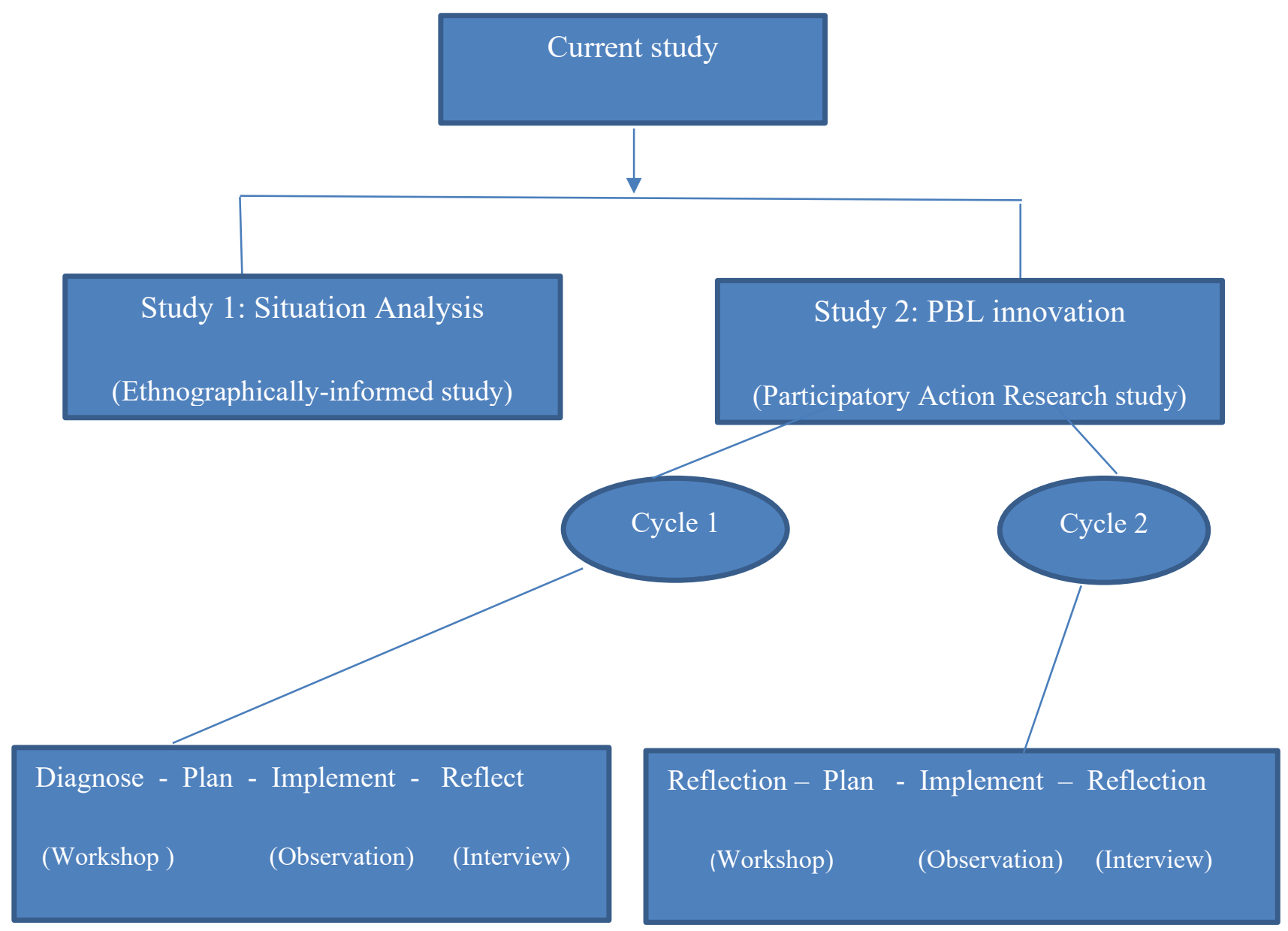

Details of the design of each of the two studies of the research are discussed below.

\subsubsection{Study 1 Research Design}

In Study 1, I adopted an ethnographically-informed approach to classroom observational research. Study 1 was ethnographically-informed in the sense that it focused on the emic perspectives of participants that structured their behaviors (Merriam \& Tisdell, 2016). This study enabled me to understand what teachers, students, and other stakeholders thought about culture teaching and learning in the research site. Through qualitative data collection methods such as interviews and observations, I obtained insights into how and why teachers and students were carrying out their teaching and learning practices concerning culture teaching and learning. Specifically, Study 1 investigated (a) teachers' perceptions and practices of culture teaching, (b) students' perceptions of culture, (c) graduates' reflections on their past 
culture learning at the university, and (d) employers' evaluation of graduates' intercultural competence.

\subsubsection{Study 2 Research Design}

In Study 2, I drew on principles of participatory action research (PAR) (James et al., 2008; Kindon et al., 2007; Lawson, 2015). According to Kindon et al. (2007), PAR "is an umbrella term covering a variety of participatory approaches to action-oriented research”. PAR involves researchers and participants working together to examine a problematic situation or action to change it for the better (Wadsworth (1998) as cited in Kindon et al. (2007).

Consequently, participants are not treated as the subjects of research, but rather, are active contributors to research who participate in all phases of the research process (Chandler \& Torbert, 2003; Kelly, 2005). In this PAR study, I worked with two teachers to adapt a textbook, design lesson plans, implement, and evaluate the implementation of the agreed lesson plans. Streck (2014) argues that PAR not only produces changes based on the results of research but also provides learning due to changes and new knowledge created during the research process. Accordingly, I worked as a facilitator in the change process and the teacher participants worked as collaborators. This gave teachers more opportunities to make decisions that affect their teaching and for students and teachers to expand their knowledge and experience related to research.

A distinct feature of PAR is its cyclical process. According to Kindon et al. (2007), key steps in a typical PAR process are below in Figure 3.2. 


\section{Figure 3.2}

Key stages in a typical PAR process

This image has been removed by the author of this thesis for copyright reasons.

(Source: Kindon 2007)

Kindon et al. (2007) argue that "while within PAR, collaboration at all stages of reflection and action is ideal, it is important to recognize that levels of participation by co-researchers and participants may vary significantly" (p.15). In addition, as James et al. (2008) point out, the PAR process is cyclical including Diagnose - Plan - Implement - Reflection. 
My research is informed by PAR but does not strictly follow the PAR model and principles due to contextual constraints. The characteristics of PAR that are evident in my research are (1) the collaboration between the researcher and the participants in the developing and conducting of the PBL lessons and (2) the cyclical process (two cycles as illustrated in Figure 3.1). However, unlike a pure PAR, the level of cooperation in this study was not evident at all stages. For example, the observation of teachers' classes and the analysis of the findings were conducted by only the researcher due to teachers' tight workload. This difference in team collaboration at different stages is recognized in the PAR literature (Kindon et al., 2007, p.15).

\subsubsection{Research Questions}

The research questions for the two studies are as follows:

Study 1 answered the overarching question: How is culture addressed in a Vietnamese university context? This question is divided into five sub-questions:

1(a) How are cultural and intercultural content evident in the teaching of general EFL English classes and EFL culture classes at a university in Vietnam?

1(b) How do teachers explain this cultural and intercultural content in stimulated recall interviews?

1(c) How do teachers perceive the role and value of culture and intercultural content in language teaching and learning?

1(d) How do students perceive cultural and intercultural content in their language learning?

1(e) How do employers in international companies and recently graduated employees evaluate the importance of intercultural communication skills?

Study 2 investigated how a PBLL innovation fostered students' intercultural learning. It addressed the following overarching question: How can PBL foster intercultural teaching and learning in a Vietnamese EFL university context? This overarching question is subdivided into four sub-questions:

2(a) How did the three teachers implement the PBL lessons?

2(b) What intercultural learning processes were evident in the PBL lessons? 
2(c) How did the teachers perceive the PBL lessons?

2(d) How did the students perceive the PBL lessons?

As a whole, the study addressed an overarching question: "What is the potential for the PBL approach to foster intercultural teaching and learning in a Vietnamese university context?"

\subsection{Research Setting}

This section describes the research site, the research participants, and ethical considerations for the study.

\subsubsection{Research Site}

The research site for this study is the university where I have been working as a teacher of English for 17 years since 2001. Located in Hanoi, Vietnam, this university offers programs mostly in technical and business training such as Mechanical Engineering, Automobile Technology, Accounting, Auditing and Business Administration, and English. English is taught to students in all disciplines throughout their studies, and English is also a major. The study was situated in the Faculty of Foreign Languages, which offers training courses for mostly English majors, and a small portion of Chinese majors.

I opted for this research site for three reasons. First, the Faculty of Foreign Languages (FFL) recognizes a need to reform the foreign language teaching curriculum in response to the university requirements to produce more interculturally competent graduates for burgeoning enterprises in Vietnam. This fitted well with the focus on intercultural learning in the current study. Moreover, my 17 years of experience as a teacher in this university gave me access to the site and provided me with deep knowledge of the affordances and constraints that teachers and learners experienced in the context. Thirdly, I had support and encouragement from administrators and colleagues to pursue this research topic.

In order to gain access to the research site, while in New Zealand preparing for my Ethics application, I emailed the Principal of the University and the Dean of FFL to ask for permission to physically access the research site and collect data and they approved. When back in Vietnam, I met with the Principal, Vice-Principal, and the Dean of the FFL and gave 
them a copy of my Ethics Approval documents. In addition, I briefly informed them of the purpose of my study and procedures of data collection and emphasized that I would ensure the participants' confidentiality. After being notified of related ethic materials and my research purpose, the school administrators supported the research and signed the relevant documents.

\subsubsection{Participants}

Participants in Study 1 included 14 teachers, 265 students in observed classes, 61 students (in 10 focus groups), six graduates, and six employers. Participants in Study 2 were three teachers (these teachers were among the 14 teachers in Study 1) and 87 students in the three observed classes. Fifty-seven of these 87 students also participated in focus group interviews (in nine focus groups). Details of each participant group are provided below.

\subsubsection{Teacher Participants}

Teacher participants were recruited using purposive sampling. This way of sampling allows the researcher to select the participants based on pre-determined qualities (Etikan et al., 2016). I adopted Maximum Variation Sampling, which "involves selecting candidates across a broad spectrum relating to the topic of study", which yields findings with "different perspectives" (Creswell \& Poth, 2018, p.158).

At the time that I was recruiting participants, the university employed 120 EFL teachers. They were all Vietnamese. Of these only 30 were responsible for teaching major students. Since my research was situated in the program for majors, it was only this group of 30 teachers who were my potential pool of teacher participants. In my early planning for data collection, I had hoped to obtain data for quantitative analysis. Hence, I chose this large sample. As the research project developed, it became clear that a qualitative analysis was more appropriate.

In choosing teacher participants from this group of 30 teachers, I sought participants who were a mix of the following criteria:
(a) age
(b) teaching experience 
(c) culture class teachers and general class teachers

(d) BA and MA graduates

(e) experience of contact with English speakers ${ }^{1}$

(f) male and female teachers

Because all 30 teachers were female. Criterion 6 was not applied. I narrowed down the group to 16 potential participants and invited them to participate in the research. Two declined because they were busy, which left me with 14 participant teachers.

Fourteen invited teachers agreed to take part in interviews. In choosing teacher participants for observations in Study 1 from this group of 14 teachers, I sought participants who were a mix of the following criteria:

(a) culture class and general class teachers

(b) different skills: listening, speaking, reading, writing for different years (year1, year 2, year 3)

(c) teaching experience

I invited eight teachers who met the criteria for observations and they agreed. So, in total 14 teachers participated in interviews and eight of these 14 teachers participated in classroom observations for Study 1.

In choosing teacher participants for interviews and observations in Study 2 from the group of 14 teachers, I sought participants who were a mix of the following criteria:

(a) teaching speaking for Year-1 students

(b) teaching experience

(c) BA and MA graduates

Criterion (a) was applied because I needed teacher participants for an intervention course in speaking class for Year-1 students. This selection was based on my assumption that all Year 1 students had similar English scores in national university entrance exams, which might be an advantage for analyzing the relation between teachers' guidance and students' learning

\footnotetext{
${ }^{1}$ English speakers include native English speakers and non-Vietnamese speakers
} 
outcomes in the three intervention classes. Of these 14 teachers, I invited three teachers and they all agreed to take part in Study 2 interviews and observations. Table 3.1 provides each teacher participant's biodata.

Table 3.1

Teacher participants' profiles (Studies 1 and 2)

\begin{tabular}{|c|c|c|c|c|c|c|c|}
\hline No & $\begin{array}{c}\text { Name } \\
\text { (Pseudonyms) }\end{array}$ & $\begin{array}{c}\text { Data } \\
\text { collection } \\
\text { tools }\end{array}$ & Age & $\begin{array}{l}\text { Years of } \\
\text { teaching } \\
\text { English } \\
\text { majors } \\
\end{array}$ & $\begin{array}{l}\text { Years of } \\
\text { teaching } \\
\text { culture } \\
\text { classes } \\
\end{array}$ & Qualifications & $\begin{array}{c}\text { Contact } \\
\text { with } \\
\text { English } \\
\text { speakers } \\
\end{array}$ \\
\hline 1 & Nhat & $\begin{array}{l}\mathrm{I}(1,2)+ \\
\mathrm{CO}(1,2)\end{array}$ & 28 & 6 & 0 & MA & Rarely \\
\hline 2 & Nhi & $\begin{array}{l}\mathrm{I}(1,2)+ \\
\mathrm{CO}(1,2)\end{array}$ & 32 & 10 & 0 & MA & Rarely \\
\hline 3 & Tan & $\begin{array}{l}\mathrm{I}(1,2)+ \\
\mathrm{CO}(1,2)\end{array}$ & 23 & 1 & 0 & BA & \\
\hline 4 & $\mathrm{Tu}$ & $\begin{array}{l}\mathrm{I}(1)+ \\
\mathrm{CO}(1)\end{array}$ & 24 & 2 & 0 & BA & Rarely \\
\hline 5 & Nam & $\begin{array}{l}\mathrm{I}(1)+ \\
\mathrm{CO}(1)\end{array}$ & 33 & 10 & 0 & MA & \\
\hline 6 & Luc & $\begin{array}{l}\mathrm{I}(1)+ \\
\mathrm{CO}(1)\end{array}$ & 35 & 12 & 0 & MA & \\
\hline 7 & Bay & $\begin{array}{l}\mathrm{I}(1)+ \\
\mathrm{CO}(1)\end{array}$ & 23 & 1 & 0 & BA & \\
\hline 8 & $\mathrm{Ha}$ & $\begin{array}{l}\mathrm{I}(1)+ \\
\mathrm{CO}(1)\end{array}$ & 40 & 17 & 3 & MA & \\
\hline 9 & Thu & $\begin{array}{l}\mathrm{I}(1)+ \\
\mathrm{CO}(1)\end{array}$ & 37 & 15 & 10 & MA & Rarely \\
\hline 10 & Dong & $\begin{array}{l}\mathrm{I}(1)+ \\
\mathrm{CO}(1) \\
\end{array}$ & 32 & 10 & 9 & MA & Rarely \\
\hline 11 & Tam & $\mathrm{I}(1)$ & 37 & 15 & 0 & MA & \\
\hline 12 & Chin & $\mathrm{I}(1)$ & 35 & 13 & 0 & MA & \\
\hline 13 & Muoi & $\mathrm{I}(1)$ & 41 & 18 & 0 & MA & \\
\hline 14 & Xuan & $\mathrm{I}(1)$ & 23 & 1 & 0 & BA & \\
\hline
\end{tabular}

Note. I(1) = participating in interviews in Study 1; I $(1,2)=$ participating in interviews in Study 1 and 2;

$\mathrm{O}(1)=$ participating in observations in Study $1 ; \mathrm{O}(1,2)=$ participating in Study $1 ; \mathrm{O}(1,2)=$ participating in Study 1 and 2 


\subsubsection{Student Participants}

In Study 1, students in eight teacher participants' classes were invited to be video-recorded during observations. From each class, a focus group of students (from 6 to 8 students) was recruited using Maximum Variation Sampling basing on (a) gender; (b) English competence for student focus group interviews. The students were selected based on the teachers' rating of their students' proficiency to form mixed-gender and English proficiency focus groups. Their age ranged from 18 to 24 . Apart from several city-dwelling student participants, most student participants came from rural areas in the north of Vietnam.

In Study 2, all 71 students in three classes were invited to be video-recorded during classroom observations and to write reflections about their lessons. In addition, from each class, three focus groups of students (from 6 to 8 students) were recruited using Maximum Variation Sampling basing on (a) gender; (b) English competence. The students were selected based on the teachers' rating of their students' proficiency to form mixed-gender and English proficiency focus groups. Their age ranged from 18 to 20 . The majority of student participants came from rural areas in the north of Vietnam, and a few from the capital.

\subsubsection{Graduate Participants}

For Study 1, graduates from the university's FFL were recruited to participate in semistructured interviews, I used convenience sampling. This type of sampling allowed me to approach the most accessible subjects (Marshall, 1996). An EFL teacher at the university, who graduated from the university, helped me to contact six graduates from the university. I invited these six graduates and they all agreed to take part in Study 1. Table 3.2 depicts these graduates' profiles. 
Table 3.2

Participant graduates ' profiles

\begin{tabular}{lllllll}
\hline No & $\begin{array}{l}\text { Name } \\
\text { (Pseudonyms) }\end{array}$ & $\begin{array}{l}\text { Graduation } \\
\text { Year }\end{array}$ & $\begin{array}{l}\text { Time } \\
\text { worked at } \\
\text { the } \\
\text { international } \\
\text { business }\end{array}$ & $\begin{array}{l}\text { Frequency } \\
\text { of contact } \\
\text { with } \\
\text { English } \\
\text { speakers }\end{array}$ & $\begin{array}{l}\text { Type of } \\
\text { business }\end{array}$ & Position \\
\hline 1 & Toan & 2014 & 3 years & Daily & Trading & Interpreter \\
\hline 2 & Ly & 2015 & 2 years & Daily & $\begin{array}{l}\text { Education } \\
\text { Centre }\end{array}$ & $\begin{array}{l}\text { Teacher of } \\
\text { English }\end{array}$ \\
\hline 3 & Hoa & 2017 & 1 year & $\begin{array}{l}\text { Twice a } \\
\text { week }\end{array}$ & $\begin{array}{l}\text { Hospitality } \\
\text { Industry }\end{array}$ & Receptionist \\
\hline 4 & Su & 2016 & 2 years & Daily & $\begin{array}{l}\text { Software } \\
\text { development }\end{array}$ & Designer \\
\hline 5 & Dia & 2017 & 1 year & Sometimes & $\begin{array}{l}\text { English } \\
\text { center }\end{array}$ & $\begin{array}{l}\text { Teacher of } \\
\text { English }\end{array}$ \\
\hline 6 & Sinh & 2016 & 2 years & $\begin{array}{l}\text { Several } \\
\text { times a } \\
\text { week }\end{array}$ & Trading & Salesperson \\
& & & & & \\
\hline
\end{tabular}

\subsubsection{Employer Participants}

For Study 1, employers of graduates from the FFL were recruited for semi-structured interviews. I used convenience sampling and could contact these employers with the help of the recruited graduates. All six employers agreed to take part in Study 1. Table 3.3 describes these employers' profiles.

Table 3.3

Participant employers' profiles

\begin{tabular}{llllll}
\hline No & $\begin{array}{l}\text { Name } \\
\text { (Pseudonyms) }\end{array}$ & $\begin{array}{l}\text { Time } \\
\text { worked at } \\
\text { the business }\end{array}$ & $\begin{array}{l}\text { Frequency of } \\
\text { contact with } \\
\text { graduate } \\
\text { participant }\end{array}$ & Type of business & $\begin{array}{l}\text { Position in the } \\
\text { business }\end{array}$ \\
\hline 1 & Hanh & 5 years & Daily & Trading & Manager \\
\hline 2 & Huong & 7 years & $3-4$ times/ week & Education & Manager \\
\hline 3 & Hai & 10 years & Daily & Hospitality & Head of HR \\
\hline 4 & Long & 6 years & Daily & $\begin{array}{l}\text { Software } \\
\text { development }\end{array}$ & Manager \\
\hline 5 & Ly & 3 years & Sometimes & Education & Manager \\
\hline 6 & Do & 5 years & Daily & Trading & Vice-manager \\
\hline
\end{tabular}




\subsubsection{Ethical Considerations}

The study obtained ethical approval from the Victoria University of Wellington Human Research Ethics Committee (No. 0000026601) (see Appendix 4.1). Before the data collection, I sought the permission of the Principal as mentioned in 3.2.1. In addition, I followed ethical guidelines issued by the university to ensure that the research was conducted ethically throughout the research process. Specifically, when I began to collect data, I (a) provided participants with information about the study; (b) distributed the consent form, explaining and clarifying the information in the consent form if necessary (see Appendix 2.1). The information sheet included the purpose of the study, methods, possible outcomes, and how the results might be used. I emphasized that participation was voluntary and that participants had a right to withdraw from the research at any stage. Additionally, participants were ensured that their identities would not be revealed under any circumstances. I explained that I would use pseudonyms to protect their privacy. Furthermore, I obtained their implied consent instead of informed consent slips, which could assure the "elimination of any record of the subjects' names" (Lune \& Berg, 2016, p. 43). During data collection and data analysis, I also strictly obeyed ethic principles. In the collection process, I endeavored to "respect the site and minimize disruptions" as well as used the safest possible "security measure" to store data, according to Creswell (as cited in Creswell \& Poth, 2018, p.55) such as interviewing participants at the times most convenient for them, arriving early for the observations, and sitting in a back corner of the room quietly observing the participants. Furthermore, when analyzing data, I attempted to report "multiple perspectives and contrary findings" to "avoid siding with participants" (Creswell \& Poth, 2018) and avoided bias. Finally, I guaranteed the confidentiality of the data and protecting the participants' identities, which lessened possible negative impacts on the participants (Dornyei, 2007).

\subsection{Research Process}

This section describes the research process, which involves the overall timeline of the data collection period, the piloting of data collection instruments, and methods of data collection.

\subsubsection{Timeline}

The data collection was conducted from mid-September 2018 to early January 2019, details of the time for each type of data collection are provided in section 3.4. To prepare for the data 
collection, I developed data collection instruments and piloted the instruments before applying them.

\subsubsection{Piloting}

According to Majid et al. (2017), and Malmqvist et al. (2019), piloting is an integral part of preparing for data collection tools such as observations and interviews. The analysis of the piloted interviews or observations can reveal these data collection tools' limitations, which should be dealt with. In the current research, I piloted both interviews and observations. The type of interviews piloted included teacher interview, student interview, graduate interview, and employer interview. Classroom observation was conducted in an EFL class.

The piloting of the teacher interviews was conducted in early September 2018 before the actual data collection in Vietnam. Three Vietnamese EFL teachers who were Ph.D. students at Victoria University of Wellington participated in the piloting interview. These teachers offered their comments on the clarity of each interview question. From their suggestions, I learned that I should explain in more detail the concepts used in the questions and give examples for clarification. Therefore, I revised the interview questions for the final version based on this feedback.

The piloting of the student interview with a group of five university students was conducted in Vietnam in September 2018. This group was comprised of students from year 1 to year 4. They were asked questions for the interviews to be used in Studies 1 and 2. They gave feedback on the clarity of questions. I learned that students preferred simple questions and were willing to answer around 12 questions. After receiving feedback, I modified my questions based on their comments.

The piloting of the interview with graduates was conducted in Vietnam in September 2018. I invited a graduate who was working in an international company in Hanoi. After the interview, she commented that the questions were easily understandable and appropriate.

The piloting of an interview with an employer was conducted in Vietnam in September 2018 with an employer from an international company. She gave feedback on the clarity of questions. I learned that I needed to explain the questions carefully. Therefore, I refined my questions based on her comments. 
In all pilot interviews, I used guidelines for participants' comments including

(a) Do you understand all the questions?

(b) Which question do you find difficult to understand?

(c) Which question do you find difficult to answer?

(d) What comments do you have about the content of the interview?

The piloting of a class observation was conducted in Vietnam in September 2019 at the research site in one of the English major classes that were later observed for data collection. The teacher and students in her class gave feedback on my presence and the video recording in the class. They all found that my presence and the setting up of the video caught their attention a little bit at first. However, after some minutes, they did not mind my presence and the video recording. As such, I could observe the classes as planned. After piloting, I began to collect data. The data collection methods are detailed next.

\subsection{Data Collection Methods}

This section first gives an overview of the data collection methods used in both studies (Table 3.4). Then, it explains each method used in detail.

Table 3.4

Data Collection Methods

\begin{tabular}{lcc}
\hline Data collection Methods & Study 1 & Study 2 \\
\hline Classroom observations (CO) & 12 CO & 30 CO \\
& $(8$ General, 4 CCC) & $(10$ CO/intervention class x \\
& & $3)$ \\
\hline Semi-structured interviews (I) & 14 teachers x 1 & 3 teachers x 2 \\
& 6 graduates x 1 & \\
\hline Stimulated recall interviews & employers x 1 & 3 teachers x 2 \\
& 4 teachers x 1 & \\
\hline Focus groups (FG) & Student FG x x 10 & PAR FG x 3 \\
& & Student FG x 3/ PBL class, \\
\hline Research-generated documents & & Student journals (210) \\
& & Student project products \\
& & $(17)$ \\
\hline
\end{tabular}

The next section describes each type of data collection method in detail. 


\subsubsection{Classroom Observations (in both Studies 1 and 2)}

Observational data are a salient source of data in qualitative research as they permit the researcher to obtain "live" data from "live" situations (Louis et al., 2000, p. 305). One reason to gather data from observations is "to triangulate emerging findings" with interviews (Merriam \& Tisdell, 2016, p.139). Another reason is that this method helps the researcher to discover things that participants might not reveal in interviews (Louis et al., 2000). In addition, classroom observations provide tangible behaviors to discuss in interviews. Moreover, observations can be useful in case participants have weak verbal skills (Dornyei, 2007).

\section{Observations in Study 1}

In Study 1, I acted as an observer with limited participation. I chose a back seat and quietly took notes with little involvement in teachers' and students' activities.

Observations were conducted over eight weeks. I observed eight teachers' classes. Among these eight teachers, I observed four teachers twice and the other four teachers once. Each observation lasted from 85-90 minutes, and all were video recorded. To obtain diverse information in terms of culture teaching, I conducted my observations in various subjects such as speaking, listening, reading, writing and culture class lessons. In addition, the observations were carried in all intake groups from year 1 to year 3 . Table 3.5 illustrates these observations.

\section{Table 3.5}

Study 1 Classroom Observations

\begin{tabular}{ccc}
\hline Observation (n=12) & Subject & $\begin{array}{c}\text { University } \\
\text { Year }\end{array}$ \\
\hline 3 & Speaking & 1,3 \\
\hline 1 & Listening & 3 \\
\hline 2 & Reading & 2,3 \\
\hline 2 & Writing & 1,2 \\
\hline 4 & Cross-cultural communication & 4 \\
\hline
\end{tabular}

The textbook used in the observed lessons are Worldlink 1 (for speaking); Skillful 2 (Listening); Skillful Listening and Speaking 4; Reading Explorer 3 (for reading); Academic 
Writing 1, Academic Writing 2 (for writing). The cross-cultural communication course used complied sources for internal use.

In all my observations, I used observation sheets (Appendix 5) and took field notes. According to Schensul \& LeCompte (2013), "field notes constitute the basis for data upon which the study is based: no field notes, no data" (as cited in Merriam \& Tisdell, 2016, p. 149). My field notes included both descriptive components and reflective components.

\section{Observations in Study 2}

In Study 2 (PAR), I was the researcher and a participant in the PAR. Thus, I acted as a participant observer. Participant observation is a qualitative research method of data collection that is commonly employed in PAR (Marshall \& Rossman, 2006; Stringer, 1999). This technique involves both participating in and observing a particular context concurrently. Participation could mean interacting with people such as teachers while they are carrying out their instruction tasks (Christiansen, 2020; Heigham \& Croker, 2009). In this research, the participation aspect of my observation was reflected in my interaction with the teachers in the planning and reviewing of lessons.

I conducted 30 observations in intervention classes ( 3 classes x 10 observations/class) in 10 weeks. All observed lessons were year 1 speaking lessons using the textbook Worldlink 1. Table 3.6 illustrates the summary of the observations. 
Table 3.6

Study 2 Classroom Observations

\begin{tabular}{|c|c|c|c|}
\hline \multirow[t]{2}{*}{ Time } & \multicolumn{3}{|c|}{ Class observations } \\
\hline & Teacher Nhat & Teacher Nhi & Teacher Tan \\
\hline $\begin{array}{l}\text { Week } 1 \\
\text { (Introduction) }\end{array}$ & \multicolumn{3}{|c|}{ Workshop - No class observation } \\
\hline Week 2 & $\begin{array}{l}\text { Unit 1: New friends, new } \\
\text { faces }\end{array}$ & $\begin{array}{l}\text { Unit 1: New friends, new } \\
\text { faces }\end{array}$ & $\begin{array}{l}\text { Unit 1: New friends, new } \\
\text { faces }\end{array}$ \\
\hline Week 3 & Unit 2: Express yourself & Unit 2: Express yourself & Unit 2: Express yourself \\
\hline Week 4 & $\begin{array}{l}\text { Unit 3: What do we } \\
\text { need? }\end{array}$ & $\begin{array}{l}\text { Unit 3: What do we } \\
\text { need? }\end{array}$ & $\begin{array}{l}\text { Unit 3: What do we } \\
\text { need? }\end{array}$ \\
\hline Week 5 & Unit 4: Vacation & Unit 4: Vacation & Unit 4: Vacation \\
\hline Week 6 & Unit 7: In the city & Unit 7: In the city & Unit 7: In the city \\
\hline $\begin{array}{l}\text { Week } 7 \\
\text { (Review 1) } \\
\text { Week } 8 \\
\text { (Progress Test) }\end{array}$ & \multicolumn{3}{|c|}{ Workshop - No class observation } \\
\hline Week 9 & Unit 8: All about you & Unit 8: All about you & Unit 8: All about you \\
\hline Week 10 & Unit 9: Change & Unit 9: Change & Unit 9: Change \\
\hline Week 11 & \multicolumn{3}{|c|}{ Electric Power off - No class observations } \\
\hline Week 12 & Unit 12: At the movies & Unit 12: At the movies & Unit 12: At the movies \\
\hline Week 13 & Speaking project & Speaking project & Speaking project \\
\hline Week 14 & Speaking project & Speaking project & Speaking project \\
\hline $\begin{array}{l}\text { Week } 15 \\
\text { (Review 2) }\end{array}$ & \multicolumn{3}{|c|}{ No class observation } \\
\hline
\end{tabular}

In the class, I chose a back seat and quietly observed the lessons, taking notes using an observation sheet. Due to teachers' tight teaching schedules, they could not observe their peers' lessons.

\subsubsection{Teacher Interviews (in both Studies 1 and 2)}

Interviews were conducted with teacher participants. According to DeMarrais (2004), an interview is "a process in which a researcher and participant engage in a conversation focused on questions related to a research study" (as cited in Merriam \& Tisdell, 2016, p.108). Interviews are carried out to find out what is "in and on someone else's mind" (Patton, 2015, p. 426). In addition, through interviews, we can find out feelings, thoughts, and intentions that we cannot know from observation (Patton, 2002). According to Louis et al. (2000), Heigham and Croker (2009), Prior (2018), and Merriam and Tisdell (2016), there are three common types of interviews: structured, open/unstructured, and semi-structured interviews. I used semi-structured interviews. 


\section{Interviews in Study 1}

In Study 1, I conducted 14 individual semi-structured interviews with teachers. Each interview lasted about 45-75 minutes. Eight observed teachers were also invited for interviews (roughly 40 minutes) using video stimulated recall shortly after classroom observations. I used semi-structured interviews because this type of interview can allow the interviewee to "follow up interesting developments" and "elaborate on certain issues" (Dornyei, 2007, p. 136). This process is made possible is because the interview contained both structured and unstructured questions (Merriam \& Tisdell, 2016). In these interviews, I used interview guides, which went through trial runs before the actual interviews. I asked the participants (a) their perceived goals of teaching English; (b) how they defined culture; (c) their perceived goals of teaching culture; (d) how they integrate culture into their teaching practice; (e) their thoughts about culture content in the textbook; (f) what hinders their culture teaching; (g) their willingness to teach culture.

The Video Stimulated Recall (VSR) technique was adopted in eight individual interviews with eight teachers whose lessons were videoed. According to Sturtz \& Hessberg (2012), VSR is "a technologically advanced observation protocol that involves replaying videorecorded segments of a teacher's classroom instruction and asking questions about their pedagogical reasoning" (as cited in Endacott, 2016, p. 29). This approach allows the exploration of participants' thought processes at the time they conduct original activities (Gass \& Mackey, 2016). Accordingly, regarding my field notes, I played the segments in the video so that the teachers could recall and respond to my questions about their teaching activities. I asked the teachers what intentions they had for their specific activities, why, what they were thinking when they performed the activities, etc. Interviews with VSR were conducted within some hours or one day after the lessons were delivered, based on teachers' availability. All interviews with teachers were conducted in Vietnamese.

\section{Interviews in Study 2}

In Study 2, I conducted two rounds of individual semi-structured interviews with the three participant teachers. The first round of interviews was conducted within a week after the three teachers had implemented PBL lessons 1-4. These interviews aimed to elicit information about their experience with PBL approach. The interviews were in Vietnamese to 
help the participants feel comfortable. I asked the teachers about (a) what they thought about the PBL lessons 1-4; (b) their roles in their students' implementation of their projects; (c) the aims of assigning projects to the students; (d) their difficulties in implementing lessons 1-4; (d) what should have done better to promote students' IC. Each interview lasted approximately 45 minutes and was audio-recorded.

The second round of interviews occurred right after the project was completed. Each of the three teachers participated in a semi-structured interview. Each interview lasted approximately an hour and was audio-recorded. I used an interview guide. I asked them about (a) their feeling about the 10-week PBL classes; (b) their teaching goals and how far they think they have achieved these goals; (c) what they thought about the effect of the intervention on students' learning in general and in enhancing IC in particular; (d) why they thought so ; (e) how their perceptions of culture teaching had changed (if any); (f) how the intervention (including the workshop) changed the way they assessed students' projects; (g) the probability that they would continue to raise students' IC (via PBLL/ not via PBLL) and why or why not.

\subsubsection{Focus Group Interviews}

\section{Student Focus Group Interviews (in both Studies 1 and 2)}

Focus group interview is a subtype of interviewing (Dornyei, 2007) as it involves a different format and interviewer role. A focus group interview is "an interview on a topic with a group of people who have knowledge of the topic" (Merriam \& Tisdell, 2016, p. 114). This type of interview is timesaving but effectively gathers a large amount of data and a broad range of responses can be obtained in focus groups (Galloway, 2020; Louis et al., 2000). In this type of interview, the typical scene is "participants thinking together, inspiring and challenging, and reacting to the emerging issues and points (Dornyei, 2007, p. 144).

\section{Focus group interviews in Study 1}

In Study 1, I conducted ten focus group interviews. The interviews were to elicit students' information about their culture learning experience and explore their perspectives of culture learning. Each interview lasted approximately 60 minutes and was conducted in Vietnamese. The questions focused on students' perceptions of the aims of learning English, the factors 
affecting their success in intercultural communication; their cultural learning in class; their needs/willingness to learn culture, and obstacles in their culture learning.

\section{Focus group interviews in Study 2}

In Study 2, I conducted nine student focus group interviews after the intervention. The interviews were conducted in Vietnamese to help student participants feel comfortable. I asked them about their feelings about the course, what interested them, the reasons, what they thought the lessons would have been different without the intercultural activities (I explained what intercultural activities were in the course). In addition, I asked them how the cultural activities changed their perceptions of English learning targets and the factors for successful intercultural communication, how the cultural activities affect their project implementation (such as writing the content of the script), and what were the challenges in their learning in the course.

\section{PAR Focus Groups (only in Study 2)}

In Study 2, PAR members included the researcher and three teacher participants. PAR focus groups were carried out in the form of group discussions. Time for group discussions was agreed upon by all team members. Each focus group discussion lasted for more than two hours and was audio recorded. In total, there were two formal PAR discussions (two workshops) and several informal PAR discussions throughout the implementation of the PAR lessons.

\subsubsection{Interviews With Graduates (only in Study 1)}

Individual semi-structured interviews were conducted with six graduates. Each interview lasted from 40 to 55 minutes and was audio-recorded. The interview occurred at a place convenient for the participants and conducted in Vietnamese.

\subsubsection{Interviews With Employers (only in Study 1)}

Individual semi-structured interviews were conducted with six employers. Each interview lasted from 40 to 55 minutes. The interview occurred at a place convenient for the participants. 


\subsubsection{Research-generated Documents (only in Study 2)}

Research-generated documents, typically used in participatory action research, are "documents prepared by the researcher or for the researcher by the participants after the study has begun", which serves to provide the researcher with more knowledge of the people, situation, and event investigated (Merriam \& Tisdell, 2016, p.174). Research-generated documents could be in the form of reflections or artifacts (Merriam \& Tisdell, 2016). Reflections in the forms of diaries provide rich insider accounts of participants' real-life experiences (Rose, 2020). In Study 2, each student was asked to write reflections on their lessons after every three lessons. In total, I collected 210 reflections and 17 project products from students.

\subsection{The PAR Process and PBL Lessons}

\subsubsection{The PAR Process}

The PAR process was informed by the Interconnected model of professional growth (Clarke $\&$ Hollingsworth, 2002) (Figure 3.3), and aligned with principles of teacher education (Hawkins \& Norton, 2009).

\section{Figure 3.3}

The Interconnected model of professional growth

This image has been removed by the author of this thesis for copyright reasons. 
This model includes four interrelated domains: the personal domain, the external domain, the domain of practice, and the domain of consequence. Changes in the domains occur as teachers put change into action and reflect on outcomes. In the PAR process implemented in the current study, the external domain is the two workshops in which I worked with three teachers to collaboratively learn about ILCLT and PBL and to design and implement PBL lessons. The formal and informal discussions in the workshops and before, during, and after each PBL lesson were also a part of the external source of information and provided multiple opportunities for reflection. The domain of consequence is illustrated by teachers' implementation of the PBL lessons and their reflections in the interviews, and in the students' learning outcomes. The PAR process also aligned with the principles of teacher education (Hawkins \& Norton, 2009): the situated nature of programmes and practices, responsiveness to learners, dialogic engagement, reflexivity and praxis. Details of the PAR process and PAR workshops are provided below.

Study 2 PAR involved two research cycles. Each cycle began with a workshop, followed by observations of the teachers' implementation of their PBL lessons (four lessons after workshop 1, and six lessons after workshop 2) and two post-observation interviews with each teacher. Each of these two research cycles is detailed below.

Research Cycle 1. Research cycle 1 included workshop 1, observations of four lessons for each teacher, and post-observation interview 1.

Workshop 1. This workshop was conducted at the beginning of Study 2. It lasted for over three hours. The workshop aimed to provide the researcher and the three teachers the chance to explore together perspectives and approaches to intercultural language teaching and learning and PBL. In addition, it sought to reach an agreement among the researcher and the three teachers, on the principles of PAR, on the approach for the research lessons as well as the outline of the four first intervention lessons. Accordingly, the workshop had four parts: teachers' reflective discussion, presentation of both ICLTL and PBL theoretical frameworks, guided discussion of lessons for the first four weeks, and concluding section. 
In this section, I played a minor facilitator role in the teachers' discussion by generating the discussion with questions about how they would deliver their lessons 1-4. Next, I asked them what they normally do to address culture in their language lessons. The discussion then expanded to include their understanding of current culture teaching in tertiary education in Vietnam, its significance, and its limitations. After that, the teachers talked about constraints and supporting factors for teaching culture in the research context. All the teachers Nhat, Nhi, and Tan agreed that teaching culture is significant to foreign language teaching in the research context and acknowledged the constraints, such as lack of experience and resources, and not having received professional training on teaching culture. This section lasted over 35 minutes.

\section{* Presentation of theoretical frameworks}

I introduced the three teachers to the theoretical frameworks of Project-Based Learning (PBL) and Intercultural Language Teaching and Learning (ICLTL). More specifically, regarding PBL, I focused on the characteristics of PBL, stages of implementing PBL lessons, and assessment in PBL (Alan \& Stoller, 2005). Regarding ICLTL, I highlighted Byram's (1997, 2009) model of intercultural competence, Liddicoat's (2013) principles of ICLTL, and Newton et al.’s (2016) set of principles to guide the Teaching of Intercultural Spoken Communication. This section took 30 minutes.

\section{* Guided discussion}

After being introduced to PBL and ICLTL theoretical frameworks, and previous studies using projects to foster ICLTL, the three teachers discussed choosing a teaching approach for integrating culture into their foreign language lessons. With my supporting role, I clarified the theoretical principles as required by the three teachers. I suggested using PBL but tried not to impose my ideas on the teachers by directly clarifying that the teachers and I had equal power in the decision-making of the teaching approach and designing the lessons.

The teachers and I decided that they would adopt PBL in their lessons to enhance ICLTL in their classes. However, they raised concerns over how to meet the goals of the curriculum, such as language-focused content in the textbook, and the goals of the PBL approach 
concurrently as they recognized that would take up a proportion of their class time.

Subsequently, we agreed on how to flexibly adopt PBL in the current research context by: making the best use of the textbook content previously chosen for the course as the input materials for the language facilitation purpose; reducing or removing unnecessary listening to printed dialogues in the textbooks; expanding some speaking activities in the textbook in light of ICLTL and using these intercultural activities as input for teachers' facilitation of students' projects; changing roles from teachers to facilitators, encouraging experiential learning, and collaboration; giving feedback, and agreeing on the assessment criteria for the outcome of the project.

I suggested some intercultural activities for lessons 1-3 and how to shift the traditional lessons into PBL lessons. The teachers discussed what they thought about these activities, what they liked and disliked, what the benefits of the newly reframed lessons were, whether these activities might be feasibly conducted, and how, and what the supporting factors or constraints might be in conducting these activities. All the teachers noticed the predominant differences between the model lessons and the traditional lessons, namely, promoting interactions, exploration, reflection, intercultural awareness, and project skills. This section lasted for one hour and 35 minutes.

* Concluding section

This section lasted approximately 25 minutes. The teachers reviewed the handouts from the workshop and shared with the researcher what they benefited from the workshop and their possible plans of action for the first four PBL lessons.

Post-workshop classroom observations. Following workshop 1, each teacher implemented their first four PBL lessons. Before each lesson, I either met them or called them to resolve any concerns they might have about the lessons. During classroom observation, I took a limited-participation role by sitting quietly at the back of the class, observing and taking notes. The teachers did not observe each other's lessons.

Post-observation teacher interviews. Each teacher participated in one individual semi-structured in-depth interview with the researcher within a week after lesson 4 . The interview lasted for around one hour and a half for each of the teachers. Each interview was conducted at the place of the teachers' convenience (in an unoccupied staff room). Each 
interview had two parts. Part 1 was a stimulated recall component in which the teacher watched sections of the video replay of her observed lessons. The video replay was to remind the teacher about her teaching and to elicit her explanation about the teaching activities shown in the video replay. The stimulated recall section was followed by the semi-structured in-depth interview in which the teacher was asked about their perceptions of implementing the PBL lessons. Each teacher was asked questions such as: "What do you think about the lessons? What aspect of the lessons do you like most? How do you compare the lessons with the traditional lessons in terms of completing the curriculum goals and addressing culture?"

Research Cycle 2. Research cycle 2 included workshop 2, observations of six lessons for each teacher, and post-observation interview 2.

Workshop 2. Workshop 2 was organized after the three teachers had implemented their first five PBL lessons. This workshop had dual purposes. The first purpose was to investigate what went well and what did not go as expected in the lessons. Thus, the teachers were encouraged to reflect on their teaching of the four PBL lessons, specifically on the advantages, gains, challenges, limitations, and students' learning and responses to the lessons. The second purpose was to involve the teachers in the co-construction of another six PBL lessons, which would be adopted in the following six weeks. Accordingly, the main activities of the workshop included teachers' reflective discussion and co-constructions of lesson plans. This workshop lasted over three hours.

\section{* Reflective discussion}

In this section, the teachers were encouraged to share with the researcher and among themselves their experience of implementing the first four PBL lessons. The discussion revolved around questions such as "What were your difficulties in delivering these PBL lessons?", "What part did you find useful and interesting?", "What should not have been included in the lessons? Why?" "What were the students' responses to the lessons?". The discussion indicated that the teachers possessed ambivalent feeling towards the PBL lessons. On the one hand, they acknowledged the gains in the PBL lessons in terms of exposing students to a lot more interaction activities than previously, raising students' intercultural awareness and the teachers' interest in including intercultural activities in the lessons. On the other hand, they acknowledged the amount of extra time they needed to devote to the lessons 
as well as greater efforts needed to successfully engage the "not very principled students" in their group projects. The solutions they recommended were to use time more efficiently in class, such as controlling time for students' discussion. To address the need to engage "not very principled students" in their group projects, the researcher and the teachers agreed on renotifying the students of the requirements of the course privately and encouraged these students to adhere to their groups' regulations.

* Co-construction of lesson plans

This section aimed at the teachers' collaborative productions of six PBL lesson outlines and their key activities. Before the discussion, I clarified that they had the power to design the outline that would work best for them. Then, the teachers were guided to discuss: (1) how to develop the next PBL lessons; (3) what each teacher's tasks were in preparation for each lesson. The discussion yielded their consensus in continuing to adopt the PBL lesson outlines as in the first four PBL lessons, with flexibility in reducing or removing sections from textbooks due to each class's specific context. In addition, they agreed that they would take turns preparing intercultural activities for the lessons and contact other teachers about their prepared activities one week before each lesson. However, each teacher could flexibly adopt these activities in their own classes. This meant that they could extend the activities or shorten them.

\section{Post-workshop classroom observations}

Following workshop 2, each teacher implemented their next six PBL lessons. Before each lesson, they contacted each other about the lesson. Though taking a less supportive role in this stage, I either met them or called them to resolve any concerns they might have about the lessons. During the classroom observation, I took a limited-participation role by sitting quietly at the back of the class, observing and taking notes. The teachers did not observe each other's lessons.

\section{Post-observation teacher interviews}

One week after implementing all the post-workshop 2 PBL lessons, each teacher participated in one individual semi-structured in-depth interview. The interview lasted for around one hour and a half for each of the teachers. Each interview was conducted at the place of the 
teachers' convenience (i.e., either in an unoccupied staff room or a coffee shop). Each interview had two parts. Part 1 was a stimulated recall component in which the teacher watched sections of the video replay of her observed lessons. The video replay was to remind the teacher about her teaching and to elicit her explanation about the teaching activities shown in the video replay. The stimulated recall section was followed by the semi-structured in-depth interview in which the teacher was asked about how they perceived their experience of implementing the PBL lessons. Each teacher was asked questions such as: What do you think about the lessons? How do you compare the first four PBL lessons with the lessons after workshop 2? What do you think about students' presentations of their projects?

\subsubsection{The PBL Lessons}

Six reasons for me to suggest the PBL approach in fostering intercultural language teaching and learning in the research context are

(1) Students' expressed need to improve their intercultural competence, as the results of Study 1 showed

(2) Teachers' willingness to teach culture

(3) The objective of training students to be competent intercultural communicators is referred to in the Vietnamese Ministry of education and Training in Decision 14

(4) PBL has been advocated as a useful approach in many previous studies as mentioned above in the literature review.

(5) Both PBL and ICLTL encourage experiential learning and support each other (according to literature review).

(6) This approach has not been applied in the research context.

The PBL lessons were adopted over 10 weeks in three classes to replace the standard speaking lessons. In these 10 lessons, the students were introduced to a whole class project:

\section{Creating a mini-bank of video-recorded performances for subsequent use in speaking}

classes. Students were guided to work in groups of 5-6. Each group had to write a script and present a mini-drama/role-play in English (and use some Vietnamese if necessary) which represented real-life conversations and involved intercultural encounters. Topics for the minidrama/role-plays had to be chosen from the topics in the textbook that were selected for the speaking class. Students had to note their group's reflection on the intercultural encounters 
that they designed in the script. Each group's script and reflections had to be handed in to their teacher at least one week before their performance).

The PBL lessons did not have totally different content and used totally different teaching materials. Instead, the PBL lessons made the most of the previously chosen textbook for the speaking course and adopted this material for the language facilitation purpose of the project. In addition, these lessons integrated the intercultural content extended from the topics in the textbook materials. This intercultural content served the purpose of raising students' cultural awareness, and thus, facilitated the students in their preparation for their project. Moreover, the teachers were guided to provide students with necessary project skills for the projects such as searching for information and speaking in public. The PBL lesson procedure in classrooms is illustrated in Table 3.7, and the intercultural content in Table 8 below. 
Table 3.7

PBL lesson procedure in classrooms

\begin{tabular}{|c|c|c|}
\hline Lesson & Teacher activities & Student activities \\
\hline 1 & 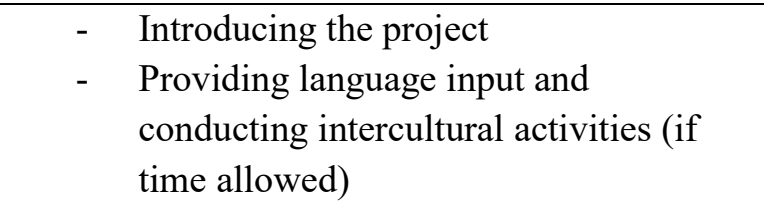 & $\begin{array}{ll} & \text { Forming groups } \\
\text { - } & \text { Determining name of project } \\
\text { - } & \text { Dividing project work }\end{array}$ \\
\hline $2-8$ & $\begin{array}{l}\text { - Providing language input } \\
\text { - Introducing intercultural activities to } \\
\text { encourage students to notice, compare, } \\
\text { and reflect. Activities can be: } \\
\text { + creating scenario, asking } \\
\text { students to guess } \\
\text { + involving students in role- } \\
\text { plays }\end{array}$ & $\begin{array}{l}\text { - Guessing what the people in } \\
\text { the scenario would say, stating } \\
\text { reasons for the guess } \\
\text { - Performing the role-plays }\end{array}$ \\
\hline & + telling stories & - Listening and asking questions \\
\hline & $\begin{array}{l}\text { + playing video } \\
+ \text { inviting guest speakers to talk } \\
\text { with students }\end{array}$ & $\begin{array}{l}\text { - Watching, noticing, comparing } \\
\text { and reflecting } \\
\text { - } \quad \text { Talking with guest speakers } \\
\text { and reflecting }\end{array}$ \\
\hline & $\begin{array}{l}\text { Introducing research skills for this } \\
\text { project (searching for materials, } \\
\text { interviewing) }\end{array}$ & $\begin{array}{l}\text { - Performing drill tasks as } \\
\text { required }\end{array}$ \\
\hline & - Giving feedback on project work & - Reporting on project progress \\
\hline \multicolumn{3}{|c|}{ Note: Activities in lessons 2-8 can be flexibly conducted in any order } \\
\hline $9-10$ & - Watching students' performance & 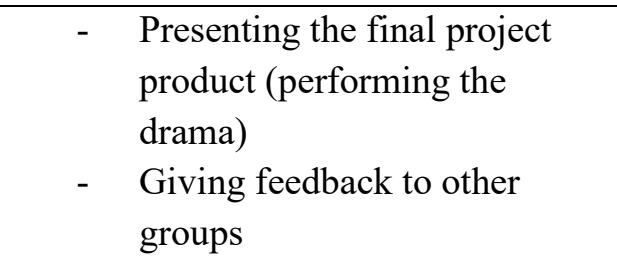 \\
\hline
\end{tabular}


Table 3.8

Intercultural content in eight PBL lessons

\begin{tabular}{llrl}
\hline Lesson & Topic & Intercultural content \\
\hline 1 & Greeting & - & Common questions to ask each other when meeting for the first time \\
& & & in English and Vietnamese \\
& & - & Commonalities and differences in greeting older people, people from \\
& & higher social status (verbal and non-verbal) \\
\hline 2 & How do & - & Responding to positive comments on appearance \\
& you look & - & Perceptions about tattoos \\
\hline 3 & Shopping & - & Open-air markets, bargaining \\
& & - & Queuing to pay \\
& & - & Who shops for the groceries in a family? \\
& & - & Garage sales \\
\hline 4 & Travelling & - & Talking to the bus-driver when getting off the bus \\
& & - & Asking for permission before taking photographs \\
\hline 5 & Education & - & Contributing ideas in a lesson \\
& & - & Reporting individual students' progress before class \\
\hline 6 & Health & - & Talking with English speakers \\
\hline 7 & Change & - & Responding to wedding invitations \\
& & - & Moving out from 18 years old \\
\hline 8 & Movies & - & Talking with English speakers \\
\hline
\end{tabular}

More details of the intercultural elements in the lessons by one of the three teacherparticipants (Nhat) are below.

\section{Lesson 1: Greetings}

After introducing the project and implementing some grammar and language activities, the teacher implemented activities focused on formal and informal greetings in English and Vietnamese (verbal and verbally). The students were put in groups to discuss how to greet in Vietnamese and English in different contexts. The students explored and reflected on their experience of greetings. The teacher guided whole-class discussions that raised awareness of the cultural diversity and complexity both within and across cultures. For example, even among Vietnamese, the way to greet may be different among people from different generations, different social and academic backgrounds. After that, the students listened to a short conversation in which an Australian student greeted his professor by the professor's first name. The students gave their comments on this way of greetings from their own cultural perspectives. The teacher prompted more discussion, asking students to think about how they would react if they were in the position of the Australian student. Then the students watched 
a video clip showing different ways of greeting around the world. They discussed how their ways of greetings different from people in the video clips and explored the reasons behind the differences. The teacher also shared their experience of greeting interculturally with the students. After that, the teacher wrapped up the lesson.

Lesson 2: How do you look

After reviewing the previous lesson, checking students' project progress, and addressing language and grammar points, the teacher asked the students to work in groups to discuss how they respond in Vietnamese to positive comments. Students came up with different answers and explored the reasons for the diversity in their ways of responding to comments. Then they were asked to role-play different scenes in which they received positive comments in different contexts such as from a USA friend and an Australian teacher. After that, the students watched a video clip from a film showing how a Vietnamese urban teenager responded to a compliment, and another video clip showing how an American woman responded to a compliment. After watching the video clips, the students reflected on their own experience of being complimented. Some students from rural backgrounds noticed the difference in the way they, the urban teenager, and the American women in the video clips reacted to compliments. The teacher prompted deeper reflection by asking questions such as "why do you think so?" "What would you do if you were the urban teenager/the American woman?" Students also had opportunities to discuss their attitudes about tattoos and their perceptions of people who have tattoos. Then the teacher showed students an image of a Vietnamese man with tattoos over his arms. The students gave diverse comments on the image, labeling the man in the picture with different adjectives. After that, they saw pictures and a short clip about a success story of a teacher in a New Zealand school, and they noticed tattoos over his arms. They discussed among their groups about what they saw and related to their previous assumptions about people who had tattoos. Then they read some materials about the meaning behind tattoos for some groups of people around the world and reflected on the materials. The teacher then wrapped up the lesson.

\section{Lesson 3: Shopping}

After reviewing the previous lesson, checking students' project progress, and addressing language and grammar points, the teacher asked students to discuss the types of shopping in 
Vietnam and America, Australia and Singapore, and how students often spoke to the sellers in the open-air market and the supermarket. The students discussed bargaining in Vietnamese open-air markets, and the reasons behind garage sales in some countries including New Zealand. Students also engaged in role-playing a scene in a Vietnamese family and watched video clips showing men carrying babies in shopping centres in the USA and buying groceries in an open-air market in Australia. They reflected on their experience and discussed the roles of men and women they knew in their own communities, the commonalities and differences in sharing work among men and women in the household, and the perceptions of men and women's roles in families behind this responsibility-sharing. The teacher then wrapped up the lesson.

\section{Lesson 4: Travelling}

After reviewing the previous lesson, checking students' project progress, and addressing language and grammar points, the teacher asked students to discuss a short conversation in a video clip in which a British man asked for permission to take a photo of a Vietnamese woman on the street. They also read a letter from a New Zealand school asking parents of a child whether the parents agreed for their child's images to be posted on their school's website. The students reflected on their experience of taking photos of other people on the street without asking for permission and having their images posted on school's websites without being asked. They noticed the differences in the perceptions of privacy in their experience and the British man and New Zealand school examples. In addition, through roleplaying scenes of getting on/off buses/taxis, some students from rural backgrounds noticed the difference in the way people from their community and people from city areas talked to taxi drivers when paying taxi fares. The students also learned about the differences in the way people perceive politeness in interacting with bus/taxi drivers in Vietnam, France, and New Zealand. After that, the teacher wrapped up the lesson.

\section{Lesson 5: Education}

After the teacher had reviewed the previous lesson, checked students' project progress, and addressed language and grammar points, the students explored and compare differences in the way they and students in an American class (in a video clip) contributed their ideas to a lesson. They were guided by the teacher to reflect on the reasons behind their actions, and 
their perceptions of politeness associated with this practice. The students also explored and reflected on the differences between the way they gave feedback to peers and how American students did in the video clip. They were also encouraged to notice the variety among themselves, in how to comment on peers' study progress. After that, the teacher wrapped up the lesson.

Lesson 6: Health

After checking students' project progress, reviewing previous lessons, and addressing grammar and language points, the teacher facilitated interaction between the students with guest speakers from Australia, Thailand, and China. Students asked the speakers general questions and discussed practices in health systems in Vietnam and their countries, such as how to book an appointment with a doctor. After that, the teacher wrapped up the lesson.

\section{Lesson 7: Change}

After reviewing the previous lesson, checking students' project progress, addressing language and grammar points, the teacher put students in groups and the students discussed wedding invitation cards that the teacher showed them printed in Vietnamese, and English. The students noticed the similarities and differences in the content, design, and colors of these cards. The students also shared the different ways they thought appropriate to reply to a wedding invitation. The teacher then shared a story of receiving a response from an American friend after she sent him an invitation. Students commented on this practice from their culture's point of view. Then they explored how to respond in English and why the American responded to a wedding invitation. Then the students reflected on their experience, and discussed a scenario in which they were invited to an American friend's wedding party, what would they do? Would they respond? How? And why? Then the students role-played a conversation between two American students about their plan to move out of a house. They explored and reflected on the practice of many 18-year olds in America moving out of home. They discussed the perceptions that many Vietnamese have of moving out of home and the implications of moving out at different ages in Vietnam. After that, the teacher wrapped up the lesson. 


\section{Lesson 8: Movies}

After checking students' project progress, reviewing previous lessons, and addressing grammar and language points, the teacher facilitated interaction with two English speakers from Holland and Britain who were invited to their class as well as interacting online, with two other speakers. The students and guest speakers began with general questions, then talked about the traditions of celebrating New Year in Holland, Britain, and Vietnam (since the New Year was coming at the time of the talk) and then discussed movie-related topics such as what type of film they often watched, whether they have to be exactly on time when they are invited to movies, and what the guest speakers knew about Vietnam through films. After that, the teacher wrapped up the lesson.

Lessons $9+10$

The lessons involved students' doing their project performances and receiving feedback from the teacher and peer students.

\section{General comments}

Overall, across the PBL lessons, there was sometimes a tendency by both the teachers and students to slip into a kind of essentializing discourse, for example, comparing Americans with Vietnamese, as if these were two singular undifferentiated cultural identities. But equally, the lessons were full of opportunities for learners to notice specific examples of behavior and to reflect not only on how they perceived these behaviors and to compare them to their own expectations, but also to reflect on why they thought and felt the way they did about examples of culturally-shaped behaviors that are different from their own. Similarly, there was a consistent emphasis across the lessons on getting students to reflect criticality on their own culturally-shaped values. Naturally, despite the lessons being planned, each of the three teachers adopted slightly different practices and emphasized or deemphasized different dimensions of cultural content and intercultural learning as described in detail in Chapter 5.

As mentioned above, the researcher and the teachers agreed on the overall outline of the PBL lessons as well as key steps and content. However, it was each teacher who determined what they would do to best suit their lessons. The time for talks with English speakers could also 
change according to English speakers' availability. The following section will present how the thematic analysis was used as a data analysis approach in this thesis.

\subsection{Data Analysis}

This section describes (a) the thematic analysis method used in this study, (b) theoretical frameworks used for data analysis and interpretations, and (c) how I analyzed the data.

\subsubsection{Thematic Analysis}

For both Study 1 and Study 2, I used thematic analysis (Braun \& Clarke, 2006, 2012). Thematic analysis is "a method for identifying, analyzing and reporting patterns (themes) within data (Braun \& Clarke, 2006, p.79). Two primary ways in the thematic analysis are (i) inductive or 'bottom up' (e.g., Frith and Gleeson, 2004), or (ii) theoretical or deductive or "top-down" (e.g., Boyatzis, 1998). Inductive analysis is "a process of coding the data without trying to fit it into a pre-existing coding frame, or the researcher's analytic preconceptions" (Braun \& Clarke, 2006). It is data-driven. On the other hand, in deductive analysis, data are analyzed based on "the existing framework" (Patton, 2002, p.453). In this research, both inductive and deductive analyses were adopted at different stages of data analysis.

Specifically, in the coding process, inductive analysis was used. Later, when patterns, themes, and/or categories had been established, I adopted deductive analysis to confirm the "authenticity" and "appropriateness" of the "inductive content analysis" (Patton, 2002, p.454). I followed six steps in thematic analyzing (Braun \& Clarke, 2006, p. 87) as follows:

Step 1: $\quad$ Familiarizing yourself with your data

Step 2: $\quad$ Generating initial codes

Step 3: $\quad$ Searching for themes

Step 4: $\quad$ Reviewing themes

Step 5: $\quad$ Defining and naming theme

Step 6: $\quad$ Producing the report

\subsubsection{Theoretical Frameworks}

Theoretical frameworks are considered the frame of qualitative research that inform the research in its all aspects from structuring the problem statement to formulating the research 
questions, determining what to look at and look for in data collection and data analysis (Maxwell, 2013; Merriam \& Tisdell, 2016; Merriam, 2009). Anfara and Mertz (2015) define a theoretical framework as "any empirical or quasi-empirical theory of social and/or psychological processes, at a variety of levels (e.g., grand, midrange, explanatory), that can be applied to the understanding of phenomena" (p.15). Accordingly, the theoretical frameworks are generated from the concepts, definitions, models, theories of the literature that orientates the research.

I take this stance that theoretical frameworks underpin research and use theoretical frameworks to orientate all aspects of my research such as in forming research questions, selecting data collection methods, and analyzing data. My research questions were formulated to examine teachers' practices and stated perceptions, students' perceptions in terms of culture teaching and learning and their experience of a PBL approach in fostering intercultural competence. Therefore, I critically reviewed scholarship on language and culture, intercultural competence, intercultural language teaching and learning such as Byram (1997, 2009), Corbett (2003), Newton et al. (2010), Newton (2016), Liddicoat and Scarino (2013), and project-based learning such as Alan and Stoller (2005), Stoller \& Myers (2019) and used the relevant scholarship in the interpreting and discussing of findings. The analysis of different sets of data is discussed in detail below.

\subsubsection{Analysis of the Representations of Cultural/ intercultural Content in}

\section{Observed Lessons (Study 1)}

The data set for this analysis included observation and stimulated recall interview data. The analysis of these sources of data addressed the questions of how cultural/ intercultural contents were present in observations and how teachers explained their lessons (research question 1a and 1b). According to Patton (2002), data analysis commences when ideas for making sense of data emerge during data collection. My analysis of the observed lessons began when I collected data, then continued after I completed my data collection. The primary analysis right after observations revealed teachers' predominant pattern of following textbook activities. In addition, most teachers sequenced their lessons in four phases: warmup, presentation, practice, and production. Particularly, lessons of the same textbooks for the same intake of students in different classes were similarly taught by different teachers because they shared their lesson plans and teaching materials. Cultural/ intercultural content 
was not planned. These preliminary results provided ideas and insights for the main analysis of the observations.

After primary analysis, I examined the observational data in more depth. I did not transcribe the audio-videoed lessons in full. Instead, I watched the videos several times to familiarize myself sufficiently with the data. Then, I chose to transcribe classroom episodes that typically illustrated ways of implementing the key stages in the lessons. When I watched each recorded lesson, I described exactly what the teacher did at each phase of the lesson. By doing this, I had summary descriptions of 12 lessons. To better ensure the quality and accuracy of the description, I used my field notes for comparison and supplementation. Finally, I conducted initial coding on each complete summary according to what the teacher did concerning cultural/ intercultural content. After working through each entire summary in this manner, I re-examined the codes and noted the frequency of certain practices, and generated themes for the cultural/ intercultural contents in observations.

Second, I transcribed stimulated recall interviews in full. I iteratively read each interview transcript to familiarize myself with the data. To identify how the teachers justified their decisions in implementing their lessons, I examined teachers' statements of rationales in the stimulated recall interview transcripts. After the initial coding on each interview transcript, I collated the codes to identify patterns and themes related to teachers' rationales in each transcript and all transcripts. Finally, codes assigned to the interview transcripts and classroom observation summaries were pulled together for the identification of patterns and themes for each teacher and all teachers. For better re-examination of the theme-generating process, the codes were put in a table and a thematic map was drawn.

\subsubsection{Analysis of Teachers' Perceptions of Culture and Culture Teaching}

\section{(Study 1)}

Teacher interview data analysis aimed to further explore teachers' perceptions of culture and culture teaching and how their perceptions shaped their teaching practices, which addressed research question 1.c. Data for this analysis comprised of follow-up individual interviews with fourteen teachers. First, I listened to the recordings many times to make sense of the data and summarized the main points, and noted down interesting and unexpected quotes. I transcribed all the interviews. I adopted "member check" to double-check the accuracy of the 
transcriptions. Because the interviews were conducted in Vietnamese, I translated all the quotes in the interviews that I decided to use in the writing up of the findings into English. During the translation process, to ensure the "accuracy and subtlety in translation" (Marshall \& Rossman, 2006, p.112), I invited a Vietnamese EFL teacher to double-check my translated materials.

After reading over each interview transcript to familiarize myself with the data (Braun, 2006), I used a color highlighter to mark words/phrases which I found the focus of each sentence and potentially relevant for addressing the research questions. Then, in the margins of the pages, I wrote the initial codes that I generated. These codes were then put together for the identification of patterns and themes.

\subsubsection{Analysis of Students and Other Stakeholders' Perceptions (Study 1)}

The analysis of students' and other stakeholders' perceptions of the contextual culture learning and teaching involved recordings of students' focus group interviews and individual interviews with graduates, and employers. The analysis answered research questions $1 \mathrm{c}, 1 \mathrm{~d}$, and 1e which aimed to explore the perceptions of students, graduates, employers' views of the orientation to culture in the research context.

I used the same steps in the analysis of teacher interviews for analyzing interviews with focus group students and other stakeholders such as graduates, and employers. Table 3.9 provides an example of coding teacher interview data.

\section{Table 3.9}

Example of coding

\begin{tabular}{lll}
\hline Transcript & Coding & Theme
\end{tabular}

Dong: .... oh, it depends on what I taught that day, uhm, if, for example, if the lesson, I mean, the topic of what I taught was about culture, like greetings in different countries, of course, students learned that from reading the text. I also told them if I knew something else besides the content of the text. However, if the lessons' objectives, for example, were to focus on grammar, such as using superlatives, we had to focus on helping students practice making sentences and practice conversations using that grammar.
Topic dependence

Behavior norm

Prioritize language

competence
Teachers' perceptions of teaching culture 


\subsubsection{Analysis of Teachers' Perceptions (Study 2)}

The analysis of teachers' perceptions in Study 2 included three interviews with three individual teachers after they had conducted PBL lessons 1-4 and three interviews at the end of the intervention. The analysis of teacher interview recordings addressed research questions 2c, which explored teachers' perception of PBL lessons in fostering intercultural learning. I adopted the same approach in analyzing interviews in Study 2 as in Study 1. All interview data were transcribed, carefully translated into English. After that, I manually coded the data. From the codes, I generated the patterns and found the themes from the data.

\subsubsection{Analysis of Teachers' Implementation of the PBL Lessons and}

\section{Intercultural Learning Processes (Study 2)}

The analysis of teachers' implementation of PBL classes involved observations of three teachers in PBL (innovation) classes and the stimulated recall component in teacher interviews. The analysis addressed research question $2 \mathrm{a}$, which explored the extent of expertise development in terms of fostering intercultural learning using the PBL approach. The three teachers in PBL classes individually implementing their PBL lessons, the lesson plans of which had been previously collaboratively agreed on by the PAR group. I followed the same stages of analysis of observations in Study 1. Specifically, I watched each videoed lesson repeatedly until I fully grasped the clear stages of the lesson. After that, I described in detail what each teacher did at each stage of a lesson. I compared each description with its field note summary to double-check the accuracy. To understand teachers' rationales behind their decisions in the conduct of the lessons better, I searched for statements of rationales in the interview transcripts. For each teacher case, I put together all data sources I had about each teacher, including video recordings and field notes. By doing this, I could generate initial themes from the popular codes drawn from multiple sources of data and compared data within each teacher and across teachers. During data analysis, I highlighted quotes in the transcript that vividly illustrated student-student or teacher-student interactions for later inputting in the writing up of the findings as extracts for illustration. Table 3.10 provides an example of coding observation data. 
Table 3.10

Sample analysis of how Tan implemented a PBL lesson

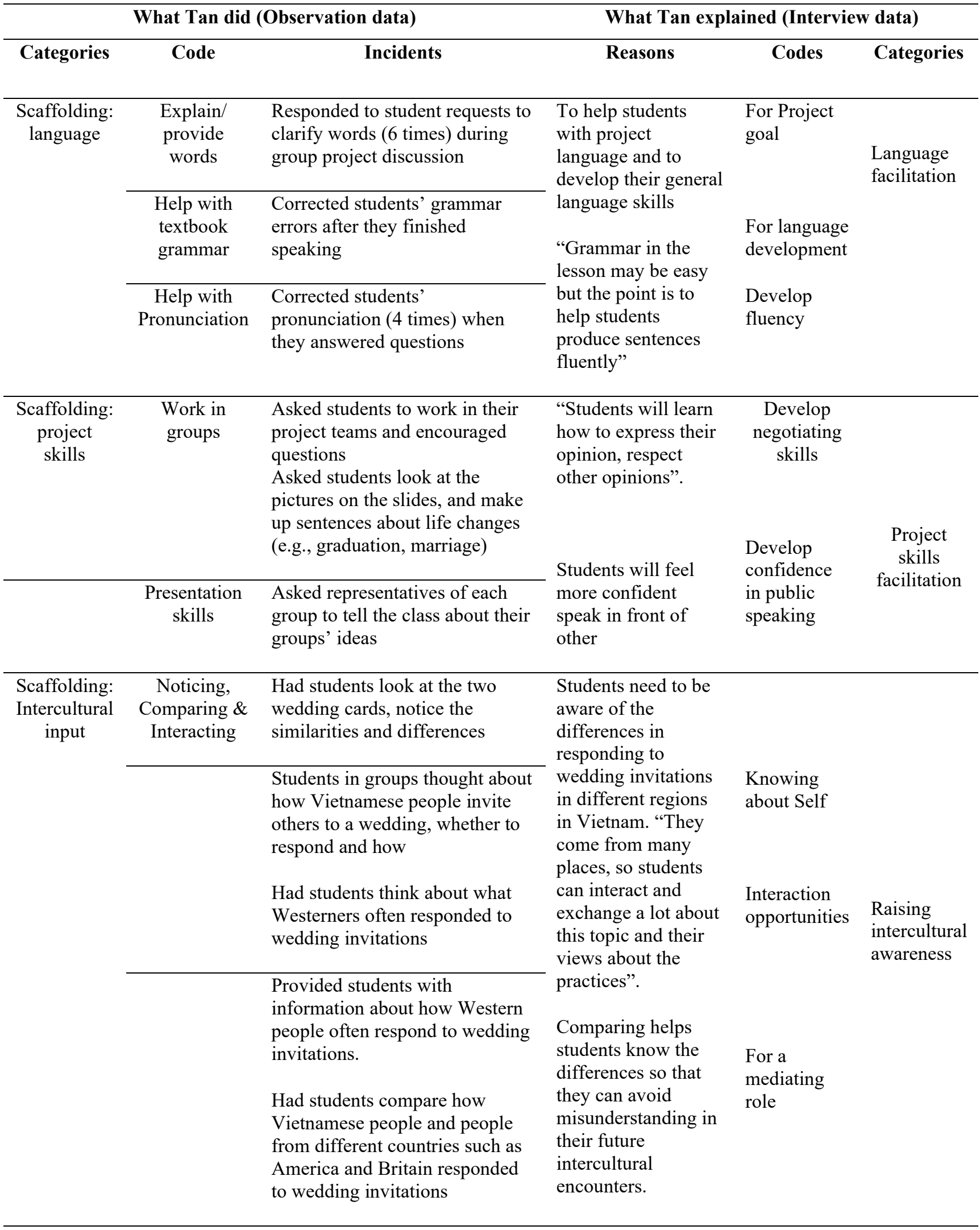


The analysis of IC learning processes focused on both IC processes evident over eight PBL lessons and IC learning processes reflected in students' performances in lessons 9-10. Data for this analysis process included classroom observations and students' reflections on their projects. The approach used for the analysis of IC learning processes was the same as for the analysis of teachers' implementation of the PBL lessons.

\subsubsection{Analysis of Students' Views of the PBL Lessons (Study 2)}

Data collected from focus group interviews with students and their reflective journals were analyzed to examine how the students thought about their experience with the PBL lessons. All interviews were transcribed in full. I used the same approach with the teacher interview data to analyze the student focus group interview data. For example, I repeatedly read the transcripts. I coded students' responses and sought popular patterns. I compared students' responses among different groups. I generated themes from the codes that I created during the analysis process. Table 3.11 illustrates an example of coding journals.

Table 3.11

Example of coding journals

Raw data Initial codes Categories Themes

Trước kia em có suy nghĩ hơi cực đoan, ví dụ như các bạn Hà nội thường kiêu hơn, dân tỉnh thì hòa đồng, hoặc người Anh thì lạnh lùng. Nhưng bây giờ sau khi tiếp xúc em thấy còn tùy, không hẳn ai thuộc nước đó hay vùng đó cũng vậy

I used to think as an extremist, for example, I PBL thought Hanoians are more arrogant than people from the countryside or the English people are cold. Now I think that it depends, not everyone in a region or belong to a nationality is the same.

Moving away

from

stereotypes develops students' intercultural competence
Hồi học cấp 3 em thường không thích những gì khác với văn hóa ở nơi em ở. Bây giờ em thây sự khác biệt cũng có cái hay riêng.

When I was in high school, I did not like what was different from my culture. Now I think differences might be interesting. (English translation)

$\begin{array}{ll}\text { More tolerant to } & \begin{array}{l}\text { Change in } \\ \text { attitudes }\end{array} \\ \text { differences } & \end{array}$

Change in

differences 
Sau khóa học, bây giờ em thấy không nên vội vã phê phán cái gì khác mình. Nếu mình phê phán người khác vì văn hóa khác, họ cũng có thể phê phán mình.

After this course, I think that I should not rush to Respect the conclusions and criticize others because of their differences cultural differences. If we criticize them, they can also criticize us. (English translation)

\subsection{Reporting Findings}

I reported findings and discussion of Study 1 in Chapter 4, and findings and discussion of Study 2 in Chapter 5. Chapter 4 deals with findings from classroom observations, teachers' perceptions, students' perceptions, and graduates' and employers' perceptions. in this order. I used a multiple case approach to report findings from each set of data. The same approach was also applied in the presenting of findings of Study 2. Study 2 findings drew from classroom observations, teachers' perceptions, and students' perceptions. Due to the complexity of Study 2, the findings from classroom observations were divided into findings on teachers' implementation of the PBL lessons and indications of intercultural learning processes. Each chapter includes a discussion after the presentation of the findings.

\section{Role of the researcher}

My roles in Study 1 and Study 2 were different. In Study 1, I was a researcher but possessed emic views of the research site since I was a senior university lecturer there before I became a researcher. With this insider position, I had close relationships with the teacher participants, and graduates. These relationships were significant to the data collection.

My collegial relationship with the participants helped to prevent a possible negative power distance between the researcher and teacher participants. Therefore, my process of recruiting participants and data collection went smoothly. Of the 14 teacher participants, I knew 11, the other three were newly recruited as teachers at the research site and I actively introduced myself to them, invited them to join in my study. When they knew about my teaching profession at the site and the aim of my research, they were enthusiastic to accept my invitations. Despite the advantage of being an insider, I was fully cognizant of the potential bias related to my relationship with the participants. Therefore, I sought to minimize any 
potential research bias. In addition, I was mindful of my previous role as a lecturer in the research site with certain preconceptions of how lessons were conducted there. Therefore, before the interviews, I made it clear to all teachers the reasons why I was conducting the interviews, that their authentic and honest responses were crucial for the integrity of my study, and that I was not expecting the socially desired responses. During the interviews, I withheld personal opinions and experience and tried to elicit information from the teacher participants with fresh eyes.

To minimize the "Hawthorne" effect (Cook, 1962; Dornyei, 2007), that is the likelihood that the teachers and their students could have performed or behaved differently from what they normally would have done, I made it clear for the teachers and students that my observations were solely for research purposes without affecting the evaluation of their study or teaching job performance. Teacher and student participants were used to being observed by other peer teachers during their teaching terms. They had been previously invited to join other research projects by Ph.D. candidates. Therefore, as I noticed, they were very willing to join my project without any concerns about being observed.

My role in Study 2 was different. As Study 2 was PAR-oriented, neither participants nor the researcher can "unilaterally enforce their point of view on each other" and the participants have a role as well as a voice in the decision-making processes (Coghlan \& Brydon-Miller, 2014). To put it simply, I worked as a member of a PAR team consisting of other participants and me. Selected participants included three teachers who already participated in Study 1. The relationship between the researcher and participants established before and during Study 1 brought about a straightforward participant recruitment for Study 2. My prior knowledge of the research context put me at an advantage when discussing the question of inquiry with other participants. They told me what they truly thought about the issue raised at the discussion without any hesitations. Due to our long-established and maintained rapports, the teachers actively joined the process of planning their lessons, implementing, and collaboratively evaluated our PAR process.

\section{Inter-coder reliability}

To ensure inter-coder reliability, I asked a Ph.D. student to help me code part of the interview data and observation data for Studies 1 and 2. Inter-coder reliability was carried out for the 
coding of the scripts of three teacher interviews and two FG students' interviews, scripts of three episodes in classroom observation data. The inter-coder agreement was $88 \%$ for the coding of the script. The interrater reliability was $90 \%$ for the coding. Disagreements were resolved through follow-up discussion. Those items where the other coders and I could not reach an agreement were excluded from the analysis. The final agreement rates were $98 \%$. These scores show satisfactory reliability (Miles \& Huberman, 1945).

\subsection{Trustworthiness}

The trustworthiness of research convinces readers of the value or the rigor of research so that the readers can decide whether findings of a research are worth paying attention to or taking account of (Amankwaa, 2016; Lincoln \& Guba, 1985). Due to the different nature of quantitative and qualitative research, the standards for rigor in qualitative and quantitative research are different (Merriam \& Tisdell, 2016). Lincoln and Guba (1985) suggested credibility, transferability, dependability, and confirmability as criteria to ensure trustworthiness in qualitative research. In more recent works in qualitative research, credibility is termed "transparency" (Holliday, 2013; Lew et al., 2018) and reflexivity is considered important to ensure validity in qualitative methodology (Rabbidge, 2017). To increase the trustworthiness of the study, I have applied various strategies to ensure the study's transparency, transferability, dependability, and reflexivity.

Transparency/credibility or internal validity "deals with the question of how research findings match reality" (Merriam \& Tisdell, 2016, p.242). As regard credibility, I used three strategies: triangulation, member-check, and peer-debriefing. For triangulation of data, I used multiple data collection methods (observations, semi-structured interviews, focus group interviews) and multiple sources of data (from teachers, students, graduates, employers). As (Patton, 2015) explains, "triangulation, in whatever form, increases credibility and quality by countering the concern (or accusation) that a study's findings are simply an artifact of a single method, a single source, or a single investigator's blinders" (p. 674).

In addition, I implemented member checking to minimize researcher bias that I was constantly aware of. When I conducted my research, I brought with me my knowledge, worldview, and experience. Inevitably, my gender, age, ethnicity, cultural background, beliefs, and life experiences - my worldview -affected the constructions of reality I 
developed with the participants (Heigham \& Croker, 2009). By doing member check, I could clarify any points from the data that I could not fully comprehend. For example, I asked some teacher and student participants to read the transcripts of their interviews for accuracy (Stake, 2013).

Furthermore, I used peer debriefing, in which I sought support and guidance from professionals such as their comments, feedback, and critiques on research (Guba, 1981). For example, I discussed with two Ph.D. peers who conducted research in the field of intercultural language teaching about scholarship in the field and qualitative analysis. They gave me some comments on whether my findings were "plausible" based on the described raw data (Merriam \& Tisdell, 2016, p. 250). Moreover, I presented my findings in a seminar in New Zealand. These various interactions with professionals helped to test my growing insights (Guba, 1981) and expanded my perspectives about conducting the research.

Transferability (external validity) is "concerned with the extent to which the findings of one study can be applied to other situations" (Merriam \& Tisdell, 2016, p253). These authors further contend that it is readers' choice to decide whether they should apply a study's findings to their specific contexts. As Lincoln and Guba (1985, p. 125) state, the best way to ensure the possibility of transferability is to create a "thick description of the sending context so that someone in a potential receiving context may assess the similarity between them and the study."

My study does not aim to generalize its findings. However, so that users in similar contexts can apply my findings, I tried to depict the research phenomenon in detail and state the results as clear as possible. First, I provided rich descriptions of the context including detailed descriptions of the research problem, research context, data collection methods, and data analysis. In addition, I presented the findings in detail. For example, I depicted teachers' class activities and provided cross-case discussion. I focused on indicators of students' intercultural competence in classroom interactions. I examined how students reflected on their projects, and finally, I reported on teachers' and students' stated experience of the PBL lessons. Thick descriptions of the data, and interpretations of the findings can help readers make sense of the research phenomenon and its findings. Accordingly, readers can evaluate the study and decide whether the findings are applicable in their context (Guba, 1981). 
Dependability refers to the consistency of the findings and the extent to which the findings can be repeated if a study is replicated with similar participants in similar contexts. (Lincoln $\&$ Guba, 1985). To ensure dependability, Lincoln and Guba (1985) suggest using an inquiry audit, inquiry audit means having another researcher, who is not involved in the research, examine both the process and the findings of the research. The inquiry audit evaluates whether the findings are reliable, that is, whether the findings, interpretations, and conclusions are supported by the data and the recorded research process. To enhance the research's dependability, I documented research processes in detail and provided a clear description of the data process including prior data collection procedures, data collection, and data analysis. Specifically, I recorded my research activities, reflections, and regular supervision meeting contents in a research notebook, and organized data systematically in folders. These processes supported me in reporting all research process in my thesis, which allow readers to audit and evaluate my research.

In addition, I followed the code-recode strategy in data analysis as suggested by Guba (1981) and Krefting (1991). During both observation and interview data analysis, I familiarized myself with the data, made summaries of the data, generated initial codes, and determined the themes after a thorough examination of the themes against theme criteria (Braun \& Clarke, 2006, 2012). After producing the first round of findings and discussion, I repeatedly rechecked all my analysis procedures, especially the coding process, and compared the results. Each round of rechecking occurred at least two weeks after the previous.

Furthermore, I used triangulation and peer-examination to increase dependability. Specifically, I conducted methods triangulation and source triangulation (Patton, 1999). Methods triangulation involves checking the consistency of findings using multiple methods and source triangulation means examining the consistency of findings from different sources of data using the same methods. Accordingly, I collected data from (a) multiple methods including observations, interviews, and journals; and (b) multiple perspectives from teachers, students, and other stakeholders. In addition, as part of the peer-examination process, I invited a Ph.D. peer to code part of the data, then we compared the results and the final findings were determined when a satisfactory agreement rate on the findings was reached. I also sought $\mathrm{Ph}$.D. peers' comments on my data collection methods and data analysis as a source of reference in the revision of my thesis. 
Reflexivity shows researcher's conscious self-awareness. With this awareness, the researcher will treat data as a subjective construction of reality rather than objective truths while analyzing data (Finlay, 2002), and will acknowledge the impact of contextual factors on their research (Mann, 2016). To achieve reflexibility, I kept regular records of my research steps, my views, and perceptions in my research diary, which helped me to be aware of my potential biases and therefore attempted to minimize them. In addition, when analyzing data, I always considered contextual factors that could influence participants' responses. For example, when I interviewed teachers to investigate their perceptions of culture, I took into consideration such factors as their prior intercultural experience and their university intercultural learning.

In brief, this section has presented the strategies I have taken to ensure the trustworthiness of my study. The following section will summarize the whole methodology chapter.

\subsection{Chapter Summary}

This chapter has presented the methodology employed to conduct this study. It has depicted and justified the interpretive approach, research design (ethnographically-inform approach in Study 1; PAR design in Study 2). In addition, the chapter has provided detailed descriptions of participants, and justifications for multiple data collection methods and thematic data analysis. Finally, it has provided insights into how trustworthiness has been ensured. The following chapter will present the findings and discussion of Study 1 . 


\section{Chapter 4: Study 1 Findings and Discussion}

This chapter presents the findings and discussion of findings from Study 1, which was a situation analysis of cultural and intercultural content in EFL programs at a Vietnamese university. Data were collected from twelve classroom observations followed by stimulated recall interviews (SRIs), interviews with fourteen teachers, ten student focus groups, six recent graduates, and six employers who employed them. The data were collected to address overarching research question 1: How is culture addressed in a Vietnamese EFL university context? This question is divided into five sub-questions:

$\begin{array}{ll}\text { RQ 1.a: } & \text { How is cultural and intercultural content evident in the teaching of } \\ & \text { general EFL English classes and EFL culture classes at a university in } \\ & \text { Vietnam? } \\ \text { RQ1.b: } \quad \text { How do teachers explain this cultural and intercultural content in } & \text { stimulated recall interviews? } \\ \text { RQ 1.c: } \quad \text { How do teachers perceive the role and value of culture and } & \text { intercultural content in language teaching and learning? } \\ \text { RQ 1.d: } \quad \text { How do students perceive cultural and intercultural content in their } & \text { language learning? } \\ \text { RQ 1.e: } & \text { How do employers in international companies and recently graduated } \\ & \text { employees evaluate the importance of intercultural communication } \\ & \text { skills? }\end{array}$

The first main section of the chapter provides descriptive accounts of four lessons taught by four teachers, two from general English lessons and two from cross-cultural communication (CCC) lessons. Each account includes demographic information about each teacher and her students, a description of a lesson delivered by the teacher, and a post-lesson interview using video stimulated recall with the teacher. The analysis of the full data set revealed that these four accounts are representative of how these four teachers taught their other lessons in the data set, as well as how other teachers taught in the program. These four accounts are presented at the beginning of the chapter to provide a rich descriptive picture of actual lessons and the teachers' reflections on those lessons. In each account, the detailed description of each lesson focuses on the teacher's actions rather than on students' responses. 
The second section of the chapter presents findings from a thematic analysis of 12 classroom observations and the follow-up stimulated recall interviews. These findings give a broad view of how culture was addressed in this EFL program. The third section of the chapter consists of interviews with 14 teachers, 10 student focus groups, six graduates, and six employers. The chapter concludes with an overall discussion of the findings.

\subsection{Descriptive Accounts of Four Lessons}

This section presents descriptive accounts of four lessons taught by four teachers, two general English teachers, and two CCC teachers. Each account includes each teacher's profile and her students, a description of a lesson delivered by the teacher, and a stimulated recall interview with teacher. For each lesson, I acted as an observer with little participation. I chose a back seat and video-recorded the lesson, and took field notes.

For each semi-structured interview, I used an interview guide with a set of questions to ask participants. However, the questions were not rigid. The structure was open and there were opportunities for participants to speak more about unexpected aspects of the inquiry. In these instances, more questions would be asked to elicit information in that direction.

\subsubsection{Nhat - General English Class}

\subsubsection{Nhat's Profile}

Nhat is a Vietnamese teacher from the North of Vietnam. She studied her BA and MA at a university in Vietnam and had been teaching English for six years at the time of data collection. She had been assigned to teach general English classes for English majors covering four English skills: listening, speaking, reading, and writing and had never taught culture classes.

She did not train overseas, has never worked for any international company, and rarely has contact with non-Vietnamese. However, she sometimes visits Asian countries as a tourist for around a week. She uses Vietnamese with friends, family, and other social contacts and English with colleagues most of the time. Most cultural information she has obtained is from the media, and some from her university lessons when she was a student. 


\subsubsection{A Lesson by Nhat}

\section{Physical Setting}

The classroom is well-lit, newly painted white, around fifty spare meters in size with a long green chalkboard, a teacher's desk, and 12 new desks and seating benches arranged in three rows. There are twenty-four students (20 female and 4 male students) in the class, 2-3 students per desk. The room is soundproof with thick glass doors.

\section{Students}

The students are first-year English major students from 18 to 20 years old. Some of them come from Hanoi, the capital of Vietnam but most from nearby provinces. Their learning English at high schools mainly focused on grammar and they have had little contact with people from other countries.

Class: Speaking class (15-week program, a lesson/ week, 90 minutes/ lesson)

\section{Teaching material}

Material: A selected English teaching textbook World link 1

Topic: Unit 6 - Movies

Time: 90 minutes from $3 \mathrm{pm}$ to $4.30 \mathrm{pm}$.

\section{Objectives}

- To provide students with words relating to movies;

- To increase students' speaking skills, focusing on the way of expressing feelings using adjectives such as interested; bored; describing things using adjective ending with V-ing such as boring, interesting

- To give students practice in taking messages from phone conversations

\section{Lesson Description}

\section{A. Warmup}

- Nhat walks into the classroom. The class stand up and greet her. She responds and asks them to sit down. 
- She asks the whole class how they feel. Some students reply with "Fine, thank you". Some students sit quietly, saying nothing.

- Teacher asks the whole class whether they have prepared new words for the lesson. Some students respond with "Yes", some remain silent.

\section{B. Presentation}

- Nhat shows a PowerPoint slide with pictures and names of the movies from today's textbook lesson. She introduces the names of the movies using both Vietnamese and English. She asks whether students know more types of films other than the types of films introduced.

- Nhat introduces the use of adjectives ending with $e d$, and ing in English; for example, interesting, interested and gives two examples of using these adjectives to express feelings (he is excited about the trip) and describing things (the film is exciting). She explains the use of adjectives in the expressions above in Vietnamese

\section{Practice}

\section{Practice 1: Reading the review}

- Nhat asks three students to take turns to read out some film reviews from the PowerPoint slide and asks the whole class if they agree with the reviews.

\section{Practice 2: Taking a phone message in English}

- Nhat plays a recording about a person inviting a friend to a movie and explains expressions used to take a message. Then she asks students to work in pairs, repeat the conversation as in the recording.

- After ten minutes, Nhat asks two pairs of students to stand up and repeat the conversation.

- She explains in Vietnamese the expressions used to take a message and comments on the pronunciation of the students who read the dialogue from the textbook 


\section{Practice 3: Making conversations}

- Nhat asks students to work in groups of four, looking for adjectives ending with -ing and $e d$ in the reviews in the textbook

- She asks students to work in pairs, each student tells the other his experience of going to a movie including the name of the film and his/her feeling when watching the film.

- She calls two students to take turns to go to the board and talk about his/her friend's story of going to the movie. The story should include the name of the film, his/her feeling.

\section{Wrap-up:}

- Nhat assigns homework to the students: Talk about a movie they have seen recently.

\subsubsection{Stimulated Recall Interview (SRI)}

An SRI with Nhat was conducted three hours after the observed lesson. The interview took place in an unoccupied staff room. I played some parts of the videoed lesson and asked Nhat what she was doing, why, for what purposes; her objectives of the lessons, her feelings of the lesson; whether there were any cultural activities; what was the purpose of the cultural activities.

Nhat stated that the lesson was a typical one. She went through all the intended steps in the lesson plan, which was collectively designed, by a group of teachers in charge of the same subject in different classes. The lesson was mostly based on the textbook. She said that the objectives of the lesson were to provide students with (a) words about movies, (b) expressions using $e d$ and $V$-ing, and (c) practice taking messages from phone conversations. She added that the objectives were to enable students to use these words and structures in class activities. Nhat thought that culture aspect in the lesson was reflected by the topic "The movies" itself because films are part of culture.

Honestly, I just followed the book. When I taught, I did not think about teaching culture, I paid attention to helping students to practice expressing feelings. However, now, I think that the title can be considered as part of the culture learning. (S1-SRI-Nhat) 
She also stated that practicing expressing feelings and taking messages in the lesson also reflected English culture. She had no intention to add any other cultural elements in the lessons and even if more time was allowed, she would not find it necessary to supplement the lesson with any other cultural activities.

This lesson was simply presenting students with ways to express feelings and describing things. I cannot think of any ways to include cultural element, maybe not necessary. (S1-SRINhat)

However, she said that she was willing to add more cultural activities if these activities were provided for her, if she was guided to teach these activities, and if the teachers involved in designing the course agreed to include more cultural content in the lesson.

\subsubsection{Summary}

From the observation, Nhat prioritized teaching skills in this lesson. Cultural information about films was briefly introduced using some slides.

\subsubsection{Nhi - General English Class}

\subsubsection{Nhi's Profile}

Nhi is a Vietnamese teacher from the North of Vietnam. She got her BA and MA at a university in Vietnam and has been teaching English for ten years. At the time of the study, she was assigned to teach general English classes for English majors covering four English skills: listening, speaking, reading, and writing. She has neither taught culture classes nor worked for an international company. Nhi rarely has contact with non-Vietnamese and has never been abroad. Most cultural information she has obtained is from the media and her university lessons.

\subsubsection{A Lesson by Nhi}

\section{Physical Setting:}

The classroom has a long green chalkboard, a teachers' desk, a projector, and 12 long old desks and seating benches arranged in rows. There are 23 students (19 female and 4 male students) in the class, 5-6 students per desk. 


\section{Students}

The students are third-year students from 20 to 22 years old. Some of them come from Hanoi, the capital of Vietnam, but most from nearby provinces. These students have had little contact with people from other countries.

Class: Listening class (15-week program, a lesson/ week, 90 minutes/ lesson)

\section{Materials}

Materials: English teaching textbook: Skillful Listening and Speaking 4

Topic: Tradition and Progress

Time: 90 minutes from 8.45 am to 10.15 am

\section{Objectives}

- To help students develop listening skills, listen for main ideas,

- To widen students' vocabulary about traditions in some countries

\section{Lesson Description}

\section{A. Warmup}

- Nhi asks students how they feel and how they performed the test the previous week

\section{B. Listening \\ Pre-listening}

- Nhi asks students to work in pairs, look at the pictures in their textbooks and describe the pictures. The pictures are about people in Peru, Japan, Mongolia, India, Tanzania using different tools for their work.

- She calls three students to describe the pictures, talk about how they feel, and asks what they find the most interesting in different traditions in different countries.

- She asks students to work in groups and list the reasons why people in the mentioned countries keep their traditions. She calls a representative from each group to answer why people in the mentioned countries keep their traditions. Students answer with explanations. 
- She asks students to work individually to compare people in the pictures mentioned above with Vietnamese people. She asks students whether Vietnamese people feel happier.

- She asks students to work in groups to discuss negative and positive changes in Vietnam. Then she calls two students to represent two groups of students to go to the green board. She asks one student to write about one group's ideas on negative changes, one student writes about positive changes in Vietnam society, respectively.

\section{Listening 1}

- Nhi asks students to read the text about traditions in Tanzania while listening. She asks students to work individually to find the words that match their definitions in the textbook.

- She calls two students to answer and then she provides the correct answers.

\section{Listening 2}

- Nhi asks students to listen to the recording about Butan and chose the correct answers from the options in the textbook for the questions while listening.

- She plays the recording a second time and asks three students in turn to answer the questions. Then she gives the correct answers.

- She plays the recording, pauses at the keywords that can be hints for the answer, and explains to the students the reason for the answer.

\section{Wrap-up}

- Nhi repeats some new words in the reading in the textbook and suggests that students should listen and pay attention to keywords that can help answer the questions in listening tasks

\subsubsection{Stimulated Recall Interview}

An SRI was conducted five hours after the observed lesson. The interview took place in an unoccupied staff room. I played some parts of the videoed lesson and asked Nhi what she was doing, why, for what purposes; her objectives of the lessons, her feelings of the lesson. 
Nhi reported that this lesson was her typical lesson. She had gone through all the intentional steps in the lesson plan, the same collectively designed lesson plan as Nhat used. The content of the lesson was mostly based on the textbook. She assumed that the objectives of the lessons were achieved because students had learnt some vocabulary and strengthened their skills of listening for main ideas.

Most of the students could listen and choose the right answer for the listening task. This shows that they understood the lessons and knew how to use the tactics for listening. (S1-SRINhi)

She stated that there were some cultural elements in the lesson but she had not planned to develop students' intercultural communication. She simply followed the textbook, and the topic of this lesson sounded "cultural" to her. The topic was about traditions and habits in some countries (e.g., Tanzania and Bhutan). In addition, Nhi asked students to talk about changes in Vietnamese society between generations and asked students to compare some traditions of the countries in the lesson with Vietnam. She stated that the purpose of asking students to compare in her lesson was a way of following up the activity of describing the pictures, and not for deliberately teaching culture.

I was not thinking about teaching intercultural skills at that moment. Just because the lesson involved some traditions, an idea suddenly occurred in my mind that I should ask them to compare with Vietnam, and I did, simple as that. (S1-SRI-Nhi)

\subsubsection{Summary}

Overall, Nhi focused on language and skills in her lesson. However, she did mention culture, though to a limited extent. For example, she asked students to compare changes in Vietnamese life in different generations. Her reflections revealed that she did not intend to strengthen her students' intercultural skills in the lesson.

\subsubsection{Thu - Culture Class}

\subsubsection{Thu's Profile}

Thu is a Vietnamese female teacher from the North of Vietnam. She got her BA and MA at a university in Vietnam. At the time of data collection, she had been teaching English for 15 
years and assigned to teach culture classes for 10 years and general English classes for English majors covering four English skills: listening, speaking, reading, and writing.

Thu did not have any training overseas. However, she has been abroad three times as a tourist to Asian countries. In addition, she worked for an international company one year after she got her BA. During one year working in this company, her contact in English was mainly with Korean clients and workmates. Now, she rarely has contact with non-Vietnamese.

\subsubsection{A Lesson by Thu}

\section{Physical setting}

The classroom is well-lit with a long green chalkboard, a teachers' desk, projector, and 12 long old desks and seating benches arranged in rows. There are 33 students ( 28 female and 5 male students) in the class, 5-6 students per desk.

\section{Students}

The students are fourth-year students from 22 to 25 years old. Some of them come from Hanoi, the capital of Vietnam, and most from nearby provinces. These students have had little contact with people from other countries.

Materials: English teaching textbook: Intercultural Communication

Topic: Verbal Communication

Time: 90 minutes from 8.45 am to 10.15 am

\section{Objectives}

To help raise students' awareness of cultural differences and body language

\section{Class: Culture class}

Lesson Description

\section{A. Warmup}

- Thu asks students to turn off mobile phones and she introduces the topic of the lesson: Verbal communication 


\section{B. Presentation}

\section{Presentation 1}

- Thu asks students whether they know what is verbal communication. She asks students to work in pairs and discuss what is verbal communication

- She calls two students to define the term verbal communication and then she explains the term using the PowerPoint slides

\section{Presentation 2}

- Thu asks one student the meaning of subject, subjectivity, object, objectivity. Then she asks the whole class the meaning of the above terms in Vietnamese.

- She asks students to work in pairs to discuss the meaning of the word "subjectivity". Then she asks two students to define "subjectivity"

- She explains "subjectivity" using the PowerPoint slides; stressing the meaning of the word "ego"

- She asks students to work in pairs, and think about the meaning of "objectivity". Then she asks one student to define "objectivity".

- She explains "objectivity" in Vietnamese and English using a sentence as an example. From the example: the bird is flying in the sky (on the sky: in Vietnamese), she explains why Vietnamese use the preposition meaning "on" and English use "in" and concludes that the Vietnamese language is more subjective than the English language

- She gave one more example: The fish is swimming in the water. (under the water in Vietnamese);

\section{Presentation 3}

-Thu presents the use of addressing forms, with examples. She explains objectivity in English addressing forms, subjectivity in Vietnamese addressing forms

- She asks students to work in groups to find all possible Vietnamese translated versions of the pronoun "he" 
- She calls one student to answer. Then she gives the answer, explains the positive, neutral and negative meaning of different translated versions.

- She presents the use of "đurọc" and "bị" in Vietnamese. She explains that "được" and "bị" both equals was/were in English. However, the first infers positive meaning, the latter negative. In English, the mood of the speaker cannot be found only in "was/were)

- She gives one example sentence to illustrate her points, explains in both English and Vietnamese

\section{Presentation 4}

- Thu presents evaluative and non-evaluative infixes for doers of action with examples. In Vietnamese, the infixes add emotions of the speaker - respect/ disrespect the doer. In English, the suffixes added to the verbs only express the doers.

- She asks the whole class to translate the word "photographer" in Vietnamese in many ways revealing different views of the speakers and gives the answer

\section{Practice}

\section{Practice 1}

- Thu asks students to work in pairs, find examples to illustrate objectivity and subjectivity in English and Vietnamese

\section{Practice 2}

- Thu gives an English sentence, asks students to work in pairs to find different ways to translate into Vietnamese. Then she explains the reasons for the variety of the translation

\section{Wrap-up}

- Thu repeats the difference in Vietnamese and English in the use of preposition and the way of greeting in relation to subjectivity and objectivity

\subsubsection{Stimulated Recall Interview}

An interview with Thu using stimulated recall was conducted six hours after the observed lesson. The interview took place in an unoccupied bright, clean, tidy, quiet staff room. I 
played some parts of the videoed lesson and asked teacher Thu what she was doing, why, for what purposes; her objectives of the lessons, her feelings of the lesson; and what were the purpose of the cultural activities.

Thu reported that the lesson described above was among the lessons that helped students realize the differences in cultures in the two languages - Vietnamese and English. Like other lessons, in this lesson, Thu had followed all the steps such as warm-up, presentation, and practice.

Thu assumed that the objectives of the lessons were achieved because students had enriched their cultural knowledge, which helped them later in their intercultural communication.

Thu stated that the cultural content in the lesson dealt with culture in language, namely subjectivity and objectivity, and the difference in the use of prepositions in the two languages. According to Thu, this knowledge was crucial, which enabled students to deeply understand the reasons behind the use of prepositions in the two languages.

Of course, due to limited time, we could not teach students everything. But examples of subjectivity and objectivity inspired students' curiosity about cultural differences and they will explore more about culture. (S1-SRI-Thu)

Thu added that by asking students to work in pairs, she could help them communicate better. She explained that even though students come from the same country, each student is different because of their background and personality. Sharing knowledge would help them learn how to communicate, and how to negotiate the differences.

Later when working in international companies, students need to work in teams. Thus, I intentionally grouped them so they gradually learn to work harmoniously. (S1-SRI-Thu)

She added that by asking students to give examples, students could demonstrate whether they understood the lesson and the teacher could give necessary feedback.

\subsubsection{Summary}

Overall, in this culture lesson, Thu incorporated examples of cultural aspects of English and Vietnamese languages, and engaged learners in activities to raise their awareness of these differences. However, she mostly spent time explaining and asking students to give single sentence examples without thorough consideration of specific situations and intercultural 
situations. Her reflection shows her willingness to raise students' intercultural communication skills.

\subsubsection{Dong - Culture Class}

\subsubsection{Dong's Profile}

Dong is a Vietnamese female teacher from the North of Vietnam. She obtained her BA and MA in Vietnam. At the time of data collection, she had been teaching English for ten years and was in charge of teaching English classes for English majors covering four English skills: listening, speaking, reading, and writing. In addition, she has nine-year experience of teaching culture classes. Dong has never worked for any international company and rarely contacts English speakers. She has been abroad several times to Asian countries as a tourist.

\subsubsection{A Lesson by Dong}

\section{Physical setting}

The classroom is around thirty spare meters, with a long green chalkboard, a teachers' desk, projector, and 12 long old desks and seating benches arranged in rows. There are 24 students (19 female and 5 male students) in the class, 5-6 students per desk.

\section{Students}

The students are in their fourth year, and from 22 to 25 years old. Some of them come from Hanoi, the capital of Vietnam, and most from nearby provinces. They rarely contact people from other countries.

\section{Teaching materials}

Materials: Intercultural communication book; PowerPoint slides

Topic: Object language and Environmental language

Time: 90 minutes from 8.45 am to 10.15 am

\section{Objectives}

- To help students enrich their knowledge about object language and environmental language

- To increase awareness of the differences in the way people perceive the meanings of 
colors

- To help students avoid stereotypes and develop intercultural skills via engaging in problem-solving activities

\section{Class: Culture class}

\section{Lesson Description}

\section{A. Warmup}

- Dong asks students how they feel. Then she talks a little bit about the weather.

\section{B. Presentation}

\section{Presentation 1}

- Dong asks the whole class about the difference between verbal communication and nonverbal communication. She points at the slides and explains the meaning of verbal communication and non-verbal communication

- She gives examples of object language such as the kind of dresses suitable to go to weddings and funerals.

- She asks students to guess what people would think about the character of a person who wears jeans or wears clothes in black or yellow

- She talks about the effect of yellow on children with autism. She says that yellow could help autistic children to get calm.

- She asks students whether they know the concepts of environment language. She gives an example of a yellow room, a pink room that could affect people's emotion

\section{Presentation 2}

- Dong uses PowerPoint slides to present principles of cross-cultural communication such as avoiding stereotypes.

- She uses examples to explain stereotypes about Vietnamese, Japanese, French people. She translates these examples into Vietnamese 


\section{Practice}

- Dong gives students a situation and asks students to give their views on behaviors of four men and a woman in a story

- She emphasizes that there are no right or wrong answers, just differences in views in the students' evaluation

- She calls four students to give their answers. She says that there should be no judgement in students' answers, no answer is better than the other.

- She concludes that the same is true in intercultural communication. What is appropriate in one culture might not be proper in another culture. So, people from different cultures should respect the difference from other cultures

\section{Wrap-up}

- Dong highlights the need to understand and respect the differences between cultures to avoid misunderstanding in intercultural communication

\subsubsection{Stimulated Recall Interview}

An SRI with Dong was conducted six hours after the observed lesson. The interview took place in an unoccupied bright, clean, tidy, quiet staff room. I played some parts of the videoed lesson and asked Dong what she was doing, why, for what purposes; her objectives of the lessons, her feelings of the lesson, and what were the purpose of the cultural activities.

Dong reported that the observed lesson was typical. She had gone through all the intended steps in the lesson plan and added some stories of her own to illustrate her ideas for students to better understand the lesson. Dong assumed that the objectives of the lessons were achieved because students had developed some cultural knowledge and skills to solve problems in certain situations dealing with communication with people from other cultures. More specifically, she emphasized that students raised their awareness and developed positive attitudes towards the dissimilarities they would encounter in communication. Pointing to a snapshot of the video, she explained:

I was repeating several times that there is no right or wrong in the behaviors. They are just different and we should respect the differences. (S1-SRI-Dong) 
Dong stated that cultural content in the lesson did not deal with culture in language. Additionally, she contended that the knowledge about object language and environmental language was significant to students' knowledge in communication. She clarified her purpose when she highlighted the need to care about the choice of clothes in the lesson:

The way you dress tells who you are. Dressing is part of the culture. Students should know the meaning people can make of the way they dress in certain situations such as funeral or wedding, and tell who you are. Raising students' awareness of object language will improve their communication skills culturally and interculturally. (S1-SRI-Dong)

With respect to the concepts of stereotype and generalizations, Dong maintained that every student should be aware of, and avoid stereotypes. Thus, students should realize not all individual members in the same culture acted exactly the same. Talking about the practice section in the lesson, the teacher found that it did not link with the presentation of the lesson. However, it was also about culture and her objective was to raise students' awareness of the differences.

\subsubsection{Summary}

Dong's treatment of culture in the lesson shows her focus on raising students' awareness of cultural differences and the need to avoid stereotypes. She provided students with examples of stereotypes and explained the differences in behaviors even among members of a social group. In the comments she made in the SRI, she acknowledged the value of cultural awareness in the intercultural interactions that students are likely to face in the future.

\subsubsection{Section Summary}

This section has provided four rich accounts of four lessons, two taught by general English teachers and two CCC teachers. Unsurprisingly, in the general English classes, the two teachers prioritized language skills and paid little attention to culture while in the CCC classes, the teachers focused on raising students' awareness of cultural differences. The next section reports on the thematic analysis of the whole data set. This broader analysis inevitably picks up themes reported in the previous section. 


\subsection{Findings from Thematic Analysis of Classroom Observations}

This section presents findings on how cultural and intercultural content was present in the EFL classes. It also reveals what teachers said about their teaching practices. Classroom observation data were from 12 lessons taught by eight teachers and stimulated recall interviews (SRIs) after each lesson. The 12 lessons were comprised of eight general EFL lessons in different language skills for Year-1, Year-2, Year-3 students, and four crosscultural communication (CCC) lessons for Year-4 students.

As described in Section 3.6, classroom observation data (field notes and audio-video recordings) were analyzed to identify any instances of cultural or intercultural content. Similarly, interview data were selectively transcribed and cultural or intercultural content analyzed. Both sets of data were subject to thematic analysis, which involved an iterative process of coding and generating themes. Section 4.2.1 describes the representations of cultural and intercultural content in general EFL classes and section 4.2.2 in CCC classes.

\subsubsection{Cultural and Intercultural Content in General EFL classes}

Overall, there were few instances of cultural and intercultural content in the general EFL classes. Table 4.1 provides an overview of the instances that occurred, how long they were and what aspects of cultural or intercultural content the teachers addressed.

As the column heading shows, four main themes emerged from the thematic analysis of the classroom observation data: cultural content in the textbook, explaining cultural content, explaining culture-laden words, and explaining culture in general text structure. Each of these themes is discussed in detail in the following section. 
Table 4.1

Representations of (inter)cultural content in general EFL lessons

\section{List of observations}

\begin{tabular}{|c|c|c|c|c|}
\hline & $\begin{array}{l}\text { Cultural content in the } \\
\text { textbook }\end{array}$ & $\begin{array}{l}\text { Explaining cultural } \\
\text { content }\end{array}$ & $\begin{array}{l}\text { Explaining culture- } \\
\text { laden words }\end{array}$ & $\begin{array}{l}\text { Explaining culture in } \\
\text { general text structure }\end{array}$ \\
\hline & \multicolumn{4}{|c|}{ Instance/ Activity (time ${ }^{2}$ ) } \\
\hline $\begin{array}{l}\text { Ob1: Teacher Nam } \\
\text { Speaking: Persuasion } \\
\text { Language Focus: Ways to express agreements, disagreements }\end{array}$ & & & & $\begin{array}{l}\text { Ins 1: practice (6') } \\
\text { Ins 2: wrap-up (3') }\end{array}$ \\
\hline $\begin{array}{l}\text { Ob2: Teacher Luc } \\
\text { Reading: Powering of the future } \\
\text { Language Focus: Reading for specific information }\end{array}$ & & Ins 1: presentation (2') & & \\
\hline $\begin{array}{l}\text { Ob3: Teacher Nhi } \\
\text { Reading: Stories and storytellers } \\
\text { Language focus: Reading for specific information }\end{array}$ & Ins 1: while-reading (10’) & $\begin{array}{l}\text { Ins } 1 \text { : while-reading } \\
\left(5^{\prime}\right)\end{array}$ & $\begin{array}{l}\left.\text { Ins 1: while-reading ( } 1^{\prime}\right) \\
\text { Ins 2: while-reading (1') }\end{array}$ & \\
\hline $\begin{array}{l}\text { Ob4: Teacher Nhi } \\
\text { Listening: Traditions and Progress } \\
\text { Language Focus: Listening for specific information }\end{array}$ & Ins 1: while-listening (12’) & $\begin{array}{l}\text { Ins 1: pre-listening (2') } \\
\text { Ins 2: pre-listening (6') }\end{array}$ & & \\
\hline $\begin{array}{l}\text { Ob5: Teacher Nhat } \\
\text { Writing: Descriptive paragraph } \\
\text { Language focus: Describing things }\end{array}$ & Ins 1: pre-writing (10') & & Ins 1: pre-writing (1') & $\begin{array}{l}\text { Ins 1: presentation }\left(7.5^{\prime}\right) \\
\text { Ins 2: wrap-up (1') }\end{array}$ \\
\hline $\begin{array}{l}\text { Ob6: Teacher Nhat } \\
\text { Speaking: New friends, new faces } \\
\text { Language Focus: Simple present tense }\end{array}$ & & Ins 1: practice (1.5') & & \\
\hline $\begin{array}{l}\text { Ob7: Teacher Ha } \\
\text { Writing: The essay - Opinion Paragraph } \\
\text { Language focus: Express opinion }\end{array}$ & & & & $\begin{array}{l}\text { Ins 1: presentation }\left(8.5^{\prime}\right) \\
\text { Ins 2: wrap-up }\left(1.5^{\prime}\right)\end{array}$ \\
\hline $\begin{array}{l}\text { Ob8: Teacher Bay } \\
\text { Speaking: What do we need? } \\
\text { Language focus: Talking about shopping }\end{array}$ & Ins 1: practice $\left(5^{\prime}\right)$ & Ins 1: practice (4') & $\begin{array}{l}\text { Ins 1: practice }\left(1.5^{\prime}\right) \\
\text { Ins 2: practice }\left(0.5^{\prime}\right) \\
\text { Ins 3: practice }\left(1^{\prime}\right) \\
\text { Ins 4: practice }\left(1.5^{\prime}\right)\end{array}$ & \\
\hline
\end{tabular}

${ }^{2}$ Time: rounded to the nearest half minute 


\subsubsection{Cultural Content in the Textbooks}

In four of the eight observations, teachers instructed students to read or listen to textbook passages that contained cultural content in the form of information about cultural practices (e.g., garage sale), cultural facts (facts about Bhutan), and cultural arts (e.g., Grimm fairy stories). These reading activities aimed to look for specific information for reading tasks (observations 3,8), to answer questions for the pre-writing stage (observation 5), and to answer questions for pre-listening and while-listening stages (observation 4). Teachers only asked students to do language tasks and did not explain any cultural points in these reading texts. Furthermore, students did not raise any questions concerning these cultural points throughout the observations. For example, in observation 8 , students were asked to skim a text about garage sales and choose the correct answers. In observation 3, Nhi asked students to read a passage about the Brothers Grimm and their tales before answering multiple-choice questions. Similarly, in observation 5, students read a passage about Sari to search for information for a True/False exercise. Nhi said that she believed students in observation 4 enriched their knowledge about the Hadza people while they read and listened to the text even though the listening section emphasized some new words which were not related to culture. In the interviews, teachers in these observations reported that they believed students' knowledge about culture would grow when they read or listened to a passage with cultural information. As Bay said:

There are many interesting things in shopping habits in different places. In this lesson, I think that students found out more about the 'garage sale' culture, which is strange to us. (SRI GET7)

Nhi also explained her pedagogical intentions:

I would like students to read quickly and look for answers. For example, question 2 asks "What does the word many in line 5 refer to?". Students should pay attention to the words around the word "many" and decide which word it refers to, folktales or traditional stories. (SRI-GET2)

These comments indicated that the teachers' priority was to focus students' attention on completing the reading tasks although they also perceived that culture learning could also occur while doing these tasks. 


\subsubsection{Explaining Cultural Content}

The teachers' explanation of cultural content was observed in five lessons. In observation 4, students learned some facts about Bhutan, such as its flag, population, capital, and area, when Nhi introduced these facts from the textbook. In observation 6, Nhat read the culture note from the textbook. The culture note was "in some countries, it may not be appropriate to ask women's age". Then she moved to their speaking activities. Students did not ask any questions concerning the culture note. Nhat explained:

When students finished the speaking tasks, I saw a culture note near the task. I think it is necessary to let students know about culture, so I read it out and I think they will memorize it. It is a short and clear note. (SRI-GET1)

It was necessary to tell them about this because it is ok to ask about women's age in our culture. Everyone knew that, so I just told them what they might not know. (SRI-GET1)

Nhat's comments reveal that the teaching of culture was not a priority, and as such, reflects the overriding curriculum emphasis on language skills and knowledge. Hence, her decision to tell students the textbook culture note occurred when students finished the speaking task. Nhi, Bay, and Nhat all reported that they assumed that students were aware of their home culture, and thus, they did not touch upon home culture in their lessons. These teachers believed that their cultural teaching practices were appropriate. They said that they prioritized language skills, which resulted in quick clarification of cultural points when necessary. They added that they could not share much cultural experience with students because their experience was limited. As Bay put it:

In this lesson, to tell the truth, I wish I had had a lot of cultural knowledge and experience about various types of shopping in other countries. I would have talked with the students, maybe in the pre-speaking section, to raise their interest in the lesson. Students will learn from listening to my stories. (SRI-GET7)

Bay's statement shows her desire to equip students with more cultural knowledge. In observation 3, in the warm-up section, home culture was present. This was when Nhi showed the name of 'Stories by Hung King' with some names of fairy tales in Western cultures, such as 'Red Riding Hood' on PowerPoint slides. In the interview, she explained: 
The topic of this reading lesson is about fairy tales. So, I put on the PowerPoint slide the names of fairy tales in the book, and one name of a Vietnamese one. The Vietnamese one is not in the book. This is to give the list a sense of variety, both Vietnamese and Western fairy tales, also students will easily understand what I say if I talk about some things that they know. (SRI-GET2)

From Nhi's comments, it can be inferred that her provision of the names of some Vietnamese stories was to help students understand the term "fairy tales". Like in other observations, most of the cultural content was from textbooks.

In observation 2, teacher Luc spent a couple of minutes introducing John Venn, a mathematician with a portrait of him on a PowerPoint slide. She explained that she took the picture from the textbook and presented it on the PowerPoint slide to make a more vivid instruction for students to use a Venn diagram to classify information in a reading task. Luc further explained her stress on students' knowledge of the diagram, not the author.

The teachers in all the above observations stated that the tasks were designed for developing language. Although these teachers had not planned to raise students' cultural knowledge, they believed that their students learned about culture through their encounters with the cultural content in the lessons.

\subsubsection{Explaining Culture-laden Words}

In three of the eight observations, Nhi, Nhat, and Bay used Vietnamese to clarify the meaning of words or expressions in textbooks that might confuse students. These teachers reported in the SRIs that they believed these words were associated with culture and students needed help to understand. They said they found it necessary to explain the meanings of these words to students. For example, in observation 3, Nhi stated that witches were bad female characters in Western fairy tales with a pointed nose, travelling on a broom. In addition, she explained the word "castle" as the place a king and queen live in western fairy tales, like a kingdom in Vietnamese fairy tales. In observation 8, Bay explained that desserts were what people in western countries had after they finished their main course, which was different from the conventional one-course meal of Vietnamese. She added that a common Vietnamese meal consisted of cooked rice, a dish, or some meals made of fish/pork/chicken processed in various ways and vegetables. In another example, she clarified the word "Pizza". "Pizza" was a new concept to the students because most of them came from rural areas of Vietnam. No 
equivalent term exists in Vietnamese. Thus, Bay explained that pizza was a type of fast food that originated from Italy. Furthermore, Bay clarified the word "Garage sale". She said that people sold their used goods at cheap prices in their garages in many Western countries, which never happens in Vietnam. In observation 5, Nhat told her students about the sari, a traditional dress of Indian women that a lot of students had never heard about.

The teachers reported attempting to ensure that students understood all possible new words so that these words would not hinder their process of completing the language tasks. Bay said:

The reading text has the word "garage sale". I find it strange. To be honest, I have never seen a garage sale. If students are not clear about its meaning, they will find it harder to answer questions in the reading text. Therefore, I thought I should help them understand by explaining the words in more detail. (SRI-GET7)

As can be seen from Table 4.1, teachers spent less than two minutes each time they explained a word. The explanation of these words occurred in different lesson stages among the observations, in the warm-up, presentation, or practice of the lessons. Nhat explained:

When I designed the lesson plan, I did not think about this word. I simply followed the textbook. The pre-reading has the word "sari', so I explained it. I thought students probably did not know this word. All I know is "sari' is a traditional dress, so I stopped at a simple explanation. I thought students just needed to comprehend the text. There was no need to explain further. (SRI-GET1)

It is clear from Nhat's statement that the explanation was unplanned, and therefore, superficial because it was not the focus of the lesson. Extract ST1EX1 also reflects the role of explaining culture-laden words in Nhi's lesson:

T: Các bạn đọc cho cô phần reading, sau đó trả lời câu hỏi bên dưới (Please read the passage, then answer the questions below

\section{Students look at textbooks, read for 3 minutes}

T: $\quad$ Any questions? Any new words?

\section{Silent 1 minute}

T: Ok, now, the word "castle" do you know its meaning

\section{Silent 1 minute}


T: $\quad$ It is a place where a king and a queen lived. Tiếng Việt là gì nhỉ?

S: $\quad$ cung điện (palace)

T: $\quad$ Yes, that's right. OK, now continue to read, please

S: $\quad$ Excuse me, what does "witches" mean?

T: $\quad$ Ah, it means bad female characters in western fairy tales with a pointed nose, travelling on a broom. Got it? Any other words?

\section{(Extract ST1EX1)}

In the interview, Nhi expressed her intention to help students know the difference in the typical images between the bad female characters in Vietnamese and western fairy tales.

In our fairy tales, Vietnamese bad characters are generally described as beautiful but with a cruel heart or ugly. But as I know, the witches in Western fairy tales often have hooked noses and fly on a broom. When we explain the meaning, students will compare and understand the differences. (SRI-GET2)

Although Nhi mentioned the differences in the images of bad characters, she did not talk about bad Vietnamese female characters in the observation or ask students to compare the differences between the characters in Vietnamese and Western fairy tales. In other observations, the explanation of words occurred in the same manner - incidentally, briefly, and superficially to aid students' comprehension of the whole text. In each case, after the teacher had explained the word, they focused on language skills for the rest of the lesson. In all observations, students did not ask any other questions after the teachers' explanations.

In summary, the explanations of words or giving cultural facts simply arose from the fact that these words or cultural content occurred in the reading passage or listening/speaking/writing tasks. The teacher clarified their meanings so that students could understand the words that were associated with other cultures.

\subsubsection{Explaining Culture in General Text Structure}

In three of the eight observations teachers addressed culture by explaining culture in discourse. In observation 7, Ha presented the way an opinion paragraph should be structured in English, such as the use of the hook, the introduction, the body, and the conclusion of the paragraph. To illustrate her points about components in an opinion paragraph, she used a sample opinion paragraph showing a person's preference for Coke. In observation 5 , Nhat 
introduced the way to describe things in English. In order that students could complete their task of describing a possession, Nhat told them to follow the structure of a descriptive paragraph with a topic sentence, supporting sentences, and concluding sentences. Similarly, Nam introduced the phrases used for expressing agreements and disagreements in English. In all these observations, teachers presented the knowledge from the textbook, and students were passive listeners. After teachers introduced the knowledge, students followed teachers' instructions to do the language tasks. In these observations, teachers and students did not talk about the Vietnamese way of writing a paragraph or expressing agreement and disagreement. Extract ST1EX2 below reflects Ha's treatment of culture in her lesson:

T: A descriptive paragraph is. ... một đoạn văn miêu tả là gì nhỉ (what is a descriptive paragraph) .... một đoạn văn có thể mô tả người, nơi chốn, hay ...con vật right. (It can describe people, places, things, or .... animals.

T: $\quad$ So, it needs a topic sentence - câu chủ đề các bạn nhé (topic sentence) - để - to introduce the item that the writer will describe

T: $\quad$ Tiếp theo là gì nhỉ? (What's next?)

T: $\quad$ Supporting sentences. Các bạn nhớ là (remember that) supporting sentences có thể là (can be): give background information about the item - cung cấp thông tin về đồ vật mô tả (give information about the item); or describe how the item looks, smells, or tastes, may describe how the writer feels about them - cảm nghĩ của tác giả đúng không ạ (what writers think, right?) Các bạn nhớ (remember) concluding sentence nhé - to restate - nhắc lại (to restate) ideas in different words.

T: $\quad$ Understand?

Ss: $\quad$ Yes

T: $\quad$ Good, now move to the exercise

(ST1EX2)

In the extract, Ha used some Vietnamese to explain paragraph structure to students. In the interview, she reported that she believed that using some Vietnamese would help students understand easier because they could relate to the Vietnamese way of writing a descriptive paragraph. Similarly, Ha expressed her teaching intention:

Vietnamese ways of writing an argument or showing an opinion are different from English. You know, we [Vietnamese] are not direct either in speaking or writing. We often beat around the bush before going to the main point. Therefore, it is important to show them [students] 
how to do it [write an opinion paragraph in English]. Otherwise, they just translate from Vietnamese to English in their writing. (SRI-GET12)

It can be inferred from her comments that she was aware of the differences in the writing styles in Vietnamese culture and target cultures. However, she did not explicitly mention how Vietnamese opinion paragraphs were structured nor did she state in the lesson that there were differences in Vietnamese and English ways of structuring the opinion paragraphs. Although her comments inferred her expectations that students would compare the differences between their own culture and target culture or make some kind of cultural relation, there was no evidence or checking from Ha that the comparison or relating occurred. In addition, she did not create chances for students to compare and voice their thoughts about these differences throughout this lesson. By explaining culture in general text structure, the teachers in these observations aimed to foster their students' language skills, which indicates that the teachers saw the language and culture relationship, but prioritized language.

\subsubsection{Summary}

Section 4.2.1 described different ways in which the cultural component was present in the observations in general EFL classes, including culture content in textbook passages, explaining cultural content, explaining culture-laden words, and explaining culture in general text structure. Overall, the cultural content was from the textbook, and teaching activities were designed to improve students' language skills.

These teachers reported their cultural teaching practices as peripheral to developing students' language skills, and thus, did not plan to help their students to develop any intercultural skills. However, in terms of cultural knowledge, all teachers stated that students expanded their cultural knowledge to some extent when they were exposed to the culture-related content.

While EFL classes focused on language proficiency, cross-cultural communication classes were designed for cross-cultural awareness. Section 4.2.2 below will discuss the representations of culture teaching in cross-cultural communication classes.

\subsubsection{Representations of Cultural and Intercultural Content in CCC classes}

Thematic analysis of four CCC class observations and stimulated recall interviews reveals three themes in the teachers' treatment of culture: teachers' lecturing on general cultural 
concepts, explaining culture in language at the levels of pragmatic and interactional norms (Crozet \& Liddicoat, 1999), and developing students' cultural/intercultural skills (Table 4.2). Details of how teachers addressed culture are presented below.

Table 4.2.

Representations of (inter)cultural content in CCC lessons

\begin{tabular}{|l|c|c|c|}
\hline \multirow{2}{*}{ List of observations } & \multicolumn{2}{|c|}{ THEMES } \\
\cline { 2 - 4 } & $\begin{array}{l}\text { Lecturing on general } \\
\text { culture in } \\
\text { communication } \\
\text { concepts (60-70\% } \\
\text { total 90-min lesson) }\end{array}$ & $\begin{array}{l}\text { Explaining culture } \\
\text { in language (10- } \\
\text { 15\% total 90-min } \\
\text { lesson) }\end{array}$ & $\begin{array}{l}\text { Raising students' } \\
\text { intercultural } \\
\text { awareness via } \\
\text { activities (10-15\% } \\
\text { 90-min lesson time) }\end{array}$ \\
\hline $\begin{array}{l}\text { Ob C1: Teacher Thu } \\
\text { Lesson: Verbal Communication }\end{array}$ & $\checkmark$ & $\checkmark$ & $\checkmark$ \\
\hline $\begin{array}{l}\text { Ob C2: Teacher Thu } \\
\text { Lesson: Object Language and } \\
\text { Environmental Language }\end{array}$ & $\checkmark$ & $\checkmark$ & $\checkmark$ \\
\hline $\begin{array}{l}\text { Ob C3: Teacher Dong } \\
\text { Lesson: }: \text { Verbal Communication }\end{array}$ & & & \\
\hline $\begin{array}{l}\text { Ob C4: } \text { Teacher Dong } \\
\text { Lesson: Culture shock }\end{array}$ & $\checkmark$ & $\checkmark$ & $\checkmark$ \\
\hline
\end{tabular}

\subsubsection{Lecturing on General "Culture in Communication" Concepts}

In all CCC class observations, both Thu and Dong allocated around three-quarters of their lesson time to lecturing on general concepts. For example, in observation $\mathrm{C} 1$, Thu introduced the definitions of verbal communication, subjectivity, and objectivity. In observation $\mathrm{C} 2$, Dong provided students with concepts about non-verbal communication and principles of cross-cultural communication such as avoiding stereotypes. In observation C4, Dong defined culture shock, listed symptoms of culture shock, and phases in culture adjustment including phase 1 - the honeymoon period, phase 2 - culture shock; phase 3 - initial adjustment; phase 4 - mental isolation; phase 5 - acceptance and integration. Also, Dong mentioned strategies for adjusting to a new culture and recommended open, tolerant, accepting attitudes in a new cultural environment. Dong shared her underlying beliefs for this teaching practice:

I believe that by showing students the stages of cultural adjustment, students will feel confident and not afraid once they encounter cultural differences in their life. The reason is that if they can envisage the whole path that they will go through, they will know where they are, at what stage of culture shock and feel confident that they will overcome when they apply 
the guidelines. Of course, it takes time. But I think it (proving guidelines) is very crucial. (SRI-CCCT2)

In observation C3, Dong introduced facial expressions and examples of different meanings attached to different cultural gestures. In the interviews, both teachers believed that knowledge about how to communicate well was salient in fostering students' cultural awareness. Thu explained:

The important thing is that we should provide them with the whole picture of communication. I mean, the factors that constitute successful communication, for example, non-verbal communication like eye contact. Westerners consider keeping eye contact important in conversations while Asian people may judge it not respectful for a young person to look straight into an older person's eyes. When they are aware of possible problems in, for example, non-verbal communication, they will learn how to avoid possible misunderstandings. (SRI-CCCT1)

Thu's comments indicated that she saw culture as fixed behaviors, which could lead to misleading stereotypes. Interestingly, students were not observed to raise any questions or express any concern about the content in the teachers' talk. In the interviews, Thu and Dong stated that their facilitation in constructing students' knowledge of the possible areas of communication would inspire students to autonomously search for appropriate behaviors in specific cultural settings.

In summary, the curriculum and teaching materials for the CCC lessons focused on general concepts of culture in communication and the CCC teachers closely followed the materials. Additionally, the teachers occasionally gave illustrative examples. However, these examples could be misleading because they were prone to stereotype.

\subsubsection{Explaining Culture in Language}

In addition to lecturing on common concepts of culture in communication in the CCC lessons, the two CCC teachers also focused on the pragmatic meanings and interactional norms informed by cultures. For example, in observation C1, Dong used examples to explain the evaluative and non-evaluative infixes for doers of action. She gave another example of how to translate the pronoun "you" into Vietnamese. She explained different nuances of meanings of "you" in Vietnamese based on specific contexts such as gender, age, and social status between interlocutors. In observation C3, Dong gave students the expressions used to 
compliment someone in English and the default responses to compliment. She further explained the influence of culture in interactional norms in Vietnamese in a similar context. She pointed out that a Vietnamese would respond to a compliment without "Thank you" as in English. Instead, the compliment receiver should show modesty by denying the compliment like "Oh, no. I am not so good".

While cultural comparisons have been claimed to support intercultural language learning (Byram, 1997; Liddicoat \& Scarino, 2013; Newton et al., 2010), the fact that the information is presented by teachers as facts will deny students' opportunities to construct their cultural/intercultural understanding and reflect on their own cultural/intercultural experiences.

\subsubsection{Raising Students' Intercultural Awareness via Activities}

Even though the teachers lectured most of the time, they reported and were observed to provide students chances to participate in some short activities that focused on some aspect of culture in communication. For example, teacher Thu raised the question of what topics were considered safe in small talk for two people meeting for the first time. Then she divided students into groups to discuss this question (observation C2). Students were also encouraged to notice and compare the differences between Vietnamese and English in the way to respond to the question "How are you?" and share their thoughts with peers. In this lesson, student pair-work was prevalent. For example, students exchanged ideas on the appropriateness of an American nurse's pointing gesture in Ethiopia. Students were also asked to do a gap-filling task in which they had to fill in the appropriate ways to greet different people in English and Vietnamese in different situations. Thu reported her pedagogical intention:

I think that group work or pair-work is very important in teaching this culture course.

Through talking with peers, they will gradually learn how to negotiate their ideas, how to defend their views and at the same time respect other people and increase their communication skills. (SRI-CCCT2)

In observation $\mathrm{C} 1$, teacher Thu told the whole class a story about an American man eating out with his Vietnamese girlfriend and a friend of his girlfriend. When the three people finished their meals, the American guy just paid for him and his girlfriend's food, letting the friend of his girlfriend pay for herself. His girlfriend expressed great disappointment because she had assumed that her American man was "manly" enough to pay for all three people. She felt 
ashamed. Students were asked to notice, and compare the differences between an American man's behavior and a Vietnamese in the same situation. In addition, students were asked to discuss the situation, explain why the Vietnamese women felt disappointed, and state what they thought about the American man. In the SRI, Thu explained:

In the culture lessons like this, I often try to include examples so that students can discuss and through the discussion, I hope that they will recognize that people from different cultures in the examples act differently because they hold different views and beliefs. (SRI-CCCT2)

Only in this observation did the teacher address culture as lived experience. In other observations, no lived experience was shared by teachers or students. Both teachers in the culture classes emphasized the need to raise students' awareness of cultural similarities and differences to prepare for students' intercultural communication. They asserted that their lessons targeted providing students with cultural knowledge and concurrently helping students to be more open to what students deemed as different. They reported that their activities were correspondingly planned to provide chances for students to notice the differences and compare them. Dong said:

I think that students will soon go to work, and we need to help them realize that people from different cultures may act differently and they should possess an appropriate attitude towards the differences. (SRI-CCCT1)

Both teachers shared the view that their approach to teaching culture was, to some extent, relevant. They added that they tried to be flexible in teaching so that students could understand the lessons. For example, teacher Dong assumed that the notions of subjectivity and objectivity were challenging for students. Thus, she took an active role in providing knowledge. In contrast, they stated that tasks that were related to social behaviors such as how to respond to "How are you?" in both Vietnamese and English were more suitable in promoting students' active participation in comparing. They thought that their students enjoyed their lessons, though both teachers expressed a desire to enhance their teaching in terms of lesson content and teaching practices.

\subsubsection{Summary}

In summary, the teachers in the CCC classes addressed culture by introducing general culture-in-communication concepts, explaining culture in language, and raising students' 
intercultural awareness via cultural activities. In these three approaches, lecturing accounted for most of the time and cultural activities the least time. Opportunities for students to reflect on their intercultural experience were rare, and teachers' overall provision of formulaic expressions reflects a static view of culture.

\subsection{Findings From Interviews}

This section first presents teachers' beliefs about culture teaching and uncovers how their perceptions and attitudes shaped their culture teaching practices. It then continues with students' beliefs about culture learning and the view of other stakeholders relating to culture learning. These include recent graduates' reflections of their past culture learning at university and its influence on their recent work communication, and six employers' evaluations of the intercultural communication of these six university graduates. The section ends with a summary of the main findings from the interview data.

\subsubsection{Findings From Interviews With Teachers}

A thematic analysis of individual interviews with 14 teachers identified four key themes: conceptualizations of culture, roles of teaching culture in language education, approaches to teaching culture, and constraints in teaching culture. Each theme is presented below.

\subsubsection{Conceptualizations of Culture}

Teachers were asked what culture in EFL teaching meant to them. Their responses were largely similar, falling into one category or both categories: culture "in general" and culture in language and communication. Table 4.3 summarizes all 14 teachers' definitions of cultures, with the categories discussed in detail below. 
Table 4.3

Teachers' conceptualizations of culture

\begin{tabular}{clcccc}
\hline No. & Teacher & \multicolumn{2}{c}{ Categories of culture } \\
\hline & \multicolumn{2}{c}{ Culture in general } & Culture in language and communication \\
\hline & & Visible culture & Invisible culture & Culture in language & $\begin{array}{c}\text { Culture in } \\
\text { communication }\end{array}$ \\
\hline 1 & Nhat & $\checkmark$ & $\checkmark$ & $\checkmark$ \\
\hline 2 & Nhi & $\checkmark$ & $\checkmark$ & $\checkmark$ \\
\hline 3 & Tam & $\checkmark$ & & $\checkmark$ \\
\hline 4 & Tu & & $\checkmark$ & $\checkmark$ & $\checkmark$ \\
\hline 5 & Nam & $\checkmark$ & $\checkmark$ & $\checkmark$ & $\checkmark$ \\
\hline 6 & Luc & $\checkmark$ & $\checkmark$ & $\checkmark$ & $\checkmark$ \\
\hline 7 & Bay & $\checkmark$ & & $\checkmark$ \\
\hline 8 & Tan & $\checkmark$ & & $\checkmark$ & $\checkmark$ \\
\hline 9 & Chin & $\checkmark$ & & $\checkmark$ & $\checkmark$ \\
\hline 10 & Muoi & $\checkmark$ & $\checkmark$ & $\checkmark$ & $\checkmark$ \\
\hline 11 & Xuan & & $\checkmark$ & $\checkmark$ & $\checkmark$ \\
\hline 12 & Ha & $\checkmark$ & $\checkmark$ & $\checkmark$ & $\checkmark$ \\
\hline 13 & Thu & $\checkmark$ & $\checkmark$ & $\checkmark$ & $\checkmark$ \\
\hline 14 & Dong & & $\checkmark$ & & $\checkmark$ \\
\hline
\end{tabular}

As can be seen in Table 4.3, the teachers' culture definition involved "visible culture" and "invisible culture". Twelve out of the 14 teachers defined culture as cultural artifacts, customs, traditions, and behaviors. Ten out of the 14 teachers also reported the "invisible" elements of culture such as values and beliefs. For example, Tam commented only on the observable elements:

Culture is what we contact every day, from the way you wear your dress, the way you greet others Culture can also be seen in festivals, religions (Tam, S1IT8)

In contrast, Ha talked about invisible elements of culture and culture's role in communication:

Culture includes unwritten rules. For example, on the first day of Tet [Vietnamese Lunar New Year] we should not sweep our house since people believe that sweeping the house will bring misfortune to the family, like sweeping all your luck out of the house. Knowing culture also helps us to understand others in our conversations. (Ha, S1IT12)

The "visible" or "invisible" elements of culture that the teachers referred to are similar to the various cultural elements that form the outer layer of culture (e.g.: behaviors, costumes, food, languages) and the layers of norms and values in Trompenaars and Hampden - Turner's (1998) terms. These teachers' descriptions also included cultural elements that form different levels of culture in Ting - Toomey and Chung's (2005) onion model, such as the surface level 
(cultural artifacts such as Vietnamese Dong Son drum); the intermediate-level culture (customs and language), and deep level culture (traditions, values, beliefs).

Two teachers noted how culture is changeable, reflecting Faulker et al.'s (2006) emphasis on culture as a process. As Tu commented:

I see many changes in culture. Many things which did not exist in Vietnam before are now popular. For example, people celebrate Valentine's Day or Christmas Day. Even kids at kindergarten know Halloween. Our generation did not have any notions of these days. So, if we do not catch up, we will lag. (Tu, S1IT4)

Similarly, Nam commented:

Culture to some extent is relative. What was not good before may be accepted now. For example, in Vietnam, it was considered bad for young people to live together as husband and wife before marriage 20 years ago. Now, we do not encourage trial living - living in a house as husband and wife before marriage (sống thử) but we do not judge that as bad. (Nam, S1IT5)

Nam's statement implies that her generation's view about trial marriage was more open. However, the way she saw the changes as occurring in a whole generation suggests a view of culture as monolithic. Such a view underplays the variations that exist among different individuals in the same generation, and of the same age and gender.

Two teachers explicitly gave a static view of culture. They perceived culture as a fixed system of rules in a society. As Bay put it:

When we mention culture, we mean a society's systems of behaviors that regulate people' behaviors such as acting properly in the right place. People have to follow the social norms. For example, in Vietnam, we have to follow hierarchy in a family or the employer-employee relationship. (Bay, S1IT7)

As regards culture in language and communication, eight teachers mentioned the relationship between culture in language such as culture in linguistic forms and pragmatics. For example, Bay said about culture in language

It is interesting how culture affects language. In Vietnamese, we do not add anything after a verb to show that the action is in the present continuous or present perfect. We also have no notion of the present perfect. (Bay, S1IT7) 
Referring to culture in pragmatics, Luc mentioned culture in vocabulary use through the use of "to be" in the passive voice. In English, "is/ are" are fixed when used for the passive voice for singular/ plural subject(s) while in Vietnamese, the words used for "to be" can be duợc/ bi for both plural and singular, carrying negative/ positive/ neutral meaning depending on the context. Similarly, Nam and Bay commented on other examples of culture in pragmatics such as using "you" and formulaic greetings:

It is hard to trace the reasons why English has only the word "you" for the second person in a conversation. We, Vietnamese have many words to refer to the other person in a conversation depending on the relationship, age, and gender. They are because of cultural differences. (Nam, S1IT5)

I think that culture is comprised of what people often do daily according to the popularly accepted ideology in the society. For example, people should know what kind of clothes they should wear, how to express their politeness to the old. In teaching English, I think that the simplest thing like how to greet someone is very different in English and Vietnamese and this reflects cultural differences. In Vietnam, we often greet by asking where are you going or have you had lunch/ dinner? You see, it may sound strange for native people if asked such a question. (Bay, S1IT7)

Another teacher, Dong, mentioned cultural meaning in language. She stressed the cultural influence on the meaning of proverbs such as the Vietnamese proverb "trời sinh voi trời sinh có", which advises people not to worry too much about their troubled situation. She further argued that, this Vietnamese proverb has another layer of meaning that has no equivalence in English. It means people can give birth to many babies and there is no need to worry about food to feed them. This proverb reflects old Vietnamese beliefs that Vietnamese should have many children so that they can depend on them when they get old. These comments show Dong's acknowledgement of the Vietnamese people's beliefs in the proverb, which might indicate her understanding of the cultural aspect reflected in the language.

Also, all teachers reported that culture was related to communication, such as ways of speaking and writing, cultural concepts, taboos, and non-verbal language. For instance, Ngoc believed that directness and indirectness were two different manners of communication between Vietnamese and Westerners. Xuan added: 
Ways of communication are different between cultures, e.g., Westerners go straight to an issue, whereas Vietnamese often beat around the bush before going to the focus of the conversation. For example, if I come to my friend's house and would like to borrow something, I would spend time talking about many other things before asking her to lend me something. (Xuan, S1IT11).

Two teachers, Tam and Chin, noted that culture in communication involved cultural topics in small talk such as the weather talk in common conversations among English, talk about location among Americans, and talk about personal matters among Vietnamese. Tam said:

English people talk about the weather when they meet, we [Vietnamese, both men, and women] can ask about marital status or age, which should be avoided in English culture. (Tam, S1IT8)

In summary, teachers gave a range of definitions of culture including culture as visible and invisible. All of them emphasized cultural practices and the significance of cultural knowledge in communication. The explanation provided by most teachers indicated a rather static view of culture. Only two teachers commented on the changeability of culture.

\subsubsection{Role of Culture Teaching in Foreign Language Education}

The analysis of data from interviews reveals two themes related to teachers' perceptions of culture teaching in foreign language teaching (a) the marginal role of culture teaching in language teaching, and (b) the culture knowledge focus for a job-oriented goal.

\section{The marginal role of culture teaching in language teaching}

All teachers reported being aware of the inseparable relationship between language and culture as well as the significance of raising students' cross-cultural awareness. However, their responses indicated that culture was marginalized in their teaching, including limited attention in their lesson planning and textbook.

All teachers stated that they had never deliberately included any culture learning goals in their lesson plans. Twelve teachers said that their lesson plans were largely based on textbook materials, which aimed at improving students' linguistic knowledge and language skills. In situations where they added extra materials in their lessons, these materials were for language teaching purposes. Muoi and Chin commented: 
When we design lessons, we have to follow the textbooks. As you know, textbooks include sections such as vocabulary, grammar, reading comprehension, listening, and speaking. Therefore, the goals are to help students speak, listen ... better. (Muoi, S1IT10)

Sometimes I give students extra exercises. For example, when teaching listening to environmental topics, I google for a similar listening task about the environment so that students learn more words about the environment and listen better. (Chin, S1IT9)

Apart from focusing on language skills in planning lessons, teachers stated that the integration of culture teaching heavily relied on textbook materials and/or topics that sound "cultural". All teachers reported that the set topics for lessons determined whether culture was included in their lessons. Chin said:

When I teach students speaking skills, if the topic of the lessons relates to culture, for example, "greeting", I will spend some minutes talking about some cultural traits that I know in English culture. (Chin, S1IT9)

Luc commented:

I often teach writing and reading skills to students in their year 3. Reading at this level involves many academic and scientific issues such as climate, solar energy. I find no cultural elements relevant to talk about because the climate and fossil fuel are something related to science, I mean the truth, it has no relation with people's values or beliefs. (Luc, S1IT6)

In addition, teachers perceived that integrating culture in language lessons was optional. For example, Tam insisted that the ultimate objective of training students is to help them become competent language users, so language training should primarily focus on linguistic components. She stated that time for culture should be limited. She explained:

I think that we do not deny the relationship between culture and language. However, we have to focus on vocabulary and grammar, and language skills such as speaking, listening, writing, and reading. These skills will definitely help students in their future work. I think we should make the most of our time in class for teaching language, just sometimes mention culture, which should not account for more than $5 \%$ of the lesson time. (Tam, S1IT3)

Eight teachers suggested that culture teaching could be like "some spice, bringing more flavor to the EFL dishes" (Nam, S1IT5). They further emphasized the role of a separate 
culture course in preparing students for their future intercultural communication. Two teachers remarked:

It is good if students know something about culture in our EFL lessons. Anyway, we try but it is not our responsibility to teach culture. Maybe students can learn it [cultural knowledge] in a separate culture course. (Tam, S1IT3)

Our job is teaching English, not culture. So, we are not obliged to teach culture. We just provide students with extra knowledge outside the course descriptions that we know. (Chin, S1IT9)

\section{Goals of culture teaching}

As mentioned above, teachers rarely included cultural goals in their lesson planning. However, when asked about their goals for the times when they incidentally taught aspects of culture, teachers' responses indicated that they had two goals: to support students' target language use; and to prepare students for their future intercultural communication.

Firstly, all fourteen teachers stated that culture teaching contributed to students' target language use. They held the view that if they taught culture, students would be more aware of the cultural differences, thus they would pay more attention to the relevant expressions to use in specific situations. Additionally, eight teachers highlighted the positive effect of the cultural information on students' interest in their EFL lessons. Tu explained:

If students have more cultural knowledge, they will probably communicate better. For example, instead of asking a British person "Have you had lunch/ dinner?" as a way of greeting, they will say "How are you?". (Tu, S1IT4)

I occasionally provide students with extra cultural information. As I observe, students express extraordinary interest in cultural content, which motivates students to study English. (Muoi, S1IT10)

Secondly, eleven teachers emphasized the significance of preparing students for their future intercultural communication, such as for communication in their jobs in international companies. Notably, they emphasized the need to provide students with cultural knowledge. They explained that cultural knowledge was knowledge about their own culture (L1 culture), target culture (L2 culture), other cultures, and cross-cultural awareness. Specifically, all 14 teachers mentioned L2 culture, five stated the need to understand the L1 culture, seven 
mentioned other cultures and seven teachers mentioned cross-cultural awareness. For example, Tan and Tam talked about the need to prepare students with cultures of native English speakers:

I often tell my students that they are studying English so they should imitate English natives, both in language and cultural behaviors. (Tan, S1IT8)

Cultural knowledge is very broad. Therefore, we just need to provide our students with cultures from the main English-speaking countries such as Britain, the USA. Students should learn about how to communicate, which words to use in which situations. (Tam, S1IT3)

Seven teachers mentioned the need to teach other cultures apart from English nativespeakers' cultures. For example, Luc suggested culture learning should involve culture from the countries potentially cooperating with Vietnam.

Vietnam is expanding its international cooperation and more international companies are being set up. Understandably, in the future our students are likely to work in these companies and they will communicate with people from many countries, not only native English speakers. So, it is a matter of course that they need to know cultures from many countries, especially from our economic partners such as America, Singapore, Japan, Germany, etc. (Luc, S1IT6)

It can be concluded that when these teachers teach culture, they do so to motivate students and to prepare them with cultural knowledge for future intercultural communication. More than half of the teachers also acknowledged the importance of teaching both English native speakers' cultures and other cultures.

\subsubsection{Approaches to Teaching Culture.}

When asked about how they taught culture, most of the teachers said that they hardly ever touched upon cultural elements in their classroom lessons although they were aware of its significance in language education. They had no plan to raise students' ability to communicate across cultures when they prepared their lessons. In some rare cases when there was a culture tip in the textbook, they would quickly read the tips to the whole class. For example, Muoi and Tam said:

I just read the culture tip in the textbook or ask a student to read that part aloud. (Muoi, S1IT10) 
Not often, sometimes there is a culture note in the textbook, and I simply tell the whole class that note. (Tam, S1IT3)

Two teachers said that culture teaching was not the focus of their lessons. They also did not plan to raise students' intercultural communicative competence when they prepared their lessons. However, at some point in the lessons when they could share any experience relating to intercultural communication, they would try to raise students' awareness and sometimes ask students to compare the foreign practices they were talking about with Vietnamese culture.

I do not include any culture in my planned lessons. However, it seems to me that culture is very interesting. I visited some places in foreign countries on vacations and noticed how people in different places communicated. In my lessons, I would share my experience when appropriate. For example, after I taught students how to greet in English, I shared my experience when I went to Japan. I saw people bowing in greeting to show respect. ( $\mathrm{Tu}$, S1IT4)

Nine out of fourteen teachers argued that the students themselves enriched their knowledge of culture without the teachers' explicit instruction through culture-topic language tasks in the textbook. Dong had a contrasting opinion. She insisted on the importance of the teachers taking an active role in preparing extra materials and designing cultural activities as a way of integrating culture into language teaching. She argued:

I think that teachers can search for more teaching materials and generate cultural activities to provide students with cultural and language knowledge and skills. As I noticed, even topics of many lessons in my current speaking course are culture-related, their contents are mainly grammar or speaking skills [tasks focused on language skills]. I mean the cultural content or activities are rare. If we do not explicitly involve students in exchanging information or conversation, they will shortly forget the content they read in the lessons. (Dong, S1IT14)

The culture class teachers reported that they had different teaching approaches when they taught in general classes and culture classes. When they taught general classes, they largely gave facts. However, they reported using various activities such as role-plays, problem solving, and discussion in culture classes. For example, Ha said:

When teaching about eating practices, for example, I can give students role-play activities in which students will act like people from different countries, for example, the Indian, the 
British. Indian people will use their right hands for food and the British have their way of using a spoon to eat soup. (Ha, S1IT12)

Ha reported that she exposed students to culture learning activities in her CCC lessons. Her students mostly listened to teachers and followed teachers' instructions in mimicking the target culture behaviors in role-plays. While opportunities for reflection were rare, the cultural activities did involve students in experiential learning activities. Overall, general EFL teachers' explanations revealed a cultural teaching approach as giving facts. CCC teachers' responses indicated more experiential learning opportunities for students.

\subsubsection{Culture Teaching Constraints}

When asked about obstacles in their integration of culture into general EFL lessons, most of the teachers reported main obstacles such as teachers' limited cultural knowledge, shortage of culture teaching materials, limited time, students' English level, and assessment and course objectives. These categories are discussed in detail below.

\section{Teachers' Limited Cultural Knowledge}

Thirteen in fourteen teachers contended that their limited cultural knowledge was an obstacle in teaching culture. Teachers pointed out that they should be trained specifically for teaching culture such as how to teach, and how to design cultural activities. One teacher stated that only when teachers had a lot of opportunities to be immersed in a target culture could they teach culture confidently. As Tu said:

Most of the knowledge we obtain is from books. But life is not all reflected in books, not to mention culture is changing and we grasped knowledge from outdated books. Without living in the target culture, we cannot ascertain whether what we tell the students is still proper. $(\mathrm{Tu}$, S1IT4)

Xuan further explained the challenges in teaching culture when she lacked knowledge of the diversity in cultures that people use English. She explained:

It is hard to explain to students in detail because people speaking English come from different countries and even different regions in a country may have different ways of speaking or behaviors. (Xuan, S1IT11) 
The teachers also expressed that their limited cultural knowledge was their prime obstacle in culture teaching. Only Dong stated a different view. She stressed the role of the teacher as a facilitator in culture teaching, assisting students in constructing their knowledge. For her, it was not the pre-requisite that the teacher should be profoundly knowledgeable about the target culture. She was more concerned about teachers' pedagogical competence in inspiring students to engage in building their knowledge. As she said:

What matters is teachers' pedagogical approaches and enthusiasm. How teachers can implement activities and motivate students in their learning are what counts. Regarding knowledge, I think we can update with the help of digital development. (Dong, S1IT14)

To sum up, limited cultural knowledge is considered by the majority of the teachers as the main obstacle to culture teaching. Only one teacher believed that teachers' role in creating intercultural learning opportunities was more important than teachers' cultural knowledge, and thus, teachers' limited cultural knowledge was not a major obstacle.

\section{Shortage of Culture Teaching Materials and Limited Time}

Most teachers maintained that a shortage of culture teaching materials and limited time were other obstacles. They explained that they mainly followed textbooks, which lacked cultural activities. Additionally, they revealed that could not include their designed cultural activities because of a lack of confidence in designing tasks and limited sense of obligation in carrying out intercultural activities.

When asked about the reason for little time devoted to culture teaching, most of the teachers (10 in 14) reported that they had to prioritize language objectives. They added that even if they thought about culture content, the workload did not allow them to integrate culture into the lessons. If they tried to include culture, they could not cover language skill contents. One teacher reasoned that if students in a class engaged in a lot of cultural activities, they would be deprived of equal chances to build up their language knowledge. For example, Ha's position was illustrated in the following extract:

We have to teach from 30 to 35 periods a week. Following the book is even more than enough for us. We need to cover all necessary grammar so that students can pass the tests. If I teach my students culture, they cannot have enough time for language as students in other classes, so they may get lower marks than others. (Ha, S1IT12) 
Tu held a contrasting position. She stated that culture teaching depended on teachers' flexibility and willingness. She argued that learning culture could be an effective way to broaden students' language skills so that students could gain both language and cultural skills.

It is undeniable that we have a lot of language teaching tasks. However, if we remove the easy parts, let students do them at home and reserve class time for cultural activities, I am sure that students will embrace that idea. (Tu, S1IT4)

Tu added:

If a teacher wishes to teach culture, she will arrange a time for cultural activities, put a lot of thought into how to make students feel intrigued by the activities. (Tu, S1IT4)

To sum up, many of the teachers claimed that the workload prevented them from making time to integrate cultural content into their lessons. These teachers also reported facing time pressures in preparing students for language exams. Only Tu did not report any problems with the workload.

\section{Students' Low English Proficiency Level}

Students' low level of English proficiency was noted by 11 teachers as one of the obstacles that hindered culture learning. These teachers claimed that learning culture required a certain level of language proficiency as a prerequisite. Additionally, teachers suggested that grasping language knowledge initially would equip students with skills to study and students could use that transferable skill when learning culture. As they said:

When I teach students, especially freshmen and year 2 students, I notice that they struggle with grammar and have a very limited range of vocabulary. They should be able to use English fluently. At the level of B1, I think that they can have sufficient language to exchange ideas with friends in cultural activities. (Nam, S1IT5)

Culture learning also requires certain skills, I think so. If students learn skills such as speaking, listening, reading, and writing in some semesters, they can apply those skills later when they study culture. (Chin, S1IT9) 
One teacher expressed concern about students' readiness for culture teaching from a psychological perspective:

Normally, students do not want to make mistakes or appear foolish in front of peers. To be safe, they will try to study vocabulary and grammar first. Once they feel confident in speaking, they will be eager to participate in cultural activities. (Luc, S1IT6)

In contrast, two teachers argued that students' level of English proficiency was not important in learning culture. They said that what students should learn is cultural knowledge, not language skills. Thus, they could use their mother tongue to express their ideas when engaging in cultural activities. They noted that teachers should use mother tongue to convey ideas when students do not seem to understand.

In fact, when I teach culture classes, students sometimes find it very hard to talk about certain topics such as marriage. I often allow students to present their ideas in Vietnamese in that situation. (Dong, S1IT14)

I do not think that students' English levels really matter. We want to give them some knowledge about culture such as how people address in America, what distance is considered a public zone or intimate zone between a man and a young woman in Britain, etc. We do not teach English skills in teaching culture. (Tu, S1IT4)

Ha argued that culture teaching should commence right from the beginning because language and culture are intertwined. She commented:

I think that it would be a waste of time if we teach language and wait until they master some high level of competence then we teach culture. How could students use the language during the gap time then? And they have to come back again to the same language when they study culture, a waste of time. For example, you teach students the expressions to greet in English. Your students may come to greet Japanese people and American people with the same English sentence. But if they do not know that the proper gesture and facial expressions accompanying the utterances should be varied for communication in those cultures, they will fail easily in communication. (Ha, S1IT12)

It can be concluded that students' English proficiency level was a major concern among many of the teachers while a small number of teachers did not see students' low English level as a barrier to culture teaching. 


\section{Assessment and Course Objectives}

Regarding the impact of assessment and course objectives, ten teachers stated that they followed the description of course objectives, which focused on language skills. Only three teachers reported that they taught both culture classes and other general English classes and only the objectives of culture classes focused on culture teaching. All teachers held a similar position concerning testing in general EFL classes. They reported that all language tests were not deliberately designed to test students' culture learning. Instead, the focus was on language use, grammar, and language skills. One teacher further stated that teachers did not feel they should be obliged to teach culture and they said that they thought students did not think they should remember any cultural elements since they would not be assessed explicitly.

I have been teaching here for more than ten years, designing tests, and supervising a myriad of English tests. There is no cultural element in tests. We care about such things as whether students can listen to general information or specific information, choosing the right tenses when writing and speaking, using the right word. I think that is the cause that downgrades teachers' motivation in culture teaching. (Bay, S1IT7)

We do not assess students' cultural knowledge in language examinations. Therefore, the cultural activities that we have in the lessons, if any, are just to enlarge their knowledge. Students will not feel obliged to get involved in these activities if they do not wish to. Even for us as teachers, we do not feel it is our responsibility to raise students' cultural awareness. (Tan, S1IT8)

We should be practical. We are aware of the importance of teaching culture. But the question is what our efforts are for if that knowledge is not assessed in the exams. (Luc, S1IT6)

One teacher explained that the current teaching practices were the consequence of having no culture content in tests. She predicted that this would change if cultural content was assessed.

I believe that once teachers are guided to assess culture learning in some way, tests will have different shapes and content. Then teachers will think about how to help students score the best, they will change their lesson content and put more culture into the lessons. Students will have to learn culture. When culture teaching is supposed to be teachers' tasks, it will not their choice, but their obligation. (Nam, S1IT5)

A conflicting view was presented by $\mathrm{Tu}$. She advocated the idea of teaching culture even culture learning was not a component of tests. She contended that the focal point of language 
teaching was not merely assisting students to score high in tests then forgot what they learned after the tests. She highlighted the significance of helping students to reach the target of successful communication.

As I observed, students were more like to memorize informal stories that sometimes teachers shared. I felt that they were more relaxed, compared to the intense faces when they learned something from books. How can students absorb the knowledge if they feel intense? If students learn culture under no pressure and without any fear of culture test ahead, these cultural lessons will sensibly stay long in their minds for future use. (Tu, S1IT4)

In summary, the teachers expressed similar views on their conceptualizations of culture and the role of culture teaching in the context. For them, constraints in culture teaching included limited culture knowledge, shortage of teaching materials and limited time, students' English level, and assessment and course objectives. A minority of the teachers contended that students' English level and assessment should not be the factors that prevent the teachers from addressing culture in class.

\subsubsection{Findings From Student Focus Group Interviews}

Ten student focus groups were asked about their aims of learning English, their conceptualizations of culture, their cultural learning in class, perceived factors affecting their success in intercultural communication, their needs and willingness to learn culture, and obstacles in their culture learning. Their responses revealed three main themes: understanding of culture, expectations in learning culture, and constraints in culture learning.

\subsubsection{Understanding of Culture}

The theme "understanding of culture" can be divided into two sub-themes: culture as facts and behavioral norms; and culture as a random add-on in EFL classes.

Culture as Facts and Behavioral Norms. When asked what they thought about culture and culture learning in EFL classes, Year 3-4 students and Year 1 students responded differently. The Year 1 students had all just graduated from high school, where their EFL lessons were grammatically focused. They had little idea of culture learning. They reported not having thought about differences in people's values across cultures. For them, the key to be successful in speaking with speakers of English was to produce sentences with the right word choice and proper grammar. As a student said: 
We have just graduated from high schools. As you know, we come mostly from rural areas. Teachers in our high school only gave us grammar exercises. We had little chance to speak English. We never talked to people from other countries. We came here to study English so that we can work in international companies when we graduate. We think that the key to becoming successful in our communication with people in international companies is to speak English well, with accurate grammar and a large vocabulary. (An, S1FG1, year 1)

Nine students in the Year 1 groups attached culture learning to learning about cultural artifacts, traditions, religions, and festivals.

I guess culture learning in language is the studying of such things as traditions in different ethnic minorities in Vietnam such as the H'mong people, or festivals such as the Tomato Festival in Spain or Mud Festival in Korea. (Binh, S1FG2, year 1)

In addition, most of the Year 3 and Year 4 students in the focus groups defined learning culture as getting information about people, countries, and especially people's behaviors.

To be honest, when we first entered university, we did not have any notion of culture or culture in communication until we reached year 3. In years 1 and 2 we just followed the textbook with structures and vocabulary and learned by heart. We also learned to improve speaking, reading, listening and writing skills. From year 3 some of us took part-time jobs in restaurants with guests from foreign countries such as America, Japan, Korea, and Germany. Sometimes we misunderstood them and they misunderstood us. Then we realized even when we tried to say sentences with correct grammar, problems in communication still could occur. They had their own ways of saying and doing things. Very rarely, our teachers mentioned it briefly in class; for example; if we learned the topic Pets, then there's a saying "Love me. Love my dog". And we know that different from our culture, dogs are considered close to people in some countries. We Vietnamese can eat dog meat. If we invite them to eat dog meat, they will not feel good. We are interested in such cultural knowledge". (Tam, S1FG2, year 4)

It seems that students' views about culture and their awareness of the need for culture learning developed as they proceeded through their learning from little awareness of cultural differences (Year 1 students) to cultural awareness (Year 2-4 students). However, the conceptualization of culture remained limited to culture as facts and behavioral norms.

Culture as a Random Add-on in General EFL Classes. All ten groups of students were asked to describe common activities in their EFL lessons. They responded that teachers 
depended heavily on textbook materials in their delivery of lessons and focused on language skills. Thus, they hardly recalled any other learning activities rather than language focused activities. When I referred to culture learning, most students in year 2 and year 3 claimed that they rarely had a chance to engage in cultural activities. Rather, in rare cases, they just listened to the teachers giving some information very briefly from textbooks or teachers telling them their experience. As one student said:

Often in all subjects speaking, listening, reading and writing, teachers follow steps like asking us some questions then ask questions in books before reading, listening, etc. tasks. Teachers can pause to explain new words or grammar. In general, we learn through books. (Son, S1FG4, year 3)

I remember a long time ago, my teacher mentioned how Westerners used their spoon to eat when we learned a lesson about eating. But rarely did she add such information. And she just quickly told us little bits of information. We also do not pay attention to the culture notes in textbooks much because sometimes teachers read them, sometimes they ignore these notes. (Si, S1FG6, year 3)

Four students in a group of Year 2 students perceived that they were learning culture while the textbook content sounded "cultural". As Do commented:

It depends on the topic of each lesson. For example, when we learned about celebrations, our teacher asked us to answer questions in textbooks about celebrations. I think that is a way of learning about cultures. If the topic is about other things, like technology, of course, no culture is there to be learned. (Do, S1FG2, year 2)

This student's comment is in line with the teachers' comments in section 4.3.1. Overall, it can be concluded that culture teaching was rarely evident in the general EFL classes.

\subsubsection{Expectations in Learning Culture}

The students were asked about what they expected to learn in their EFL classes. Year 1 students only mentioned goals of language and skills achievement. When I provided them with examples of cultural activities, they said that "We have had no ideas about these activities before". In addition, they showed excitement about the possibility of doing cultural activities in their later lessons.

Wow, it would be great. We really like the idea. (Canh, S1FG3, year 1) 
Though cultural activities were rare in their EFL lessons, Year 2-4 students were impressed by those activities. They expressed their desire to engage in activities.

We want to have cultural activities in every topic that we learn in class". (Men, S1FG1, year 2)

We would love to have more chances to role play, to discuss, and especially chances to talk with non-Vietnamese speakers of English. We need more real-life communication in English with people from other countries. (Mi, S1FG2, year 3)

We would like to have many chances to participate in culture learning, not in one subject but many subjects in English learning. For example, just sometimes our teacher in speaking class tells us a piece of cultural information. In other subjects such as listening, reading, writing our teachers never gives us related cultural information. And it will be more interesting if the time for cultural learning is longer and teachers give us activities such as role-plays, and guessing. Normally, we just listen to the teacher saying some sentences. (La, S1FG3, year 3)

Year 4 students who had attended culture classes expressed their interest in cultural knowledge and cultural activities in the class. They expressed a desire for more real-life contact with people from different cultures and for chances to listen to real-life stories or experiences.

When asked which culture topics they would like to study, all groups of students in Year 1 noted that they had no idea and they just followed what their teachers told them in class. One group of students in year 2 also expressed the same view. The other groups of students in years 2-4 said that they prefer cultural activities from their lesson topics.

If the lesson is about food, cultural activities should relate to eating or things like that. (Toan, S1FG2, year 3)

Most of the students in the Year 4 groups suggested that it would be better for students to participate in cultural activities in all English skill classes. It would better than the current context in which little culture was mentioned for the first three years in EFL classes, and then students had to rush in a quick culture course in year 4 .

When asked about when they thought would be appropriate for culture learning, most students from the Year 1 groups initially had no ideas. When I explained about cultural activities, they expressed the same view as most students from the Year 2-4 groups. They 
would like to engage in culture from year 1 because this would allow them to build cultural knowledge over time.

We definitely vote for the option that we have a chance for culture learning from the first courses in year 1. (Hung, S1FG3, year 3)

I am in year 4. Looking back, I wished that I had opportunities for cultural learning since I entered this university. Learning in year 4 we have to rush and cannot fully concentrate on the lessons. We have a lot of things in mind about going to get a job. (Manh, S1FG1, year 4)

The students said that they would like to have cultural activities in all lessons and they would prefer a variety of activities.

When asked what cultures they would like to study, the culture of native English speakers, or any culture, Year 1 students said that they would like to follow native speakers as the model.

We think that we are studying and it is a matter of course that we should follow the way English speakers say, and learn their behaviors. (Duc, S1FG2, year 1)

In contrast, Year 2-4 students were more interested in broadening their knowledge of how people around the world behave. They were aware that English is the means of communication among people from many cultures, not just native English speakers. Most senior students advocate the intercultural speaker model because they are aware of the need to communicate in international companies. For example, Hoa said:

I know that many international companies are operating in Vietnam and they recruit employees. If when we graduate and want to work in those companies, we will use English with people from many countries, not just people from Britain or America. Therefore, we have to know their cultures, their behaviors, the way they use English. (Hoa, S1FG1, year 3)

To sum up, students in the Year 1 group had different needs for culture learning than the other groups. Overall, senior students expressed a greater need for culture. The reasons might be they had more life and university experience, which helped them better understand the value of culture and knowledge of cultural diversity for their future intercultural communication. 


\subsubsection{Constraints in Culture Learning}

The students were asked to describe their difficulties in culture learning. The students from different year groups had different experiences and constraints. The student groups from year 1 had no comments while the students from year 2 and year 3 believed that they had no difficulties in learning culture. Students in their last academic year, who studied culture class, noted three main obstacles: insufficient language proficiency, lack of real-life experience and the time pressure to complete other subjects' assignments in their final year. They said:

Our teachers in other subjects gave us many assignments. We are also preparing to look for jobs. The culture class is very interesting and useful to us, but we cannot devote our time to the search and preparation for the culture class. To tell you the truth, sometimes I have to complete my assignments from other subjects when I am attending culture class. (Long, S1FG1, year 4)

Yes, we cannot fully concentrate on the culture lesson. (Ha, S1FG1, year 4)

Though we are in year 4, we find it tricky to express cultural themes in culture lessons. For example, when we presented marriage customs in Vietnam, we could not remember all the words relating to the topic. So, we had to present in Vietnamese the part that we do not know how to say in English (Loan, S1FG2, year 4)

One Year 4 student expressed the difficulties when she lacked real-life experience in intercultural communication so she could not actively participate in culture lessons.

We primarily communicate with friends, teachers, and families. They are all Vietnamese. We want to contribute something real life that we know to make the lessons more interesting, but we cannot. (Trang, S1FG2, year 3)

Overall, the students saw language ability, real-life experience, and time pressures as their barriers in learning culture. These comments conformed to teachers' views in section 4.3.1.

\subsubsection{Findings From Employer and Graduate Interviews}

Six employers were asked in individual interviews about the significance of "intercultural skills" in their international companies, the roles of intercultural skills, and their evaluation of the intercultural skills of six employees - who graduated from the university in this research and their suggestions for EFL teaching in this context. The six graduates were asked about 
their reflections on culture learning in the research context, their views of intercultural communication in their workplace, and their recommendations for culture teaching in the context. Data from these interviews revealed four main themes: the significance of intercultural skills in international companies, the "attitude" factor in the workplace; employees' limited intercultural skills, and suggestions for culture teaching at the university.

\subsubsection{The Significance of Intercultural Skills in International Companies}

All employers and employees defined intercultural skills as the ability to communicate successfully with people from different cultures in international companies. They further noted that to communicate appropriately, people should have good knowledge of cultures, good attitudes as well as good communication skills in business, such as persuading. They pinpointed that intercultural skills were critical for the relationships in and development of a company as well as with other partners and clients. Employers' views are illustrated in the following extracts:

We are an exporting - importing company and we have to deal with customers from many countries. Even if we communicate in English, our manager is from China. So, to communicate well, employees need to understand Chinese culture such as the way we show respect to the manager. In our business, sometimes we have to negotiate with partners during lunchtimes so we hope our staff will know even the small things such as who should drink first. You know, it is considered bad luck if you turn the fish over in our culture. If our client is Chinese and our Vietnamese employee does not know this, misunderstanding may occur. (Hai, S1EI3)

In the workplace environment, employees are the face of our company when dealing with clients. So, we have to make sure that our employees possess good communication skills. They know how to deal with not just Vietnamese but people from many countries. This is also one of the criteria for us to give employees a higher position or salary after a period of time working with our company. (Hai, S1EI3)

The employees shared a view that their job efficiency and chances of promotion largely counted on their communication skills.

My job requires me to contact customers every day in English. They come from Germany, Japan, and mostly from India. If the customers are not satisfied with me, they will not order 
our products and the sales will drop. You can imagine my chance of promotion will reduce if I cannot work well. (Toan, S1GI1)

I observed one of my workmates who missed a chance for a work promotion. He has good expertise in technical work. However, he does not know much about cultural differences and has a lot of difficulties in communicating with people from other cultures. (Ly, S1GI2)

Overall, comments from employers and graduates show that both employers and employees viewed the ability to communicate interculturally as a significant skill for employees in these international companies in Vietnam. While mentioning many factors that led to successful communication, they highlighted the importance of positive attitude, which is discussed in detail below.

\subsubsection{The "Attitude" Factor in the Workplace}

Employers listed some factors leading to successful intercultural communication. Four of the six employers noted that attitude was the most significant factor. They contended that if employees possessed a positive attitude, they would work to best fit in the working environments by observing others' behaviors and figuring out what they should do. Their views are illustrated in the following extracts:

I believe that the attitudes of the employees will decide everything. Of course, they need to know the culture of the people that they work with. But no one knows everything. Moreover, life is complicated. For example, they learn from books that Japanese people often bow when they meet. But not all Japanese do. I know a boss who comes from Japan but he travels a lot and he likes a different way of greeting. What I mean is the employees should be flexible, open to learn new things, observe others and decide on the actions that suit. (Hanh, S1EI1)

My company belongs to the hospitality industry. We have recruited some graduates, at different times, from your university for the receptionist position. I think that what makes the communication with tourists from many countries successful is that students have basic knowledge of culture such as greeting, thanking, offering for help, asking for information, answering the phone, answering customers, etc. I think that universities cannot teach them all so they need to have a good attitude, always try to be polite, be patient, and always aware that misunderstanding may occur, and do not show their anger even if they think something is ridiculous. The other thing is to be always flexible and watch how people behave and learn from that. (Huong, S1EI2) 
What we expect from employees are their flexibility and great communication skills. If employees are not experienced enough in their technical skills, we are confident that we can train them professionally. But if they do not possess a positive attitude and communication skills, they will easily fail. (Hanh, S1EI1)

In the employees' opinions, important factors in communicating include linguistic competence, cultural knowledge, and attitudes. Their responses also indicated an emphasis on open attitudes:

To be successful in communication in an international environment, I think we should have basic knowledge of behaviors in the cultures of the countries our workmates, bosses, and clients come from. More importantly, we should also be flexible and open to differences because the ways a person acts do not always follow the majority of people in his or her culture. (Su, S1GI4)

In summary, both employers and employees emphasized that attitude was important for intercultural communication. A positive attitude includes attributes such as curiosity, openness, and tolerance in intercultural communication, which are consistent with attitudes in Byram's (1997) model of ICC.

\subsubsection{Employees' Limited Intercultural Skills}

The employers were asked to evaluate their employees' communication skills in using English with people from other cultures in their companies. These employees have recently graduated from the university where the research was conducted. All six employers shared the same view that during the first days on the job these employees had a lot of difficulties in communicating with their workmates, customers, and employers due to their limited cultural knowledge, improper attitudes, and limited interaction skills. They reported that the difficulties hindered their chances of promotion in their workplace.

Long clarified his employee's shortcomings in communication. He claimed that this graduate was too dependent on what she learned at university, which prevented her from being flexible and sometimes caused her to encounter misunderstandings. He illustrated his view as follows:

I can tell you an example, a simple example. I guessed that in your university students may listen to a recording in which people can respond to peers' offers for help like "OK, thanks". I observed a similar situation in my company between your university graduate, $\mathrm{Su}$, and a 
workmate from the UK. This man really cares for words, we know him very well. So, one day when he kindly offered to help her and she simply said, "Thanks", the workmate did not appear to be happy. He would wait for longer sentences showing appreciation. And he would think that Su was not polite enough. Su should have observed how her workmate often behaved and interacted with him appropriately. (Long, S1EI4)

This example might indicate that the employee had not been observational enough and thus, not flexible and not displaying the desired interactional skill. In another example, Huong commented on Ly's attitudes:

Ly is polite and always tries to obey the company's rules. However, she appears to avoid confrontation in our meetings. Here in our company, we love to hear direct opinions. (Huong, S1IE2)

In Huong's opinion, Ly did not adapt to the differences in cultural values in Huong's company. She acted according to what she considered polite in her own culture without relating to the culture in her company, thus Ly did not interact as expected.

The employees also revealed that they knew many students who failed in job interviews because they were not interculturally competent during job interviews. These employees noted that their cultural learning history during their time at university greatly influenced their communication in the workplace. As they said:

The teachers at my university did a great job raising my awareness that cultural differences exist. To tell the truth, before attending the culture course, I just thought about grammar and vocabulary as sufficient elements for making sentences to talk with people in English. However, I still faced a lot of difficulties in the early days working in this international company, while at university I was guided to follow English native speakers' models, in this company, no behavior is the model. English is the only tool. It depends on where your partner in the conversation is from and you should flexibly interact. (Dia, S1GI5)

When I worked as an office staff in a language center, most of the teachers I contacted were from English-speaking countries, so I could apply what teachers taught me in the culture course and the English-speaking skills in the speaking course. However, when I moved to this Japanese company, things were different. I need to know who the person I am talking with is or writing to so that I could use English properly. I have to consider my body language. I wish we had more chances to notice and contact people from many cultures since we first started university education. (Sinh, S1GI6) 
The employers' and employees' comments showed that students from the university were not well equipped for their intercultural communication in international companies. Specifically, the employees highlighted that their university cultural lessons focused on native speakers' culture, which, according to them, was not sufficient.

\subsubsection{Suggestions for Culture Teaching at the University}

The employers suggested that teachers should enhance students' intercultural skills for future intercultural communication. They said that teachers should also pay more attention to teaching authentic English, which people often use for their work. They also recommended that teachers should provide students with cultural knowledge of the target language as well as other cultures. In addition, they stressed the importance of paying attention to awareness of cultural differences, good attitudes, and flexibility in communication. As Long said,

I think that the university should prepare students with cultural knowledge and help them form a good attitude. Formulaic exchanges of information in the workplace are easy to learn.

But how to deal with many people from many cultures in a company is very complicated so potential employees should always have an open attitude, do not conclude that whether a person is good or bad based on their own culture, and most importantly, adjust their behaviors to suit the specific working environment, specific workmate or client or boss. (Long, S1EI4)

The graduates suggested that students should be taught culture as early as possible and culture teaching should be integrated into language teaching with more chances for sharing life experiences and problem-solving tasks. They contended that it would have been better if their linguistic knowledge had been improved in parallel with cultural knowledge.

Culture is something we cannot absorb in a single subject. We are aware that the culture course helps us in some way. However, in many cultural activities when we studied, we expressed ourselves in Vietnamese because we did not know how to express it in English. And the culture course gave a lot of theories and we needed a lot of practice. If the cultural content is combined into the topic lessons in all skills subjects throughout the whole time at university for future intakes of students, I am confident that their cultural knowledge and skills to communicate with people from different cultures will enormously increase. (Dia, S1GI5)

I think that for students in future intakes, teachers should teach culture in speaking lessons as early as possible so that in every topic students will know how to communicate successfully. 
For us, we had to wait until we were in year four to begin our understanding of cultural differences. (Sinh, S1GI6)

In summary, both the employers and employees believed that intercultural skills, especially attitudes, were crucial in an intercultural business environment. Additionally, they believed the graduates were not adequately prepared for intercultural interactions in their companies and that this problem should be addressed in the university's English program.

\subsection{Summary of Findings}

Study 1 investigated how the intercultural content were addressed in EFL classes at a Vietnamese university. The investigation encompassed five sources of information (1) the representations of culture and intercultural content in EFL classes, (2) teachers' perceptions of the role and value of culture in language teaching and learning, (3) students' perceptions of the role and value of culture in language teaching and learning, (4) graduates' reflections on their past culture learning at the university, and (5) employers' evaluation of their graduates' intercultural communication competence. Findings from all these sources showed teachers' little attention to culture in EFL classes, teachers' limited understandings of culture, and their constraints in addressing the inter(cultural) dimension of the lessons and students' great interest in culture learning. Reflections from graduates and employers' comments also showed the need for fostering intercultural learning in this Vietnamese EFL tertiary context.

\subsection{Chapter Discussion}

The reported findings in Chapter 4 provide a comprehensive picture of culture teaching and learning in the research context. The remainder of this chapter discusses the key findings and relates them to relevant research on ICLTL.

\subsubsection{Representations of (Inter)cultural Content in the EFL classes}

Observations were conducted in general EFL classes and culture classes. Section 4.5.1.1 and 4.5.1.2 will discuss findings from each type of class.

\subsubsection{1 (Inter)cultural Representations in General EFL Classes}

The analysis of the classroom observations and SRIs from the general classes generated four main themes: cultural content in textbook, teachers' explaining cultural content, explain 
culture-laden words, and explaining culture in general text structures. These findings provide both positive evidence of and challenges in addressing the dimensions of culture in language teaching and learning in the context.

Observation data revealed positive evidence of teacher engagement with (inter) cultural topics. However, these instances were limited and teachers tended to focus on factual knowledge of culture. Findings also indicated three main challenges in addressing culture: heavy dependence on textbooks, the peripheral role of intercultural content in skill-focused EFL classes, and teachers' static views of culture.

First, all observed EFL lessons were heavily textbook dependent, and the textbook used contained no overt intercultural content or learning opportunities. Not surprisingly, therefore, the few references to culture that were observed in the lessons all arose from the textbooks. This dependence might lead to unsystematic and random touching on culture in a superficial, essentialist manner because "the learner is positioned as an external observer of cultural facts rather than as someone who is invited to interpret cultural practices as relevant to his/her communicative repertoire as a language user" (Liddicoat \& Scarino, 2013, p 89).

Additionally, the textbooks chosen were directed at generic EFL students, written by writers from target culture thus, "the target language culture is in isolation and without explicit connection to the culture of the learner" (Liddicoat \& Scarino, 2013, p 89). Liddicoat and Scarino (2013) also argue that textbooks are not designed for a particular context, needs, and expectations of particular learners, thus relevant content in learners' culture is not available. Therefore, dependence on EFL textbooks for culture teaching is problematic. In the observations, no connection between Vietnamese and the target culture was found since teachers followed textbooks, which did not include comparisons between Vietnamese and target cultures. This might limit students' chances for developing their intercultural communicative competence because students were not exposed to chances to know about the Self, and their perceptions towards their own culture (Byram, 1997).

Second, the teachers' treatment of culture suggests a peripheral role of culture in EFL lessons. For example, the teachers' explanation of culture-laden words or culture in general text structures simply supported the teaching of language skills. This finding is consistent with findings from other studies on culture teaching in tertiary education in Vietnam by Ho (2011), Nguyen (2013), Le (2015b), Trinh (2016), and Chau and Truong 
(2018). In foreign contexts, similar findings have been reported (e.g., Castro et al., 2004; East, 2012; Luk, 2012; Nhem, 2020; Siregar, 2016; Tian, 2013). Castro et al. (2004) showed that Spanish teachers overwhelmingly prioritized linguistic competence over cultural objectives. Similarly, Sercu et al. (2005), Luk (2012), and Siregar (2016) showed that cultural objectives in language teaching were treated as less important than linguistic goals in the teaching practice of the teachers in these respective studies.

Third, the findings show that the teachers adopted a static view of culture. In the lessons, these teachers introduced cultural facts from the textbooks. Díaz and Dasli (2017) argue that this "essentialist" view treats culture as a collection of independent factors that determine what one can or cannot do in given situations, and therefore, lead to stereotyping. Hence, the teachers' focus on teaching cultural facts/knowledge is contrary to the intercultural language teaching principle that teachers should engage students in exploratory and reflective culture learning rather than on learning cultural facts (Liddicoat \& al., 2003; Newton et al., 2010).

In short, the findings show that the teachers rely on textbooks and treat culture as static. However, given the test-oriented context and the constraints from lack of professional development, the attention to the cultural content, though limited, provides evidence of affordances for culture teaching.

\subsubsection{2 (Inter)cultural Representations in Culture Classes}

Findings from the culture classes show that teachers adopted three main teaching approaches: lecturing on common communication concepts, explaining culture in language, and raising students' awareness via activities. Among these, lecturing accounted for most of the time, while chances for students to interact were limited. While lecturing, the teachers showed students formulaic expressions and behaviors without clarifying the "fluid" nature of culture (Liddicoat \& Scarino, 2013). The teachers' traditional teacher-centered approach did not encourage students to actively construct their knowledge and their students were rarely given a chance to notice, compare, reflect, and evaluate cultural content, these being key intercultural learning processes (Liddicoat \& Scarino, 2013).

These findings were different from Ho (2011) although our studies were both conducted in the Vietnamese context. While teachers in the current study treated culture as culture in 
communication, teachers in the study by Ho (2011) addressed culture as "area studies" (Liddicoat \& al., 2003) meaning that his participating teachers gave students facts about target nations' geography, language, and people. These differences reveal an increasing demand for intercultural communication in Vietnam and a growing awareness of communication dimensions of intercultural competence. My findings from the culture class data also indicate dissimilarities with Siregar (2016) who pointed out that Indonesian teachers focused on national attributes and facts. However, the commonality was the lecture style in both studies. This commonality suggests a deeply ingrained view of teacher-centeredness among Asian language teachers.

The teaching practices in the culture classes reflect teachers' attempt to address students' ability to communicate across cultures and raise their awareness of intercultural dimensions of communication. However, the teachers made limited efforts in encouraging students' active contribution and cultural exploration.

\subsubsection{Teachers' Perceptions of the Role and Value of Culture in Language Teaching and Learning}

The findings from interview data show teachers' conceptualizations of culture and culture teaching, their perceived role as a teacher in EFL classes, and their constraints in teaching culture. Positive findings are that all teachers acknowledged the relationship between culture and language. They saw the importance of the cultural dimensions in language teaching and were willing to integrate culture into the language lessons. Importantly, more than half of the teachers suggested that the target cultures to be addressed in the lessons should include those in both English speaking countries and other countries as well. This view aligns with the new roles of English as a lingua franca in intercultural communication (Baker, 2016; Byram, 2015). This finding contrasts with Ho (2011) and Tran (2020). The teachers in these two studies viewed target cultures as belonging to those inner-circle English-speaking countries.

Apart from the above positive findings, there are some limitations in teachers' perceptions. First, the teachers defined culture as static with fixed facts, expressions, and behaviors. This way of conceptualizing culture is contrary to a dynamic view of culture (Liddicoat, 2002), which underpins intercultural language teaching. This approach with emphasis on nativenorms has been criticized as "monolithic, essentialized, and static" (Liddicoat, 2017, p.23), 
and "reductionist" and "stereotypical" (Díaz \& Dasli, 2017, p.7). Additionally, the teachers assumed that culture can be learned without explicit instructions. They revealed in SR interviews that they instructed students to read or listen to passages with cultural content and expected that the students would enrich their knowledge from their encounters with the content without the teachers' explanations. This assumption is contrary to the intercultural language teaching principle that in order for students to develop their intercultural competence, culture needs to be explicitly taught (Crozet \& Liddicoat, 1999).

These findings show teachers' limited understanding of culture and intercultural language teaching principles. The findings are in line with studies by Ho (2011), Nguyen (2013), Cheng (2007), and Trinh (2016). The participating teachers' limited understanding of culture and intercultural competence is not surprising since they reported that they hardly received any training in intercultural language teaching and they saw their role as a language teacher, not a culture teacher. This belief led them to center their teaching attempts on students' language skill development. According to Byram et al. (2002), Aguilar (2009), and Kohler (2015) teachers should be aware of their dual roles as language and culture teachers in intercultural language teaching.

In foreign contexts, Peiser and Jones (2014) and Oranje and Smith (2018) also found that teachers did not have an integrative view of fulfilling culture and language goals concurrently. For example, Oranje and Smith (2018) found that New Zealand schoolteachers favored intercultural language teaching but did not put it into practice.

The teachers explained that students' low English level and limited cultural knowledge constrained their teaching practices. Seeing students' English level as a constraint contradicts a principle of intercultural language teaching, that language and culture integrate from the beginning (Liddicoat \& al., 2003; Newton et al., 2010). Kramsch (1993) also argues that culture is

always in the background, right from day one, ready to unsettle the good language learners when they expect it least, making evident the limitations of their hard-won communicative competence, challenging their ability to make sense of the world around them (p.1).

The teachers also claimed that their limited cultural knowledge restricted culture teaching because they only know about their host culture. But as Byram (2012) pointed out: 
What is more important than native speaker knowledge is an ability to analyze and have specific training in systemic cultural analysis.... regardless of the teacher's mother tongue.

Language teachers are not expected to know everything about the 'target culture'. According to Aguilar (2009), non-native teachers as intercultural teachers are in fact in a better position than native speakers as they can move between the learners' home culture and the target culture easily, and help students to connect their own culture with others, and raise curiosity about differences and otherness. Similarly, Kramsch (2003) also claims that non-native speakers (NNS) have the privilege of a unique multicultural perspective that native speakers (NS) do not have access to. Finally, Byram (2015) argued that in terms of addressing ICC dimensions in language classes, NS teachers do not have more advantages than NNS. He contends that the NNS teacher may well have privileged knowledge of learners and their cultural experience, which is crucial in cultural comparisons for ICC development.

\subsubsection{Students', Graduates', and Employers' Views}

The analysis of student interviews, graduate interviews, and employer interviews reveals students' limited intercultural knowledge and skills. Students' stated beliefs in the interviews show a static understanding of culture, which could lead to attempts to mimic target cultures without considering that culture is changing and fluid. However, they reported that they were highly interested in cultural knowledge and were aware of the need to be prepared for intercultural communication. This positive attitude to culture learning is favorable for the integrating of culture into language teaching. In addition, students believed that they should follow the "intercultural" model rather than the native speaker model. This is consistent with Byram's (1997) view of the intercultural speaker. These students also showed positive attitudes towards learning other cultures, which is in contrast to students in Drewelow \& Mitchell (2015), who were more interested in the target language than in their intercultural skills and knowledge. The different contexts of these two studies may account for this. For Vietnamese students, English is important for them to keep their jobs in an intercultural environment. In Drewelow and Mitchell (2015), the foreign language is Spanish, and the native English students might not need to use Spanish as a significant tool for job hunting. 
Findings from interviews with graduates and employers reveal challenges the graduates faced in their communication and employers' expectations of more interculturally competent graduates from the university where the research was conducted. Overall, findings from all stakeholders' interviews suggest an urgent need to equip students in the context with better intercultural capabilities.

\subsubsection{Overall Discussion}

Integrated findings from all sources of data reveal limitations in addressing culture and affordances for fostering intercultural language teaching in the context. Limitations in addressing culture are reflected in teachers treating culture as static, and peripheral in their language lessons. In addition, teachers' perceptions show their lack of understanding about intercultural language teaching and learning.

Reasons for this limited attention to culture arose from contextual constraints such as heavy workload, lack of professional development, language proficiency-oriented curriculum, and students' English level of proficiency (as teachers reported). Many studies have reported similar constraints such as lack of time (Ho, 2011; Sercu et al., 2005; Vo, 2017), lack of cultural knowledge and skills (Conway \& Richards, 2018; Nhem, 2020), language-oriented curriculum (Nguyen, 2013; Young \& Sachdev, 2011), and teachers' lack of awareness about government policy (Nguyen, 2015).

Despite the limitations, the findings reveal some affordances for fostering intercultural teaching and learning in the context. First, the teachers and students were very willing to adopt an intercultural stance in their lessons. The teachers were aware of the culture and language relationship and paid attention to culture in their practices although to a limited extent. Both teachers and students perceived English as a lingua franca, which could direct focus to various cultures rather than a few cultures where English is the official language.

Considering all the above points, I would argue that intercultural language teaching should be promoted as a response to students' needs and the requirements from the national policy. I would also contend that professional development on ICLT should be provided to the teachers to facilitate their teaching practices. As Kohler (2015) points out, the role of teachers in the language class has shifted from a teacher to a mediator 
between students' culture and the target culture. That is to say, teachers should be updated pedagogically to respond to the newly assumed role in the language class. Byram (2015) further suggests that teachers should grasp (1) all the elements of the ICC model, 2) knowledge of the theories which underpin ICC model, and 3) and pedagogical competence to teach ICC.

The positive outcome of teacher professional development on teachers' integration of culture into language classes has been reported in studies such as Lázár (2011), Peiser and Jones (2014), Tolosa et al. (2018), and Tran (2020). Lázár (2011) reported more frequent meaningful classroom activities after teachers received training on cultural awareness and intercultural communication. Tolosa et al. (2018) found that teachers shifted their view of culture and applied ICLL in their classrooms after reflecting on their practices. Recently, Tran (2020) provided her case study teachers with ICC literature and a context-relevant lesson design model. She found that the teachers improved in their integration of culture into language lessons and developed a better view of ICLL.

In short, the limitations in addressing culture in the context, affordances for adoption of intercultural lessons, and the findings from previous literature on the outcome of professional development on ICLT have inspired the implementation of Study 2.

\subsection{Chapter Summary}

This chapter has presented and discussed the overall situation of culture teaching and learning in the study context. It has revealed how teachers addressed culture in the lessons, how they perceived culture teaching, and how students, graduates, and employers thought about culture learning in the context. The discussion of the findings shows teachers' limited understanding and treatment of culture in this setting and affordances for adopting an intercultural stance in Study 2. It also suggests an urgent need to foster ICLTL to better cater to students' needs and to fulfill the aims of the national policy to train students to become interculturally competent graduates. The chapter further suggests teacher professional development as a way to support teachers in their practices in Study 2 of the research. 


\section{Chapter 5: Study 2 Findings and Discussion}

This chapter presents and discusses Study 2 findings on Project-based learning (PBL) and intercultural learning in three EFL classes taught by three different teachers. Data were collected from classroom observations, semi-structured interviews with the teachers, student focus group interviews, and students' written reflections. The chapter begins with descriptive accounts of the 10 PBL lessons taught in each class and evidence of intercultural learning in these lessons. It continues with teachers' and students' perceptions of their lessons. Finally, the chapter discusses the findings from the three classes. The findings answer the overarching research question (2):

How can project-based learning foster intercultural teaching and learning in a Vietnamese EFL university context?

This overarching question is divided into the following sub-questions:

2(a) How did the three teachers implement the PBL lessons?

2(b) What intercultural learning processes were evident in PBL lessons?

2(c) How did the teachers perceive the PBL lessons?

2(d) How did the students perceive the PBL lessons?

\subsection{Descriptive Account of the PBL Lessons}

This section presents the key categories from observations of three teachers' PBL lessons (10 lessons/ teacher). The descriptive accounts provide an overview of how the three PBL teachers conducted the PBL lessons according to the agreed PAR plan. An analysis of the teachers' implementation of the PBL lessons showed that they all followed the three main planned stages for implementing the PBL lessons:

1. Introducing the project (Lessons 1 and 2)

2. Guiding and supporting student project work (Lessons 3-8)

3. Evaluating student performances (Lessons 9 and 10)

Each of these three instructional stages is described in a separate section below. 


\subsubsection{Introducing the Project}

All three teachers introduced the project to the students in the first PBL lesson. They all clarified the objective of the project, outlined what students should do, and provided students with the assessment criteria. However, the time teachers spent on this section and how they familiarized students with the project varied as discussed below.

\section{Teacher 1: Nhat}

Nhat devoted the first 35 minutes of her first PBL lesson to introduce the project and the last five minutes to summarize the main points about the project. She began by introducing the project, outlining the assessment criteria, and telling students how to divide the workload among themselves. She emphasized that the students should include an intercultural encounter scenario in the drama. Then, she gave the students ten minutes to think about and raise questions concerning the content and the preparation of the project. She walked around the class and encouraged students to raise questions. After that, some students asked questions in Vietnamese such as "Can we choose our group members?", "What do you mean by 'intercultural encounters'? "Does the conversation in the story need to be the same as reallife or can we make up?" "The mark for each member is the mark of the whole group or each group member will be given a different mark?". Nhat took time to answer each question in full and then asked students to choose their group members and discuss what they would do next for their project. During the lesson wrap-up, she again went over the requirements of the project and the assessment criteria.

\section{Teacher 2: Nhi}

Nhi spent about 20 minutes in the first PBL lesson and over 25 minutes in the second PBL lesson introducing the project. At the beginning of PBL lesson 1, Nhi informed the students of the project that they were going to conduct. Her introduction included the content of the project, final project products, number of students in a group and assessment criteria. She asked the students if they had any questions. She walked around the class, waiting for questions. No students raised any questions. She asked the students to form groups and to think about how they would proceed with the project. Then she reminded her students that project reports had to be handed in the following week. 
In the second PBL lesson, the students reported that they had many problems in determining the name of their project and the content of the drama because they did not understand much about the real-life and intercultural encounters in the project. In response, Nhi explained what she meant by real life and intercultural encounters. She further illustrated her answers with examples. Nhi revealed later in an interview that she did not mean to split her introduction into two parts. The second part of her introduction arose because of the difficulties experienced by the students in understanding the project requirements. On reflection, she thought she should have given more details in her introduction in the first lesson.

\section{Teacher 3: Tan}

Tan's project introduction lasted around fifty minutes at the beginning of her first PBL lesson. First, she engaged students in a free chat with her about their perceptions of studying in university after their recent transition from high school. She asked them whether they had to do any language assignment in reading and writing skills and whether these assignments were individual or group tasks. Next, she asked students if they would like to do a group project. The students showed enthusiasm and agreed. In her reflection after this lesson, she revealed that she aimed to raise students' interest and focus their attention on what she was going to say about a group project. She then introduced the project content, requirement, assessment criteria. She highlighted the intercultural content and gave examples. She also emphasized the need for the students to equally contribute to the project. She emphasized the weekly reporting on project progress and promised to give feedback on these reports. The students were given a chance to ask questions. For example, Tuan asked if their marks would be reduced when their presentation lasted longer than the pre-determined time. Tan asked whether the plot of the story for the drama could be modified from a real story. After answering the questions, Tan asked the students to form groups and outlined the tasks they were going to do. Then Tan summarized her introduction.

Overall, all three teachers introduced the project to their students in a similar amount of time. However, while Nhat and Tan finished their project introduction in their first PBL lessons, Nhi had to explain the project again in her second PBL lesson in response to her students' requests. In addition, although Nhat completed this section in the first PBL lessons, she broke up this section into two parts: 35 minutes in the beginning and five minutes in the lesson wrap-up, while Tan had a straight 50-minute introduction. 
Regarding the way of introducing the project, Nhat and Nhi directly informed the students of their tasks while Tan spent some minutes asking students questions to raise their interest in doing a group project. Nhat and Tan repeatedly attempted to elicit students' questions while Nhi gave students only one opportunity to raise questions. By the end of lesson 2, all groups had come up with tentative topics and titles for their projects. The final titles for the projects, which were confirmed in later lessons, are listed in Table 5.1 below.

\section{Table 5.1}

Students' performances

\begin{tabular}{ll}
\hline Group & Performance/mini-drama \\
\hline Group 1 & Food in many countries \\
\hline Group 2 & Vietnamese traditional dress and others \\
\hline Group 3 & New Year \\
\hline Group 4 & Visiting a friend's house \\
\hline Group 5 & Travelling \\
\hline Group 6 & Who does housework? \\
\hline Group 7 & Pets in your eyes and ours \\
\hline Group 8 & On the way to a restaurant \\
\hline Group 9 & Drunk \\
\hline Group 10 & A new bride \\
\hline Group 11 & Shopping in open-air markets \\
\hline Group 12 & Travelling to Vietnam \\
\hline Group 13 & Misunderstandings \\
\hline Group 14 & Impressions \\
\hline Group 15 & Going to a movie \\
\hline Group 16 & Festivals \\
\hline Group 17 & Hospitality \\
\hline
\end{tabular}

\subsubsection{Guiding and Supporting Student Project Work}

5.1.2.1 Language-Focused Instruction. All three teachers assisted their students' project implementation by (i) conducting language-focused activities and (ii) giving feedback on students' unfinished projects.

(i) Conducting Language-Focused Activities. First, in all PBL lessons, the teachers conducted language activities, mostly based on the textbook. They all followed the main steps in the textbook such as grammar focus, working in pairs, and making up conversations. They also modified the textbook by removing the checking vocabulary section, omitting the "Listening and repeat" section in the textbook, and working quickly through the grammar points. Notably, Nhi gave each group a mini-presentation task in which they needed to gather 
information on their favorite topic and present it to the whole class for five minutes in the following lesson. Nhi commented that she aimed to develop students' vocabulary and grammar when they read for information for their presentation through this activity. She added that presenting a topic in class also developed students' confidence in speaking and increased their fluency.

(ii)Giving Feedback on the Project. Second, the teachers provided language-focused instruction through comments on students' unfinished written project work. They either provided students with better word choices for their drama scripts or asked students to look for better word alternatives. For example, in a script draft, the students in Group 1 in Nhat's class wrote:

Chap 1: Hue and Charles are going to come in a class, then Hue's book falls to the floor, Charles holds it up.... Chap 2: Suddenly a knock on the door, then Kim Soo Min (Korean) appeared...

(Extract ST2EX1)

The students handed this to Nhat when she visited this group. Nhat suggested that they think about how to use "going to", what preposition should go with "fall", other phrases to replace "holds it up" and whether there should be a subject in the sentence "suddenly a knock on the door..."

5.1.2.2 Raising Students' Awareness of Intercultural Issues. This was the central focus. Analysis of the classroom observations showed that all three teachers followed the agreed procedures for helping their students with the intercultural content in two ways: (i) engaging them in intercultural activities and (ii) giving feedback on their project work.

(i) Engaging Students in Intercultural Activities. The three teachers involved their students in intercultural activities such as role-plays, watching videos, and discussions. Nhat and Tan had a similar length of time for these activities while Nhi spent less time. All the teachers encouraged students to discover and notice the similarity and differences in Vietnamese and English or other cultures and relate the topic to their own experience. Nhat and Tan more frequently invited students to join discussions and gave suggestions for these while Nhi just moved on to other tasks when she heard no responses from her students. Table 5.2 below summaries a sample activity in these three classes. 
Table 5.2

Sample intercultural activities in lessons 2 in the three classes

\begin{tabular}{|c|c|c|}
\hline Nhat's class & Nhi's class & Tan's class \\
\hline \multicolumn{3}{|c|}{ Intercultural activities (PBL Lesson 2) } \\
\hline $\begin{array}{l}\text { PRE-ACTIVITIES } \\
\text { In the previous lessons, teacher } \\
\text { (T) asked students (Ss) to: } \\
\text { interview friends, family } \\
\text { members about how they } \\
\text { often greet other Vietnamese. } \\
\text { prepare stories to share with } \\
\text { the class about intercultural } \\
\text { encounters (greetings) (can } \\
\text { be their own experience or } \\
\text { second- hand experience }\end{array}$ & \multicolumn{2}{|c|}{ NO PRE-ACTIVITIES } \\
\hline \multicolumn{3}{|c|}{ While-activity } \\
\hline $\begin{array}{l}\text { - T allows students to talk in } \\
\text { groups about how to greet } \\
\text { someone in Vietnamese, in } \\
\text { English. } \\
\text { - Ss work in groups and come } \\
\text { up with answers. } \\
\text { - Ss share their own stories. } \\
\text { - } \quad \text { T shows video. } \\
\text { - T tells her own stories. } \\
\text { - Ss reflect on experience. }\end{array}$ & $\begin{array}{l}\text { - T asks the whole class about } \\
\text { how to greet someone in } \\
\text { Vietnamese, in English, call } \\
\text { some students to answer. } \\
\text { - } \quad \text { T asks students to think of } \\
\text { more examples. } \\
\text { - } \quad \text { T shows video. } \\
\text { - T tells her own stories. } \\
\text { - Ss share their own stories. } \\
\text { - Ss relate previous } \\
\text { knowledge to new } \\
\text { knowledge. }\end{array}$ & $\begin{array}{l}\text { - T begins by asking students to suggest } \\
\text { how to answer the question "Chi co } \\
\text { khoe khong" (How are you) if the } \\
\text { speaker is a Vietnamese, if the speaker } \\
\text { is an English friend? } \\
\text { - T asks if the answer is different even } \\
\text { among Vietnamese in different } \\
\text { contexts (close, not close relationship, } \\
\text { age) } \\
\text { - T shares a story. } \\
\text { - T plays a video. } \\
\text { - T has students to talk in groups, } \\
\text { sharing their experience. }\end{array}$ \\
\hline
\end{tabular}

Note. $\mathrm{T}=$ teacher, $\mathrm{Ss}=$ students

As observed, in all the intercultural activities, Nhat and Tan included some Vietnamese in their explanation and encouraged students to illustrate their views concerning specific Vietnamese language patterns. Nhi used less Vietnamese. While Tan asked students to pay attention to diverse ways of using language even among Vietnamese in different contexts, Nhat and Nhi paid less attention to this aspect. Nhat and Tan allowed more time for students' discussion and giving prompts to students, while Nhi tended to provide students with cultural knowledge after their discussion. In this way, Tan and Nhat's lessons were more student- 
centered and provided more opportunities for exploratory and experiential learning than Nhi's lessons. In Tan and Nhat's lessons, this focus was more evident in lessons 5-8 compared to lessons 1-4. In their classes, students talked more in groups and, when asked questions, many students raised their voices. In contrast, in Nhi's class, students worked enthusiastically in groups, but only a few students from these groups volunteered to answer Nhi's questions. After the lessons, Nhi commented that she tried to call on a range of students, but some students who were more confident and enthusiastic than others dominated the classroom interaction.

(ii) Giving Feedback on the Project. Another way that the teachers helped students in preparing the intercultural content in their drama was to give feedback on their project. All three teachers visited each group and asked for reports on project progress. In lessons 1 and 2, the students discussed and outlined the scenes for their dramas. In each of the following lessons, the students handed in their incomplete drama scripts to show their progress. The teachers gave some comments on the choice of the scenarios, and on whether the proposed intercultural encounters were relevant. All three teachers performed this part similarly. They did not point out what the students should change or suggest a scene. Instead, they just told students whether it was necessary to revise the scene and reminded students of the goals of the project. The three teachers continued to give feedback on the developing projects in every PBL lesson.

5.1.2.3 Introducing Project Skills. The project skills that the teachers provided in the PBL lessons were (i) data gathering, (ii) interviewing, and (iii) presentation skills.

(i) Data Gathering Skills. All three teachers suggested their students use Google, YouTube, and some websites such as the Discovery Channel to search for information that may be useful for their scripts. In addition, they recommended that their students gather information from talks with friends, relatives, or people they met, and from the mass media, books, and magazines. After talking to the whole class, Nhat went to each project group and checked whether they had any questions about gathering data from the Internet. Tan did the same in her class. Nhi asked the whole class if they had any questions. In all these classes, the students did not raise any questions about using search tools. 
(ii) Interviewing Skills. This was observed in Nhat's lessons 4 and 5, Nhi's lessons 5 and 6, and Tan's lesson 5. Details are below.

\section{Teacher 1: Nhat}

In the middle of lesson 4, Nhat asked her students whether they would like to talk with English speakers. The students agreed with excitement. Then, she notified her students that they were going to have the chance to talk online with an English speaker in the following lessons and talk in person with two English speakers in another lesson. The whole class became noisy with students enthusiastically talking with each other about the upcoming rare speaking opportunities with English speakers. After several minutes, Nhat asked her students to think about questions that they would like to ask their guest speakers. She emphasized that the students should pay attention to the content and the structures of the questions. Then, she allowed 10 minutes for her students' discussion. After 10 minutes, she asked three students to reply. The students gave their answers. Nhat did not give any feedback on their students' questions but instead, asked all students to gather information from all sources about what questions to ask when first meeting a native English speaker. She emphasized that her students should pay attention to the content of the questions as well as the form, the expressions, the context and think about the same situations as applied to Vietnamese speakers. The students were expected to present their answers in the following lessons. Subsequently, in lesson 5, Nhat asked four students to report what they had found about questions to ask English speakers for the first time and gave feedback on their answers. Examples of students' questions were "What's your name?", "How long have you been in Vietnam?", "What do you like about Vietnam?” and "Are you married?". Nhat gave feedback on both grammatical and intercultural dimensions. Nhat revealed in a subsequent interview that the reason she asked her students to explore what they should ask was to develop their learning autonomy. Additionally, she hoped that when exploring questions to ask Vietnamese and English speakers, students would notice the differences and commonalities. This would raise students' intercultural awareness alongside language features.

\section{Teacher 2: Nhi}

At the end of lesson five, Nhi informed her students of the upcoming talk with an English speaker in the following lesson. Then, she asked her students to think about questions to ask 
this speaker and reminded them when to email her the questions so that she could correct these questions in the following lesson before the talk. In lesson 6, Nhi showed all the students' questions that she had gathered from emails on the PowerPoint slides and corrected them in terms of grammar. In her reflection, Nhi reported that she aimed to help students produce correct questions so that they would feel confident when interacting with the guest speakers.

\section{Teacher 3: Tan}

At the end of lesson five, Tan briefly let her students know that they could talk with an English speaker online in lesson 6 and talk in person with two other English speakers in lesson 7. She asked them to think about the questions that they should ask the English speakers, especially questions that could help find useful information for their project implementation. Then, the students asked her some questions about the guest speakers, such as where they were from, what they were doing in Hanoi. Tan answered these questions. In lessons 6 and 7, Tan did not check her students' preparation for their talk with the speakers because, as she recalled later, there was not enough time in that lesson to help students prepare for the interview with the English-speaking guests. Additionally, she said she wanted her students to experience real conversations without her control. She expected that the students could learn from both the good points and the struggles they had in their conversations in terms of language and culture.

(iii) Presentation Skills. The three teachers equipped their students with oral presentation skills in lessons 7 and 8, as the time of the final performances neared. All three teachers reminded their students about the need to keep eye contact with the audience, use signposts when beginning, presenting, and concluding their presentation, and use clear PowerPoint slides (if necessary). Notably, Nhi spent ten minutes at the end of each lesson to ask one of the student groups to present their prepared topic using a poster-size paper to outline the content and illustrative images. Then each group shared their ideas on the paper with other groups. In the stimulated recall interview, Nhi said that she used this activity to help students enlarge their vocabulary and become more confident in speaking in front of the whole class. 
From the observations, all three teachers helped their students prepare for the projects through language-focused instruction, by raising awareness of intercultural issues, and equipping the students with project presentation skills. In their language-focused instruction, the teachers flexibly adapted textbook tasks, conducted language-focused activities, and gave comments on students' unfinished written project work. To raise students' intercultural awareness, they engaged them in intercultural activities and gave feedback on their work. They also showed them how to use questions for interviews, and search for information and prepare to present their role-play in class.

\subsubsection{Evaluating Students' Performances}

In the last two PBL lessons, the students presented their final projects - performing their roleplays/mini-dramas. All three teachers gave oral feedback on their students' presentations. Their comments focused on the choice of topics, use of words and expressions, fluency, implications for intercultural encounters, the collaboration of team members in the presentation, the costumes, and the way the students performed. As detailed below, there were some differences in how teachers gave feedback.

\section{Teacher 1: Nhat}

During the drama presentations, Nhat chose a seat at the back of the class and quietly watched each group of students performing while she took notes. In each of these two lessons, three groups performed. After the three groups had finished their performance, Nhat gave overall comments on all three presentations. For example, she said, "You have chosen very real-life topics for your drama ... you have used a wide range of vocabulary and you work well with group members ...." In her talk with me after the lesson, she revealed that she did not comment right after each group's performance because of time constraints and because she did not want to benefit later groups from the feedback that she gave to earlier groups.

\section{Teacher 2: Nhi}

Nhi chose a seat at the back of her class, watched her students' performances attentively and took notes. After all performances were completed on the second performance day, she gave her feedback on each group including general positive points and limitations of each 
presentation. For example, she said about group 2: "I like your scenario and conversation, real to life ... However, you should pay more attention to your intonation, try to make the conversation sound more natural" (English translation). In her follow-up interview, Nhi explained that she delayed her feedback until the end so that students could have a whole picture of all performances and share their opinions before she concluded with her comments.

\section{Teacher 3: Tan}

During the project performances, Tan sat quietly at the back of the classroom and took notes. After each group finished their performance, she invited other groups to ask questions or give comments. Then, she asked a representative of the group to give the group's opinion about their presentation and the message they want it to convey about intercultural communication. Tan concluded the comment section by stating what she thought were the strong points, and what the group could have done better. She illustrated each point with examples from the performances. On reflection, Tan explained that giving instant feedback was better because the performance was still fresh in students' minds and hers, which aided her in giving detailed and more valuable feedback. She was aware that the later groups would benefit from these comments and so she set higher criteria for marking later groups to ensure fairness.

Among the three teachers, only Tan was observed to elicit students' overall feelings about the PBL approach. She carried out this activity when the session for feedback for the last group ended. She began her talk in Vietnamese with her students in a relaxed, friendly manner. She asked the students how they felt after the presentations, what they thought about partaking in the project, what they would like to include or change in the project, and whether they would like to continue doing such a project and why. The students answered her questions enthusiastically. In general, they responded with positive comments such as "Very interesting," "We like to work in a team, so much fun," "It's helpful," "We speak English better" "We know more about culture" ... "I like the speaking with guest speaker ... so wonderful." In addition, they told her about some difficulties in the implementation of their projects such as limited access to research tools and working with peers with different personality traits.

Overall, each of the three teachers gave feedback at different times: Nhat at the end of each day, Nhi at the end of the second day, and Tan after each performance and after inviting peer 
feedback and presenter feedback. Their comments focused on language, acting skills, and content of the performances. In the three teachers, only Tan invited students to talk about what they thought of the project value and what they suggested for future projects.

\subsubsection{Section Summary}

This section described how the three PBL teachers implemented their lessons. Despite some variations in the details of lesson implementation, the three PBL teachers all conducted the lessons as collectively agreed on, including introducing the project, helping students with the project, and assessing the project. Students in all the observed lessons appeared engaged in their work and all groups completed their projects. The next section presents evidence of intercultural learning in the PBL lessons.

\subsection{Intercultural Learning in PBL Classes}

This section presents evidence of the students' engagement in intercultural learning in (i) the eight PBL lessons in each class and (ii) the project performances in the two final lessons in each class. This section addressed research question $2 \mathrm{~b}$ : What IC learning processes were evident in the lessons? Data are from audio-visual recordings of whole-class interactions, audio recordings of two to three groups in each class, and researcher field notes, transcriptions of 17 project performances by 17 student groups (Table 5.1, section 5.1.1), and students' post-presentation reflections. These data were subject to thematic analysis, which involved the iterative process of coding, categorizing, and generating themes and sub-themes, as described in Chapter 3. Through this process, two overarching themes of intercultural awareness and intercultural attitudes were identified along with various sub-themes across the three classes. The number of instances of each theme varied considerably between the classes. Despite this variability, in all three classes, a consistent pattern is seen of an increasing number of instances of intercultural learning processes in the later lessons, with these later instances being interculturally richer. The themes and sub-themes are detailed below.

\subsubsection{Intercultural Awareness}

The first theme that encapsulates students' engagement in intercultural learning in PBL lessons is intercultural awareness. This theme includes three sub-themes: awareness of their 
own culture, awareness of the similarities and differences between their own culture and other cultures, and awareness of responsibilities for successful intercultural communication.

5.2.1.1 Awareness of Their Own Culture. Students viewed their own culture from multiple perspectives. They discussed cultures in monolithic terms in 24 observed lessons. In eight of these 24 observations, students acknowledged the diversity and dynamism in their culture. First, in all 24 lessons, when the teachers asked students broad questions about Vietnamese culture such as "How do Vietnamese people greet each other? What do you think about the way Vietnamese people greet each other?" students commented after discussing in groups or pairs. Their answers showed that they perceived Vietnamese culture as monolithic. For example, when Nhat asked her students to think about how Vietnamese greet each other when they meet and why Hoang commented on Vietnamese culture in his group discussion:

Vietnamese people always want to show they care about each other. So, they greet each other by asking about health and whether they have had lunch or dinner. (Hoang, Ob.1A)

Similarly, Lien talked with her group about starting a meal in Vietnam:

We Vietnamese respect the old, and so we always invite them to eat before we start eating. (Lien, Ob.6C)

The number of instances of students referring to culture as monolithic was similar in all three classes (around 30 instances in each class). Notably, the number of instances of students expressing their views of culture as monolithic in lessons 1-4 were like lessons 5-8. In a few instances, some students identified diversity and dynamism in their own culture. They acknowledged that among Vietnamese, there are diverse ways of responding to a similar event and that practices are changing with time. Comments by Nam and Hong illustrate these points. In his group discussion on the practice of inviting the elders to eat at the start of a meal, Nam said:

It depends, not everywhere in Vietnam do people invite each other before eating. People from the south do not. Maybe because they are affected by American society. The American army was there in the war. (Nam, Ob.6A)

This comment came after Nhat suggested that all groups of students should think about the differences (if any) and the reasons for these differences among Vietnamese from different 
regions. Before Nhat's suggestions, all the groups produced similar comments such as "Vietnamese people often invite each other to start the meal, American people do not". In a similar vein, the following extract showed how Tan guided students to engage in the topic "Travelling":

T: $\quad$ How do you often travel to our university?

Nhan: I walk.

Ss: $\quad$ By bus.

T: $\quad$ It seems that most of you travel by bus. What do you often say to the bus driver when you get off the bus?

Ss: Nothing.

Thanh: Why? If we don't hurry to get off, the driver will shut the door quickly and we will fall on the road.

Lan: It is normal not to say anything. We pay the fare, and we get off at the bus stop.

T: $\quad$ How about travelling on other kinds of transportation such as taxi?

Men: I ask "how much" then pay the money and "bye bye"

Ss: $\quad$ Yes, that's what we often do.

T: $\quad$ Any other ideas?

T: Work in pairs. Talk to your friends about your experience of travelling by taxi, or bus with someone in Vietnam that you noticed any difference from the way they say to the driver? What do you think about the difference? And why?

After 10 minutes

T: $\quad$ Any ideas?

Huong: Many times, I travelled by taxi with my countryside relatives, and they just paid money to the taxi-diver when we got to the destination. Once, I was in a taxi with my friend, and his father, a wealthy businessperson, in the city, I was surprised to hear him say "Thank you" to the diver when we got out. I was so surprised, why we had to say, "thank you" to the taxi-driver because we are customers, like the saying "customers are god". Another time I saw the same thing, my cousin who lives in Hanoi said such a thing. I realized that they showed their politeness... I think that, for them, it does not matter who is the buyer or the seller ... so some Vietnamese people thank the taxi driver because they want to show politeness while others think that they pay so they do no need to thank the diver.

(Extract ST2EX2) 
Huong added that she talked with her friends and many of her friends coming from the outskirts of Hanoi thought the same as her. That is, the service providers should be the ones to thank the service receivers because the service receivers bought the service and paid money. In the previous comments, Nam and Huong dug deeper into the reasons why people in different regions in Vietnam started a meal differently, and why some people said "thank you" when they received a service, and some did not. This shows that their understanding of their own culture was not simply limited to the concept of culture as defined by national borders. This activity generated the awareness that culture is variable across different regions and people.

In lesson 2, when the teacher asked students to think about how Vietnamese people responded to positive comments on their appearance, most students replied that Vietnamese people tended to show politeness by denying the fact that they looked good. When the teacher provided further prompts, such as "Do people in your provinces respond to comments the same as people in Hanoi? Do older people, for example, your parents, react the same as you?" students gave further comments. For example, when Nhi visited a group of students discussing the topic 'commenting on appearance' Hong, a student in the group, shared with Nhat that she realized her own culture was changing and modified her behavior accordingly:

Many Vietnamese people tend to deny that they look good or have something beautiful. For example, if someone says, "Your dress looks so good" you will say. "No, it is so so". I think now, not everyone says that. Maybe we have contact with foreign culture now. Many people say "Good, isn't it"? I used to deny it, but after being in the city for 2 months, I have changed from denying to saying “Good. Isn't it", too? (Hong, Ob. 2A)

Similarly, in observation 2C, Tan showed her class a picture of a Vietnamese man with some tattoos over his arms and generated a discussion among her students:

T: What words appear in your minds when you see this picture? What do you think about the man?

Ss: $\quad$ Black society

Ss: Gangsters

Tham: Social evils. Not good.

La: In my village, parents often tell children to stay away from guys with tattoos. 
Luyen: Really? Too extreme. I don't think all men with tattoos are bad. Can you judge a man simply by their appearance?

Huong: I have never seen anyone having a respected job wearing a tattoo.

Huyen: I agree with Luyen. It depends. I live in a busy street in Hanoi. I know a man. He is an artist. He is very talented and helpful to people in my street. My parents used to tell me not associating with him because they saw his tattoos. I did believe so when I was small. But now I do not think he is bad; it is not fair to hate him because of his tattoos.

(Extract ST2EX3)

In the above discussion, the students had chances to discover other students' perspectives about "tattoos". Tham, La, and Huong showed their stereotypes when displaying negative thoughts to all Vietnamese people with tattoos. Luyen and Huyen did not agree with this stereotype. Huyen even saw the differences in perspectives due to the generation gap. She also noticed her shift from believing in the negative meanings associated with tattoos to suspending this belief.

In brief, the students displayed their varied understanding of their own cultures in 24 observations. They mostly viewed culture as defined by national borders and infrequently identified culture as diverse and dynamic. Most of the time, students' comments on the diversity and dynamism of culture were triggered by teachers' further explicit questions.

The awareness of their own culture was also demonstrated in 16 performances and reflections in which the students showed that they understood how Vietnamese people often acted or spoke in some typical situations such as crossing the road (performance 8), and the role of men and women in the house (performance 6) below:

\section{Extract from performance 8:}

[Thao - Vietnamese intends to cross the road to catch the bus.

Jim - American suddenly pulls Thao back]

Jim: We must go to the traffic corner and waits for the green light to cross the road.

Thao: But the vehicles are from far, we can run quickly. 
Reflecting on this performance, the students revealed that they intentionally let the character Thao speak about what people often do in Vietnam. They said that crossing the road in the wrong place was not a should-do thing and could pose danger to traffic attendants. One student from the group further added that they hoped the scene would alert the audience about the consequence of the image of Vietnamese as not following the laws in the eyes of people from other cultures.

Performance 6 displayed a scene in which gender roles in the family were portrayed:

\begin{tabular}{|c|c|}
\hline Jack: & Let check it out! Khuong? Why don't you come and help your wife? \\
\hline Khuong: & $\begin{array}{l}\text { None of my business! That's her work! ... We are men! So, we only need to } \\
\text { sit and wait for the meal! }\end{array}$ \\
\hline Sara: & Poor you Huyen! My honey helps me everything! \\
\hline Huyen: & $\begin{array}{l}\text { That's the rule of Vietnam! Women must do all housework! It is very strange } \\
\text { if he sweeps the floor or washes the dishes! }\end{array}$ \\
\hline Sara: & So lazy he is! He doesn't do anything? \\
\hline Huyen: & Yep! Drinking all day! Then eating and sleeping! \\
\hline
\end{tabular}

(Extract ST2EX5)

In this scene, Jack and Sara (Australians) visited Khuong and Huyen (Vietnamese). The conversation revealed the perceptions of men's role in the Vietnamese family as more powerful and that men are not expected to do housework. In addition, Vietnamese women were depicted as obediently accepting their housewife roles. The students performing the drama said that they came from rural areas and this perception was dominant in their community. They also revealed that they understood the perception of the role of men and women in the sharing of the housework was different in different cultures. In the American culture, men felt happy to share work with their wives, as in another scene in the performance:

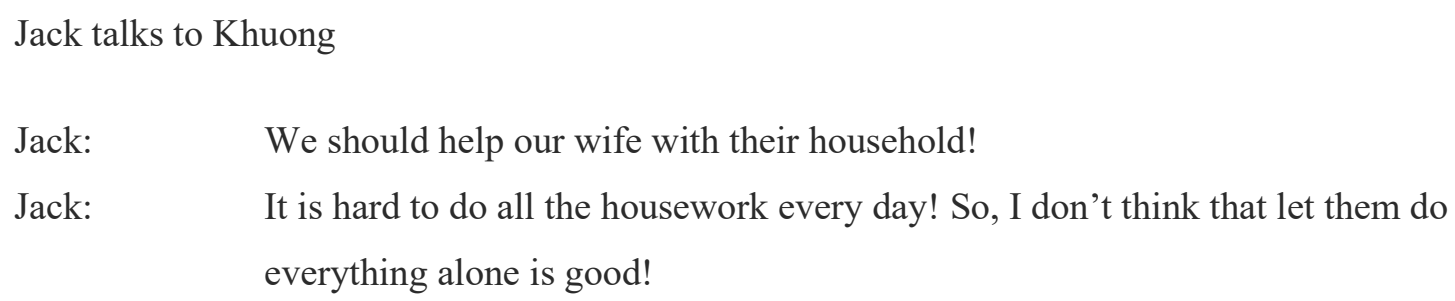


Sara talks to Jack

Sara: $\quad$ Honey, could you help me with these dishes!

Jack: $\quad$ Yeah! On my way!

(Extract ST1EX6)

The students shared their views that after gathering information for the drama and learning about the perceived men and women's roles in the target cultures, they expected men in their community to act like the men in the target culture. While performances 6 and 8 contained scenes that revealed students' awareness of their own culture as not positive, including Vietnamese passing the road in the wrong place, men not sharing housework with women, performance 4 included a scene in which the students showed their preference for their cultural practice:

Fiona: Jane, could you pass me the pepper?

[Fiona turns to Lan]

Fiona: Lan, this is Jane, my aunt.

Lan: $\quad \mathrm{Hi}, \ldots$ aunt Jane.

[Lan talks with a bit of surprise, pauses before greeting Jane]

(Extract ST2EX7)

The students said that they learned the difference between how to address in Vietnamese and the target culture. The Vietnamese language requires a word before the name to show respect when their ages are different. The word varies according to the relationship and age difference between interlocutors. In Australia, people call others by their first name. In this case, Lan was shocked when she heard her friend call her aunt by only first name, which is disrespectful, and not acceptable from the Vietnamese perspective. Students in this group confessed that though respecting the differences, they found it hard to call the people who were older by their name for fear of showing disrespect. Sang, a student from the performing group further commented: 
I think Vietnamese have a way of greeting that can signal relationship and respect, very interesting. Vietnamese society follows hierarchy models, so the way of greeting to show respect is absolutely necessary. (Sang, RF-P4)

Sang's comment shows his understanding of the underlying value behind the way Vietnamese greets each other. Other students in the group also commented that character Lan in the scene greeted Fiona "Hi, Aunt Jane" with the pause and suppressed surprise in her voice to convey a message that these students valued Vietnamese ways of greeting. Though they respected the difference in the way the Australian character called her aunt, they found it hard to adopt the difference and therefore, put the word "aunt" before the name Jane to show respect.

The students also demonstrated their understanding of stereotypes and the need to avoid stereotypes to successfully communicate interculturally in six performances and reflections. This understanding was present in performance 13. In this performance, there was a conversation between two Vietnamese customers, Tuan and Manh, in a restaurant. They were served by an African man, Jim, the waiter.

Tuan (talks to the waiter)

Tuan: Where were you? You should have been here immediately when I sat down.

Jim: I'm so sorry, sir. We have so many customers.

$\cdots$

Jim: I'm so sorry. Can I help you?

Tuan: Give me the menu! [strong voice]

Jim: Here you are!

[When Jim goes to get the food, Tuan talks to Manh]

Tuan: Those African men getting into our country just cause troubles, theft and drug, slowness, dirty.

(Extract ST2EX8)

The students reported that they wanted to emphasize negative stereotypes among Vietnamese people towards Africans migrating to the South of Vietnam. These students acknowledged 
that there were cases of theft and drug-related cases involving African immigrants. However, it did not mean that all Africans were the same. Therefore, they invented another scene in the performance in which they revealed how Tuan, the Vietnamese customer, found his lost wallet thanks to Jim:

[The two Vietnamese finished their dinner and was about to ask for the price when Tuan found that he lost his wallet].

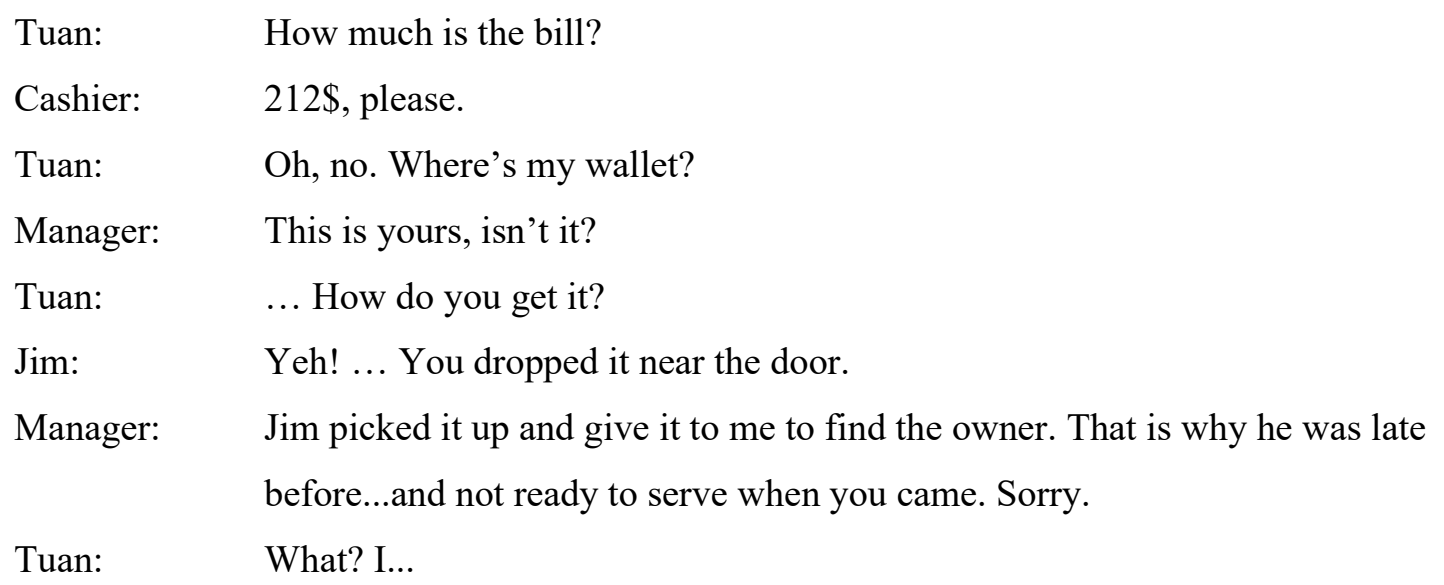

(Extract ST2EX9)

Tuan's words were accompanied by his face showing surprise and regret about what he had said to Jim when he first entered the restaurant. Through the scene, the students showed that stereotypes might mislead people into an incorrect understanding of people and phenomena and could ruin their relationships.

5.2.1.2 Awareness of Cultural Similarities and Differences. The students showed their awareness of cultural similarities and differences in all observed lessons. For example, in lesson 2, when students were new to intercultural activities, they compared cultural differences at a factual level in a group discussion on the topic "shopping":

\footnotetext{
Nguyet: $\quad$ Actually, both Vietnam and Australia have open-air markets and supermarkets.

Lan: $\quad$ Yes, but also some differences like, in Vietnam people often bargain. In Australia, people do not.

Nam: $\quad$ Vietnamese only bargain in open-air markets. We do not bargain in supermarkets. So, this is the same in every country. (Ob.3A)
}

(Extract ST2EX10) 
Similarly, the students in observation $8 \mathrm{C}$ noticed the commonalities and differences in the practice of sending wedding invitations to friends and relatives in their own culture and American culture:

Hoa: $\quad$ Both Vietnamese and Americans send paper wedding invitations. They print their names, place, and time of the event on the wedding cards.

Lan: $\quad$ Yeah, but the Americans add RSVP. And the colors of the cards are different. They are ok with many colors like white, cream, and blue. In Vietnam, we mostly use red cards.

\section{(Extract ST2EX11)}

In this lesson, at a later stage of the project, the students had been acquainted with activities with intercultural topics. Before the lessons, the teachers had encouraged them to gather information about the intercultural topics, especially the underlying reasons for the differences. As such, apart from noticing these easily spotted commonalities and differences, the students displayed their awareness of the differences at a deeper level, such as the meanings underlying the color of the wedding cards, in the following extract:

The Vietnamese often use red for the wedding cards because red is associated with happiness and prosperity in Vietnamese culture. (Linh, Ob.8A)

Vietnamese never use black for their wedding cards. Black makes people think about funerals. (Hoa, Ob.8B)

Similarly, the students expressed their understanding of the underlying values in the diverse ways of choosing topics for small talk between people in Vietnamese culture and Australian culture:

Both Vietnamese and Australians want to show politeness to people when they meet for the first time. However, how to show politeness is different. We ask about their children, jobs, age ... to show our willingness to talk. Sometimes we care, but we do not mean to invade others' privacy. (Giang, Ob.1A)

These examples show how the students discussed cultural similarities and differences at both a factual and at a deeper, more abstract level. Abstract comparisons were more frequent in 
lessons towards the end of the project when the teachers further guided students to explore the topics more deeply.

In 16 performances and reflections, awareness of cultural similarities and differences was also displayed at both a low level - factual level and a higher level with a deeper understanding of the underlying perceptions. A scene in performance 1 is a vivid illustration of students' understanding of differences at a factual level. This scene involved a conversation between students about food in different countries, and about the Tet holiday in Vietnam.

\section{Extract from performance 1}

[Four international students Kamayato (Japanese), Linh Linh (Chinese), Charles (American), Soo Min (Korean) were talking about their countries.]

Kamayato: My country is not only beautiful scenery but also delicious food and good for health, especially seafood such as Sushi and Sashimi.

Linh Linh: Oh. I really want to come to your country. Each country has its own food culture. However, if you go to China, do not miss famous dish called: Beijing Ducks. It will make you want to come back to China again.

Charles: $\quad$ That's great! I love Asia food. I will come to your country in the future. If you have the opportunity to US, you should try the Fast food such as sandwiches, Pizza, Snacks, etc.

Soo Min: $\quad$ My country is famous for Kim Chi, Kimbap, etc.

\section{(Extract ST2EX12)}

Students in performance 1 said that they wanted to express the cultural differences in cuisines in many countries through the voices of the characters. This reflects understanding only at factual levels, with no further exploration into the hidden values of the cultural facts.

The following two Performances (16 and 6) illustrate students' understanding at a deeper level. 


\section{Extract from performance 16}

[Two friends - Smith from America and Ly from Vietnam are walking on a Vietnamese street]

Smith: It's crowded. It seems that on the face of everyone has the expectation? What's happen?

Ly: Oh, we're preparing for the New Year. That is the biggest holidays of the year.

Smith: Wasn't the New Year gone? The first day of the year?

Ly: Oh, it's the first day of a year. But the culture of my country has the New Year's Day different from other countries. It based on another calendar, which is called lunar calendar and the holidays are called Tet holidays. We give kids money in a red envelop, meaning that we wish them good health and good luck. Red color is considered luck in our culture. In your culture, red may be a sign of something negative, such as anger, isn't it?

(Extract ST2EX13)

This scene in performance 16 reveals students' understanding at a deeper level. Students dug into hidden cultural values when they noticed similarities and differences between cultures. Through the character Ly, the students showed that they knew the meanings behind the practice of Vietnamese giving red an envelope with money inside to kids when Tet comes, and the positive meaning associated with color red in eastern culture and adversely negative meaning in American culture. A scene in performance 6 and students' reflections also reveal their deep understandings of underlying values of the phenomenon they observed.

\section{Extract from performance 6}

[A Vietnamese couple are talking with the mother of the husband]

Mother-in-law: $\quad 2$ đứa định bao giờ mới cho bà bế cháu? Bà đợi hơi lâu rồi đấy! (When are you having baby for me to have grandchild? I have been waiting for long)

Khuong: Mẹ cứ từ to! con mới 25 thôi mà! Mẹ cứ phải cuống lên! (Take time, mom. I am just 25. No need for you to rush).

Mother-in-law : $\quad$ Lại còn cãi được à? Nhà người ta lên ông bà lâu lắm rồi ! tôi đây 45 tuổi đầu mà vẫn chưa 1 mụi đây! (Dare to argue back ? Others at my age became grandmom for long. I am 45, still having no grandchild).

(Extract ST2EX14) 
The students explained that the mother-in-law's complaint about the couple's late childbearing plan was to express her care about the couple. The students' explanation reveals their understanding of hidden meaning in the Vietnamese mother-in-law's words, in this case, contrast with her complaints. They further commented that, if the conversation happened between an American wife, a Vietnamese husband, and a Vietnamese mother-in-law, the misunderstanding would occur because the wife would interpret the mother-in-law's words as being impolite, and disrespectful of her own decision.

\subsubsection{Awareness of Responsibility for Successful Intercultural Communication.}

Students in all three classes displayed their awareness of responsibilities for successful communication. They indicated the need to follow the target culture norms in most of the lessons. However, towards the end of the project, there were some instances of students expressing their intentions to mediate between cultures, instead of strictly following other cultures. For instance, students in the three classes expressed their views of adapting to the target cultures when communicating with others. Some illustrations follow:

We think that from now, to avoid misunderstanding when communicating with English speakers, we should not ask personal questions such as asking about salary or ask a woman about ages. (Hong, Ob.1C)

If we are asked "how are you?" by Westerners like Americans, we should not tell them our real health situation, just consider it as a way of greeting and reply briefly such things as "Good, thank you", I mean do it like how they do it to fit in their culture. (Manh, Ob.1A)

In these examples, Hong and Manh emphasized that the learners should follow the target culture norms to gain success in intercultural communication. These comments reveal the students' sense of responsibility in making the potential intercultural interactions successful.

Additionally, the students showed their awareness of responsibilities for successful communication through mediating between cultures. That is, they found a "third place", interacting in a way so that the other interactors felt comfortable without necessarily sticking to either their own culture or the others' cultures. For example, in observation 8A (almost the end of the project), the teacher played a video showing an American classroom scene in which many students asked a teacher many questions without the teacher inviting questions. These students did not stand up but remained seated. They also expressed their different ideas 
to what the teacher said. In his group discussion on the way the American students actively contributed their opinions to the lesson, Hoang shared his view:

I think that the Vietnamese way of trying not to let others lose face by avoiding expressing ideas is an important thing. Americans also have a wonderful way of being active in their contribution, they raise their voice even though they have contrasting ideas. For me, if I study in the American culture, I will have my way, not exactly like typical Vietnamese or American students. I will try to be active, by raising my voice, but not so directly, but in some other way, such as emailing the lecturer, or asking questions privately after the lessons to avoid puzzling situations for the lecturer if my ideas are opposite to what the lecturer said. (Hoang, Ob.8A)

Similarly, in observation 6C, Nam shared his ideas about inviting friends to restaurants. He said:

The Americans, Canadians, and New Zealanders may invite you to have lunch with them but still, you must pay for your food. Vietnamese people pay for everything once you invite others. If I invite my friends from foreign cultures, I think I will still both keep the Vietnamese way of showing hospitality by telling them that I will pay for Vietnamese dishes, such as spring rolls that we can share, and the rest each pays for her/his food. (Nam, Ob.6C)

Hoang and Nam's comments show they had thought about ways to successfully interact with others in a way that mediated between their perceptions of positive cultural traits of their culture and another culture, thus avoiding the false dichotomy of abandoning their culture or assimilating to another culture. Their comments also reveal their sense of responsibility in intercultural interaction. Only a minority of students expressed this view about mediating between cultures and only when the teachers encouraged students to think about what they would do in similar situations and whether they would keep their own culture or abandon it and follow the target culture.

The students also displayed their understanding of the need to adopt their behaviors so that they can fit in a target culture in most of their performances and reflections. This is illustrated in detail in performance 14 below. 


\section{Extract from performance 14}

[Jim came to his girlfriend's house. Na is his girlfriend, and Nam, her father.]

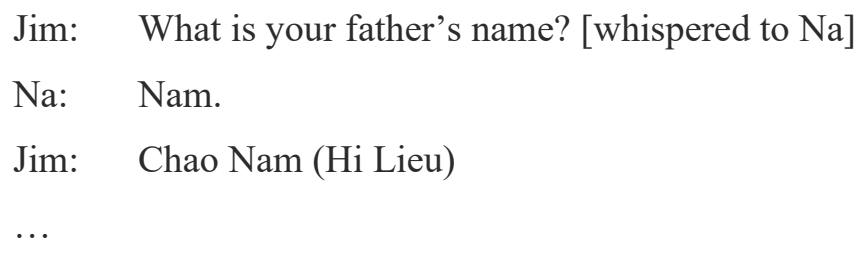

Nam [talked to Na when Jim was talking on the phone in another room)

Nam: Cái anh chàng này tây mà không lịch sự, để bố bạn gái mà chào ngang hang. (This man comes from the West, but he is so impolite. He evens calls his girlfriend's father only by name) [without the word "uncle" before name]

\section{(Extract ST2EX15)}

As explained by the students, the misunderstanding occurred because Jim did not know the appropriate form of address in Vietnamese culture. To be successful in his communication, he needed to know that he should add the word 'uncle' before the name Nam to show the difference in age and relation between him and Nam.

The mediating role of the intercultural speaker was not evident in the performances but was explained in students' comments on their performances in seven of 17 performances. The students demonstrated their critical evaluation of how people do things differently across cultures and suggested ways of acting for themselves. They added that these ways might be more comfortable for them than imitating the foreign culture or conservatively keeping their deeply ingrained perspectives or practices. Following are illustrations from performance extracts.

\section{Extract from performance 4}

Lan, a Vietnamese, visits her American friend, Fiona in her house. Fiona strokes her dog.

Fiona: Darling, here's your food.

[Fiona lets the dog sit on her lap, puts the dog's food on the table. The dog licks on her cheek, she showed happiness and when the dog finishes the plate]

Fiona: Good job. 
Lan: ... [showing surprise]

(Extract ST2EX16)

The students shared their intention in the creation of the scene to inform the audience of the target culture's love for their pets. They considered their pets as family members. Lan showed surprise because, in her culture, dogs were treated as house guards and a source of food. The students acknowledged the diverse perceptions and confessed that though they were open to the differences, they could never treat dogs like humans such as letting them lick their face. However, the students stated they changed a bit in their perceptions and would treat dogs better such as giving them better food and shelter and talked nicer to them rather than giving demand with a loud voice of a boss to his servant such as "go out".

Similarly, there is a scene in performance 17 in which an American friend, Mary, was invited to share a dish with shrimp paste by Thao, a Vietnamese friend, at a restaurant. Mary refused but Thao insisted on inviting Mary. Mary accepted to please Thao. Mary had a terrible stomachache after dinner. The students said that in this case, Mary was aware of the Vietnamese culture, and instead of refusing and directly telling that she was not comfortable with the dish like she typically did in her own culture, she reluctantly accepted the invitation, which resulted in her further trouble. The students shared their opinion that in the same situation, they would have another option, they would politely refuse the dish with shrimp paste, explaining their uncomfortable experience with the food, and ask for another Vietnamese dish that they could both enjoy. For the students, this option would still help them avoid stomachache while making the Vietnamese friend feel that they appreciated her hospitality.

In short, findings showed students' engagement in intercultural learning by displaying their intercultural awareness in the PBL lessons and in their project performances. Among the indications of intercultural awareness, the awareness of their own culture, and cultural similarities and differences were present in all three teachers' lessons. Awareness of culture as diverse and dynamic and of the intercultural as the mediator were deliberately cultivated by the teachers. 


\subsubsection{Intercultural Attitudes}

Another theme identified in the interactions that occurred in the lessons was intercultural attitudes. This theme included three sub-themes: judging others from one's own cultural perspectives, judging others from the others' perspectives, and curiosity and openness. The sub-themes are presented below.

5.2.2.1 Judging Others from One's Own Cultural Perspectives. In the first observations, the students often used their own culture's frame of reference to judge people from other cultures when their teachers asked them gave their first impressions on what people said or behaved in the intercultural activities. In the following example, the teachers asked students to give their opinion about a conversation between a professor and a student (Ob.1B) and two classmates (Ob.1C) that they listened to. In the example, the Australian students address their professor by name. As Phong commented:

So strange, if not to say, shocking to me. It is so impolite. We should show respect to our teachers. We can never call a professor just by name (Phong, Ob.1B)

Likewise, in another class, Phuong commented on the way "How are you?" is used by English speakers as a greeting:

Why they cannot be as honest as we can. If we really want to ask about other's health, we ask, "How are you". If they do not, why not just say "hello", so strange to me (Phuong, Ob.1C)

In these examples, Phong and Phuong evaluated others from their Vietnamese perspectives. They viewed calling a professor by their name as disrespectful (because Vietnamese people must show respect by addressing lecturers with titles) and asking, "How are you" as dishonest (because Vietnamese people expect the respondents to reply with health information). These judgments were students' first responses to teachers' general questions about the intercultural content. Notably, the occurrence of judging others from the students' first language perspectives was more frequent in the first lessons and less in the final lessons while the trend for judging others from the others' perspective was the reverse.

5.2.2.2 Judging People from the Others' Perspective. While some students in the three classes judged people from their own perspectives in the first lessons, throughout the project, there was evidence of the students increasingly seeking to understand the behaviors 
of others from the others' cultural perspective. These changes were usually triggered by guidance from the teacher such as "why do you think their behavior is unacceptable?" "What do you think were the reasons they acted that way?" "If you also come from that culture, what would you do in similar situations?" These questions required students to put themselves in the others' positions and try to explain their actions from their values and beliefs. For example, in observation 8A, in discussion with her peers, Minh commented on the way the students in an American class raised their voices and interrupted their teacher's lecture:

I have searched for information, and I found that it is acceptable and seen as positive and active learning in American if the students ask questions or speak out what they do not agree with the lecturers. In this case, the students in this class acted appropriately. (Minh, Ob.8A)

Minh understood the American values and gave her opinion on the American students in the video clip based on this understanding. In doing so, she did not use her own cultures' beliefs to judge others. Instead, she displayed her ability to step out of her own perspective to view others' behaviors from their cultural standpoint.

In the same way, in observation $8 \mathrm{C}$ when the teacher further asked, "If you were in the position of the American professor, what would you think about the way the American greeted you?", Thang and Lien commented:

Thang: I think it is ok for the American students to greet the professor as 'Hi, James", not professor Muoi like we call our professor. If the professor thinks it is ok, their society accepts that then it is normal. I also imagined what if American students attend our lessons and call our professor that way, our professor would be frustrated and thought the American as impolite.

Lien: I agree. And our professor would not think so if he knows that it is ok to call a professor by name. So, understanding differences is important to avoid serious misunderstandings. (Ob. $8 \mathrm{C})$

\section{(Extract ST2EX17)}

Thang's comments showed his belief that the way the American students greeted their professor in this example should be judged by the values of their cultures. Thang and Lien further envisioned the scenario of an intercultural encounter and the consequences in case the 
participants in the scenario were aware/unaware of the different other. Their talk showed their awareness of cultural differences and their advocacy for understanding these differences rather than judging them from their perspectives.

This subtheme was also revealed through most of the performances. For example, in presentation 15, the students created a scene in which an American man, John, came to the house of his Vietnamese girlfriend, Hong, to take her to a movie. He met his girlfriend's mother (Lieu) and greeted her:

John: Hi Lieu. I come to pick up Hong. We are going to a movie.

[Hong translates what John says into Vietnamese to Lieu]

Lieu: Chao (Hello)

[Hong translates Lieu's words into English to John]

John: Bye.

When Hong returned home, Lieu said to Hong:

Lieu: Mẹ thấy thằng này không ổn. Người gì mà đến nhà bạn gái mà không biết hỏi thăm, chào hỏi gì cả! [Showing anger]

(I think this guy this not ok. What a man! He does not know how to greet, how to greet me!)

Hong: Người nước ngoài họ không hỏi lòng vòng như Việt nam mình đâu mẹ ơi, chứ John không có ý bất lịch sự đâu ạ.

(The Americans do not beat around the bush like us. John does not mean to be impolite).

(Extract ST2EX18)

The students commented that the mother thought John was impolite because John just called her by name went straight to the conversation by telling his intention of taking Hong out for a movie. The mother had expected John to ask her many questions before talking about the plan to go out with her daughter. The mother judged John from the perspective of Vietnamese 
culture. The students intentionally let the daughter in the scene explain why John was not beating around the bush. The daughter understood John and respected John's way of greeting because she judged his behavior from the perspective of the Americans. The creation of the scene helped the students to show the audience that there are underlying reasons for the American's ways of greeting. By putting themselves in the position of a man from another culture and understanding his perspective, the students showed their empathy and respect towards the difference that caused misunderstanding between people from different cultures.

5.2.2.3 Curiosity and Openness. A third sub-theme is curiosity and openness. In all three PBL classes, the students showed their desire to learn about other cultures and respect the differences in their discussions in groups and their conversations with English guest speakers. For example, Nhat asked her students to discuss what they think about the way the students in a video clip asked their teacher's questions after she played a short video clip about a teacher lecturing and being interrupted by many questions from her students in an American class. In a group, Hoai commented:

I noticed that the students could ask questions. The teacher did not show surprise. So, it is a normal thing in that society. It is different from us, even when do not understand very much or have some concerns, we feel hesitant to ask, mostly do not ask. Why is that? Why the students in American society want to interrupt their teacher? (Hoai, Ob. 8A)

Hoai was curious to know about the other culture. In contrast to Phuong's comment (discussed in section 5.2.2.1), Hoai did not judge the students in the clip from her first culture positioning. She simply acknowledged that they are different and expressed her desire to know the reasons for the differences. Similarly, Loan was eager to know about how the Dutch celebrate their New Year when the two English speakers from the Netherlands came to speak in her class:

Could you please tell me how you welcome your new year? What do you often do?

Is there anything we should not do on the first day of the New Year in your culture? Why? (Loan, Ob.5B)

Loan's questions show her interest in exploring the differences in the way people welcome a new year. Loan commented to her teacher when the guests left the class: 
Interesting. There are commonalities and differences. The guests were very respectful and interested in our culture, and we think that we should respect their cultures, too. (Loan, Ob.5B)

In lesson 8, the groups were discussing how people in Vietnam and some countries like America, Australia, New Zealand, and Canada responded to wedding invitations. When the teacher visited her group, Lieu summarized to the teacher what they were discussing as follows:

We discussed and we all thought that we were lucky to be directed to notice the similarities and differences. We, Vietnamese people, do not reply to wedding invitations, but it does not mean we are impolite. However, the westerners consider it polite to respond to their invitations to let you know whether you will come or not. Therefore, we should know their expectations to act appropriately when we receive invitations from the westerners. (Lieu, Ob. $8 \mathrm{C})$

Lieu and Loan's comments reveal that they respected the differences and were willing to adapt to them. This was evident in all PBL lessons, particularly from the fourth observation of each teacher's lessons.

The curiosity in others' perspectives was also present in the presentations and revealed in student reflections on the presentations. The students showed their interest in discovering other perspectives and different habits in their own and other cultures. Out of 17 performances, 16 performances conveyed their curiosity about other cultures through creating drama scenes in which the people from other cultures showed their perspectives about Vietnamese cultures. Excerpts from performances 7 and 5 illustrate this point.

In performance 7 Duc and Anh are from Vietnam and Julia is from Germany. Duc and Anh invited Julia to eat dog meat when they go to a Vietnamese restaurant and Julia refuses. Duc and Anh are surprised at Julia's refusal to eat dog meat and curious to know the reasons.

\section{Extract from performance 7}

Julia: I smell flavor. Oh ... What's this? Yummy!

Duc: This's dog meat, a traditional food in some region. You're not a vegetarian right?

Julia: Yes, ... but I can't eat this

Anh: Oh, why? 
Julia: Dogs are pets. You know, chickens and pigs aren't like pets. They can be food. But dogs aren't. Dogs are friends, are intelligent.

(Extract ST2EX19)

In creating the scene, the students wanted to show their curiosity in understanding others' perspectives, as echoed in their reflections:

We know that westerns do not eat dog meat. We do not know why. The food is really delicious and it is a normal thing to eat the food in Vietnam. After searching for information, we found out that the reason is not that they do not eat meat, but they consider dogs very close friends. We created the characters to reflect what we know and think about this habit as well as why people from other cultures react to this practice. (Thu, RF-P7)

Similarly, students demonstrated their curiosity in others' perspectives in performance 5 . In this scene, three friends, Ly (Vietnamese), Mary and Peter (Americans) are waiting for a bus at a bus stop in Vietnam and a passer-by steps on Mary's foot. Peter is surprised when seeing people on the bus pushing each other. As revealed by the group's post-performance reflection, the idea behind this scene was curiosity about how people from other cultures may feel about a normal scene in a public place in Vietnam.

\section{Extract from performance 5}

Ly: Now, we must to wait the bus 32. It will go pass many beautiful places. Oh, Look! It's coming!

[Scene: People in a waiting crowd push each other to get on the bus]

Mary: Ouch!

Peter: What's happened?

Mary: Someone has just stepped on my foot [face showing discomfort], ... but I'm ok. Don't worry.

Ly: This bus is usually very crowded and chaotic.

Peter: I am wondering that why people don't stand in line.

Ly: Oh, I don't know. But maybe everybody wants to get on quickly [smile]. This is a popular thing in Vietnam.

(Extract ST2EX20) 
The students also showed their open-mindedness and non-judgement in most of their performances. They realized that there were different ways of doing things in different cultures. For example, in the following extract from presentation 4, the students showed their understanding of different ways in which an Australian friend (Fiona) offered drink and food to a Vietnamese friend (Lan) when they were about to go leave the Australian friend's place and go to a movie.

\section{Extract from performance 4}

Fiona: Would you like anything to drink?

Lan: No, thanks.

Fiona: Anything to eat? It is late now.

Lan: No, thanks.

[Fiona drinks and eats, then the two friends go to see a movie]

Back home, Lan talked to her mother, Hoa

Lan: I am so hungry.

Hoa: Did you eat anything? I thought you went out with Fiona.

Lan: $\quad$ She offered me [offered food and drink] but I refused. ... I thought that she would invite me at least several times before I accepted.

\section{(Extract ST1EX21)}

Reflecting on the invention of the two characters Fiona and Lan, the students said that they wanted to show that Vietnamese and Australians have different ways of inviting guests to have drink/food. In this case, the Australian friend, Fiona, was direct in offering drink/food and believed that Lan refused because she was not thirsty or hungry. In fact, Lan was thirsty but still refused because it was her culture it is polite to refuse several times before accepting the offer. Therefore, Lan expected that Fiona would insist on offering food and drink several times. The students' creation of the scene reflects their open-mindedness about the differences in the host and target cultures in this specific context. Hoa, one of the students performing the scenes further commented:

We should not think of Fiona, the Australian in the scene, as impolite and mean. She was different in her way of receiving guests because in her culture it is a normal, appropriate thing to do. (Hoa-RF-P4) 
The comment reveals that Hoa was open-minded and non-judgmental. These attitudes might have been developed with her growth in her understanding of the views of other cultures when she engaged in intercultural exploration.

\subsubsection{Summary}

In summary, evidence from the $24 \mathrm{PBL}$ lessons and the project performances showed how the students engaged in intercultural learning processes on cultivating intercultural awareness and intercultural attitudes. Their intercultural awareness involves awareness of self, awareness of stereotypes, awareness of cultural similarities and differences, awareness of how to communicate appropriately across cultures, and awareness of the intercultural speaker as the mediator. Findings also show that the students were curious in others' perspectives, open-minded, and shifted towards non-judgement in later lessons. These attitudes and awareness were fostered through their engagement in their project, which shows the ability to foster students' intercultural learning through a project-based approach.

\subsection{Findings from Interviews with PBL Teachers}

In the two interviews: one interview after lesson cycle 1 (lessons 1-4), one interview after lesson cycle 2 (lessons 5-10), the three teachers were asked to reflect on their experience of implementing the PBL lessons. From a thematic analysis of these interviews, I identified five themes; each of which is discussed below.

1. The benefits of PBL lessons

2. Challenges in conducting PBL lessons

3. Student engagement

4. The benefits of the PAR model

\subsubsection{The Benefits of PBL Lessons}

All three teachers believed that PBL lessons were beneficial to students' language knowledge and skills, intercultural competence, project skills, and raising teachers' understanding of ICLTL and PBL.

5.3.1.1 Students' Language Knowledge and Skill Development. First, all three teachers commented that the PBL lessons provided a valuable approach for students to 
enhance their learning, such as enriching their vocabulary and grammar, speaking, and listening skills. As Nhat noted:

When the students needed to search for words for their projects, they had to read a lot, looked up the words' meanings in the dictionary, and thought about how to create dialogue, for example. Therefore, it is clear that in this way they would know more words and used them in specific contexts. These words are real to life, easy to remember, not bookish, which is hard to remember. (Nhat-S2IT)

Nhat implicitly contrasted the picking up of words in the traditional methods and that in the newly adopted PBL lessons. She perceived word development takes place in PBL to be more efficient than in traditional methods. She argued that students' vocabulary did not only expands but also can be better absorbed due to the inherent real-life nature of their project and the students' process of actively engaging in searching for words.

In the same vein, Tan saw how the PBL lessons helped her students develop their speaking skills. As she put it:

As I observed, the students in my class were very shy at the beginning of the term. When I asked simple questions, it took them a lot of time to respond. When they were asked to create conversations with friends, they simply based on the structures in books and followed very rigidly, hardly changed anything from the book. After many PBL lessons, contacting each other in groups, they become more confident, bold, not afraid of being asked, ready to answer, speak more fluently, not dependent on the textbook, and develop their conversations naturally. (Tan-S2IT)

Tan's account showed that she believed her students improved their fluency and became more actively engaged in interactions. The PBL approach provided chances for more frequent interactions as students worked in groups, which allowed the growth of knowledge and skills during interactions. These interactions shift students from passive (e.g., "wait to be asked questions" to active learners (e.g., "discussed much more enthusiastically”). As Nhi elaborated:

They have discussed much more enthusiastically since working in Project groups. Normally, if we follow the traditional way, the shy students just sit and listen. (Nhi-S2IT) 
Nhi added that in previous semesters, she sometimes asked students to conduct projects. However, these projects were treated like homework, with no teacher guidance and support in project work, and no discussion on projects with group members in class. For example, students just gathered information about a topic, learnt by heart and presented in class. Nhi found that this old approach deprived students of chances for making learning progress through interactions in class and through teacher support.

5.3.1.2 Fostering Students' Intercultural Competence. All three teachers reported that the PBL lessons developed their students' intercultural competence including intercultural knowledge, skills, and attitudes. For Tan, the knowledge of "Self" - students' own culture - was a valuable feature of the PBL lessons:

We used to take it for granted that our students know our cultures, so no one mentioned it when teaching English. After this term, I found it very important. Students discussed how Vietnamese used their language before discovering how people from other cultures speak and why. In this way they could see the differences clearly, even they saw the differences among themselves - Vietnamese students. (Tan-S2IT)

The extract shows the contrast between Tan's pre- and post-PBL lesson views of teaching culture. Conducting PBL lessons helped her realize that understanding of their own culture assists students in their comparisons and their understanding of culture as more than a monolithic concept and that variabilities exist among members of the same culture. Tan also noted how the lessons helped the students to take the position of the cultural "other":

For example, students took part in a role play, one played the role of an American woman talking with a Vietnamese woman and the Vietnamese woman asked questions about salary, then the students should put themselves in the "American's shoes" - the American position, thought about the American woman could be thinking. At that point, the student figured out the uncomfortable feeling the American person might have had, and then became aware of the differences, and then found that they needed to act interculturally appropriately. (Tan-S2IT)

For Tan, the decentering process occurs internally and makes students aware of the need to adjust their expectations and communication in intercultural encounters. Similarly, Nhi emphasized the understanding of "Self" and the possible impact of reflection activities on students' future behaviors: 
In one of our lessons, we talked about how Vietnamese people responded to wedding invitations and the gifts that we often gave to the bride and groom. The discussion was so heated, and the students showed their common and different ways of responding and giving gifts, receiving gifts as well as the way target culture people did. In the reflection section, one of the students said that she received a wedding invitation to an international friend, but she did not turn up, did not respond, and just asked another to send her a present. It is totally ok in Vietnam. Then two other students added that they did the same in their situations. These three students told me that now, thinking back, they wondered whether their no-responses were considered impolite. They thought they would do differently in similar situations. (Nhi-S2IT)

Additionally, the teachers found that the intercultural activities in the PBL lessons had a positive impact on students' attitudes, as illustrated in the following extracts:

When they know about the differences, they want to know more about these differences and why. (Nhi-S2IT)

Putting themselves in others' shoes helps them see that their cultures can have some problems in others' eyes, and therefore, stop thinking that we are right and base on our cultures to judge others from different cultures. (Tan-S2IT)

The extracts show teachers' perceptions of students' attitudes shifting towards curiosity and openness as well as an understanding that their culture is relative. The teachers recognized that students' curiosity was developed and fostered through intercultural teaching. Without explicit intercultural instruction, students might have attended primarily to language features, as in the traditional approach.

5.3.1.3 Students' Project Skills Development. Another gain from PBL lessons that all three teachers noted is students' skills development such as collaboration skills, autonomy, and presentation skills. The teachers considered students' efforts in managing their time to fulfill their part in the project, actively looking for project materials, and asking questions as positive signs of growing autonomy. As Nhi put it:

Each student has to finish his/her part in the project, not to be told what to do anymore. They have to arrange time properly. (Nhi-S2IT)

Similarly, Nhat perceived that her students' negotiation skills grew when they were more engaged in group discussions: 
As I observed, Binh in group 1 expressed his view but other group members did not agree. He kept quiet, displaying frustration on his face. Another group member expressed her idea and some group members disapproved. However, she patiently explained her reasons. In the next discussion, Binh appeared to be patient and tried to convince others with his information. The group member might have influenced Binh. To work well in groups, of course, you have to try. (Nhat-S2IT)

Nhat saw that her students developed their responsibility for their learning and adjusted their behaviors through collaborating with peers.

The teachers also highlighted the benefit of the PBL lessons in developing students' presentation skills. They noticed students' improvement in their non-verbal communication, managing time well, and maintaining fluency. As they said:

After they practiced many times, they became confident in front of the whole class, and in how to keep eye contact. (Tan-S2IT)

The project teams divided their performance time so that they did not exceed the time allowed. (Nhat-S2IT)

Many rehearsals helped them not to stumble. They corrected each other - yeah, very helpful. They did not just depend on teachers' comments. I think working closely in teams for a period made them feel easier to frankly comment on others, not being afraid that friends would hate them. (Nhi-S2IT)

From Nhi's cultural perspectives, being critical was a hindrance to team collaboration when members were not "close". Therefore, as commented by the teachers, the PBL approach does benefit the students as it provides the chances for interactions, which removes the dare-notto-be-critical attitude and encourages idea construction.

5.3.1.4 Raising Teachers' Understandings. Additionally, the teachers noted how the PBL lessons raised their own understanding of the PBL approach, and of intercultural language teaching and learning. All three teachers commented that they had no previous knowledge of PBL. As Tan explained:

Before I thought simply that a project is a like a type of homework that teachers assign students to do. Simple as that. In reality, it is different. We do not teach, we "facilitate" 
leaning, so that they can complete the project themselves, and be active in their learning process. (Tan-S2IT)

This reflection reveals a change in Tan's perceptions of a project and the roles of teachers in PBL. Similarly, Nhat explained the role of the teacher in PBL:

Before this term, we rarely assigned projects to students. When we did, we never gave feedback during students' process of conducting projects. They took care of their projects throughout. In retrospect, it was very problematic. Now I understand why students struggled with projects in previous terms, and saw little benefits in projects. Now I realize that we need to help students and give feedback during their course of doing their project as well, not only on the outcome. In fact, to give feedback, we need to understand what they are doing in their projects. This has also increased our knowledge. (Nhat-S2IT)

Nhat's remarks show a growing awareness of the value of feedback and how giving feedback pushes teachers to become more knowledgeable about the work the students are doing in the projects and the problems they face. Notably, she perceived giving feedback as a chance for teachers to expand their knowledge.

The teachers also reported that their understanding of intercultural language teaching and learning had been developed. For example, Tan talked about the concept of an ideal intercultural teacher:

I used to think that native English speakers are ideal for teaching culture since we do not know much about their culture as they do. No, it is not true. They do not know much about our culture, either. It is not a must for us to know everything so that we can teach. What is important is to guide students so that they can increase their intercultural awareness.

Therefore, I am more confident to teach now. (Tan-S2IT)

This perception aligns with the intercultural teaching and learning literature that the intercultural teacher does not need to know everything, to be the expert cultural informant but instead, has the role of guiding students in the process of discovery (Byram et al., 2002). Nhi recognized the feasibility of teaching culture without having to compromise the communicative language goals:

I had not thought that we could combine language and cultural goals. I was wrong. Actually, students did not lose chances for their speaking activities. (Nhi-S2IT) 
The teachers also admitted that their knowledge of intercultural language teaching principles was enhanced. They said:

Now we know the objectives of intercultural teachings and the principles. (Nhi-S2IT)

We need to provide chances and encourage students' noticing, comparing, reflecting, not just giving information and students passively listen as before. (Tan-S2IT)

The recognition of the need to focus on experiential learning rather than simple fact giving shows a salient shift in teachers' perception of teaching culture.

Overall, the interview data show that the PBL lessons were beneficial to both students and teachers. For the students, they enhanced their language skills in tandem with intercultural skills and project skills. For teachers, the process of implementing PBL lessons gave them insights into how to adopt the PBL approach in their specific context and concurrently fostered students' intercultural learning. However, the teachers also reported challenges as discussed next.

\subsubsection{Challenges in Conducting the PBL Lessons}

The thematic analysis revealed four challenges the teachers faced in implementing the PBL lessons: lack of experience with PBL and ICLTL, time management, limited teaching resources, and student-related issues.

5.3.2.1 Lack of Experience. All three teachers identified a lack of experience with PBL and ICLTL as a constraint that they faced. As Tan and Nhi commented:

Although we had discussed PBL and ICLTL in the workshops, sometimes in actual teaching I forgot, really ... really confused. Sometimes I wondered whether my feedback was adequate. Sometimes I forgot and returned to the traditional method, so instead of encouraging students to discuss, note the differences and compare differences in cultures, I jumped too quickly to explain to students the cultural differences. (Tan-S2IT)

It is really interesting, but to be honest, I was scared at first. It is a new method. I have never taught students this way. Students might look at us as not confident as normal. In fact, it is not so scary. I did it quite well [delivered the lessons], I think so. (Nhi-S2IT) 
These comments show that teachers needed time to develop familiarity with PBL and ICLTL, and with applying these new approaches in their teaching.

5.3.2.2 Time Management. Another challenge for the teacher is time management, both in the lessons and lesson planning. As Nhat said:

The first lessons lasted longer than scheduled and ended at $12.10 \mathrm{pm}$. instead of $11.55 \mathrm{pm}$ ). Maybe because I allowed too much time for students' discussion and reflections and in subsequent lessons, it did not happen when I was used to the new approach. (Nhat-S2IT)

Nhi emphasized the lack of time for preparing lessons. In her opinion, her tight teaching schedule impeded her from maximizing her lesson preparation. She noted:

You know, I teach many periods a week so I feel really tired. I cannot work to the full but I tried to give feedback to students' project and thought about how to conduct the teaching activities so that the lessons go on smoothly. (Nhi-S2IT)

This comment suggests that heavy workload from teaching may influenced teachers' working performance. However, the extract also reveals Nhi's efforts and responsibility towards her lessons under the time constraint.

5.3.2.3 Limited Teaching Resources. Additionally, the lack of resources concerned the teachers. They explained the difficulty in designing intercultural teaching materials. As Nhi put it:

It is very hard for us to teach interculturally when teaching resources are not ready for us. Designing each activity took time and expertise. We needed to choose materials that fitted with textbook topics, and then gathered data in both Vietnamese culture and target cultures. After that, we thought hard to come up with ideas about activities that could engage students. (Nhi-S2IT)

5.3.2.4 Student-related Issues. Finally, the teachers reported some student-related issues. Problems sometimes arise from students' characteristics and specific circumstances. Nhat explained that some students might hinder the whole group's process:

Some students were very stubborn or had a low sense of discipline. For example, frequently being late or lazy in thinking and constructing ideas to group. (Nhat-S2IT) 
In contrast to Nhat's comments on "stubborn" students, Nhi commented that some of her students were too shy to speak in groups. However, she was happy because they "turned out to participate and speak much more with enthusiasm later".

The three teachers shared their common approach in dealing with these students. They said that they attempted to privately persuade the students to actively participate in their groups and reminded them that their scores could be reduced for not performing their roles in their assigned projects.

Concerning the students' circumstances, the teachers noted that students' demographical features and financial situation affected their learning. For example, in their opinions, students from remote areas tended to form groups with peers from other outskirts rather than with students from cities. This tendency might leave the students with limited chances to choose groups to be part of.

Students coming from the same or neighboring provinces often sit near each other in lessons. (Tan-S2IT)

Moreover, the teachers expressed concern over their students' limited budget and residential conditions, which hampered their learning efforts due to limited access to technology tools for learning. As Nhi explained:

Some students told me that they rent the houses, so it was not convenient to buy laptops. You know, thieves often break into cheap rental houses. No internet, no laptop how they could frequently contact other project team members. They could use the university library, but it was not very convenient. However, it was good that they let me know so I encouraged them to meet in person on campus and discuss with their group members in the lessons. (Nhi-S2IT)

It can be inferred from Nhi's account that learning facilities are not well supported by the institutes in terms of PBL. It then became a challenge for students if they could not afford the necessary technological devices.

In brief, lack of experience with PBL, time constraints, limited teaching resources, and students' characteristics were four challenges the teachers faced. However, they reported seeking ways to limit negative impact of these challenges. In the interviews, the teachers also 
shared their evaluations of student engagement in the PBL lessons, as discussed in the following section.

\subsubsection{Student Engagement}

The thematic analysis of the two interviews revealed teachers' common perceptions of students' growing dynamic engagement in the PBL lessons.

Nhat and Tan emphasized their students' considerable progress in the lessons in the second half of the project compared to their learning over the first half of the project. For example, Nhat recalled in the first interview:

I guess that sometimes they did not understand but did not want to speak, so, you know, I often asked them then explained to them. I know, it was hard, because it is new to them. They spoke little in their discussion. For the intercultural content, they showed excitement, but I still had to give them many prompts for discussion. I need to repeat many times what they should do. (Nhat-S2IT)

Nhat's students were passive in their learning, to begin with, as seen in their unwillingness to raise their voice when they did not understand. Nhat's explanation that "it is new to them" suggests that, in part, this is a result of being exposed to a new teaching method. In the second interview, Nhat and Tan highlighted her students' improved engagement in the lessons. As they said:

They are accustomed to PBL lessons now, discuss enthusiastically, not sitting quietly as before. (Nhat-S2IT)

They began to notice the differences between cultures and shared what they knew, and their real-life stories. (Tan-S2IT)

They prepared questions and asked guest speakers. Before that, I told them not to be afraid, assured them that talking with guest speakers can be fun could informal, and mistakes did not matter. In addition, I helped them check their prepared questions. (Nhat-S2IT)

These comments indicate that Nhat's students became more active in group discussion, sharing knowledge, preparing for, and getting involved in intercultural interactions. The quotes above show that the teachers saw improvement in both project skills and intercultural skills. 
The two interviews with Nhi revealed similar trends. In the first interview, she said:

A group of students ... about four students are very active. They get involved in every activity. The rest of them have been mostly passive, waiting for me to give instructions many times before participating in group discussions. I think the characteristics of students that counts and also, Nam the leader in the group has some experience overseas as a tourist, he is also a city-dweller, so have more advantages in terms of English and intercultural experience. (Nhi-S2IT)

In the second interview:

Nam's group members have become more and more active. In addition, the rest of the class has gradually discussed much more. They asked questions, shared their ideas. I do not have to encourage a lot as before. (Nhi-S2IT)

Nhi's comments show that all her students became more engaged in the PBL but that those with an urban background adapted more easily and quickly to PBL.

In addition to improved engagement, all three teachers noted positive effects on learning. For example, Nhat said:

They spoke with much better pronunciation, better word choice, and fluency. They integrated cultural content in their drama very lively. After each time I gave feedback to their work, they provided me with a better version. (Nhat-S2IT)

In brief, all three teachers saw students' improvement in language skills, intercultural and project skills, and a shift from passive to more active engagement over the course of the PBL lessons.

\subsubsection{The Benefits of the PAR Model}

In the two interviews, all three teachers expressed their views about the value of PAR model. From the thematic data analysis, I identified two subthemes: (i) the value of workshops in professional development and (ii) the PAR collaboration among PAR members. These two themes are discussed in detail below.

5.3.4.1 The Value of Workshops in Professional Development. In both interviews, all three teachers reported that they considered the two workshops as rare and valuable 
chances for their professional development. In their opinions, the workshops provided them with knowledge about ICLTL and PBL. For example, Nhat said:

The workshops are very useful. Honestly, I have never heard about ICLT before. Now I understand. You help me to understand. Thank you. It is kind of ... I can be more confident and know what I should do and why in my teaching job. (Nhi-S2IT)

Similarly, Tan articulated her desire to be "equipped with such up-to-date information more often". She added that her source of reference since university education was "always out of date, about 30 years before" and in particular, she emphasized, "never be trained on teaching culture or project". In the same vein, Nhi commented:

For a long time, maybe five years, I have not attended such an interesting workshop with new, helpful information. I know much more about teaching culture and project approach now, very necessary for us. We were so naïve before, we just taught without following any sound principles. I also hope that we continue to have chances to join such workshops. (Nhi-S2IT)

The teachers' comments suggest the importance of the information the workshops provided for the teachers in this context who have limited access to professional learning on current methodologies.

Additionally, the teachers valued the chances to discuss their teaching practices and specific issues in groups, as seen in the following comments:

I had a problem; actually, I was not very pleased with a student. Kind of stubborn. Not a big problem ... Nhi and Tan advised me to ask the student to meet me a few minutes after the lesson and patiently explained why he should join the project, and should be hard working. It worked. Not very complicated. Sure. Nevertheless, I had not thought about it [solving the problem as suggested]. (Nhi-S2IT)

We tried to generate intercultural activities in the lesson about important life events. I suggested wedding and wedding invitations as a topic for discussion. Nhat and Nhi agreed. Then Nhi suggested the pictures to put on slideshows and Nhat added the prompts for students to notice and discuss the differences [between cultures]. If each of us, I mean, if we did separately, we could not come up with as many ideas [as the whole group]. (Tan-S2IT)

Overall, the teachers valued the workshops for their information value as well as for offering a venue for collectively resolving pedagogical issues. This suggests the significance of the 
workshops to the outcome of each teacher's lessons when they drew on the workshop discussions and applied them to their actual teaching practices.

5.3.4.2 The Collaboration among PAR Members. The three teachers gave positive comments on the collaboration among PAR members. For them, this collaboration was effective in the conduct of their lessons and served to reinforce the relationship among teacher participants.

(i) Effective in the Conduct of Lessons. As they described in the interviews, the teachers assisted each other in addressing their teaching problems through their discussions in workshops and their preparation for lessons via casual meetings and emails. They stated that they attempted to discuss every time they met, even in the "only 10 minutes break between lessons" (Nhat), "at 9 pm on Friday ... I chatted on Messenger with Nhat and Nhi, asked about preparation for students' intercultural encounters with guest speakers" (Tan). Give the time constraints they faced, their frequent meetings, either formal or informal reveals how much the teachers valued exchanging ideas with each other.

(ii) Reinforce Collegial Relationship. Another feature of the PAR collaboration perceived by the teachers is the role that PAR collaboration plays in reinforcing the collegial relationship among the teachers. As Tan explained:

Before ...I knew Nhat and Nhi, but not very well, so at first, I felt reluctant and cautious ... even to be safe, I thought I should keep silent in the discussions. Gradually, I feel that we are closer, perhaps talking more with them makes me realize that they are friendly and open, so I have become more open, so we work effectively... also, the number of members is enough and convenient to contact. (Tan-S2IT)

As Tan explained, the connections among teachers grew when they got more involved in the PAR through their contact with each other. Likewise, Nhi commented that they were on good terms with each other and "generally respect each other, and frankly voice our thought, not afraid of offending each other". Nhat noted the positive impact of collaboration on their work:

One of the things I like best about joining this research is that we could work together ... We have reasons to contact each other. Normally, each of us is very busy ... rarely has a chance to talk to understand each other ... especially about these interesting issues like culture and 
project. So cool ... this environment allows us to voice what we think, not like in super formal meetings with dozens of teachers when it was safe to keep silent whether you agreed or not. It is; therefore, I have to say, wonderful to discover things together ... understanding one another helps us to work more effectively. (Nhat-S2IT)

To sum up, this section has presented findings from individual interviews with teachers. The findings revealed teachers' perceived benefits of PBL lessons, challenges in conducting PBL lessons, students' growing dynamic engagement, and the benefits of the PAR model. Overall, these findings show teachers' positive attitudes toward adopting the PBL approach in fostering students' intercultural learning.

\subsection{Findings from PBL Student Focus Group Interviews and Reflections}

The following section discusses findings from the analysis of nine student focus group interviews. The students were asked questions such as whether they liked the PBL lessons and the project, why they liked or disliked, what part of the project they preferred, whether they were willing to take part in similar projects in the coming courses, three overarching themes emerged:

1. Perceived learning outcomes

2. Attitudes towards the PBL lessons

3. Challenges in conducting the project

Each theme is presented in detail below.

\subsubsection{Perceived Learning Outcomes}

When asked about their experience of the PBL lessons, the majority of the students interviewed in nine focus groups revealed that they made progress in three aspects of learning: intercultural learning, language learning, and project skills.

5.4.1.1 Intercultural Learning Outcomes. The most prominent aspect of learning outcomes reported by the student is intercultural learning outcomes. All students in nine focus groups acknowledged the benefits of intercultural learning in PBL lessons. In particular, they mentioned their (i) growth in their intercultural awareness, (ii) improvement in cultural knowledge, (iii) improved intercultural skills, and (iv) positive changes in their intercultural attitudes. 
(i) Growth in Intercultural Awareness. All nine student focus groups revealed their growth in intercultural groups. Students from Nhat's class spent more time talking about this growth than students in Nhi and Tan's classes. In addition, more students from Nhat's class reflected on their intercultural awareness. Following are some examples:

Before the course, I only thought that cultures around the world were basically similar. But after the course, I found out what I previously thought was totally wrong. Each culture is different such as in greeting or shopping. I was also surprised that men and women can greet differently ... using different kinds of eye contact and gestures. (Loan, FG1, CL1)

Before the course, I never thought about other cultures except our own. (Tan, FG4, CL2)

I used to focus only on translating from Vietnamese to English word by word, now I think I should understand other cultures. I used to think speaking English well is successful ... now I realize studying English without knowing cultures is a terrible mistake. (Lan, FG2, CL1)

The students' reflections show that they recognized their prior misunderstanding of the nature of successful intercultural communication. The value of this awareness is that it can encourage the students to continue to explore the intercultural dimensions of their learning. For example, Lan (FG7) noted, "from now on, I will try to know much more about cultures". $\mathrm{Ha}$ (FG8, CL3) realized that "these are very helpful for our life and future jobs".

(ii) Improvement in Intercultural Knowledge. The students all nine groups noted improvement in intercultural knowledge. For example, the following students (FG9, CL3) talked about politeness as follows:

Lan: Now I understand that Vietnamese and English speakers view politeness differently. For example, we consider inviting before eating is polite. If not, very impolite. Not the same in English culture.

Nam: Yes, right. And even in Vietnam, it is different among regions, and relationship and ages of the eaters.

Hoa: I agree. We are now aware that many things seem normal in our countries but are not considered normal in other cultures.

Linh: And not just in words, in gestures as well, even distance when standing and sitting. In Vietnamese, we do need to thank the bus driver, and it is ok to stand close, like no distance from each other. The opposite may hold true in many cultures.

(FG9, CL3) 
The extracts show that the students have developed their knowledge of cultural verbal and nonverbal differences in specific situations. These comments also reflect growing sophistication in students' understanding of their own culture and other cultures. In the above focus group discussion, Lan treated cultures as divided by national borders. When the conversation developed, Nam recognized culture as variable, context-bound, and diverse within a nation.

(iii) Improved Intercultural Skills. In four instances, students talked about their improved intercultural skills ( 2 instances from Nhat's class, 1 instance from Nhi's class, 1 instance from Tan's). They acknowledged their major changes from not noticing to "keen on exploring the cultural differences in intercultural interactions" (Thang, FG4, CL2). In addition, they detailed how they handled possible misunderstandings when they interacted with guest speakers:

I remember in lesson 5, I had a chance to chat online with an English speaker. I began with some common greetings, and I felt a bit nervous. She sounded very friendly. When I was about to ask, "How old are you," I suddenly remembered from the lessons that it is not polite to ask a woman such a question. So, I did not ask about age. Instead, I asked her about her place ... (Ha, FG3, CL1)

In lesson 6, when I was talking with a guest speaker, she told me that she did not like some of the food I mentioned. I asked why. Then she paused a moment. I wondered about the silence. Then, I realized that I might have asked a silly question. Then I moved to another topic, talking about the hobby. If I had not been involved in cultural activities in class, I would have guessed that she did not understand my English and I would have kept asking. She would have been uncomfortable if I had asked, I guessed. (Huong, FG9, CL3)

It can be inferred that Ha actively applied her intercultural knowledge in her real communication and Huong showed her intercultural sensitivity in dealing with her own intercultural encounters including being sensitive to her conversation partner's feelings.

(iv) Positive Change in Intercultural Attitudes. Seven focus group students (3 groups in Nhat's class, 2 groups in Nhi's, 2 groups in Tan's class) perceived that they had made positive changes in their intercultural attitudes. The students noticed that they became more tolerant, open, and shifted from ethnocentric to ethnorelative attitudes. For example, they said: 
When I did not know, I thought that some language use and behaviors in other cultures were unpleasant, not polite. Now I just think they are different from ours. (Binh, FG1, CL1)

Now I think we should respect cultural differences. I used to judge others based on our cultures. (Duong, FG7, CL3)

Previously, I viewed others who were different from mine as ridiculous and asked myself "What the hell are they talking or doing?". Looking back, I felt ashamed of what I did think. (Lien, FG2, CL1)

As illustrated in the reflections, the students moved from rejecting the differences to viewing them as different and finally respecting the differences. The students explained that their attitude changes resulted from engaging in intercultural activities in the lessons and their experiential learning for the completion of their project.

5.4.1.2 Language Learning Outcomes. The second aspect of progress reported is in language learning. In seven of the nine focus groups, the students talked at length about their development in speaking skills. The following discussion in focus group 6 illustrates this finding:

Ha: Previously I reacted slowly, I used to think, have to make sure about whether the sentence is correct - I mean the grammar, so it took time to answer the teacher's questions or talk with classmates. Now I speak much quicker, more natural. I learn to think in English, not in Vietnamese anymore.

Hung: We are more familiar, and practice through lots of activities - so we make better conversations in a shorter time.

Huong: I used to write down before speaking. Not anymore.

Lien: And much more naturally, not much preparation before conversations like previously, sometimes even without preparations. Now we have more words and knowledge from doing projects, so we feel that our conversations are more interesting, more ideas, more words, more sentences, not relying on textbook phrases.

(FG6, CL2)

In this extract, the students identify improvements in using English for speaking, including better and quicker responses in conversations, less time to prepare for a conversation, and 
more natural language production. In addition, the students also noted improvements in their language, and in particular in improved pronunciation, more language structures, and better control over pronunciation:

I can distinguish how to pronounce 's' and 'sh'. This is the result of practicing in class and chatting in groups. They [group members] reminded me when I pronounced incorrectly. (Hoang, FG4, CL2)

I used to raise my voice and lower my voice randomly without any principle, just try to sound like native speakers. Later, my teacher helped me realize this big mistake by telling me about the rule for raising voice and lowering voice. Then I intentionally noticed how English speakers raised their voices and lowered their voices. The meaning can be different or contrasting if using intonations improperly. (Toan, FG3, CL1)

These speaking skill improvements were made through their engagement in a range of speaking activities such as role-playing, rehearsing for the project, relating to personal experience, and reflecting. The students recognized language improvements not just from teacher instruction but also in their independent preparation for their project. This suggests that the students became more active and autonomous learners. Finally, the students noted their project skills outcomes, which are detailed next.

5.4.1.3 Project Skill Outcomes. The final aspect of learning reported by the students is project skill outcomes. All nine focus groups highlighted public speaking skills and collaboration skills. Regarding public speaking skills, the students in focus group 5 commented that they had progressed a great deal:

An: Now we know how to use words to start, continue and end the presentation

Hoai: Right. In addition, inviting the audience to join is fun, too, and makes it interesting.

Lan: We care more about intonation and voice.

Long: I agree. Body language and costumes as well.

(FG5, CL2)

As seen in the extract, the students acknowledged factors to be considered in a presentation. In addition, most of them displayed satisfaction over their project presentations. In their explanations, the success of their presentations was attributed to their arduous work and the help from the teacher. Some students recognized minor limitations in their presentation such 
as "not timing quite well" and "speaking a little too soft". However, awareness of their limitations also demonstrates an improvement in self-monitoring, thus, might contribute to improved future performances.

Concerning collaboration skills, the students said that participating in the projects helped them to know "how to persuade peers, how to contribute diverse ideas without fear of threatening others' face" (Hung, FG5, CL2). These skills developed in parallel with language development and intercultural skills. This illustrates the value of the integrated skill approach in PBL. Alongside learning outcomes, the students shared their attitudes toward the PBL lessons. The following section is devoted to present this theme.

\subsubsection{Attitudes towards the PBL Lessons}

In their focus group interviews, the students were asked about their experience of PBL lessons. Most of them highlighted their interest in intercultural activities, feeling empowered when given authority over their own project, appreciation for teacher facilitation, passion for interactions with peers, and their desire for the PBL approach to be continued in their learning programs. Details are discussed below.

5.4.2.1 Interest in Intercultural Activities. In all focus group interviews, the students expressed their interest in intercultural activities. All student groups talked and length and with great enthusiasm about these activities. For example, students in group 2, Nhi's class said:

Hung: Wonderful. Wonderful. These activities bring life to our lessons. Talking about our own cultures, and think what people from other cultures do and talk ...raise our curiosity ... I love that. The lesson brings a lot of joy. We learn more and laugh more.

Lien: I like the session to talk with English speakers, like it so much ... I was a bit scared at the beginning, not now. I feel I like to talk much more with them.

Lan: The videos are so fascinating - they help us to talk and talk naturally. Previously, I did not have that type of motivation to talk ... and we can talk about our real experience.

Nhu: It made us all feel so comfortable, I mean, a lot of fun when roleplaying, not like normal lessons, I mean before these lessons. Normally, in roleplaying we simply act exactly like in textbook conversation, or change a bit - boring, and not real.

(FG2, CL2) 
Similarly, in their reflections, students noted their experience with intercultural activities:

Normally, I study English by learning by heart. I do not care, to be exact, I do not know about culture. Today the teacher guided us to think about how Vietnamese greet and compare with English speakers. I understand that even in English, we should not use hello, or good morning in every situation, it depends. In addition, "How are you?" is different from "how are you" in Vietnam ... the activity is very interesting and helpful. I like it. The lessons were so relaxing with fun moments (Loan, FG1, CL1)

I previously thought that there was no need to respond to invitations to parties or weddings. In Vietnam, you can turn up with gifts or if you can ask others to give the presents on your behalf. I thought it was the same in English culture. I was wrong. How impolite I would be if later I acted the way I thought ... the lesson is so important. It is not only very helpful; it is fun and I felt relaxed. I like to have many activities like this (Hang, FG8, CL3)

Overall, the evidence from the students' statement is that the students embraced the intercultural activities for the perceived benefits these activities offered them for intercultural learning.

5.4.2.2 Feeling Empowered. One reported aspect of the PBL lessons that intrigued the students was that they were given autonomy to plan and implement their projects. Most of the students affirmed their preference for being empowered to decide their project plans and work division among group members. This is illustrated as in the following extracts:

We had the right to choose our teams, split our work, and prepare for our presentation. This is the first experience of this type. This makes us feel that we are respected and ... I like to do what I want rather than being told from A-to-Z steps. (Toan, FG1, CL1)

Similarly, Nhu elaborated her sense of ownership towards the project:

The thing I like about the project is that we agree on our plan of action ... and responsible for it. Of course, we need guidance from our teacher, but I mean it is our project. Our teacher does not tell us to obey her ideas. Therefore, we feel ... not restricted, have the freedom to develop such as the content of our drama. (Nhu, FG8, CL3)

In addition, the students further detailed the changes in their responses to the newly adopted PBL model. This is exemplified in the following focus group 4 interview extract: 
Hoa: Initially, we felt strange. We were used to being told what to do ... so, like newcomers to an unfamiliar environment, we felt puzzled, then we got familiar with it, then once we fully understand, we like it.

Tiep: Exactly, it took time for our group, luckily, not long, to move from the old method to these new lessons. We learned to think, to ask questions, not wait for our teachers to tell us about every move like before. Cool. I think we have learned to be more independent. The more we got into the project, the more we enjoyed coming up with decisions for our projects.

(FG4, CL2)

In brief, the students maintained that they supported handling the project on their own and saw this as a step towards more independent learning. This finding aligns with findings from teachers' interviews and observations of lessons.

5.4.2.3 Appreciation for Teacher Facilitation. All nine focus group students said that the teachers' dedicated and helpful facilitation helped make the lessons intriguing. They depicted their teachers as "caring", "gentle", and "tolerant", "not showing dissatisfaction when we make mistakes", and thus they feel "easier to talk", "talk naturally without fear of making mistakes". The students in focus group 7 elaborated their views about the teachers' guide as in the following extract:

Nam: I like Ms' Tan's lessons. She is very open and close to students. She often went to our desks and listened to our questions and helped.

Hoa: Yeah, we are new students. Without Ms. Tan's help, we could not do what we want to. I like her feedback on our ideas for the project. And I appreciate her detailed comments on our project.

Thuy: Yeah, we prefer detailed comments than general comments. Detailed comments helped us to know our good points and shortcoming in our project.

Lan: We are so thankful to her. She makes us feel like to study. She, kind of, explored things with us, especially in intercultural activities and when we expressed our ideas, she listened to us.

Duong: Yes, she is so helpful.

Nhu: She reminded us of checking progress weekly, and she did check. Thanks to this, I feel I know how to work according to schedule, not without a plan like before.

(FG7, CL3) 
The students' positive comments on the teachers' facilitation reveal their interest in receiving guidance during their project implementation. This suggests that the teachers motivated students' engagement in their learning, which contributed to the success of the lessons.

5.4.2.4 Passion for Interactions with Peers. All nine focus group students also referred to their interest in interactions with peers in intercultural activities as well as in their cooperation when doing their projects. For example, some students from group 2 said:

Hung: Study like this, I can speak English with classmates much more often ... very good for our English. Great.

Lan: For me, what important is what we talk about as well. We talk more and talk deeper, I mean we discussed every aspect of our project, in intercultural activities, in role-plays ... not simply practiced conversations based on textbooks as usual ... and with more peers.

Nhu: Thanks to interesting topics, we expressed our agreement or disagreement and views, and then the debate became interesting. Previously we just made up conversations using prompts. I mean, previously we did not have to think much and did not have to discuss. Very boring.

Thanh: Our group worked well. We discussed every week. I like this, like making a toy, it will be more beautiful and works better by more designers, especially we feel relaxed and closer, understand one another better.

$(\mathrm{FG} 2, \mathrm{CL} 1)$

Interestingly, they noted the difference in their level of interaction between standard lessons and PBL lessons. For them, the PBL lessons offered not only more chances to speak with more peers but also generated discussions with interesting content and created bonds between them.

5.4.2.5 A Desire for a Continued PBL Approach. Finally, all the nine focus group students expressed a desire for the continuation of the PBL lessons. They explained the reasons for the possible gains and losses if the PBL model would be further adopted or not. For example, students from group 3, Nhat's class, said:

Ha: I like the lessons like these: fun but effective. I do not like lessons to be too serious. I hope that we continue like this.

Nam: If not, very boring, just following books. 
Lien: I agree. Study this way, we know more about knowledge, culture, and work in teams with classmates. Fun. Not only boring grammar, structure, and repeating after the voice of a person in an audio.

Hung: I wish we still had culture content next terms. We need to get out of books and get into real life.

Huong: I agree. Books are not enough.

Nhu: Sure, this way of learning sounds much better for me. I hope we continue to role plays, do cultural projects, have sessions with English guest speakers...We need these things for our life and work, need to know how to communicate with people from other cultures ... much more important than books, I mean, many things [in books] are not used in life, not close to life.

(FG3, CL1)

In these extracts, the students alluded to their comparison of the PBL lessons and their standard lessons. They pointed out that what they needed from the language lessons was beyond the textbook content. They also needed other life skills. It can be inferred from the students' comments that the missing elements in the standard lessons can be offset by the PBL lessons.

The analysis shows that the students displayed a great interest in the PBL lessons, specifically the intercultural activities, the teachers' facilitation, and interactions with peers and express their desire for the model to be continued. They explained the benefits of the intercultural activities, teachers' useful and dedicated guidance, and interactions with peers as the reasons for their interest. These findings reveal the appropriateness of the model for the students in this context. Additionally, the findings indicate the shift in students' engagement towards active, experiential, and collaborative learning. Apart from the perceived learning outcomes and positive attitudes towards the PBL lessons, the students also noted challenges in conducting the project.

\subsubsection{Challenges in Conducting the Project}

The challenges that the students revealed included limited reference sources, limited intercultural experience, and different peer personalities. 
5.4.3.1 Limited Reference Sources. All nine focus student groups briefly reported on their challenges due to limited access to reference sources such as relevant printed materials in the school library. As Thang (FG4, CL2) said:

I spent hours looking through the bookshelves in the library. All language books in the library are about speaking, listening, and pronunciation activities. It was very hard for us to find something we needed for our project. (Thang, FG4, CL2)

Similarly, Nhu (FG8) put it:

Without sufficient materials from the school library, we struggled to find information from online sources and from talking with friends, relatives about their own intercultural experience, so that we could have the input for our project. (Nhu, FG8)

Despite the shortage of school reference sources for the project, the students actively looked for materials using internet tools and networking with friends and relatives.

5.4.3.2 Limited Intercultural Experience. All the nine focus groups revealed that their biggest challenge is limited intercultural experience. Specifically, they talked about their limited interactions with people from other cultures:

I was born in a small village in a northern province. From birth, I just contacted families and friends around my village. You know. Therefore, it is a big challenge for me to do such a project. I need to read and gather a lot of information. (Duong, FG7, CL3)

I am living in the capital. To be honest, many tourists were speaking English in my street. However, I did not notice anything about cultures before participating in the lessons. Even sometimes, I chatted with them, I just cared about grammar. Therefore, I did not have much for the project. (Huong, FG9, CL3)

As these comments show, students' limited intercultural experience can result from a contextual issue (in Duong's case), which can be due to students' being not attending to intercultural issues (Huong's case). Huong's explanation suggests that, without being directly guided to attend to intercultural aspects of communication, students are unlikely to pay much attention to them.

5.4.3.3 Different Peer Personalities. Only students in two focus groups (FG3, FG6) considered different peer personalities as one of their challenges. These students identified 
being reserved and lack of responsibility as a hindrance to group work and project implementation. As they said:

I like it when all members in a group shared their thoughts about the project. It is good to tell both when they agreed and disagreed with others and me. I felt uncomfortable when a group member kept silent most of the time, just listening to other group members. We had to encourage her to be more confident and talked about what she thought. (Thao, FG3, CL1)

Most of my group members were actively involved in the project. Only one member always handed in the documents he prepared to groups many days after the deadline and forgot our appointment time for rehearsal. We felt frustrated with his attitude. We had to ask our teacher to talk with him about obeying groups' rules. (Hung, FG6, CL2)

Poor collaboration with peers by a small number of students negatively affected some groups' performances. However, active students worked to resolve this challenge by persuading their peers or seeking help from teachers.

Overall, findings from student focus group interviews reveal learning outcomes that they identified including improvements in language, intercultural learning, and project skills. Findings also show students' positive attitudes towards PBL lessons, especially attitudes towards intercultural activities, teachers' facilitation, and students' collaboration. The positive learning outcomes generate more interest in the PBL lessons, and in turn, students will obtain more knowledge and skills if they display more interests, thus, become greater explorers in their learning world. Apart from the positive outcomes, the students acknowledged some challenges in their project work including limited reference sources, limited cultural experience, and peers who were unwilling to contribute.

\subsection{Summary of Key Findings}

Study 2 investigated whether an interculturally informed project can be successfully implemented in a Vietnamese EFL tertiary context. Sections 5.1-5.4 have presented the findings from four data sources: classroom observations, teacher interviews, student focus groups, and student reflections.

Findings from the observation data of PBL lessons have answered research questions 2(a) and 2(b): 
2(a) How did the three teachers implement the PBL lessons?

2(b) What intercultural learning processes were evident in PBL lessons?

For answering research question 2(a), there are four main findings: (a) all three teachers complied with all steps for implementing project work as agreed upon by all PAR members; (b) they systematically followed the ICLT principles; (c) teachers developed their expertise in addressing culture over the two workshop cycles; and (d) teachers faced some difficulties in implementing the lessons.

For answering research question 2(b), the data for analysis included the two subsets of observation data sources: (i) eight PBL lessons in three different classes and (ii) students' performances of their final PBL projects. The analysis has revealed evidence of intercultural learning in the PBL lessons. The common findings from the two sources are students' developing (a) intercultural awareness (awareness of self, of stereotypes, of cultural similarities and differences, of how to communicate appropriately across cultures, awareness of the intercultural speaker as the mediator), and (b) intercultural attitudes (judging people from one's own culture, judging others from the others' perspectives, and curiosity and openness).

Findings from the teacher interview data answered research question 2(c):

2(c) How did the teachers perceive the PBL lessons?

Findings from teacher interview data has revealed teachers' perceptions of the PBL lessons including (a) the benefits of the PBL lessons; (b) challenges in implementing the PBL lessons; (c) students' learning acquired in the PBL lessons; and (d) the benefits of PAR collaboration.

Findings from the student focus group interviews and their reflective journal have answered research question $2(\mathrm{~d})$ :

\section{2(d): How did the students perceive the PBL lessons?}

The findings include students' (a) perceptions of the learning outcomes (in terms of language, intercultural skills, and project skills); (b) attitudes towards the PBL lessons (interest in intercultural activities, feeling empowered, passionate to work with peers, appreciative of 
teachers' facilitation and desire for a continuation of the model); and (c) challenges in implementing the project (collecting data, personality differences in the group, no prior experience);

\subsection{Discussion}

A synthesis of common themes across all four data sets (classroom observations, interviews, student focus groups, and written reflections) provides support for four main claims:

1. Project-based learning can enhance intercultural learning.

2. Participatory action research is a viable model for teacher professional development.

3. Teachers and learners who are accustomed to more traditional approaches will face predictable challenges in transition to PBL.

4. The PBL approach can be integrated into the mainstream curriculum.

Below is the discussion of these themes.

\subsubsection{Project-based Learning for Intercultural Learning}

Triangulated findings from all sources show that project-based learning is a viable approach for enhancing intercultural learning. For example, findings from observations reveal that the students gradually enhanced their intercultural awareness throughout the PBL lessons and their final performances. Among the indicators of intercultural awareness, the awareness of their own culture, and cultural similarities and differences were strongly evident across all three classes. Awareness of culture as diverse and dynamic, of stereotypes, and the intercultural speaker as the mediator were less frequently observed. This might be due to the homogeneous context where all the students speak the same language and have little experience with intercultural encounters and intercultural learning. In comparison with the findings from Study 1, students in Study 2 moved from viewing culture as static and defined by national borders to viewing culture as dynamic and diverse. Additionally, students acknowledged the role of the intercultural speaker as mediator, which is a meaningful change in their perception.

According to Byram $(1997,2009,2020)$, awareness of the intercultural speaker as mediator is paramount to the development of intercultural competence. These findings bear some similarity with findings in Ho (2011) and Tran (2020) about students' development of 
intercultural awareness after an intercultural intervention course. However, the current study show that students acknowledged the intercultural speaker as the mediator and culture as being dynamic and diverse while student participants in Tran (2020) tended to view culture as monolithic and defined by national borders. Ho (2011) found that his student participants in the intervention class gained awareness of cultural diversity, but there was limited evidence of students' awareness of the dynamic nature of culture.

Additionally, the findings show that students developed intercultural attitudes. Most of the students in the three teachers' classes demonstrated curiosity about the others' perspectives. This is important because students can only enhance their intercultural competence when they notice and understand others' perspectives and thus can negotiate in intercultural encounters (Byram, 1997). This intercultural attitude was observed to strengthen over the lessons because of engaging in intercultural activities. As students shared in the subsequent focus group interviews, they had not been interested in the others' perspectives before the current study because they had previously assumed that most codes of conduct were the same in many cultures. Their acknowledgement of the gap and their positive attitudes support Liddicoat's (2003) principle of explicit culture teaching.

Another attitude that developed in the three teachers' lessons was a willingness to suspend judgement. Like curiosity, non-judgmental attitudes were more evident in later lessons than in early lessons in all three classes. This finding aligns with findings in Ho (2009). The students in the cultural class in Ho (2009) also demonstrated intercultural attitudes such as curiosity, openness, and sympathy through engaging in intercultural activities.

Furthermore, the findings from the focus group interviews demonstrate students' gradual construction of understanding about the PBL approach. They acknowledged their active roles, the facilitative role of teachers, and the significance of group collaboration in the project outcome. Moreover, most of the students recognized the benefits of the PBL approach in enhancing their language, intercultural, and project skills. These findings confirm the literature on the advantages of the PBL approach as discussed by Stoller (2006), Fried-Booth (2002), Beckett (2002), and Farouck (2016).

An important aspect in students' improved understanding is that they acknowledged the gaps in their perceptions before the PBL lessons, when they equated intercultural learning to 
passively listening to the teacher giving facts about national cultures. They recognized intercultural learning as involving their active engagement in the experiential and exploratory learning processes. In addition, they became aware of the dynamic and diverse nature of culture when explicitly guided by the teachers. Despite this positive development in students' understanding, some of the students still embraced the ideal native speaker model, that is, they implied that they should follow the way target language speakers communicate. This view is contradictory to Byram's $(1997,2009,2020)$ view of an intercultural speaker who finds a third place to negotiate between the Self and the other.

The findings also reveal students' positive attitudes toward the PBL approach in fostering their intercultural learning. They saw that the distinct features of the PBL approach allowed them to explore and actively engage in their project. In addition, PBL provided them a lot more chances to interact compared with traditional approaches and these interactions contributed to their enhanced intercultural skills. These findings correspond with findings in Allen (2004), and Liu (2018). Allen (2004) found that most of the student participants in the study highlighted their growth in cultural understanding and willingness to continue the project model despite acknowledging some limitations in the project. Liu (2018) found that the low-achieving students gained cross-cultural experience and confidence through the writing project and the students viewed the project as effective. As Alan and Stoller (2005) argue, students' reflection on their project work is valuable for teachers as they can decide on the necessary revision for further adopting the PBL model. Overall, the findings show that the PBL innovation fostered intercultural learning in the Vietnamese tertiary EFL context where the study was conducted.

\subsubsection{Participatory Action Research for Teacher Professional Development}

The second main conclusion from the triangulated findings is that participatory action research is a viable model for teacher professional development in the context of Vietnamese tertiary EFL. This is reflected in how the teachers implemented the PBL lessons after attending the PAR workshops, and in their reflections on their experience with the project.

All three teachers closely followed Alan \& Stoller's (2005) steps of implementing the project as agreed by PAR members such as introducing the project, dividing group work, facilitating 
student project work, giving feedback on ongoing progress and final products. Of all the steps, facilitating student project work took the most time.

Regarding giving feedback on students' project work, the three teachers undertook their facilitative roles despite some challenges. All teachers gave comments on students' performances. However, Nhat did not include the student reflection section in the final performances due to a shortage of time and Nhi forgot this part because of her overloaded teaching schedule while Tan performed this part thoroughly. She asked her students about their attitudes towards doing the project and their suggestions for further adopting the project. Eliciting students' reflection is valuable for both teachers and students to adopt the same approach in the future (Alan \& Stoller, 2005).

The finding that teachers successfully enacted their facilitative role is consistent with findings from Ruan and Du (2013), Liu (2018), and Belpoliti and Fairclough (2016). Teachers in Ruan and $\mathrm{Du}$ (2013) shifted from a traditional approach to a PBL student-centered approach. They provided students with background materials for cultural projects, chances for real-world intercultural interactions, and assisted the students in completing the projects. In the same vein, the instructor in Belpoliti and Fairclough (2016) guided students throughout each project process, such as discussing the general topic, summarizing, relating, and critically analyzing the information collected.

In addition, all the teachers in the current study followed the main principles of ICLT (Liddicoat \& Scarino, 2013; Newton, 2016; Newton et al., 2010). The principles reflected from their lessons are (i) encouraging exploratory and experiential learning, (ii) mining the learning context, (iii) aiming at linguistic goals alongside intercultural learning goals, and (iv) developing students' responsibility for intercultural communication. Despite these common focuses in their lessons, the teachers differed in the extent to which they facilitated project work through the lessons. A detailed discussion of each principle as reflected in the three teachers' lessons follows.

\section{(i) Encouraging exploratory and experiential learning}

All three teachers engaged students in intercultural learning activities in their lessons. For example, they encouraged students to participate in role-plays, provided chances for students to interview English speakers in person and via the Internet, guided students to make 
comparisons, relate to, and reflect on their experiences, and guided students to gather materials for intercultural activities from many sources. Among the three teachers, Nhat and Tan allowed a similar length of time for these activities, and Nhi spent less time on these activities. Regarding facilitating student discussion, Nhat and Tan allowed more time for students' discussion and giving prompts to students while Nhi tended to provide students with cultural knowledge after students' quick discussion. This time allocation in the lessons reflects a more student-centeredness and a stronger focus on students' exploratory and experiential learning in Tan and Nhat's lessons than in Nhi's lessons. In Tan and Nhat's lessons, this focus was better evident in lessons 5-8 compared to lessons 1-4. This growing amount of experiential learning in later lessons indicates that these teachers were becoming more familiar with the ICLT principles, as revealed from stimulated recall interviews.

\section{(ii) Mine the learning context}

Newton (2016) suggests that language teachers should mine the cultural potential of the learning context such as diverse cultural backgrounds of students. In these classes, all the students spoke the same native language - Vietnamese - and most of them had never visited other countries, which made it a challenge for the teachers to utilize students as a source of intercultural input. Despite this challenge, all three teachers have attempted to make the best of the teaching context. For example, in all the intercultural activities, the teachers asked their students to think about how Vietnamese responded to given situations. This practice gave the students the materials for understanding the Self, for comparison, and from this point, for creating a third place in intercultural encounters. It also generated opportunities to discover cultural diversity within Vietnam.

This focus on understanding the Self aligns with Byram's $(1997,2009,2020)$ model of intercultural competence. In addition, in every lesson, Tan and Nhat made repeated attempts to encourage students to express their views about given situations and recognize the differences among members of the same native language community. The differences originated from different ages, social contexts, and perspectives, which helped students acknowledge the diversity and dynamics of culture. In contrast, Nhi infrequently motivated students to discuss the differences among Vietnamese students' perspectives.

Another way that the teachers mined the teaching context was by encouraging students' reflections on their experiences. However, due to the students' limited intercultural 
experience, this practice was not frequent in the lessons despite teachers' awareness of the need to encourage student reflection. By making the most of the current context, the teachers were adopting the principle in a flexible manner.

\section{(iii) Developing linguistic goals alongside intercultural learning goals}

All three teachers closely followed the principle of developing linguistic goals alongside intercultural learning goals. In all lessons, they encouraged and guided students to discover the similarities and differences in the way Vietnamese and English respond to similar situations linguistically, relate to their own experience, and reflect on experience. Among the three teachers, Nhi spent the least time on intercultural activities. The reason for this difference was Nhi's deeply ingrained commitment to fulfill the exam-based curriculum, and so she tended to rush the intercultural learning section. In contrast, Nhat believed in the longterm impact of intercultural learning on students' future intercultural communication. She also held the view that intercultural and linguistic goals do not necessarily compromise each other, and that students enhanced their language proficiency through intercultural learning. These findings show the teachers' ability to develop linguistic alongside intercultural learning goals, even though they faced challenges in balancing the intercultural lessons and the exambased curriculum.

\section{(iv) Developing students' responsibility for intercultural communication}

Liddicoat and Scarino (2013) include responsibility as one of the principles for intercultural language learning and teaching. These authors explain this principle as the need to develop in language learners the responsibility to strive for understanding Self and others to make the communication successful. As observed, in all lessons, the three teachers attempted to raise students' sense of responsibility for the success of intercultural encounters. This was reflected in the teachers' focus on orientating students to actively prepare for successful intercultural encounters. For example, through guiding students to think about their cultural situations and others' situations from the others' perspectives, students developed understanding and sympathy towards others. Moreover, the teachers' guidance on the students' reflections helped them to realize how they had or had not communicated interculturally in prior intercultural situations and how they should adjust to better prepare for intercultural encounters in the future. 
The finding that teachers were following the principles of ICLT is similar to findings in Tran (2020). However, the teacher participants in the current research focused on both responsibility and cultural similarities and differences, while teachers in Tran (2020) paid attention primarily to guiding students to explore cultural similarities and differences.

Overall, as indicated from the observation data, the three teachers abided by the four principles discussed above. In addition, they completed the PAR-designed lessons almost as planned with interest, commitment, and students' increasingly active participation over the lessons.

Next, in the teacher interviews, all the teachers showed their growing understanding of the PBL approach. They revealed that working on the project helped them construct their understanding of the facilitative roles of teachers and students in this approach, the steps in conducting the PBL lessons, the benefits, and especially the role of scaffolding. Notably, the three teachers acknowledged the gaps in their prior knowledge of the PBL approach. Before the Study 2 intervention, the teachers considered project work as a form of homework with little significance in benefiting students' learning. In addition, after Study 2, they realized the valuable role of scaffolding students such as providing them with linguistic, intercultural, and project skill input, and regular feedback on their ongoing progress in their project. Furthermore, they contended the exploratory and experiential nature of both the PBL and ICLT that engaged students in their learning and in making progress. Reflecting on this experience with PBL, they came to realize the reasons for students' lack of motivation and the low-quality outcome of students' project before this research when the project was treated like a homework assignment without teachers' scaffolding and relevant steps of implementation.

Secondly, the teachers developed increasingly positive attitudes toward adopting the PBL approach to foster intercultural learning. Nhat and Nhi reflected on their prior attitudes towards the approach and revealed that they had agreed to participate in the project but remained doubtful about its positive impact on students' intercultural learning. This was due to their expectation that students would be inactive because of their prolonged exposure to traditional instruction approaches. The teachers' uncertainty was gradually replaced by increasing confidence about the benefits of the PBL lessons when they witnessed students' increasing interest, motivation, and linguistic and intercultural learning over the lessons, and 
as reflected in the final project products. Tan had held strong beliefs about the PBL approach in motivating students' intercultural learning since the workshops but still anticipated some challenges in conducting the lessons due to being inexperienced in adopting this innovation. Tan became more confident in conducting the lessons and contributed to the PAR preparations for the PBL lessons. All the teachers expressed their desire to continue the model in the context.

The findings on teachers' growing understanding of the PBL approach and positive attitudes towards applying this approach in fostering intercultural learning align with findings on their practices from the observation data. Teachers in Ruan and Du (2013) also noted the relationship between PBL and the learning outcomes. Additionally, these Study 2 findings support Stoller and Myers's (2019) model of implementing the PBL lessons, which emphasizes the importance of guiding students in every step of project implementation.

In brief, the findings indicate that the PAR model is effective in teacher professional development. Through attending workshops and collaborating with peers, the teachers successfully adopted PBL. Although some difficulties remained in teachers' implementation of the lessons, they achieved the aims set for the lessons. Additionally, the data showed teachers' advocacy for the PBL approach, and a willingness to continue adopting the PBL model to foster intercultural learning. This finding of teachers' ability to develop their intercultural teaching aligns with Tran (2020). The teachers in Tran (2020) attended workshops, followed the pre-designed lessons by the researcher, redesigned intercultural content in the lessons they taught after the two workshops, and successfully implemented their intercultural lessons. In contrast, these findings from the current study were different from findings in Oranje (2016). A German as a foreign language teaching in Oranje (2016) adopted and adapted cultural portfolio projects in her secondary school classes. As Oranje found, the approach this teacher adopted was much more concerned with assessment than culture and her teaching activities were not implemented through an intercultural perspective.

\subsubsection{Challenges}

The findings also reveal the challenges that should be considered in adopting PBL for intercultural learning. First, observation data showed teachers' difficulties in shifting from a traditional approach to the PBL approach. As teachers assumed, the challenges were due to 
their lack of experience, limited teaching resources, and time pressure. Another reason articulated by the teachers was the relationship between their deep-rooted perceptions and practices and personal teaching preferences. As Borg (2011) argues, it might be challenging for teachers to move away from their long-established practices and maintain a new teaching approach. In the current study, the three teachers demonstrated different levels of engagement and devotion to the intercultural teaching and these varying levels may reflect personal preferences, different experiences, and different characteristics of the teacher cognition. Overall, the challenges mentioned here suggest the need to provide teachers with support and learning opportunities that guide them to critically reflect on their beliefs and assumptions about language teaching. In addition, these findings suggest the need to provide them with positive models of successful intercultural and PBL in the Vietnamese tertiary context, such as the model adopted in the current study.

\subsubsection{Adapting PBL}

The findings show the overall development of teaching expertise and students' intercultural learning. This indicates the feasibility of integrating the PBL model into the mainstream curriculum. In this research, the textbook was used flexibly in the language-focused instruction stage to support student project work. This finding echoes Beckett and Miller (2006), who contend that project-based learning can complement traditional methods. Additionally, this finding supports Alan and Stoller (2005) who indicate that projects could range from controlled to less controlled projects.

\subsubsection{Significance of the Findings}

The findings are significant in multiple ways. First, they contribute to an under-researched area of adopting project-based learning (PBL) to foster intercultural learning, especially in Asian and Vietnamese EFL tertiary contexts. Specifically, it provides evidence of teachers' practices and students' intercultural learning in project-based learning lessons (PBL), and teachers' and students' perceptions of the project. Moreover, the research adds to the understanding of contextual factors that may inhibit or support intercultural teaching and learning and teaching in Vietnamese tertiary EFL programs. Furthermore, the research provides insights into the effectiveness of the PAR model in teacher professional development through presenting how the researcher and the teachers successfully 
collaborated to conduct the PBL lessons. Importantly, the research provides evidence for a feasible model that can integrate the project approach and the traditional method to developing students' intercultural learning in the speaking courses in Vietnam. All these contributions offer pedagogical, theoretical, methodological implications that are helpful to applied linguistic researchers, language education policymakers, curriculum designers, teacher trainers, and language teachers. The implications will be discussed in the conclusion chapter.

\subsection{Chapter Summary}

This chapter has presented findings from Study 2 data and discussed these findings in light of the current literature. Overall, findings from classroom observations, interviews with teachers, interviews with student focus groups, and student written reflections reveal teachers' growing expertise in conducting PBL lessons and developing understanding of PBL and ICLTL. In addition, the findings show evidence of students' growing intercultural awareness and attitudes throughout the PBL lessons. Despite the perceived benefits of the PBL lessons, teachers and students encountered some challenges in the lesson implementation including time constraints, lack of experience with PBL and ICLTL, and limited teaching resources.

These findings have contributed to an understanding of how a PAR model could be adopted for teacher professional development. Additionally, the findings support PBL as an effective approach in fostering intercultural language teaching and learning in the context. The next chapter will present the conclusions to the thesis. 


\section{Chapter 6: Conclusions}

This research has explored the potential for PBL to foster intercultural language teaching and learning (ICLTL) in a Vietnamese university EFL program. This chapter concludes the thesis. First, it provides a summary of the research and recapitulates the main findings from which it then draws practical, theoretical, and methodological implications. The chapter continues with an evaluation of the research limitations and offers recommendations for further research. It ends with concluding remarks on contributions to the field and reflection on my PhD journey.

\subsection{Summary of Thesis}

This research consists of two related studies. Study 1, a situation analysis in a Vietnamese university EFL context, examined teachers' teaching practices and the perceptions of culture teaching and learning amongst four groups: teachers, students, graduates, and employers. It answered research question 1:

How is culture addressed in a Vietnamese EFL university context?

Study 2, a pedagogical intervention study, investigated the impact of a PBL innovation on teachers' practices and students' intercultural competence in the context. It answered research question 2:

How can project-based learning foster intercultural teaching and learning in a Vietnamese EFL university context?

As a whole, the study addressed an overarching question: "What is the potential for the PBL approach to foster intercultural teaching and learning in a Vietnamese university context?"

Study 1 was exploratory research by nature. It adopted principles of ethnographic research to explore teachers' practice and perceptions, and other stakeholders' perceptions. To ensure the credibility of the findings, I deployed multiple qualitative data collection methods for data triangulation. To provide an account of how the teachers addressed the (inter)cultural content in the lessons, I observed 12 lessons including eight general EFL lessons and four crosscultural communication (CCC) lessons. After the lessons, I invited teachers to stimulated recalled interviews to help me better understand the rationales behind the activities that 
teachers undertook during the lessons. For understanding teachers' beliefs of the value of culture in language teaching, I invited them for follow-up interviews. Similarly, ten focus group students and six recently graduated employees were recruited to share their thoughts about their experience of (inter)cultural learning in the program. Six employers were also invited to semi-structured interviews. They gave their comments on the graduates' intercultural skills and gave suggestions for intercultural learning and teaching in the program.

A thematic analysis approach (Braun \& Clarke, 2006) was adopted to analyze the data. This was an iterative process of generating themes in which data was categorized, and then coded, recoded and final themes generated and named. The key findings are:

1. Regarding teaching practices, teachers treated culture as an add-on component to the main language goals. In rare cases when culture was addressed, the teaching method was a transmission of factual information about cultures.

2. Regarding perceptions, teachers had static views of culture and little knowledge of ICLTL.

3. First-year students lacked understanding of the need for intercultural competence, and Year 4 students perceived language lessons as not meeting their needs for intercultural development.

4. Both teachers and students showed interest in the prospect of incorporating cultural dimensions into the EFL language classes.

5. Employers and newly graduated employees saw limitations in students' intercultural learning in the research context and suggested that measures should be taken to foster students' intercultural awareness and intercultural skills.

Reflecting on ICLT (Byram et al., 2002; Newton, 2016), and the promotion of IC by Vietnamese government policy (Government, 2008), these findings reveal both constraints and affordances for adopting an intercultural orientation in this context. Firstly, in the lessons, the teachers paid attention to culture, though to a very limited extent, and mostly in the form of teaching facts about visible culture. In addition, teachers and students wanted intercultural content in the lessons. Despite these affordances, there were ongoing constraints such as 
teachers' not knowing how to teach English interculturally, teaching workloads, and a textbook-based, exam-oriented curriculum.

The findings summarized above were the inspiration for Study 2, which draws on principles of Participatory Action Research (PAR). I worked with three teachers in the design and implementation of a semester-long series of PBL lessons. The PAR included two research cycles. Cycle 1 began with a workshop in which I discussed with three teachers the principles of ICLTL, PBL, and how to design lessons 1-4 of the 10 PBL lessons. After the workshop, the teachers implemented the first four PBL lessons. I observed their lessons and helped when necessary. The PAR then moved to Cycle 2. This cycle began with a second workshop in which we reviewed lessons 1-4 and discussed plans for lessons 5-8, and for the project presentations in lessons 9 and 10. After this workshop, the teachers co-designed lesson activities for the upcoming lessons. I observed their classes and offered help when asked. The students were invited to write their reflections after lessons 3, 6, and 10. After all 10 lessons, I interviewed the teachers and nine focus groups of students. Altogether, data collected included 30 classroom observations (10 lessons in each of these three classes), six teacher interviews, nine student focus group interviews, and 17 transcripts of student performances and student written reflections. I used the same thematic analysis approach to analyze this data set. The main findings are:

1. Regarding teaching practices, the teachers successfully designed and implemented the PBL lessons, and the lessons reflected PBL and iCLT principles, despite each teacher adopting a different emphasis. Teachers' guidance played an important role in generating the intercultural learning process in the lessons.

2. Regarding the teachers' perceptions, the teachers expressed positive attitudes towards the project, PAR collaboration. They saw the benefits of the PBL lessons and developed a deeper understanding of ICLTL and PBL principles. Teachers also acknowledged challenges in implementing PBL lessons and intercultural activities.

3. The students expressed positive views of the PBL lessons and saw benefits from the lessons. They also noted that they had challenges in conducting their projects. Evidence from the lessons and students' final project showed that students' intercultural competence developed through their participation in PBL. 
The evidence from observations and interviews reveals that teachers and students had positive views of the lessons. The teachers also developed expertise in facilitating project work and intercultural learning and the students showed evidence of enhanced intercultural competence. The study suggests that the PBL approach is suitable and practical for university EFL classes in Vietnam so long as teachers are provided with appropriate guidance. The results support Alan and Stollers' (2005) claim that PBL is useful for enhancing students' IC. Overall, the study provides empirical evidence to show that PBL can be implemented in the Vietnamese EFL university context to foster intercultural competence alongside linguistic proficiency.

\subsection{Implications for Teaching and Teacher Professional Development}

Findings from the current research provide evidence to support implications for teachers, education managers, researchers, and teacher trainers. While this study was conducted in a Vietnamese university context, the implications are relevant to similar contexts in Vietnam and other countries. Each implication is discussed below.

The first implication concerns adopting PAR for teacher professional development. Findings from Studies 1 and 2 show the teachers in Study 1 had limited understanding of ICLTL, and paid little attention to cultural dimension of the lessons. In contrast, Study 2 saw teachers develop an understanding of ICLTL through attending the PAR workshops, where they learned about ICLTL principles and collaboratively designed intercultural activities. These findings suggest that without support and guidance, teachers are unlikely to be able to effectively provide students with rich intercultural learning. However, the findings from Study 2 also suggest with appropriate support through workshops and guided collaborative lesson planning, teachers are able to shift their beliefs and practices from treating culture as a peripheral lesson element and as visual facts to actively promoting rich intercultural learning. The three teachers revealed from interviews in Study 2 that the focus of their lessons was on intercultural competence. This contrasted with what they reported in Study 1, where their lessons focused on native-speaker competence. This suggests that in teaching interculturally, teachers should be mindful of the difference between native-speaker competence and intercultural competence and should seek to raise awareness of the latter. This topic also needs to be covered in teacher professional development. The extent to which it is and how it 
might be introduced in a more principled way to the future are topics that warrant further research.

The same principle applies to PBL. The current study shows that, compared to the typical approach in this context of treating projects as marginal, out-of-class activities by the students, when PBL was systematically integrated into the class, it provided much richer learning and teaching opportunities.

This suggests that education managers should consider ongoing professional development opportunities for teachers such as involving them in workshops. Teachers need to acknowledge that their role as language teachers cannot be separated from the role as intercultural teachers. They also need support to become competent intercultural teachers. As Biebricher et al. (2019) comment, the inclusion of a pre-service and in-service intercultural dimension in education programs could minimize the artificial separation between language and culture. It should be noted that teachers should be supported throughout all the stages of the innovation (Fraser \& Galinsky, 2010), as evident in the Study 2 findings.

The second implication deals with cooperation between teacher trainers and in-service teachers in promoting educational innovation. As findings in Study 2 reveal, teachers highly valued my guidance and collaboration in the design and implementation of the current innovation. Specifically, the teachers appreciated having equal power and participating in the design and implementation of the innovation. They actively participated in workshop discussions and in the design and implementation of PBL lessons. Through the process of reflecting on the challenges they faced in the first set of lessons, teachers were able to come up with solutions and implement these solutions in subsequent lessons. This shows the value of teacher trainers working alongside teachers rather than imposing their ideas on them (Manara, 2014). In this way, teachers can actively contribute to educational innovations. As Darling et al. (2017) argue, effective teacher development includes addressing issues in specific teaching contexts, supporting collaboration, and providing coaching. In this way, when researchers leave the site, the innovation can continue because the teachers have become experienced agents of change (Morales, 2016).

The third implication refers to using textbooks for PBL. Findings from Study 2 reveal that the teachers successfully integrated language skills and form-focused learning from textbooks 
into the stages in the PBL lessons. This shows it is possible to adapt existing textbooks strategically for PBL rather than abandoning them. The possibility of adapting textbooks is important in the Vietnamese context where it is obligatory to include textbook content in lessons.

The fourth implication is about the role that teacher guidance plays in intercultural learning. Study 1 revealed that even when the lessons involved cultural content, the students missed opportunities for intercultural exploration if they were not guided to explore the lessons interculturally. In contrast, in Study 2 when teachers actively guided students to notice, compare, relate and reflect on their own experience, there was compelling evidence that students developed their intercultural knowledge, skills, and attitudes. These findings show that rich intercultural processes are not likely to occur without teachers' explicit guidance. For example, teachers can ask students to find relevant intercultural examples before the lessons. The preparation is particularly valuable to students as it equips them with content for discussion in class and for reflection. Additionally, students can develop their autonomy and discovery skills while they search for materials for their lessons. During the lessons, teachers can ask questions and give students opportunities to explore their own culture and other cultures, to compare cultures, and to reflect on their experiences and interact interculturally. These opportunities are not only crucial for developing intercultural competence but also offer rich language learning opportunities (Liddicoat \& Scarino, 2013; Newton et al., 2010).

The fifth implication concerns teachers' guidance and support in student project work, especially in contexts where PBL is a new concept. Teachers revealed in the interview that before Study 2 they had treated projects like homework and let students do projects without teacher guidance. Students saw little benefit in projects, and many challenges in conducting their project when they did not receive any teacher guidance. Conversely, study 2 show that students highly valued teachers' guidance and successfully completed their work. It is important that teachers balance scaffolding student work while also letting them take control of their projects. This is especially important for students with little experience of PBL, and students who are used to traditional teacher-centric approaches to language teaching like the students in the current study. Teachers' scaffolding through structuring the sequence of the lessons involved in PBL, giving feedback, responding to requests for help and providing other forms of input for the projects helps leaners transition from teacher-centered to studentcentered learning. 
The sixth implication relates to teachers' evaluation of students' projects. As the students in the current study revealed, they preferred their teachers to give them a detailed evaluation of what they achieved in their performances rather than give them general comments on their work. This suggests that teachers need to give students detailed feedback on their final work. This is crucial because students can learn from their mistakes when these mistakes are pointed out. They also learn from positive affirmation from the teacher so as to acknowledge what they have done successfully.

The seventh implication is about who can be intercultural teachers. Findings from both studies shows that the three teachers in study 2 , who had limited understanding and experience of ICLTL in Study 1, successfully conducted interculturally oriented PBL lessons. This shows that bilingual EFL teachers can be highly effective intercultural teachers, not just those with experience living in English speaking countries. Bilingual EFL teachers can often feel inadequate in teaching culture because they see it as the preserve of English native speakers (Byram et al., 2002; Kramsch, 2003). This is a myth, which the findings from the current study dispel.

The eighth implication concerns addressing the challenges that teachers are likely to face in practicing ICLTL and PBL. Findings show that teachers encountered difficulties in implementing the PBL lessons such as a heavy teaching load, the obligation to follow the textbook curriculum, a limited knowledge of ICLTL and PBL, and student-related issues. Measures need to be taken to support teachers, such as alleviating tight teaching schedules, providing more flexibility in teaching practices and particularly opportunities for intercultural experience. The intercultural learning goals would be better achieved if teachers are not bound by the responsibility to follow all textbook steps, and are given more autonomy to adapt textbooks and modify textbook activities to serve both linguistic and intercultural goals. To provide opportunities for promoting teacher ICC skills, many activities can be organized. These activities might include talks between guest speakers and teachers, and talks between visiting scholars from other cultures and EFL teachers.

The ninth implication is about adopting the project-based learning and intercultural language teaching and learning. Findings from Study 2 show that PBL can support ICLTL. In addition, the findings indicate that the intercultural language teaching and learning principles drawn on the current study, which were originally intended for Australian, New Zealand and other 
school contexts, can be successfully adopted in Vietnamese university EFL classes and similar contexts.

The final implication concerns research design. The study shows the value of preceding an intervention study with a situation analysis. This design feature strengthens the ecological validity of the research and provides a greater likelihood of uptake of the intervention, since its development is informed by a rich understanding of the context. In the current research, Study 1 served as the foundation that gave rise to Study 2. The findings from the two studies provide a full picture of the changes in the teacher participants' practices and their perceptions, as well as students' perceptions and learning outcomes. This rich descriptive detail improves the trustworthiness of the research.

\subsection{Limitations and Recommendations for Further Research}

This section acknowledges six limitations of the current study and offers recommendations for further research accordingly.

The first limitation is that the study was conducted over a 15 -week semester. This timespan did not allow evidence to be gathered on the long-term impact of the innovation on teachers' practices and students' intercultural learning. A natural progression of this study would be to explore how PBL and ICLTL continue to be adopted in the context. Future research might take the form of a longitudinal study on the possible differences between the beliefs Vietnamese teachers hold before they join the PAR project, right after the PAR ends, and the beliefs they have several years after the PAR project ends. Future research could also explore how newly graduated employees reflect on their intercultural learning from the PBL course concerning their professional work and compare these reflections with those of graduates from non-PBL courses.

Secondly, the small data set in both Study 1 and Study 2 requires any generalizations to be drawn from the findings to be treated with caution. Study 1 explored the beliefs and practices of 14 teachers. To obtain a more complete picture of Vietnamese EFL teachers' perceptions and practices of addressing the (inter)cultural dimension of language teaching, it would be valuable to undertake studies conducted in wider locations, such as in urban and rural areas, and more diverse educational contexts in Vietnam, such as in both private and public universities. Study 2 involved only three classes in a university with all three teachers coming 
from relatively homogenous cultural and professional backgrounds. If participants had been from diverse cultural and professional backgrounds, the study could have revealed more diverse perspectives and experiences of teaching. Further studies involving participants from various backgrounds are strongly recommended to build a more robust picture of the viability and impact of PBL for intercultural language learning.

Thirdly, the findings on students' intercultural learning were mostly restricted to intercultural awareness and intercultural attitudes. Intercultural skills were not discussed as a separate theme. However, the findings on intercultural attitudes and awareness, to a limited extent, reflected intercultural skills because these skills are overlapping and interrelated (Byram, 2020). This would be a fruitful area for further work. Researchers can be inspired to investigate how students' intercultural skills are developed during interactions both in and out of classrooms and the factors determining these developments.

Fourth, the PBL lessons contained intercultural activities that lacked variety in topics. This is because the PBL adopted the current textbook curriculum and thus, had to follow the textbook topics. As per the findings of Siegel (2014), in this study, there was a clear discrepancy between textbooks' topics and the ones discussed in naturally occurring conversations. Textbooks' topics focus on universal and superficial issues, and real conversations, such as academic and school life, are often ignored. While developing students' intercultural competence requires their engagement with a global variety of topics and situations (Jin \& Cortazzi, 2017), reliance on textbook topics inevitably deprived the lessons of a wide range of sample situations. Thus, further research could engage students in a more diverse range of topics and situations.

Fourthly, the study could not collect teachers' reflections on their peer classroom observations because the teachers' tight teaching schedules did not allow them to observe each other's classes. This limited chances for teachers to contribute to the meaning making of the phenomena under investigation. Further studies involving greater levels of teacher engagement in participatory action research would be worthwhile.

Finally, the Hawthorn effect (as discussed in chapter 3, section 3.6.2) could not be completely avoided. As explained, the responses of students and teachers in interviews might have reflected what they thought the researcher wanted to hear rather than what they actually 
thought. Acknowledging all these effects, I took measures to reduce the impacts, such as using member checks and triangulation.

\subsection{Reflection}

On a personal level, this $\mathrm{PhD}$ journey has had a significant impact on my perspectives of FL teaching, doing research, and the connection between doing research and practical teaching. First, I have broadened my knowledge of intercultural language teaching and learning and project-based learning. When I embarked on my PhD study, my knowledge of ICLT and PBL principles was limited. As the research progressed, I gained a much broader and deeper understanding of ICLTL and PBL through doing a literature review of the scholarship in the field and through my own experience in collecting and analyzing the current study's data.

Second, my interest in doing research has grown. Throughout the research, I became increasingly intrigued by the nature of qualitative research, specifically participatory action research and thematic analysis. I was enlightened by the literature on participatory action research and the changes that PAR can bring to a research context. I was more convinced of this attribute of PAR when I undertook a PAR study. In addition, in terms of data analysis, I found out how to code data, how to generate themes, and very importantly, how to interpret the findings.

Third, I came to realize the important connection between doing research and practical teaching. My own story is a vivid example. If I had not started my research journey, I might neither have spent time examining the body of scholarship in the field nor conducted any informed research to bring positive changes in my FL teaching, even though I did recognize the existing issues of limited attention to the cultural aspects of language teaching in EFL classes. This is not to say that every teacher needs to take part in Ph.D. programs. However, being a teacher/researcher - though at different levels of research - could be of great value in helping teachers better complete their tasks. Overall, this Ph.D. journey has been a great success for me academically and personally.

\subsection{Concluding Remarks}

This study contributes to the intercultural language teaching and learning literature in three main ways. First, it provides insights into the actual practice of intercultural language 
teaching and learning in university classrooms in Vietnam. Second, it focuses on an underresearched area of fostering intercultural learning through project-based learning. Third, the study adds to the understanding of how participatory action research can be conducted in a Vietnamese university EFL context.

Overall, the study has achieved its main goals of exploring how culture is addressed in the Vietnamese context, and to what extent a PBL innovation could foster intercultural language teaching and learning in EFL classes for English majors. From the findings and discussions throughout the thesis, it can be affirmed now that PBL can foster intercultural teaching and learning in this specific Vietnamese EFL context. As such, the study can be of value to teachers, education managers, and policymakers in Vietnam in planning for actions to enhance intercultural teaching and learning. This in turn helps to meet the goal of the Vietnamese government of producing interculturally competent graduates who can contribute to the competitiveness of Vietnam in international trade and affairs. 


\section{REFERENCES}

Abdulrahman, T., Usu, N. R., \& Tanipu, Z. (2016). Teachers' perspectives on the integration of culture and EFL. Journal of ELT Research, 1(2), 180-193. https://doi.org/10.22236/JER

Affandi, A., \& Sukyadi, D. (2016). Project-based learning and problem-based learning for EFL students' writing achievement at the tertiary level. Rangsit Journal of Educational Studies, 3(1), 23-40. https://doi.org/10.14456/rjes.2016.2

Aguilar, C. M. J. (2009). Intercultural communicative competence in the context of the European higher education area. Language and Intercultural Communication, 9(4), 242-255. https://doi.org/10.1080/14708470902785642

Al-Amir, B. A.-H. (2017). Female teachers' perceptions of teaching culture in EFL classrooms at a Saudi university. English Language Teaching, 10(6), 28-36. https://doi.org/10.5539/elt.v10n6p28

Al-Balushi, S. M., \& Al-Aamri, S. S. (2014). The effect of environmental science projects on students' environmental knowledge and science attitudes. International Research in Geographical and Environmental Education, 23(3), 213-227. https://doi.org/10.1080/10382046.2014.927167

Alan, B., \& Stoller, F. L. (2005). Maximizing the benefits of project work in foreign language classrooms. English Teaching Forum, 43(4), 10-21.

Allen, L. Q. (2004). Implementing a culture portfolio project within a constructivist paradigm. Foreign Language Annals, 37(2), 232-239. https://doi.org/10.1111/j.1944-9720.2004.tb02196.x

Allison, E. S., \& Do, T. (2015). Contextualized culture integration through Project-Based Learning in EFL classrooms in Vietnam. Journal of NELTA, 20(1-2), 5-15. https://doi.org/10.3126/nelta.v20i1-2.19771

Alsamani, A.-A. S., \& Daif-Allah, A. S. (2016). Introducing Project-Based Instruction in the Saudi ESP classroom: A study in Qassim University. English Language Teaching, 9(1), 51-64. https://doi.org/10.5539/elt.v9n1p51

Amankwaa, L. (2016). Creating protocols for trustworthiness in qualitative research. Journal of cultural diversity, 23(3), 121-127.

Ana, M., \& Martha, E. A. (2007). Students' objectivity and perception of self assessment in an EFL classroom. The Journal of AsiaTEFL, 4(2), 1-25.

Anfara, V. A., \& Mertz, N. T. (2015). Setting the stage. In V. A. Anfara \& N. T. Mertz (Eds.), Theoretical frameworks in qualitative research ( $\left.2^{\text {nd }} \mathrm{ed}.\right)$. SAGE.

Arasaratnam-Smith, L. A. (2017). Intercultural competence: An overview. In D. K. Deardorff \& L. A. Arasaratnam-Smith (Eds.), Intercultural Competence in Higher Education : International Approaches, Assessment and Application. Taylor \& Francis Group.

Astawa, N., Artini, L., \& Nitiasih, P. (2017). Project-based Learning activities and EFL students' productive skills in English. Journal of language teaching and research, 8(6), 1147-1155. https://doi.org/10.17507/jltr.0806.16

Bakar, N., Noordin, N., \& Razali, A. (2019). Effectiveness of Project-Based Learning in improving listening competency among ESL learners at a Malaysian TVET College. The English Teacher, 48(1), 11-28.

Baker, R. D. (2006). Project-based learning, surface energy balance, and establishment of a new undergraduate weather station. Journal of Geoscience Education, 54(3), 320-328. https://doi.org/10.5408/1089-9995-54.3.320

Baker, W. (2011). Intercultural awareness: Modelling an understanding of cultures in intercultural communication through English as a lingua franca. Language and 
Intercultural Communication, 11(3), 197-214.

https://doi.org/10.1080/14708477.2011.577779

Baker, W. (2015). Culture and identity through English as a lingua franca: Rethinking concepts and goals in intercultural communication (Vol. 8). Walter de Gruyter GmbH \& Co KG.

Baker, W. (2016). Culture and language in intercultural communication, English as a lingua franca and English language teaching: Points of convergence and conflict. In P.

Holmes \& F. Dervin (Eds.), The Cultural and Intercultural Dimensions of English as a Lingua Franca (pp. 70-91). Multilingual Matters. https://doi.org/10.21832/9781783095100-007

Bakar, N., Noordin, N., \& Razali, A. (2019). Effectiveness of Project-Based Learning in improving listening competency among ESL learners at a Malaysian TVET College. The English Teacher, 48(1), 11-28.

Barak, M., \& Dori, Y. J. (2005). Enhancing undergraduate students' chemistry understanding through project-based learning in an IT environment. Science Education, 89(1), 117139. https://doi.org/10.1002/sce. 20027

Barrett, M. (2013). Intercultural competence: A distinctive hallmark of interculturalism. In M. Barrett (Ed.), Interculturalism and multiculturalism: Similarities and differences (pp. 147-168). Council of Europe Publishing.

Barrett, M. D. (2016). Competences for democratic culture: Living together as equals in culturally diverse democratic societies. Council of Europe Publishing. https://www.coe.int/en/web/education/competences-for-democratic-culture

Baş, G., \& Beyhab, O. (2010). Effects of multiple intelligences supported project-based learning on students' achievement levels and attitudes towards English lesson. International Electronic Journal of Elementary Education, 2(3), 365-386.

Beckett, G. (2002). Teacher and student evaluations of project-based instruction. TESL Canada journal, 52-66.

Beckett, G. H., \& Miller, P. C. (2006). Project Based second and foreign language education: Past, present, and future. Information Age Publishing.

Belpoliti, F., \& Fairclough, M. (2016). Inquiry-based projects in the Spanish Heritage Language classroom: Connecting culture and community through research. Hispania, 99(2), 258-273. https://doi.org/10.1353/hpn.2016.0045

Belz, J. A. (2003). Linguistic perspectives on the development of intercultural competence in telecollaboration. Language learning \& technology, 7(2), 68-117.

Bennet, M. J. (1994). Towards ethnocentrism: A developmental model of intercultural sensitivity. Education for the intercultural experience, 21-71.

Bennett, M. J. (1993). Towards ethnorelativism: A developmental model of intercultural sensitivity. In M. R. Paige (Ed.), Education for the intercultural experience (pp. 2171). Intercultural Press.

Bennett, M. (2013, May 6). Culture is not like an iceberg. Intercultural Development Research. https://www.idrinstitute.org/2013/05/06/culture-not-like-iceberg/

Biebricher, C., East, M., Howard, J., \& Tolosa, C. (2019). Navigating intercultural language teaching in New Zealand classrooms. Cambridge Journal of Education, 49(5), 605621. https://doi.org/10.1080/0305764X.2019.1581137

Biswalo, U. P. (2015). Exploring intercultural communicative competence among English language teachers in secondary schools in Tanzania: A postcolonial perspective $[\mathrm{PhD}$ thesis, Victoria University of Wellington].

http://researcharchive.vuw.ac.nz/handle/10063/4807 
Blumenfeld, P. C., Soloway, E., Marx, R. W., Krajcik, J. S., Guzdial, M., \& Palincsar, A. (1991). Motivating Project-Based Learning: Sustaining the doing, supporting the learning. Educational Psychologist, 26(3-4), 369-398. https://doi.org/10.1080/00461520.1991.9653139

Borg, S. (2011). The impact of in-service teacher education on language teachers' beliefs. System, 39(3), 370-380.

Boyatzis, R.E. (1998). Transforming qualitative information: Thematic analysis and code development. Sage.

Brassler, M., \& Dettmers, J. (2017). How to enhance interdisciplinary competence: Interdisciplinary Problem-Based Learning versus Interdisciplinary Project-Based Learning. The interdisciplinary journal of problem-based learning, 11(2). https://doi.org/10.7771/1541-5015.1686

Braun, V., \& Clarke, V. (2006). Using thematic analysis in psychology. Qualitative research in psychology, 3(2), 77-101.

Braun, V., \& Clarke, V. (2012). Thematic analysis. In H. Cooper, P. M. Camic, D. L. Long, A. T. Panter, D. Rindskopf, \& K. J. Sher (Eds.), APA handbook of research methods in psychology, Vol. 2. Research designs: Quantitative, qualitative, neuropsychological, and biological (pp. 57-71). American Psychological Association. https://doi.org/10.1037/13620-004

Buck Institute for Education. (2020). https://www.pblworks.org/what-is-pbl

Buehl, M. M., \& Beck, J. S. (2014). The relationship between teachers' belliefs and teachers' practices. International handbook of research on teachers' beliefs, 66.

Byram, M. (1997). Teaching and assessing intercultural communicative competence. Multilingual Matters.

Byram, M. (2008). From foreign language education to education for intercultural citizenship : Essays and reflections. Multilingual Matters Ltd.

Byram, M. (2009). Intercultural competence in foreign languages: The intercultural speaker and the pedagogy of foreign language education. In D. K. Deardorff (Ed.), The SAGE handbook of intercultural competence (pp. 321-332). Sage Publications.

Byram, M. (2012). Language awareness and (critical) cultural awareness-relationships, comparisons and contrasts. Language Awareness, 21(1-2), 5-13. https://doi.org/10.1080/09658416.2011.639887

Byram, M. (2015). Culture in foreign language learning - The implications for teachers and teacher training. In W. M. C. Chan, M. Nagami, I. Walker, \& S. K. Bhatt (Eds.), Culture and Foreign Language Education (Vol. 10, pp. 37-58). De Gruyter. https://doi.org/10.1515/9781501503023-003

Byram, M. (2020). Teaching and assessing intercultural communicative competence: Revisited. Multilingual Matters.

Byram, M., Gribkova, B., \& Starkey, H. (2002). Developing the intercultural dimension in language teaching: A practical introduction for teachers. Language Policy Division, Directorate of School, Out-of-School and Higher Education. Council of Europe.

Byram, M., \& Wagner, M. (2018). Making a difference: Language teaching for intercultural and international dialogue. Foreign Language Annals, 51(1), 140-151. https://doi.org/10.1111/flan.12319

Castro, P., Sercu, L., \& Méndez García, M. d. C. (2004). Integrating language-and-culture teaching: An investigation of Spanish teachers' perceptions of the objectives of foreign language education. Intercultural Education, 15(1), 91-104. https://doi.org/10.1080/1467598042000190013 
Chandler, D., \& Torbert, B. (2003). Transforming inquiry and action: Interweaving 27 flavors of action research. Action Research, 1(2), 133-152.

Chau, T. H. H., \& Truong, V. (2018). Integrating cultures into teaching EFL in Vietnam: Teachers' perceptions. LEARN Journal: Language Education and Acquisition Research Network, 11(2), 103-115.

Chau, T. H. H., \& Truong, V. (2019). The integration of intercultural education into teaching English: What Vietnamese teachers do and say. International Journal of Instruction, 12(1), 441-456.

Cheewasukthaworn, K., \& Suwanarak, K. (2017). Exploring Thai EFL teachers' perceptions of how intercultural communicative competence is important for their students. PASAA: Journal of Language Teaching and Learning in Thailand, 54, 177-204.

Chen, G.-M. (2014). Intercultural communication competence: Summary of 30-year research and directions for future study. In X. Dai \& G.-M. Chen (Eds.), Intercultural communication competence : Conceptualization and its development in cultural contexts and interactions (pp. 14-40). Cambridge Scholars

Chen, G.-M. (2017). Issues in the conceptualization of intercultural communication competence. In L. Chen (Ed.), Intercultural communication (pp. 349-368). De Gruyter Mouton.

Chen, J. (2019). To blog, not to block': Examining EFL learners' language development and intercultural competence. In T. Dobinson \& K. Dunworth (Eds.), Literacy unbound: Multiliterate, multilingual, multimodal ( $1^{\text {st }}$ ed., pp. 225-245). Springer International Publishing. https://doi.org/10.1007/978-3-030-01255-7_12

Cheng, C.-M. (2007). The influence of EFL teachers' understanding of intercultural competence on their self-reported pedagogical practices in higher education institutes of technology in Taiwan [PhD thesis, University of Minnesota]. https://www.learntechlib.org/p/129436/

Christiansen, X. L. C. (2020). Obervations and fieldnotes: Recording lived experiences. In J. McKinley \& H. Rose (Eds.), The Routledge handbook of research methods in applied linguistics (pp. 336-347). Routledge.

Clarke, D., \& Hollingsworth, H. (2002). Elaborating a model of teacher professional growth. Teaching and Teacher Education, 18(8), 947-967.

Coghlan, D., \& Brydon-Miller, M. (2014). The SAGE encyclopedia of action research. Sage.

Conway, C., \& Richards, H. (2018). 'Lunchtimes in New Zealand are cruel': reflection as a tool for developing language learners' intercultural competence. The Language Learning Journal, 46(4), 371-383. https://doi.org/10.1080/09571736.2015.1130080

Cook, D. L. (1962). The Hawthorne effect in educational research. The Phi Delta Kappan, 44(3), 116-122.

Corbett, J. (2003). An intercultural approach to English language teaching (Vol. 7). Multilingual matters.

Council of Europe. (2001). Common European Framework of Reference for Languages: learning, teaching, assessment. https://www.coe.int/en/web/common-european-framework-reference-languages

Creswell, J. W., \& Poth, C. N. (2018). Qualitative inquiry and research design: Choosing among five approaches. Sage Publications.

Crozet, C., \& Liddicoat, A. J. (1999). The challenge of intercultural language teaching: Engaging with culture in the classroom. In J. L. Bianco, A. J. Liddicoat, \& C. Crozet (Eds.), Striving for the third place: Intercultural competence through language education (pp. 113-125). Language Australia. 
Darling, H. L., Hyler, M. E., \& Gardner, M. (2017). Effective teacher professional development. Learning Policy Institute.

Deardorff, D. K. (2006). Identification and Assessment of Intercultural Competence as a Student Outcome of Internationalization. Journal of studies in international education, 10(3), 241-266. https://doi.org/10.1177/1028315306287002

Deardorff, D. K. (2008). Intercultural competence: A definition, model, and implications for education abroad. In V. Savicki (Ed.), Developing intercultural competence and transformation: Theory, research, and application in international education (pp. 3552). Stylus Publishing.

Denzin, N. K., \& Lincoln, Y. S. (2013). Collecting and interpreting qualitative materials (Vol. 4). Sage.

Dervin, F. (2010). Assessing intercultural competence in language learning and teaching: A critical review of current efforts. In F. Dervin \& E. Suomela-Salmi (Eds.), New approaches to assessment in higher education (pp. 157-173). Perter Lang.

Díaz, A. R. (2013). Developing critical languaculture pedagogies in higher education : Theory and practice. Multilingual Matters.

Díaz, R., \& Dasli, M. (2017). Tracing the "critical" trajectory of language and intercultural communication pedagogy. In M. Dasli \& R. Díaz (Eds.), The critical turn in language and intercultural communication pedagogy: Theory, research and practice (pp. 3-21). Routledge.

Do, H. T. (2006, September). The role of English in Vietnam's foreign language policy: A brief history [Paper presentation]. The 19th annual EA education conference., Canberra, Australia.

Doan, N. B. (2014). Teaching the target culture in English teacher education programs: Issues of EIL in Vietnam. In R. Marlina \& R. A. Giri (Eds.), The pedagogy of English as an international language (pp. 79-93). Springer.

Dornyei, Z. (2007). Research methods in applied linguistics. Oxford University Press.

Dressler, R., Raedler, B., Dimitrov, K., Dressler, A., \& Krause, G. (2019). Project-Based Learning in the advanced German class. In G. Beckett \& T. Slater (Eds.), Global perspectives on project-based language learning, teaching, and assessment: Key approaches, technology tools, and frameworks. Routledge.

Drewelow, I. (2012). Learners' perceptions of culture in a first-semester foreign language course. L2 Journal, 4(2), 283-302. http://doi.org/10.5070/L24213527

Drewelow, I., \& Mitchell, C. (2015). An exploration of learners' conceptions of language, culture, and learning in advanced-level Spanish courses. Language, Culture and Curriculum, 28(3), 243-256. https://doi.org/10.1080/07908318.2015.1078347

Earley, P. C., \& Peterson, R. S. (2004). The elusive cultural chameleon: Cultural intelligence as a new approach to intercultural training for the global manager. Academy of Management Learning \& Education, 3(1), 100-115.

East, M. (2012). Addressing the intercultural via task-based language teaching: possibility or problem? Language and Intercultural Communication, 12(1), 56-73. https://doi.org/10.1080/14708477.2011.626861

Endacott, J. L. (2016). Using video-stimulated recall to enhance preservice-teacher reflection. The new educator, 12(1), 28-47. https://doi.org/10.1080/1547688X.2015.1113351

Estaji, M., \& Rahimi, A. (2018). Exploring teachers' perception of intercultural communicative competence and their practices for teaching culture in EFL classrooms. International Journal of Society, Culture \& Language, 6(2), 1-18. 
Etikan, I., Musa, S. A., \& Alkassim, R. S. (2016). Comparison of convenience sampling and purposive sampling. American journal of theoretical and applied statistics, 5(1), 1-4. https://doi.org/10.11648/j.ajtas.20160501.11

Fang, X., \& Warschauer, M. (2004). Technology and curricular reform in China: A case study. TESOL quarterly, 38(2), 301-323.

Fantini, A. E. (2012). Multiple strategies for assessing intercultural communicative competence. In J. Jackson (Ed.), The Routledge handbook of language and intercultural communication (pp. 390-405). Routledge.

Farouck, I. (2016). A Project-Based language learning model for improving the willingness to communicate of EFL students. Journal of Systemics, Cybernetics and Informatics, 14(2), 11-18.

Faulkner, S. L., Baldwin, J. R., Lindsley, S. L., \& Hecht, M. L. (2006). Layers of meaning: An analysis of definitions of culture. In J. R. Baldwin, S. L. Faulkner, M. L. Hecht, \& S. L. Lindsley (Eds.), Redefining Culture (pp. 27-52). Routledge.

Feryok, A., \& Oranje, J. (2015). Adopting a cultural portfolio project in teaching German as a foreign language: Language teacher cognition as a dynamic system. The Modern Language Journal, 99(3), 546-564. https://doi.org/10.1111/modl.12243

Fraser, M. W., \& Galinsky, M. J. (2010). Steps in Intervention Research: Designing and Developing Social Programs. Research on social work practice, 20(5), 459-466. https://doi.org/10.1177/1049731509358424

Fried-Booth, D. L. (2002). Project work (2 ${ }^{\text {nd }}$ ed.). Oxford University Press.

Galloway, N. (2020). Focus groups: Capturing the dynamics of group interaction. In J. McKinley \& H. Rose (Eds.), The Routledge handbook of research methods in applied linguistics (pp. 290-301). Routledge.

Gandana, I. (2015). Critical thinking, (inter)cultural awareness and pedagogical dilemmas: Stories of three university teachers in Indonesia. In W. M. Chan, M. Nagami, I. Walker, \& S. K. Bhatt (Eds.), Culture and foreign language education: Insights from research and implications for the practice (pp. 107-131). De Gruyter

Gandana, I., \& Parr, G. (2013). Professional identity, curriculum and teaching intercultural communication: an Indonesian case study. Language, Culture and Curriculum, 26(3), 229-246. https://doi.org/10.1080/07908318.2013.833620

Gardner, H. (2006). Multiple intelligences : new horizons (Rev. and updated ed.). BasicBooks.

Gass, S. M., \& Mackey, A. (2016). Stimulated recall methodology in applied linguistics and L2 research (2nd ed.). Routledge.

Gee, J. (1990). Social linguistics and literacies : Ideology in discourses. The Falmer Press.

Gomez, A. M., \& García, P. V. (2020). Developing Multiple Intelligences Using Films in Primary Education. Journal of Education and Practice, 9-18. https://doi.org/10.7176/JEP/11-3-02

Government. (2008). Resolution number 1400/QD-TTg: Approval of the Project of teaching and learning foreign languages in national educational system for the 2008-2020 period (QUYÉT ĐINHH Về việc phê duyệt Đề án "Dạy và hoc ngoại ngũ trong hệ thống giáo dục quốc dân giai đoạn 2008 - 2020”).

http://vanban.chinhphu.vn/portal/page/portal/chinhphu/hethongvanban?class_id=1\&m ode $=$ detail\&document_id=78437

Grant, M. M. (2002). Getting a grip on project-based learning: Theory, cases and recommendations. Meridian: A middle school computer technologies journal, 5(1), 117. 
Grant, M. M. (2011). Learning, beliefs, and products: Students' perspectives with projectbased learning. Interdisciplinary Journal of Problem-Based Learning, 5(2), 37-69 https://doi.org/10.17771/1541-5015.1254

Grant, S. (2017). Implementing project-based language teaching in an Asian context: a university EAP writing course case study from Macau. Asian-Pacific Journal of Second and Foreign Language Education, 2(1), 1-13. https://doi.org/10.1186/s40862-017-0027-x

Griffith, R. L., Wolfeld, L., Armon, B. K., Rios, J., \& Liu, O. L. (2016). Assessing intercultural competence in higher education: Existing research and future directions (2330-8516). (ETS Research Report Series, Issue. http://dx.doi.org/10.1002/ ets2.12112

Guba, E. G. (1981). Criteria for assessing the trustworthiness of naturalistic inquiries. Educational communication and technology, 29(2), 75-91.

Guilherme, M. (2002). Critical citizens for an intercultural world: Foreign language education as cultural politics. Multilingual Matters.

Guo, P., Saab, N., Post, L. S., \& Admiraal, W. (2020). A review of project-based learning in higher education: Student outcomes and measures. International Journal of Educational Research, 102. https://doi.org/10.1016/j.ijer.2020.101586

Habok, A. (2015). Implementation of a project-based concept mapping developmental programme to facilitate children's experiential reasoning and comprehension of relations. European Early Childhood Education Research Journal, 23(1), 129-142. https://doi.org/10.1080/1350293X.2014.991100

Hattum-Janssen, N., \& Pimenta, P. C. (2006). Peer and self-assessment in Portuguese engineering education. In T. S. Roberts (Ed.), Self, peer and group assessment in elearning (pp. 64-84). IGI Global.

Hawkins, M., \& Norton, B. (2009). Critical language teacher education. In A. Burns \& J. C. Richards (Eds.), The Cambridge guide to second language teacher education (pp. 3039). Cambridge University Press.

Hazaea, A. N. (2019). Fostering critical intercultural awareness among EFL students through critical discourse analysis. Íkala, 25(1), 17-33. https://doi.org/10.17533/udea.ikala.v25n01a06

Hedge, T. (1993). Project work. English Language Teaching Journal, 47(3), 276-277.

Heigham, J., \& Croker, R. (2009). Qualitative research in applied linguistics: A practical introduction. Springer.

Helle, L., Tynjälä, P., \& Olkinuora, E. (2006). Project-based learning in post-secondary education-theory, practice and rubber sling shots. Higher education, 51(2), 287-314.

Helle, L., Tynjala, P., Olkinuora, E., \& Lonka, K. (2007). 'Ain't nothin' like the real thing'. Motivation and study processes on a work-based project course in information systems design. British Journal Of Educational Psychology, 77, 397-411. https://doi.org/10.1348/000709906X105986

Hernandez-Ramos, P., \& De La Paz, S. (2009). Learning history in middle school by designing multimedia in a project-based learning experience. Journal of Research on Technology in Education, 42(2), 151-173. https://doi.org/10.1080/15391523.2009.10782545

Hesse-Biber, S. N. (2017). The practice of qualitative research: engaging students in the research process (3rd edition ed.). Boston College.

Ho, S. T. K. (2011). An investigation of intercultural teaching and learning in tertiary EFL classrooms in Vietnam [PhD thesis, Victoria University of Wellington]. https://researcharchive.vuw.ac.nz/xmlui/handle/10063/4447 
Hoang, V. V. (2020). The roles and status of English in present-day Vietnam: A sociocultural analysis. VNU Journal of Foreign Studies, 36(1), 1-21.

Hoff, H. E. (2014). A critical discussion of Byram's model of intercultural communicative competence in the light of bildung theories. Intercultural education, 25(6), 508-517. https://doi.org/10.1080/14675986.2014.992112

Hofstede, G., Hofstede, G. J., \& Minkov, M. (2010). Cultures and organizations: Software of the mind. Revised and expanded 3rd Edition ( $3^{\text {rd }}$ ed.). McGraw-Hill.

Holliday, A. (1999). Small cultures. Applied Linguistics, 20(2), 237-264. https://doi.org/10.1093/applin/20.2.237

Holliday, A. (2011). Intercultural communication and ideology. Sage.

Holliday, A. (2018). Understanding intercultural communication: Negotiating a grammar of culture. Routledge.

Holliday, A. R. (2013). Validity in qualitative research. In C. A. Chapelle (Ed.), The encyclopedia of applied linguistics (pp. 1-7). Wiley-Blackwell.

Howard, J., Biebricher, C., Tolosa, C., Scott, A., \& East, M. (2016). Principles and beliefs behind teachers' existing intercultural language teaching practices. New Zealand Language Teacher, 42, 31-43.

Howard, J., Tolosa, C., Biebricher, C., \& East, M. (2019). Shifting conceptualisations of foreign language teaching in New Zealand: students' journeys towards developing intercultural capability. Language and Intercultural Communication, 19(6), 555-569. https://doi.org/10.1080/14708477.2019.1601201

Huerta-Macias, A. (1995). Alternative Assessment: Responses to Commonly Asked Questions. TESOL Journal, 5(1), 8-11.

James, E. A., Milenkiewicz, M. T., \& Bucknam, A. (2008). Participatory action research for educational leadership: Using data-driven decision making to improve schools. Sage.

Jin, L., \& Cortazzi, M. (2017). Developing speaking for intercultural communication textbooks with critical creative approaches. In H. P. Widodo, A. Wood, \& D. Gupta (Eds.), Asian English language classrooms: Where theory and practice meet. Routledge.

Jonsson, A., \& Panadero, E. (2017). The use and design of rubrics to support assessment for learning. In C. David, M. B. Susan, K. Y. C. Cecilia, \& G. Rick (Eds.), Scaling up assessment for learning in higher education (pp. 99-111). https://doi.org/10.1007/978-981-10-3045-1

Kaldi, S., Filippatou, D., \& Govaris, C. (2011). Project-based learning in primary schools: effects on pupils' learning and attitudes. Education 3-13, 39(1), 35-47. https://doi.org/10.1080/03004270903179538

Karaçalli, S., \& Korur, F. (2014). The effects of project-based learning on students' Academic achievement, attitude, and retention of knowledge: The subject of "Electricity in Our Lives". School Science and Mathematics, 114(5), 224-235. https://doi.org/10.1111/ssm.12071

Kelly, P. J. (2005). Practical suggestions for community interventions using participatory action research. Public Health Nursing, 22(1), 65-73.

Kennedy, J. (2016). Exploring opportunities for developing intercultural competence through intercultural communicative language teaching (ICLT): A case study in a Chinese as a foreign language classroom in a New Zealand high school. [MA thesis, Victoria University of Wellington] https://researcharchive.vuw.ac.nz/xmlui/handle/10063/5040

Kindon, S., Pain, R., \& Kesby, M. (2007). Participatory action research approaches and methods: Connecting people, participation and place. Routledge. 
Kohler, M. (2015). Teachers as Mediators in the Foreign Language Classroom. Multilingual Matters.

Kokotsaki, D., Menzies, V., \& Wiggins, A. (2016). Project-based learning: A review of the literature. Improving schools, 19(3), 267-277. https://doi.org/10.1177/1365480216659733

Kramsch, C. (1993). Context and culture in language teaching. Oxford university press.

Kramsch, C. (1999). Thirdness: The intercultural stance. In T. Vestergaard (Ed.), Language, culture and identity (pp. 53-89). Aalborg University Press.

Kramsch, C. (2003). The privilege of the nonnative speaker. In C. Blyth (Ed.), The sociolinguistics of foreign-language classrooms: Contributions of the native, the near-native, and the non-native speaker (pp. 251-262). Eric.

Kramsch, C. (2004). The language teacher as go-between. Utbildning \& demokrati, 13(3), $37-60$.

Kramsch, C. (2006). Culture in Language Teaching. In K. Brown (Ed.), Encyclopedia of language \& linguistics (Second Edition) (pp. 322-329). Elsevier. https://doi.org/https://doi.org/10.1016/B0-08-044854-2/00611-8

Kramsch, C. (2013). Culture in foreign language teaching. Iranian Journal of Language Teaching Research, 1(1), 57-78.

Kramsch, C. (2014). Language and culture in second language learning. In The Routledge handbook of language and culture (pp. 419-432). Routledge.

Kramsch, C. (2015). Language and culture in second language learning. In F. Sharifian (Ed.), The Routledge handbook of language and culture (pp. 403-416). Routledge.

Kramsch, C. J. (1998). Language and culture. Oxford University Press.

Krefting, L. (1991). Rigor in qualitative research: The assessment of trustworthiness. The American Journal of Occupational Therapy, 45(3), 214-222. https://doi.org/10.5014/ajot.45.3.214

Kusumaningputri, R., \& Widodo, H. P. (2018). Promoting Indonesian university students' critical intercultural awareness in tertiary EAL classrooms: The use of digital photograph-mediated intercultural tasks. System (Linköping), 72, 49-61. https://doi.org/10.1016/j.system.2017.10.003

Lawson, H. A. (2015). Participatory action research (1st ed.). Oxford University Press.

Lazar, I. (2011). Teachers' beliefs about integrating the development of intercultural communicative competence in language teaching: Case studies of Hungarian preservice English teachers. ForumSprache, 2011(5), 112-126.

Le, V. C. (2015a). English language education innovation for the Vietnamese secondary school. The Project 2020. In B. Spolsky, K. Sung, \& R. Gargesh (Eds.), Secondary school English education in Asia : from policy to practice. Routledge.

Le, V. C. (2015b). Uncovering teachers' beliefs about intercultural language teaching: An example from Vietnam. The European Journal of Applied Linguistics and TEFL, 4(1), $83-103$.

Lenkaitis, C. A., Calo, S., \& Venegas Escobar, S. (2019). Exploring the intersection of language and culture via telecollaboration: Utilizing videoconferencing for intercultural competence development. International Multilingual Research Journal, 13(2), 102-115. https://doi.org/10.1080/19313152.2019.1570772

Lenz, B., Wells, J., \& Kingston, S. (2015). Transforming schools using project-based learning, performance assessment, and common core standards. John Wiley \& Sons.

Lew, S., Yang, A. H., \& Harklau, L. (2018). Qualitative methodology. In A. Phakiti, P. De Costa, L. Plonsky, \& S. Starfield (Eds.), The Palgrave handbook of applied linguistics 
research methodology ( $1^{\text {st }}$ ed., pp. 79-101). Palgrave Macmillan. https://doi.org/10.1057/978-1-137-59900-1_4

Liddicoat, A. J. (2002). Static and dynamic views of culture and intercultural language acquisition Babel, 36(3), 4-11.

Liddicoat, \& Scarino, A. (2013). Intercultural language teaching and learning.

Liddicoat, A. J. (2008). Pedagogical practice for integrating the intercultural in language teaching and learning. Japanese Studies, 28(3), 277-290. https://doi.org/10.1080/10371390802446844

Liddicoat, A. J. (2017). Interpretation and critical reflection in intercultural language learning: Consequences of a critical perspective for the teaching and learning of pragmatics. In M. Dasli \& R. Díaz (Eds.), The critical turn in language and intercultural communication pedagogy: Theory, research and practice (pp. 22-39). Routledge.

Liddicoat, A. J., Papademetre, L., Scarino, A., \& Kohler, M. (2003). Report on intercultural language learning. Canberra ACT: Commonwealth of Australia.

Liddicoat, A. J., \& Scarino, A. (2010). Eliciting the intercultural in foreign language education. In A. Paran \& D. L. Sercu (Eds.), Testing the Untestable in Language Education (pp. 52-73). Multilingual Matters.

Liddicoat, A. J., \& Scarino, A. (2013). Intercultural language teaching and learning. Blackwell Publishing.

Lim, S., \& Keuk, C. N. (2018). A sociocultural analysis of Cambodian teachers' cognitions about cultural contents in an 'internationally imported' textbook in a tertiary English learning context. In H. P. Widodo, M. R. Perfecto, L. V. Canh, \& A. Buripakdi (Eds.), Situating Moral and Cultural Values in ELT Materials (pp. 87-110). Springer International Publishing. https://doi.org/10.1007/978-3-319-63677-1_6

Lincoln, Y. S., \& Guba, E. G. (1985). Naturalistic inquiry. Sage

Liu, K. (2018). Culture in EFL: Using an EFL writing project to facilitate culture and language learning for low-proficiency college EFL learners. European Journal of English Language Teaching, 111-123.

Louis, C., Keith, M., \& Lawrence, M. (2000). Research methods in education (5 ${ }^{\text {th }}$ ed.). Routledge.

Luk, J. (2012). Teachers' ambivalence in integrating culture with EFL teaching in Hong Kong. Language, Culture and Curriculum, 25(3), 249-264. https://doi.org/10.1080/07908318.2012.716849

Lune, H., \& Berg, B. L. (2016). Qualitative research methods for the social sciences. Pearson Higher Ed.

Lustig, M. W., Koester, J., \& Halualani, R. (2010). Intercultural competence: Interpersonal communication across cultures $\left(6^{\text {th }}\right.$ ed.). Pearson Education.

Mahoney, C. (2009). Teaching culture in the Japanese language classroom: A NSW case study. New voices (Sydney, N.S.W.), 3, 104-125. https://doi.org/10.21159/nv.03.06

Majid, M. A. A., Othman, M., Mohamad, S. F., Lim, S. A. H., \& Yusof, A. (2017). Piloting for interviews in qualitative research: Operationalization and lessons learnt. International Journal of Academic Research in Business and Social Sciences, 7(4), 1073-1080.

Malmqvist, J., Hellberg, K., Möllås, G., Rose, R., \& Shevlin, M. (2019). Conducting the Pilot Study: A neglected part of the research process? Methodological findings supporting the importance of piloting in qualitative research studies. International journal of qualitative methods, 18, 1-11. https://doi.org/10.1177/1609406919878341 
Manara, C. (2014). Intercultural dialogue on English language teaching : Multilingual teacher educator's narrative of professional learning. Cambridge Scholars Publisher.

Markham, T. (2003). Project based learning handbook: A guide to standards-focused project based learning for middle and high school teachers. Buck Institute for Education.

Marshall, \& Rossman. (2006). Designing qualitative research $\left(4^{\text {th }} \mathrm{ed}\right.$.). Sage publications.

Marshall, M. N. (1996). Sampling for qualitative research. Family practice, 13(6), 522-526.

Matsuno, S. (2009). Self-, peer-, and teacher-assessments in Japanese university EFL writing classrooms. Language Testing, 26(1), 075-100.

https://doi.org/10.1177/0265532208097337

Matsuo, C. (2012). A Critique of Michael Byram's intercultural communicative competence model from the perspective of model type and conceptualization of culture. Fukuoka University review of literature \& humanities, 44(2), 347-380. https://ci.nii.ac.jp/naid/110009465403/en/

Maxwell, J. A. (2013). Qualitative research design : an interactive approach ( $3^{\text {rd }}$ ed.). Sage Publications.

McConachy, T. (2013). A place for pragmatics in intercultural teaching and learning. In F. Dervin \& A. J. Liddicoat (Eds.), Linguistics for Intercultural Education. John Benjamins Publishing Company.

Merriam, S. B., \& Tisdell, E. J. (2016). Qualitative research a guide to design and implementation. Jossey-Bass.

Miike, Y. (2012). Harmony without uniformity: An Asiacentric worldview and its communicative implications. In L. A. Samovar, R. E. Porter, \& E. R. McDaniel (Eds.), Intercultural communication: A reader (pp. 65-80). Wadsworth Cengage Learning.

Moeller, A. K., \& Nugent, K. (2014). Building intercultural competence in the language classroom.

https://digitalcommons.unl.edu/teachlearnfacpub/161/?utm_source=digitalcommons.u nl.edu\%2Fteachlearnfacpub\%2F161\&utm_medium=PDF\&utm_campaign=PDFCove rPages

Mohamadi, Z. (2018). Comparative effect of project-based learning and electronic projectbased learning on the development and sustained development of english idiom knowledge. Journal of Computing in Higher Education, 30(2), 363-385. https://doi.org/10.1007/s12528-018-9169-1

Moloney, R. (2008). You just want to be like that: teacher modelling and intercultural competence in young language learners. Babel, 42(3).

Moloney, R. A. (2013). Providing a bridge to intercultural pedagogy for native speaker teachers of Chinese in Australia. Language, Culture and Curriculum, 26(3), 213-228. https://doi.org/ 10.1080/07908318.2013.829081

Morales, M. P. E. (2016). Participatory action research (par) cum action research (ar) in teacher professional development: A literature review. International Journal of Research in Education and Science, 2(1), 156-165.

Moss, D. (1997). Project based learning and assessment. A resource manual for teachers. Virginia Adult Education Resource Centers. https://files.eric.ed.gov/fulltext/ED442306.pdf

Munandar, M. I., \& Newton, J. (2021). Indonesian EFL teachers' pedagogic beliefs and classroom practices regarding culture and interculturality. Language and Intercultural Communication, 1-16. https://doi.org/10.1080/14708477.2020.1867155 
Munoz-Restrepo, A. (2017). Rethinking the uses of assessment in the second language classroom. Magis, Revista Internacional De Investigación En Educacion, 9(19), 115132. https://doi.org/10.11144/Javeriana.m9-19.ruas

Nakayama, T. K., \& Martin, J. N. (2014). Ethical issues in intercultural communication competence: Adialectical approach. In X.-d. Dai \& G. M. Chen (Eds.), Intercultural communication competence: Conceptualization and its development in cultural contexts and interactions (pp. 97-117). Cambridge Scholars.

Newton, J. (2016). Teaching English for intercultural spoken communication. In English Language Teaching Today (pp. 161-177). Springer.

Newton, J., Yates, E., Shearn, S., \& Nowitzki, W. (2010). Intercultural communicative language teaching: Implications for effective teaching and learning. Report to the Ministry of Education Ministry of Education, New Zealand.

Ngo, H. H. (2014). Some utilization of project-based learning for Vietnamese university students of English in the course "Intercultural Communication". International Journal of English Language Education, 2, 215-224.

Nguyen, B. T. (2016). An investigation of Vietnamese EFL teachers' perceptions of intercultural competence and its application in high schools $[\mathrm{PhD}$ thesis, University of Newcastle].

https://nova.newcastle.edu.au/vital/access/manager/Repository/uon:23434

Nguyen, H. T. M. (2011). Developing EFL learners' intercultural communicative competence: A gap to be filled? In R. Nunn \& S. Sivasubramaniam (Eds.), From defining EIL competence to designing EIL learning (pp. 86). Asian EFL Journal Press.

Nguyen, H. T. M. (2017). The EFL Context in Vietnam and East Asia. In Models of mentoring in language teacher education (pp. 1-27). Springer.

Nguyen, T. L. (2013). Integrating culture into Vietnamese university EFL teaching: A critical ethnographic study [PhD thesis, Auckland University of Technology]. https://openrepository.aut.ac.nz/handle/10292/5975

Nguyen, T. L. (2015). Integrating pedagogy into intercultural teaching in a Vietnamese setting: From policy to the classroom. International Journal of Pedagogies and Learning, 9(2), 171-182.

Nhem, D. (2020). Culture and ELT: Cambodian teachers' perception and practice of textbook adaptation to realize intercultural awareness. ELT Forum: Journal of English Language Teaching, 9(1), 65-74. https://doi.org/10.15294/elt.v9i1.38409

Oranje, J., \& Smith, L. F. (2018). Language teacher cognitions and intercultural language teaching: The New Zealand perspective. Language Teaching Research, 22(3), 310329. https://doi.org/10.1177/1362168817691319

Oranje, J. M. (2016). Intercultural Communicative Language Teaching: Enhancing awareness and practice through cultural portfolio projects $[\mathrm{PhD}$ thesis, University of Otago]. https://ourarchive.otago.ac.nz/handle/10523/6295

Pajares, M. F. (1992). Teachers' beliefs and educational research: Cleaning up a messy construct. Review of Educational Research, 62(3), 307-332. https://doi.org/10.2307/1170741

Papandreou, A. (1993). An application of project approach to EFL. English Teaching Forum, 32(3), 41-42.

Patton, M. Q. (1999). Enhancing the quality and credibility of qualitative analysis. Health services research, 34(5), 1189-1208. 
Patton, M. Q., \& Patton, M. Q. (2002). Qualitative research and evaluation methods (3 ${ }^{\text {rd }}$. ed.). Sage Publications.

Patton, M. Q. (2015). Qualitative research and evaluation methods $\left(4^{\text {th }}\right.$ ed.). SAGE.

Peiser, G., \& Jones, M. (2014). The influence of teachers' interests, personalities and life experiences in intercultural languages teaching. Teachers and teaching, theory and practice, 20(3), 375-390. https://doi.org/10.1080/13540602.2013.848525

Prior, M. T. (2018). Interviews and focus groups. In A. Phakiti, P. De Costa, L. Plonsky, \& S. Starfield (Eds.), The Palgrave handbook of applied linguistics research methodology ( $1^{\text {st }}$ ed., pp. 225-248). Palgrave Macmillan.

Rabbidge, M. (2017). Embracing reflexivity: The importance of not hiding the mess. TESOL quarterly, 51(4), 961-971. https://doi.org/10.1002/tesq.397

Rasku-Puttonen, H., Eteläpelto, A., Arvaja, M., \& Häkkinen, P. (2003). Is successful scaffolding an illusion?-Shifting patterns of responsibility and control in teacherstudent interaction during a long-term learning project. Instructional Science, 31(6), 377-393. http://www.jstor.org/stable/41953629

Rathje, S. (2007). Intercultural competence: The status and future of a controversial concept. Language and Intercultural Communication, 7(4), 254-266. https://doi.org/10.2167/laic285.0

Risager, K. (2007). Language and culture pedagogy: From a national to a transnational paradigm. Multilingual Matters.

Rokhmawan, T., \& Wulandari, B. (2019). The relevance of project-based lecture in industrial revolution 4.0: Meta-synthesis study. Jurnal Iqra': Kajian Ilmu Pendidikan, 4(2), 146-167. https://doi.org/10.25217/ji.v4i2.515

Rose, H. (2020). Diaries and journals: Collecting insider perspectives in second language research. In J. McKinley \& H. Rose (Eds.), Routledge handbook in applied linguistics (pp. 348-359). Routledge.

Ruan, Y., \& Du, X. Y. (2013). A PBL-inspired method for facilitating culture learning. Sense Publishers. https://doi.org/10.1007/978-94-6209-440-6_4

Sadeghi, H., Biniaz, M., \& Soleimani, H. (2016). The impact of project-based language learning on Iranian EFL learners comparison/contrast paragraph writing skills. International Journal of Asian Social Science, 6(9), 510-524. https://doi.org/10.18488/journal.1/2016.6.9/1.9.510.524

Salcedo, N., \& Sacchi, F. (2014). The role of culture in the EFL classroom: a study of teachers' beliefs and practices. In D. Banegas, M. Lopez-Barrios, M. Porto, \& M. A. Soto (Eds.), English Language Teaching in the Post-methods Era: Selected Papers from the 39th FAAPI Conference. http://wrap.warwick.ac.uk/63296/

Scarino, A. (2009). Assessing intercultural capability in learning languages: Some issues and considerations. Language Teaching, 42(1), 67-80. https://doi.org/10.1017/S0261444808005417

Sercu, L. (2004). Assessing intercultural competence: A framework for systematic test development in foreign language education and beyond. Intercultural education, 15(1), 73-89. https://doi.org/10.1080/1467598042000190004

Sercu, L., Bandura, E., Castro, P., Davcheva, L., Laskaridou, C., Lundgren, U., Garcia, M., \& Ryan, P. (2005). Foreign language teachers and intercultural competence: An international investigation (Vol. 10). Multilingual Matters.

Setyarini, S. (2019). Promoting Learner Autonomy in Teaching English to Young Adolescents through Higher Order Thinking Skills: An Innovation to Create 4.0 
Learning Trends. In 1st International Conference on Education Social Sciences and Humanities (ICESSHum 2019) (pp. 382-387). Atlantis Press.

Siegel, A. (2014). What Should We Talk about? The Authenticity of Textbook Topics. ELT journal, 68(4), 363-375. https://doi.org/10.1093/elt/ccu012

Sinicrope, C., Norris, J., \& Watanabe, Y. (2007). Understanding and assessing intercultural competence: A summary of theory, research, and practice (technical report for the foreign language program evaluation project). Second Langauge Studies Paper 26 (1), $1-58$.

Siregar, F. L. (2016). In pursuit of intercultural communicative competence: An investigation into English language policy and practices at a private university in Indonesia. [PhD thesis, Victoria University of Wellington]. http://researcharchive.vuw.ac.nz/handle/10063/5258

Slater, T., Beckett, G. H., \& Aufderhaar, C. (2006). Assessing projects as second language and content learning. In G. H. Beckett \& P. C. Miller (Eds.), Project-based second and foreign language education: Past, present, and future (pp. 241-260).

Solomon, G. (2003). Project-based learning: A primer. Technology and Learning, 23(6), 1020.

Spencer-Oatey, H., \& Stadler, S. (2009). The global people competency framework: Competencies for effective intercultural interaction. The Centre for Applied Linguistics, University of Warwick.

Spitzberg, B. H., \& Changnon, G. (2009). Conceptualizing intercultural competence. In D. K. Deardorff (Ed.), The Sage handbook of intercultural competence (pp. 2-52). Sage.

Stake, R. E. (2013). Multiple case study analysis. Guilford Press.

Stefanou, C., Stolk, J. D., Prince, M., Chen, J. C., \& Lord, S. M. (2013). Self-regulation and autonomy in problem- and project-based learning environments. Active Learning in Higher Education, 14(2), 109-122. https://doi.org/10.1177/1469787413481132

Stoller, F. (2002). Project work: A means to promote language and content. In J. C. Richards \& W. A. Renandya (Eds.), Methodology in language teaching: An anthology of current practice (pp. 107-119). Cambrige University Press.

Stoller, F. (2006). Establishing a theoretical foundation for project-based learning in second and foreign language contexts. In G. H. Beckett \& P. C. Miller (Eds.), Project-based second and foreign language education: Past, present, and future (pp. 19-40). Information Age Publishing

Stoller, F., \& Myers, C. C. (2019). Project-based Learning A five-stage framework to guide language teachers. In A. Gras-Velazquez (Ed.), Project-Based Learning in Second Language Acquisition: Building Communities of Practice in Higher Education. Taylor \& Francis Group.

Streck, D. R. (2014). Knowledge and transformative social action: the encounter of selected traditions of participatory (action) research. Globalisation, Societies and Education, 12(4), 457-473.

Stringer, E. T. (1999). Action research. Sage Publications.

Su, Y.-C. (2011). The effects of the cultural portfolio project on cultural and EFL learning in Taiwan's EFL college classes. Language Teaching Research, 15(2), 230-252. https://doi.org/10.1177/1362168810388721

Su, Y. C. (2011). Promoting intercultural understanding and reducing stereotypes: Incorporating the cultural portfolio project into Taiwan's EFL college classes. Educational Studies, 37(1), 73-88. https://doi.org/10.1080/03055691003729039 
Sultan, S., \& Javaid, S. T. (2018). Pakistani undergraduate students' perceptions of projectbased learning in the English composition course. Journal of Applied Research in Higher Education. https://doi.org/10.1108/JARHE-11-2017-0135

Sundkvist, P., \& Nguyen, X. N. C. M. (2020). English in Vietnam. In K. Bolton, W. Botha, \& A. Kirkpatrick (Eds.), The handbook of Asian Englishes: Blackwell handbooks in linguistics (pp. 683-703). Wiley Blackwell. https://doi.org/10.1002/9781118791882

Thomas, J. W. (2000). A review of research on project-based learning. www.bobpearlman.org/BestPractices/PBL_Research

Tian, J. (2013). Beliefs and practices regarding intercultural competence among Chinese teachers of English at a Chinese university. George Mason University.

Ting-Toomey, S., \& Chung, L. C. (2005). Understanding intercultural communication. Oxford University Press.

Tolosa, C., Biebricher, C., East, M., \& Howard, J. (2018). Intercultural language teaching as a catalyst for teacher inquiry. Teaching and teacher education, 70, 227-235. https://doi.org/10.1016/j.tate.2017.11.027

Topping, K. (2003). Self and peer assessment in school and university: Reliability, validity and utility. In D. F. Segers M., Cascallar E. (Ed.), Optimising new modes of assessment: In search of qualities and standards (pp. 55-87). Springer.

Torres, A. S., Sriraman, V., \& Ortiz, A. M. (2019). Implementing project based learning pedagogy in concrete industry project management. International Journal of Construction Education and Research, 15(1), 62-79. https://doi.org/10.1080/15578771.2017.1393475

Tran, T. (2020). Intercultural Language Teaching in Vietnamese Tertiary EFL Classes: A Participatory Action Research Study [PhD thesis, Victoria University of Wellington]. https://researcharchive.vuw.ac.nz/xmlui/handle/10063/8888

Tran, T. Q., \& Dang, H. V. (2014). Culture teaching in English language teaching: Teachers beliefs and their classroom practices. Global Journal of Foreign Language Teaching, 4(2), 92-101.

Trinh, T. T. H. (2016). Achieving cultural competence in Vietnamese EFL classes: a case study from an intercultural communicative competence perspective $[\mathrm{PhD}$ thesis, University of Newcastle].

https://nova.newcastle.edu.au/vital/access/manager/Repository/uon:24591

Trompenaars, F., \& Hampden-Turner, C. (1998). Riding the Waves of Culture: Understanding Diversity in Global Business. McGraw Hill.

Truong, L. B., \& Tran, L. T. (2014). Students' intercultural development through language learning in Vietnamese tertiary education: A case study on the use of film as an innovative approach. Language and Intercultural Communication, 14(2), 207-225.

Vaca Torres, A. M., \& Gomez Rodríguez, L. F. (2017). Increasing EFL learners oral production at a public school through project-based learning. Profile Issues in Teachers Professional Development, 19(2), 57-71. https://doi.org/10.15446/profile.v19n2.59889

Vo, P. Q. (2017). Rethinking intercultural communication competence in English language teaching: A gap between lecturers' perspectives and practices in a Southeast Asian tertiary context. i-manager's Journal on English Language Teaching, 7(1), 1-11. https://doi.org/10.26634/jelt.7.1.11404

Wang, S. (2020). Project-based language learning in China: A literature review. Journal of language teaching and research, 11(1), 66-72. https://doi.org/10.17507/jltr.1101.08 
Wang, Y. (2014). Views and attitudes of staff and students towards the significance of intercultural awareness in foreign language teaching and learning in an Australian university context. University of Tasmania.

Weaver, G. R. (1993). Understanding and coping with cross-cultural adjustment stress. In R. Paige (Ed.), Education for the intercultural experience ( $2^{\text {nd }}$ ed., pp. 137-167). Intercultural Press.

Witte, A. (2014). Blending spaces : mediating and assessing intercultural competence in the L2 classroom. De Gruyter Mouton.

Woo, Y., Herrington, J., Agostinho, S., \& Reeves, T. C. (2007). Implementing authentic tasks in web-based learning environments. Educause Quarterly, 30(3), 36-43.

Worawong, K., Charttrakul, K., \& Damnet, A. (2017). Promoting intercultural competence of Thai university students through role-play. Advances in Language and Literary Studies, 8(6), 37-43.

Xiao, Y., \& Lucking, R. (2008). The impact of two types of peer assessment on students' performance and satisfaction within a Wiki environment. The Internet and Higher Education, 11(3), 186-193.

https://doi.org/https://doi.org/10.1016/j.iheduc.2008.06.005

Young, T. J., \& Sachdev, I. (2011). Intercultural communicative competence: Exploring English language teachers' beliefs and practices. Language awareness, 20(2), 81-98. https://doi.org/10.1080/09658416.2010.540328

Yu, Q., \& Van Maele, J. (2018). Fostering intercultural awareness in a Chinese English reading class. Chinese Journal of Applied Linguistics, 41(3), 357-375. https://doi.org/10.1515/cjal-2018-0027

Yuliani, Y., \& Lengkanawati, N. S. (2017). Project-based learning in promoting learner autonomy in an EFL classroom. Indonesian Journal of Applied Linguistics, 7(2), 285293. https://doi.org/10.17509/ijal.v7i2.8131

Zare, M. H., Nemati, F., \& Jafarian, K. (2015). Iranian EFL teachers' opinions about teaching culture in EFL classroom. Science Journal (CSJ), 36(3), 1047-1067.

Zhou, Y. (2011). A study of Chinese university EFL teachers and their intercultural competence teaching $[\mathrm{PhD}$ thesis, University of Windsor, Ontario, Canada]. https://scholar.uwindsor.ca/etd/428/ 


\section{APPENDICES}

Appendix 1 Human Ethics Approval Letter

Appendix 2 Sample Consent Forms

Appendix 2.1 Consent Form for Teachers

Appendix 2.2 Consent Form for Students

Appendix 3 Sample Observation Protocol

Appendix 4 Interview Guides

Appendix 4.1 Interview Guide Study 1

Appendix 4.2 Interview Guide Study 2

Appendix 5 Observation Sheets

Appendix 5.1 Observation Sheet for Study 1

Appendix 5.2 Observation Sheet for Study 2

Appendix 6 Sample Lesson Plan

Appendix 7 Sample Textbook Lesson 
Appendix 1 Human Ethics Approval Letter

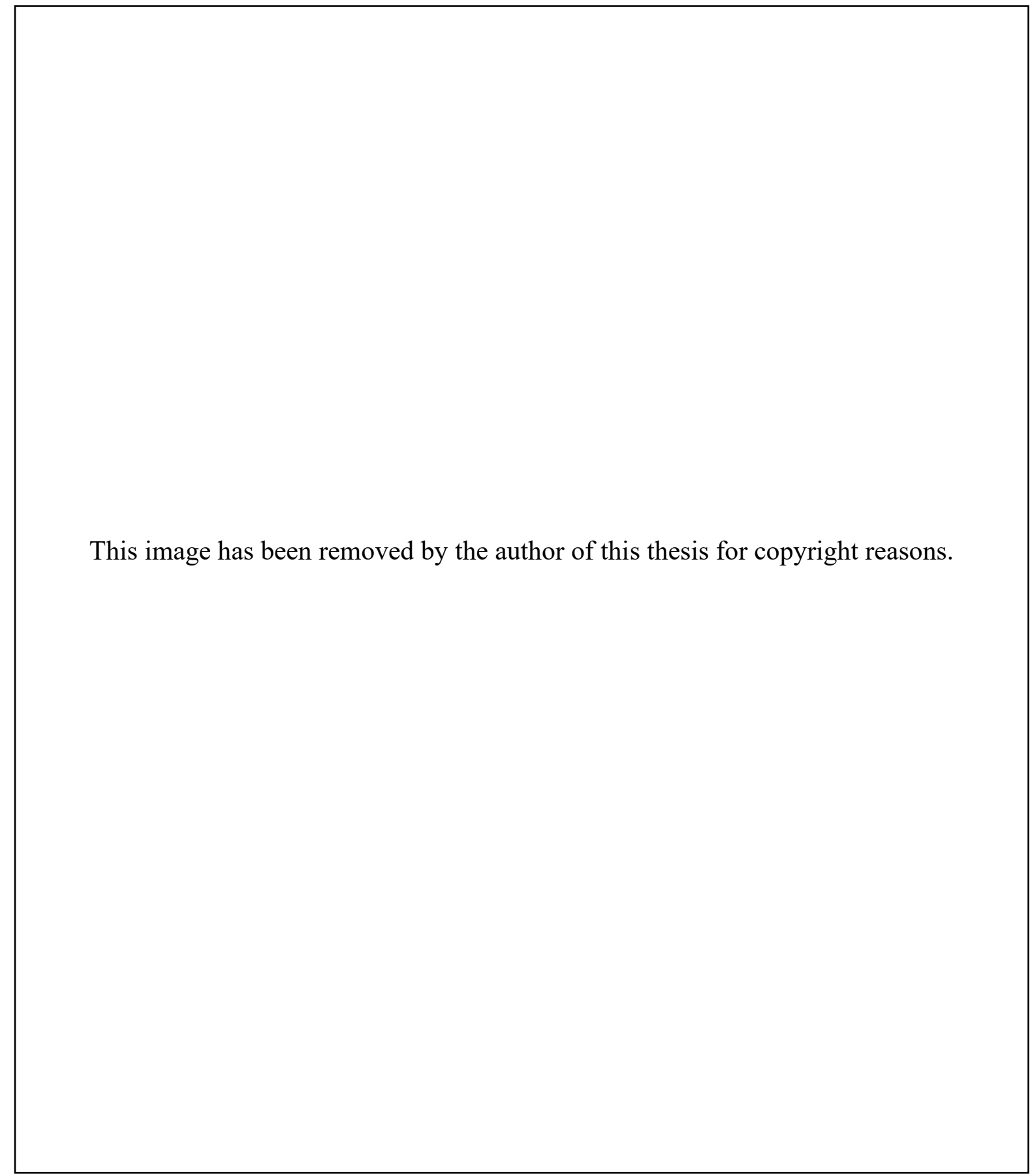




\section{Appendix 2 Sample Consent Forms}

Appendix 2.1 Consent Form for Teachers

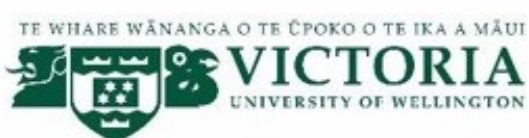

\section{Fostering Business Students' Intercultural Communicative Competence via Project Based Learning at a University in Vietnam}

\section{CONSENT TO INTERVIEW}

Researcher: Minh Ngoc Hien Ta, School of Linguistics and Applied Language Studies, Victoria University of Wellington.

I have read the Information Sheet and the project has been explained to me. My questions have been answered to my satisfaction. I understand that I can ask further questions at any time.

I agree to take part in an audio recorded interview and video-recorded observations.

I understand that:

Any information I provide will be kept confidential to the researcher and the supervisor

I understand that the results will be used for a $\mathrm{PhD}$ dissertation, academic publication or conferences My name will not be used in reports, nor will any information that would identify me. email address below.

Signature of participant:

Name of participant:

Date:

Contact details: 


\section{Appendix 2 Sample Consent Forms}

Appendix 2.2 Consent Form for Students

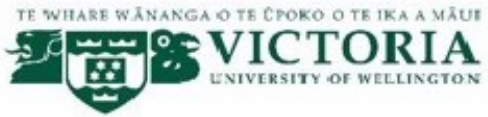

\section{Fostering Business Students' Intercultural Communicative Competence via Project Based Learning at a University in Vietnam}

\section{CONSENT TO INTERVIEW}

Researcher: Minh Ngoc Hien Ta, School of Linguistics and Applied Language Studies, Victoria University of Wellington.

- I have read the Information Sheet and the project has been explained to me. My questions have been answered to my satisfaction. I understand that I can ask further questions at any time.

- I agree to take part in an audio recorded interview.

I understand that:

- I acknowledge that I am agreeing to keep the information shared during the focus group confidential. I am aware that after the focus group. I must not communicate to anyone, including family members and close friends, any details about the focus group.

- Any information I provide will be kept confidential to the researcher and the supervisor

- I understand that the results will be used for a $\mathrm{PhD}$ dissertation, academic publication or conferences

- My name will not be used in reports, nor will any information that would identify me.

- I would like a copy of the transcript of my interview Yes No

- I would like to receive a copy of the final report and have Yes No added my email address below.

Signature of participant:

Name of participant:

Date:

Contact details: 


\title{
Appendix 3 Sample Observation Protocol
}

\section{OBSERVATION PROTOCOL}

\author{
(Used for classroom observations)
}

Project title: Fostering business students' intercultural communicative competence via Project-Based-Learning at a university in Vietnam

- Observer's role: Non-participant. That is, the observer does not take any active part in the class that is observed. The observer's activities are limited to observing the teachers' teaching practices, students' practices and taking notes of these practices

- What to be observed: During classroom observations in this project, teachers' practices of providing culture learning opportunities for the students, teachers' use of teaching materials and teaching aids and students' learning activities are observed and recorded.

- Who to be observed: In classroom observations, students and teachers are observed.

- What to be collected: In classroom observations, teachers' culture teaching activities are recorded including teachers' delivery of the lesson and managing the class activities. The focus is on teachers' provision of culture learning opportunities for the students, teachers' managing of tasks and activities that foster students' culture learning, teachers' use of teaching materials and teaching aids, students' learning activities.|

- How to record: Recordings of teachers' teaching practices and students' learning activities are conducted in forms of video-recording and run-on note taking in An A4 notebook. Notes on teachers' practices are to be taken in silence and in a manner that is unobtrusive as possible. 


\section{Appendix 4 Interview guides}

\section{Appendix 4.1 Interview guide (for interview 1)}

Date of interview: Time of interview:

Participant code:

\begin{tabular}{|c|c|}
\hline Main Questions & Possible probes \\
\hline $\begin{array}{l}\text { Q1: "Culture" is a commonly used term in } \\
\text { language teaching. How do you define this } \\
\text { term in your EFL teaching setting? }\end{array}$ & $\begin{array}{l}\text { - What do you think the aspects of } \\
\text { culture are? } \\
\text { - What do you think of when you hear } \\
\text { the word "culture"? } \\
\text { - Which do you attach this word to: an } \\
\text { individual, a group of people? }\end{array}$ \\
\hline $\begin{array}{l}\text { Q2: As an EFL teacher, what do you think } \\
\text { are the objectives of language teaching? }\end{array}$ & $\begin{array}{l}\text { - What do you want students to } \\
\text { achieve from your lessons? }\end{array}$ \\
\hline $\begin{array}{l}\text { Q3: What do you think about the role and } \\
\text { value of addressing the cultural dimension } \\
\text { in EFL classes? }\end{array}$ & $\begin{array}{l}\text { - What is the link between language } \\
\text { teaching and culture teaching? } \\
\text { - Why do we need to address cultural } \\
\text { elements in EFL classes? } \\
\text { - What is your idea about intercultural } \\
\text { communicative competence? } \\
\text { - How do you think EFL lessons can } \\
\text { prepare students for their future jobs } \\
\text { and life? }\end{array}$ \\
\hline $\begin{array}{l}\text { Q4: How do you teach culture in your EFL } \\
\text { classes? }\end{array}$ & $\begin{array}{l}\text { How often do you address culture in } \\
\text { class? } \\
\text { - What do you do to create chances for } \\
\text { students to get involved in } \\
\text { intercultural communication? } \\
\text { - What materials do you use for } \\
\text { teaching culture? (Textbooks, } \\
\text { materials developed by other } \\
\text { sources, or materials developed by } \\
\text { yourself?) } \\
\text { - What cultural activities do you } \\
\text { introduce in language class? } \\
\text { - Why do you use these activities? }\end{array}$ \\
\hline
\end{tabular}




\begin{tabular}{|l|l|}
\hline & $\begin{array}{l}\text { What difficulties do you have in } \\
\text { addressing culture? }\end{array}$ \\
& $\begin{array}{l}\text { When is the best time to teach } \\
\text { culture? (e.g., in low level/high level } \\
\text { English course)? }\end{array}$ \\
& $\begin{array}{l}\text { What target cultures should be } \\
\text { included in the EFL lessons? }\end{array}$ \\
\hline $\begin{array}{l}\text { Q4: In your opinion, what are the goals of } \\
\text { teaching culture in an EFL class? }\end{array}$ & $\begin{array}{l}\text { Do you think that giving cultural } \\
\text { facts to students is enough? }\end{array}$ \\
& $\begin{array}{l}\text { How will students need cultural } \\
\text { knowledge to communicate with } \\
\text { people from many cultures later in } \\
\text { their jobs? }\end{array}$ \\
\hline $\begin{array}{l}\text { Q5: What do you think about students' } \\
\text { responses to cultural content/activities in } \\
\text { EFL lessons? }\end{array}$ & $\begin{array}{l}\text { Do students show interest in } \\
\text { cultural/intercultural activities? } \\
\text { Why? Why not? }\end{array}$ \\
\hline $\begin{array}{l}\text { Q5: What is your attitude toward } \\
\text { addressing the inter/cultural dimension in } \\
\text { EFL classes? }\end{array}$ & $\begin{array}{l}\text { Do you like/dislike addressing the } \\
\text { cultural content in EFL lessons? } \\
\text { Why/ Why not? }\end{array}$ \\
\hline
\end{tabular}




\section{Appendix 4 Interview guides}

\section{Appendix 4.2 Interview guide (for interview 2)}

English version

Date of interview: Time of interview:

Participant code:

\begin{tabular}{|c|c|}
\hline Main Questions & Possible probes \\
\hline $\begin{array}{l}\text { Q1: What do you think about the objectives of } \\
\text { your PBL lessons and what did you achieve? }\end{array}$ & $\begin{array}{l}\text { - What were objectives? } \\
\text { - What did you do? } \\
\text { involvement in cultural activities/in the } \\
\text { project? What attitudes did they } \\
\text { express? }\end{array}$ \\
\hline $\begin{array}{l}\text { Q2: For the observed culture teaching } \\
\text { activities? }\end{array}$ & $\begin{array}{l}\text { - What was the aim of the activity? } \\
\text { - Is the activity common practice in your } \\
\text { class? } \\
\text { - How are you going to continue that } \\
\text { activity in the next semester? }\end{array}$ \\
\hline $\begin{array}{l}\text { Q3: For unobserved culture teaching activity, } \\
\text { based on teaching materials? }\end{array}$ & $\begin{array}{l}\text { - Do you think it would be a good idea } \\
\text { to... } \\
\text { - What if..... }\end{array}$ \\
\hline $\begin{array}{l}\text { Q4: What do you think about students' learning } \\
\text { of culture during the project? }\end{array}$ & $\begin{array}{l}\text { - How did students participate in cultural } \\
\text { activities? } \\
\text { - How did students increase their cultural } \\
\text { knowledge? } \\
\text { - How did students develop their cultural } \\
\text { discovery? } \\
\text { How did students develop their critical } \\
\text { cultural awareness? }\end{array}$ \\
\hline $\begin{array}{l}\text { Q5: What do you think about students' } \\
\text { language development during the project? }\end{array}$ & $\begin{array}{l}\text { How did students' speaking skills develop? } \\
\text { What were the examples? }\end{array}$ \\
\hline
\end{tabular}




\begin{tabular}{|l|l|}
\hline $\begin{array}{l}\text { Q5: What do you think about students' } \\
\text { development of project skills during the } \\
\text { project? }\end{array}$ & $\begin{array}{l}\text { How did students present their performances? } \\
\text { What skills do you think they have } \\
\text { demonstrated in the performances? }\end{array}$ \\
\hline $\begin{array}{l}\text { Q6: What do you think about the PAR } \\
\text { collaboration? }\end{array}$ & $\begin{array}{l}\text { How do you help each other in implementing } \\
\text { the PBL lessons? } \\
\text { What do you think about the workshops? }\end{array}$ \\
\hline $\begin{array}{l}\text { Q7: What were your difficulties in } \\
\text { implementing PBL lessons? }\end{array}$ & \\
\hline $\begin{array}{l}\text { Q8: Do you want to continue with the PBL } \\
\text { approach? Why? }\end{array}$ & \\
\hline
\end{tabular}




\section{Appendix 5 Observation Sheets}

\section{Appendix 5.1 Observation sheet for Study 1}

\begin{tabular}{|c|c|c|c|}
\hline \multicolumn{2}{|c|}{ Teacher's name: } & Observer's name: & $\begin{array}{l}\text { Date: } \\
\text { Time: }\end{array}$ \\
\hline Class: & Subject: & $\begin{array}{l}\text { Number of } \\
\text { students: }\end{array}$ & Room: \\
\hline Unit: & & \multicolumn{2}{|c|}{ Lesson title: } \\
\hline
\end{tabular}

\section{General observations}

\begin{tabular}{|l|l|l|l|}
\hline Lesson stages & Focus & $\begin{array}{l}\text { Teacher's main } \\
\text { activities }\end{array}$ & Students' main activities \\
\hline & & & \\
\hline & & & \\
\hline & & & \\
\hline & & & \\
\hline & & & \\
\hline
\end{tabular}

2. Observations of how inter(cultural) content is addressed

\begin{tabular}{|l|l|l|l|l|}
\hline Lesson stages & $\begin{array}{l}\text { Teacher's } \\
\text { activities }\end{array}$ & $\begin{array}{l}\text { Students' } \\
\text { activities }\end{array}$ & $\begin{array}{l}\text { Clarification } \\
\text { needed }\end{array}$ & $\begin{array}{l}\text { Notes (e.g., } \\
\text { unexpected } \\
\text { teaching/learning } \\
\text { practices) }\end{array}$ \\
\hline & & & & \\
\hline & & & & \\
\hline & & & & \\
\hline & & & & \\
\hline
\end{tabular}

3. General comments 


\section{Appendix 5 Observation Sheet}

\section{Appendix 5.2 Observation sheet for Study 2}

\begin{tabular}{|c|c|c|c|}
\hline \multicolumn{2}{|c|}{ Teacher's name: } & Observer's name: & $\begin{array}{l}\text { Date: } \\
\text { Time: }\end{array}$ \\
\hline Class: & Subject: & $\begin{array}{l}\text { Number o } \\
\text { students: }\end{array}$ & Room: \\
\hline Unit: & & & Lesson title: \\
\hline
\end{tabular}

\section{General observations}

\begin{tabular}{|l|l|l|l|}
\hline Lesson stages & Focus & $\begin{array}{l}\text { Teacher's main } \\
\text { activities }\end{array}$ & Students' main activities \\
\hline & & & \\
\hline & & & \\
\hline & & & \\
\hline
\end{tabular}

\section{Observations of how intercultural learning is evident}

\begin{tabular}{|l|l|l|l|l|}
\hline $\begin{array}{l}\text { Lesson } \\
\text { stages }\end{array}$ & $\begin{array}{l}\text { Teacher's } \\
\text { activities }\end{array}$ & $\begin{array}{l}\text { Students' } \\
\text { activities }\end{array}$ & $\begin{array}{l}\text { Clarification } \\
\text { needed }\end{array}$ & $\begin{array}{l}\text { Notes (e.g., unexpected } \\
\text { teaching/learning practices, } \\
\text { absence of activities compared } \\
\text { to pre-designed lessons) }\end{array}$ \\
\hline & & & & \\
\hline & & & & \\
\hline
\end{tabular}

\section{Observations of how teacher facilitates project implementation}

\begin{tabular}{|l|l|l|l|l|}
\hline $\begin{array}{l}\text { Lesson } \\
\text { stages }\end{array}$ & $\begin{array}{l}\text { Teacher's } \\
\text { activities }\end{array}$ & $\begin{array}{l}\text { Students' } \\
\text { activities }\end{array}$ & $\begin{array}{l}\text { Clarification } \\
\text { needed }\end{array}$ & $\begin{array}{l}\text { Notes (e.g., unexpected } \\
\text { teaching/learning practices, } \\
\text { absence of activities compared } \\
\text { to pre-designed lessons) }\end{array}$ \\
\hline & & & & \\
\hline & & & & \\
\hline
\end{tabular}

\section{General comments}




\section{Appendix 6 Sample lesson plan}

\section{Lesson plan for PBL lesson 8 (after workshop 2)}

Unit 9: Change

\section{Lesson B: PLANS AND DREAMS}

OBJECTIVES: By the end of the lesson, each student will have:

- developed intercultural awareness about different perspectives and practices relating to the topic of life changes including weddings (accepting/ refusing wedding invitations), going to university (who pay university tuition fees? parents or students), moving out after 18ish)

- used vocabulary or phrases to talk about future plans

- developed English speaking skills

- continued to build confidence in giving oral presentations

\begin{tabular}{|c|c|c|}
\hline Time & Objectives & Classroom procedure \\
\hline & To lead in & $\begin{array}{l}\text { 1. WARM-UP } \\
\text { Teacher asks students some questions about weather, } \\
\text { health, holidays }\end{array}$ \\
\hline & $\begin{array}{l}\text { - } \text { To check project } \\
\text { progress } \\
\text { - To give feedback } \\
\text { on students' } \\
\text { project work }\end{array}$ & $\begin{array}{l}\text { 2. PROJECT REVIEW } \\
\text { - Teacher goes to each project group, gives them } \\
\text { feedback on their scripts } \\
\text { - Teacher listens to each group's questions and give } \\
\text { comments } \\
\text { - Teacher has each group to discuss what they will } \\
\text { - } \text { do next for the project } \\
\text { Teacher gives comments on their plans }\end{array}$ \\
\hline
\end{tabular}




\begin{tabular}{|c|c|c|}
\hline Time & Objectives & Classroom procedure \\
\hline & & $\begin{array}{l}\text { 3. NEW LESSON } \\
\text { Language Focus }\end{array}$ \\
\hline & $\begin{array}{ll}\text { - } & \text { To provide } \\
\text { language input } \\
\text { - } & \text { To raise } \\
\text { intercultural } \\
\text { awareness } \\
\text { - } \quad \text { To foster } \\
\text { presentation skills }\end{array}$ & $\begin{array}{l}\text { - Teacher has students read the Vocabulary Link } \\
\text { section in textbook and complete tasks from p95- } \\
\text { - Teacher asks students to talk about the students" } \\
\text { future plans in English and in Vietnamese } \\
\text { - Teacher calls some representatives from 2-3 } \\
\text { groups to talk about their discussion } \\
\text { - Teacher concludes with the phrases "going to" to } \\
\text { talk about future plans in English, and the } \\
\text { equivalent in Vietnamese } \\
\text { Teacher has students work in pairs, talking about } \\
\text { their future plans } \\
\text { Teacher calls } 2 \text { students to speak in front of the } \\
\text { class about their plans }\end{array}$ \\
\hline & $\begin{array}{l}\text { - To raise } \\
\text { intercultural } \\
\text { awareness, } \\
\text { attitudes and skills } \\
\text { (noticing, } \\
\text { comparing, } \\
\text { reflecting, } \\
\text { interacting) } \\
\text { To foster } \\
\text { presentation skills }\end{array}$ & $\begin{array}{l}\text { Intercultural activities } \\
\text { Activity 1: Role play: Accepting/ Refusing wedding } \\
\text { invitation } \\
\text { - Teacher shows the slides with pictures of wedding } \\
\text { invitation cards in Vietnamese and asks questions } \\
\text { such as "What are these?" "Have you ever been } \\
\text { invited to wedding parties" "How did you reply to } \\
\text { accept/refuse the invitations?" and role play a } \\
\text { scene using Vietnamese, and English when } \\
\text { receiving/refusing a wedding invitation } \\
\text { Teacher asks students if they know anything about } \\
\text { wedding cards from other cultures and how to } \\
\text { accept/ refuse wedding cards } \\
\text { Teacher listens to students' answers, prompts } \\
\text { students to talk about hidden meanings behind }\end{array}$ \\
\hline
\end{tabular}




\begin{tabular}{|c|c|c|}
\hline Time & Objectives & Classroom procedure \\
\hline & & $\begin{array}{l}\text { wedding cards in different cultures such as the } \\
\text { color of the cards, the content of the card } \\
\text { - Teacher has students talk about the commonalities } \\
\text { and differences in accepting/ refusing wedding } \\
\text { invitations between Vietnamese culture and some } \\
\text { Western cultures such as American, Australian, } \\
\text { New Zealand cultures, and their comments on } \\
\text { these commonalities and differences } \\
\text { - Teacher shares her own experience with wedding } \\
\text { invitations } \\
\text { - Students reflect on their own experience }\end{array}$ \\
\hline & $\begin{array}{l}\text { - To raise } \\
\text { intercultural } \\
\text { awareness, } \\
\text { attitudes and skills } \\
\text { (noticing, } \\
\text { comparing, } \\
\text { reflecting, } \\
\text { interacting) } \\
\text { To foster } \\
\text { presentation skills }\end{array}$ & $\begin{array}{l}\text { Intercultural activities + Project skills } \\
\text { Activity 2: Role play: Moving out and paying for } \\
\text { university tuition fees } \\
\text { Pre-Role play } \\
\text { Teacher has students discuss in groups about where } \\
\text { they live after they finish high school, e.g., in their } \\
\text { house with parents or independently and why. } \\
\text { Students are asked to guess what people of the same } \\
\text { age from different cultures do. } \\
\text { Role-play } \\
\text { Teacher has students work in pairs, role-playing } \\
\text { two American friends talking with each other } \\
\text { about the place they moved to, including when } \\
\text { they moved, number of rooms, how they pay the } \\
\text { rent. (Teacher provides prompts in hand-out card) } \\
\text { Teacher guides students to notice the differences in } \\
\text { Vietnamese and American cultures in moving out. } \\
\text { (Reasons for moving out, their perspectives) }\end{array}$ \\
\hline
\end{tabular}




\begin{tabular}{|c|c|c|}
\hline Time & Objectives & Classroom procedure \\
\hline & & $\begin{array}{l}\text { - Teacher has students reflect on their experience } \\
\text { - Teacher shares her own experience (if any) }\end{array}$ \\
\hline & $\begin{array}{l}\text { - To raise } \\
\text { intercultural } \\
\text { awareness, } \\
\text { attitudes and skills } \\
\text { (noticing, } \\
\text { comparing, } \\
\text { reflecting, } \\
\text { interacting) } \\
\text { To foster } \\
\text { presentation skills }\end{array}$ & $\begin{array}{l}\text { Intercultural activities } \\
\text { Activity 3: Talking with two English speakers } \\
\text { (guest speakers) } \\
\text { Pre-talk } \\
\text { - Teacher helps students prepare questions to } \\
\text { interview English speakers } \\
\text { - } \quad \text { Students practice interviewing with classmates } \\
\text { Talk with English speakers } \\
\text { - Teacher introduces guest speakers to students } \\
\text { - Teachers encourages students to interact with } \\
\text { guest speakers } \\
\text { - Teacher prompts students to reflect on their } \\
\text { conversations with the guest speakers }\end{array}$ \\
\hline & & $\begin{array}{l}\text { WRAP-UP } \\
\text { Teacher reiterates the language use to talk about future } \\
\text { plans, different perspectives in some life events in } \\
\text { different cultures, the need to respect the differences, } \\
\text { some skills for interviewing and talking in front of a } \\
\text { large group }\end{array}$ \\
\hline
\end{tabular}


Appendix 7 Sample textbook lesson

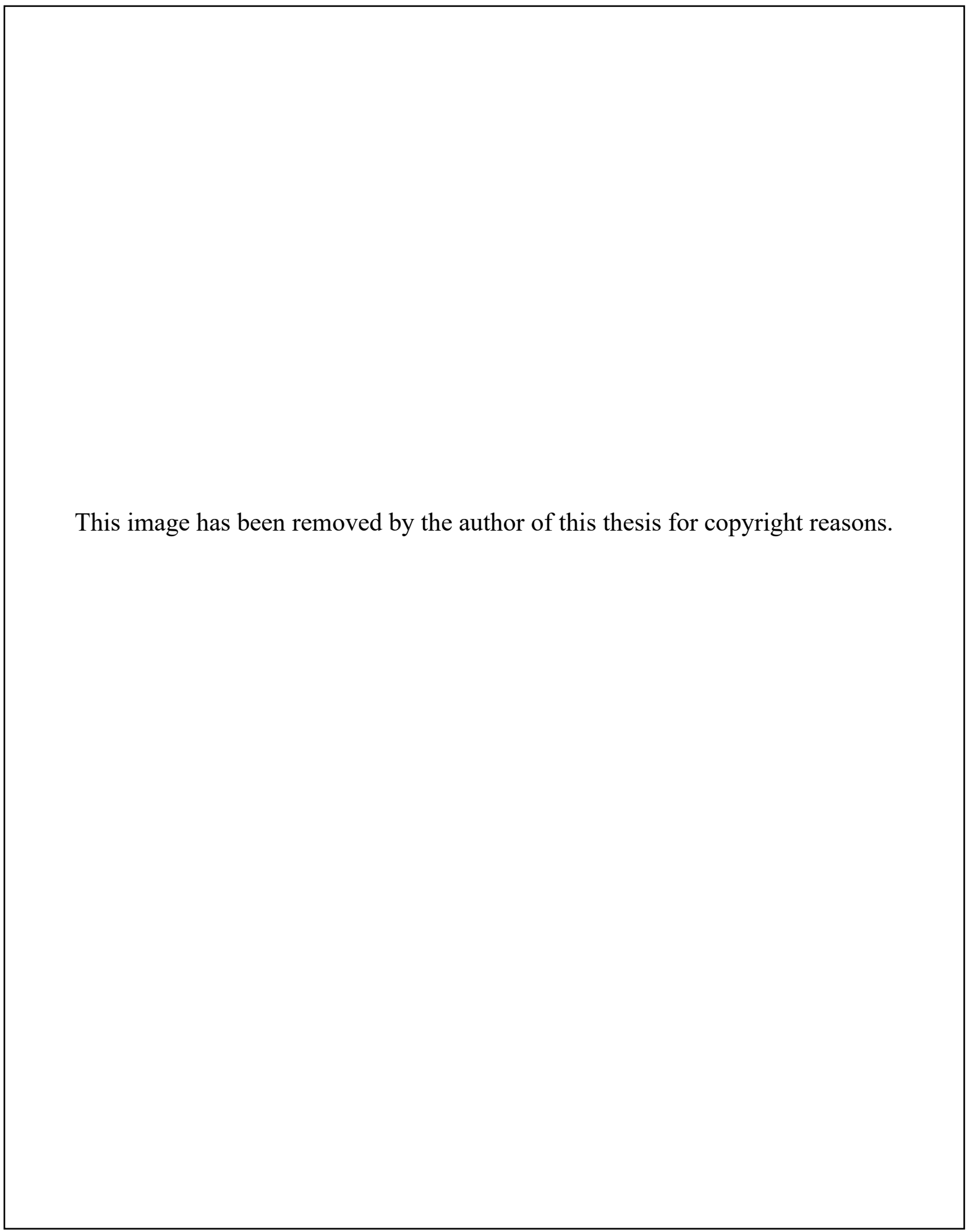


This image has been removed by the author of this thesis for copyright reasons. 
This image has been removed by the author of this thesis for copyright reasons. 
This image has been removed by the author of this thesis for copyright reasons. 
This image has been removed by the author of this thesis for copyright reasons. 